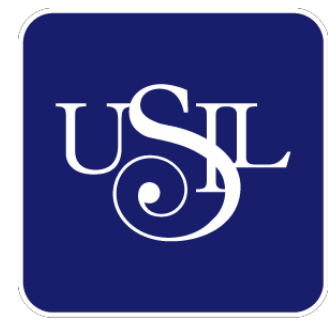

UNIVERSIDAD

SAN IGNACIO

DE LOYOLA

ESCUELA DE POSTGRADO

\title{
KAWSAY - BEBIDA NATURAL A BASE DE SANKY
}

Trabajo de Investigación para optar el grado de:

KARELIA AGUILAR ZAMORA

Maestro en Ciencias Empresariales con Mención en Gestión Financiera

MIGUEL CARDENAS ALAMEDA

Maestro en Ciencias Empresariales con Mención en Gestión de Proyectos

CARLOS MARTIN GARCIA ARANA

Maestro en Ciencias Empresariales con Mención en Gestión de Operaciones

EDGARDO DAVID OLAECHEA VARGAS

Maestro en Ciencias Empresariales con Mención en Gestión Financiera

Asesor:

Dr. Edmundo Rafael Casavilca Maldonado

Lima - Perú

2018 
ESTUDIO DE PREFACTIBILIDAD PARA LA PRODUCCIÓN Y COMERCIALIZACIÓN DE KAWSAY BEBIDA NATURAL A BASE DE SANKY 


\section{Índice}

Página $\mathbf{N}^{\circ}$

Índice 3

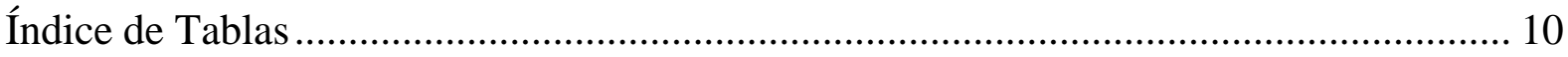

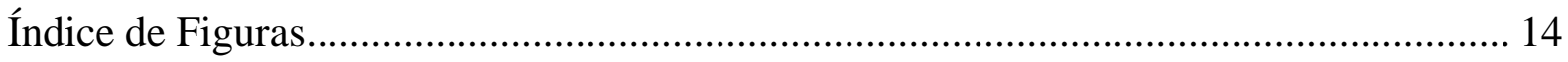

Resumen Ejecutivo ……………………………………...................................... 17

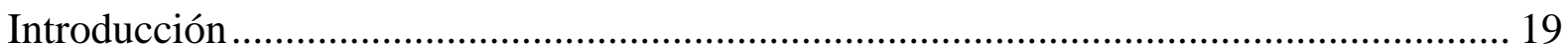

Capítulo I..................................................................................................................................... 22

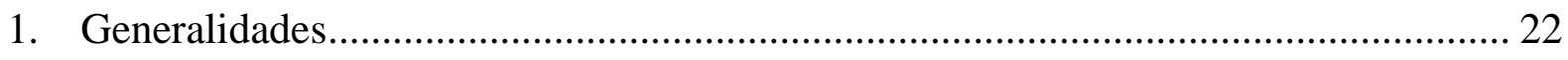

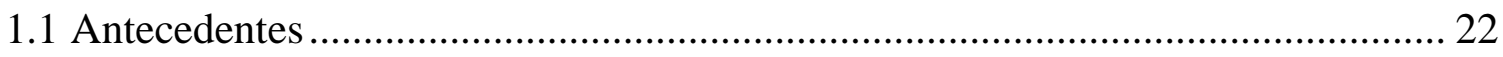

1.2 Determinación del problema u oportunidad .......................................................... 23

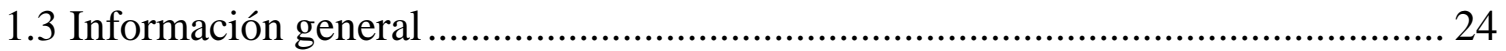

1.3.1 Nombre de la empresa, horizonte de evaluación ......................................... 24

1.3.2 Actividad económica, código CIIU, partida arancelaria.............................. 25

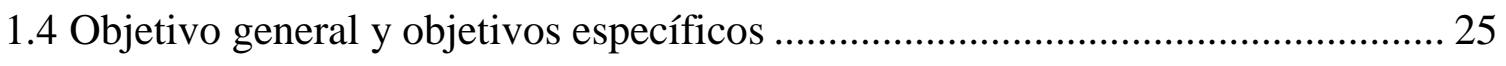

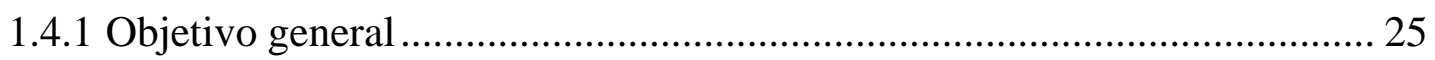

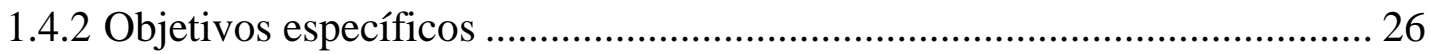

1.5 Alcances y limitaciones de la investigación …………………………………….... 26

Capítulo II .................................................................................................................................. 28

2. Estructura económica del sector manufacturero ………………………………........ 28

2.1 Descripción del estado actual de la industria de bebidas........................................ 29

2.1.1 Segmentación de la industria de bebidas ........................................................ 30

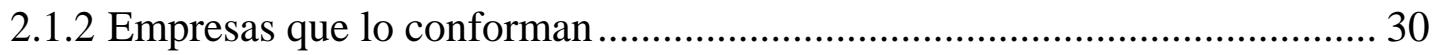

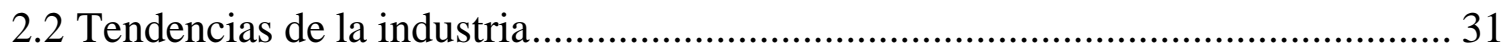

2.3 Análisis estructural del sector industrial ............................................................. 33

2.3.1 Competidores actuales: nivel de competitividad ......................................... 34

2.3.2 Fuerza negociadora de los clientes.......................................................... 35

2.3.3 Fuerza negociadora de los proveedores ………………………………...... 36 
2.3.4 Amenaza de productos sustitutos ....................................................... 37

2.3.5 Competidores potenciales barreras de entrada......................................... 39

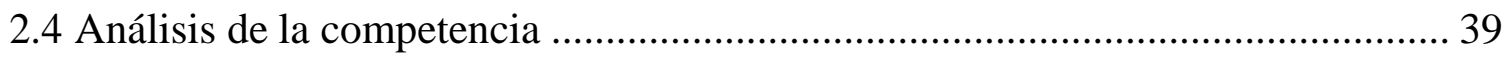

2.4.1 Empresas que ofrecen el mismo insumo en sus productos (semejanzas y

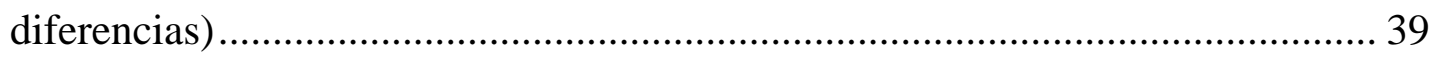

2.4.2 Empresas que ofrecen bebidas naturales (semejanzas y diferencias) ......... 40

2.4.3 Participación de mercado de cada uno de ellos........................................ 40

2.5 Análisis del contexto actual y esperado..................................................... 41

2.5.1 Análisis político-gubernamental ......................................................... 41

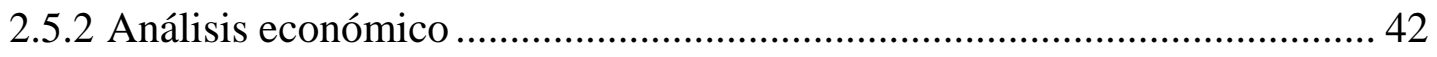

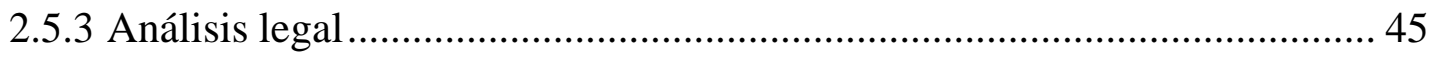

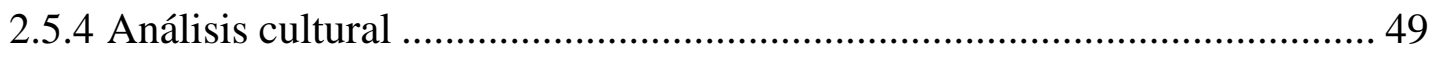

2.5.5 Análisis tecnológico ....................................................................... 50

2.5.6 Análisis ecológico ........................................................................... 52

2.6 Matriz de evaluación de factores externos................................................... 52

Capítulo III................................................................................................................. 56

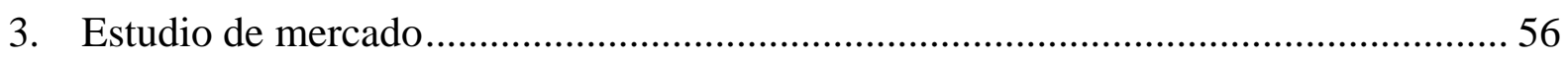

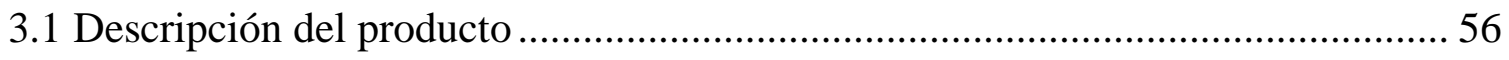

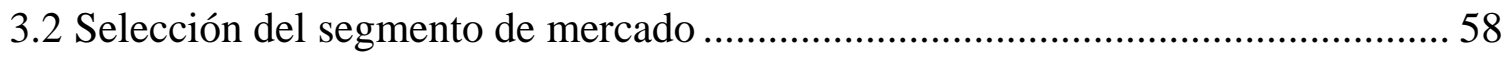

3.2.1 Geográfica 58

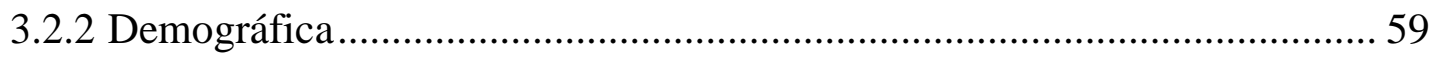

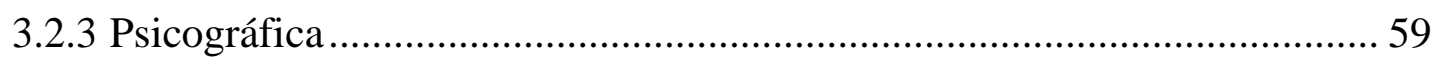

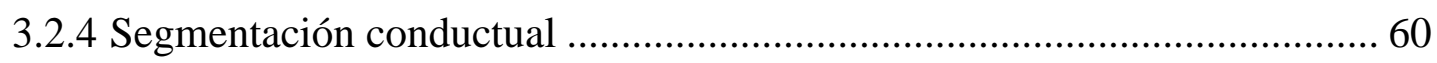

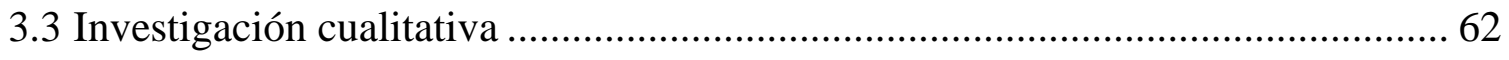

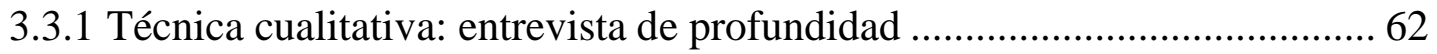

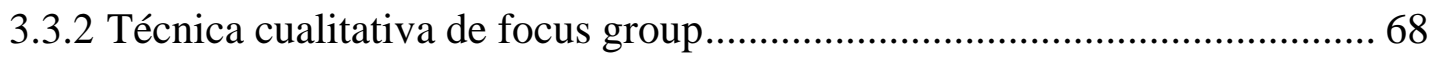

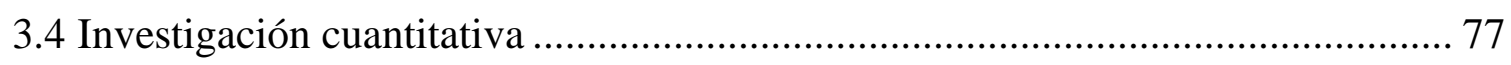

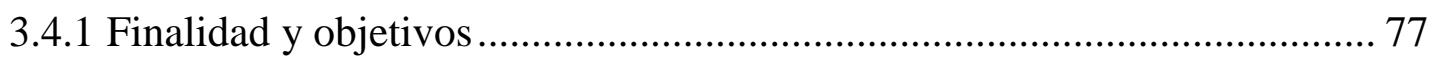


3.4.2 Características de la encuesta........................................................... 78

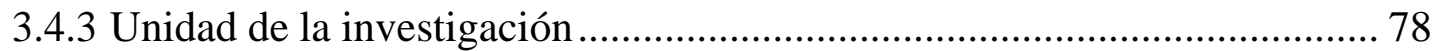

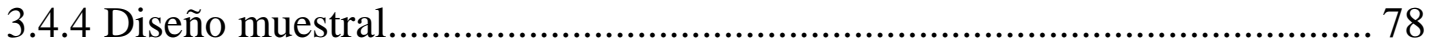

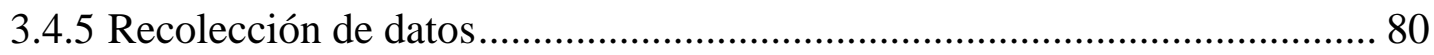

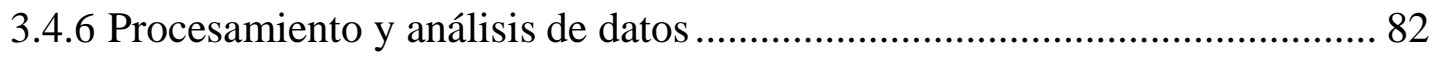

3.4.7 Resultados y conclusiones .............................................................. 111

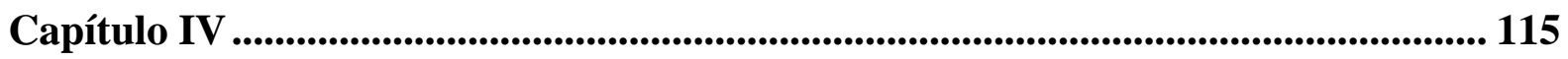

4. Proyección del mercado objetivo...................................................................... 115

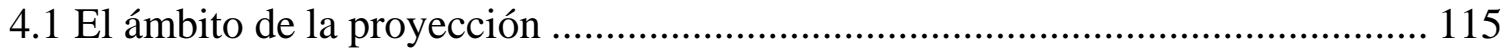

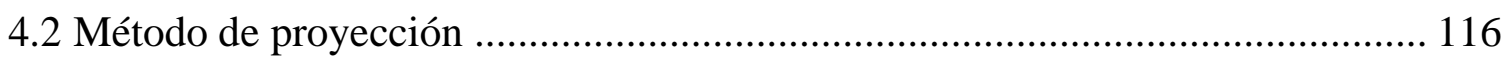

4.2.1 Mercado potencial ....................................................................... 116

4.2.2 Mercado disponible ...................................................................... 118

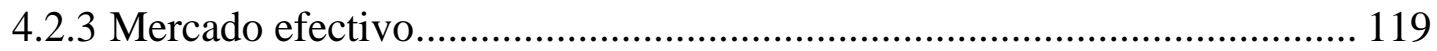

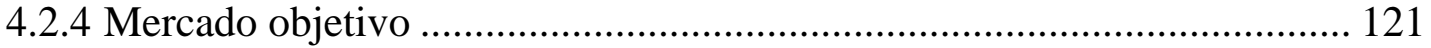

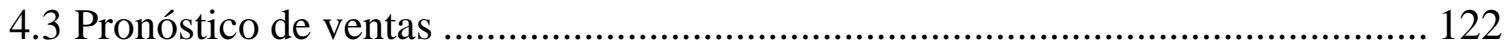

4.4 Aspectos críticos que impactan el pronóstico de ventas................................... 124

4.4.1 Factor climatológico ....................................................................... 124

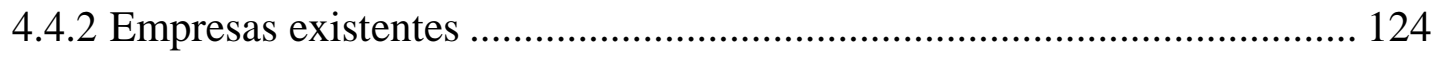

4.4.3 Factores internos ..................................................................... 125

Capítulo V.............................................................................................................................................. 126

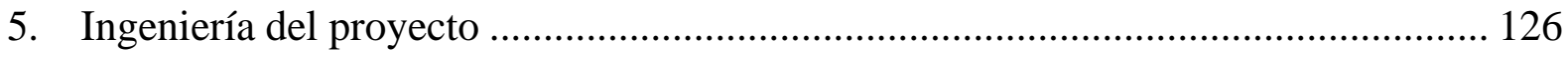

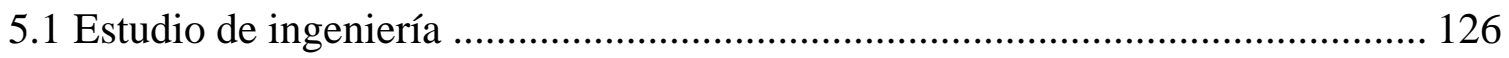

5.1.1 Moldeamiento y selección de procesos productivos ............................... 126

5.1.2 Selección del equipamiento ............................................................ 131

5.1.3 Layout y distribución de equipos y maquinarias ................................... 141

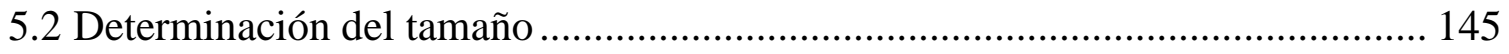

5.2.1 Proyección de crecimiento .............................................................. 145 


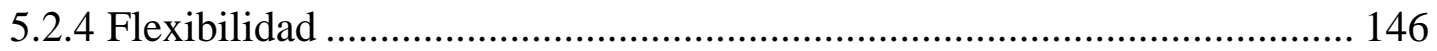

5.2.5 Selección del tamaño ideal................................................................. 146

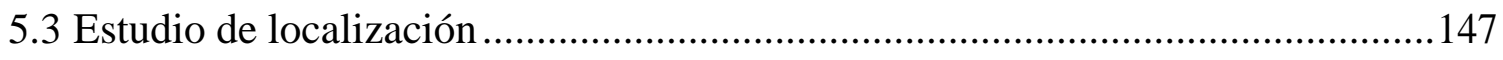

5.3.1 Macro localización ....................................................................... 147

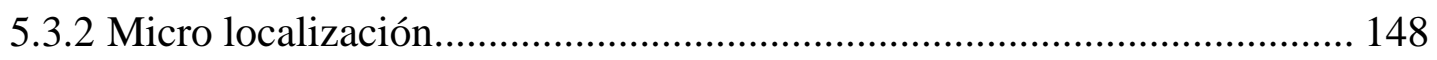

5.3.3 Ubicación de la planta....................................................................... 149

5.3.4 Determinación de la localización óptima.............................................. 150

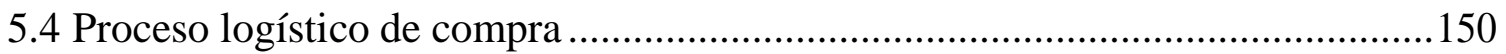

5.5 Implementación de sistemas normativos .......................................................151

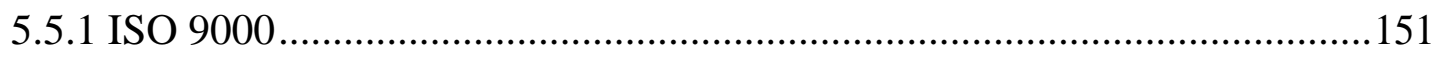

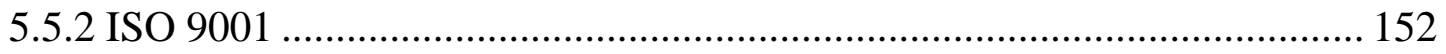

5.5.3 Aplicación del sistema iso 9000 en una planta procesadora de bebidas

Naturales ................................................................................... 153

5.5.4 HACCP (Análisis de peligros y puntos críticos de control) ..................... 155

5.5.5 Evaluación del plan HACCP en el proceso de elaboración de una bebida

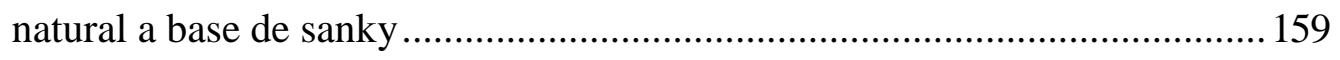

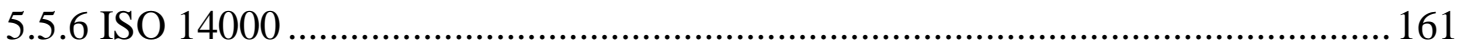

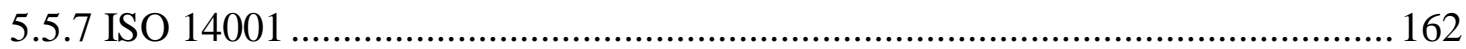

5.5.8 Aplicación de las normas iso 14000 en una planta procesadora de bebidas

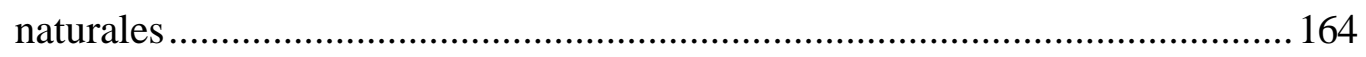

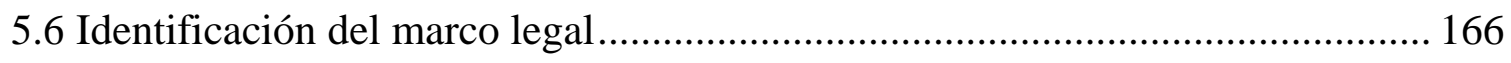

5.6.1 Ordenamiento jurídico de la empresa.................................................. 166

Capítulo VI.................................................................................................................................... 168

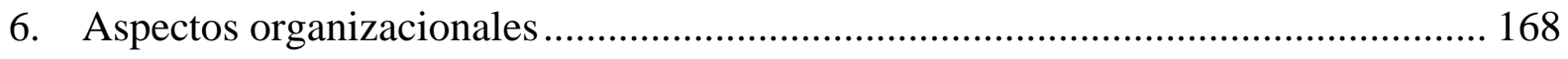

6.1 Características de la cultura organizacional deseada ..................................... 168

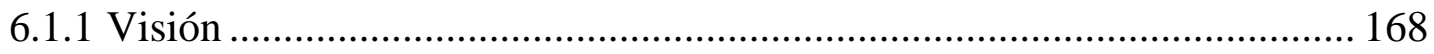

6.1.2 Misión ....................................................................... 168 
6.1.3.1 Responsabilidad 168

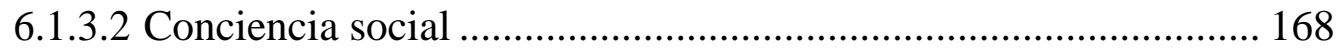

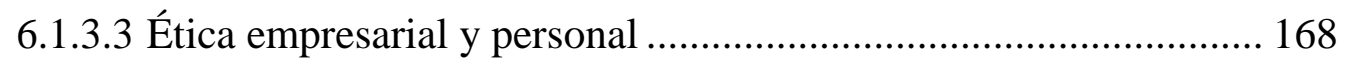

6.1.3.4 Compromiso 169

6.1.3.5 Respeto $\quad 169$

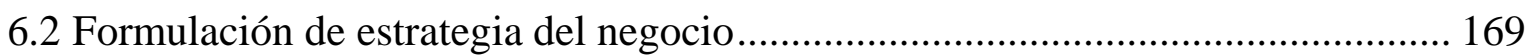

6.3 Determinación de las ventajas competitivas críticas............................................... 169

6.4 Diseño de la estructura organizacional deseada ...................................................... 170

6.5 Diseño de los perfiles de puestos clave ................................................................ 171

6.6 Remuneraciones, compensaciones e incentivos..................................................... 174

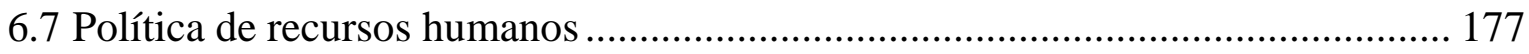

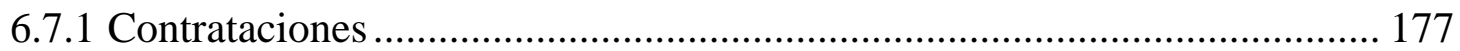

6.7.2 Régimen laboral y beneficios sociales ......................................................... 178

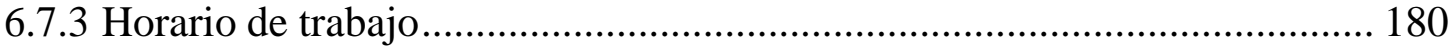

Capítulo VII ........................................................................................................................................... 181

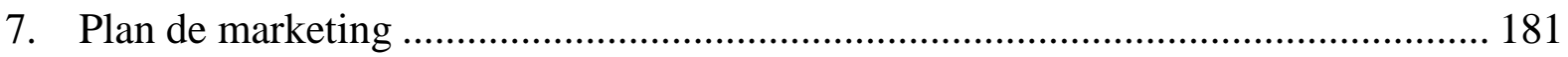

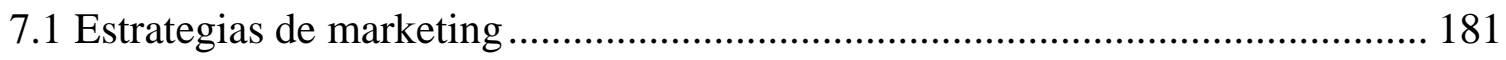

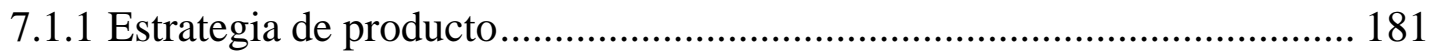

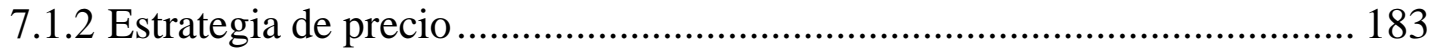

7.1.3 Estrategia de distribución............................................................................ 186

7.1.4 Estrategia de producto y publicidad.......................................................... 187

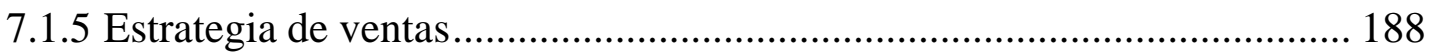

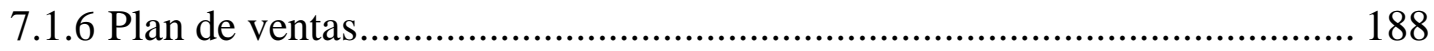

Capítulo VIII ....................................................................................................................................... 189

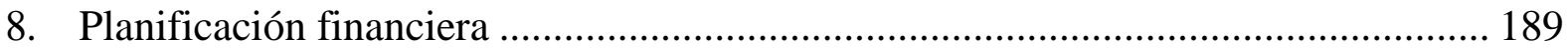

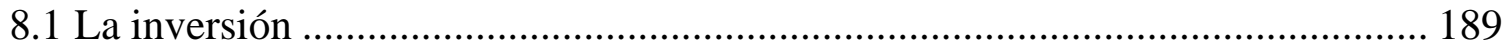

8.1.1 Inversión pre-operativa ……………………………………………….... 189 
8.1.2 Inversión en capital de trabajo ........................................................... 194

8.1.3 Costo del proyecto ........................................................................... 196

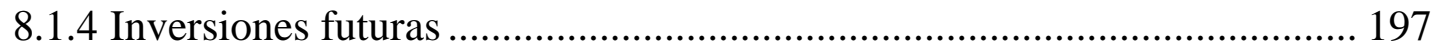

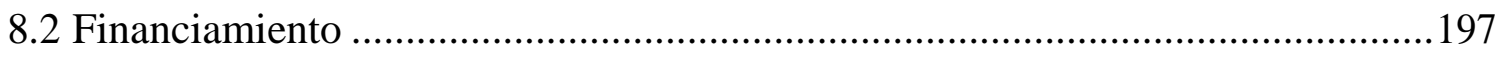

8.2.1 Capital propio y costo de oportunidad ................................................. 197

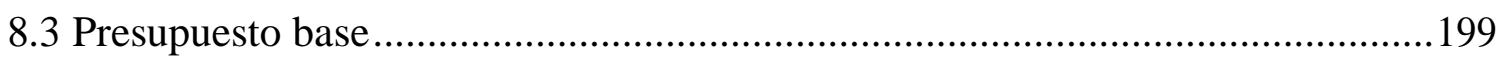

8.3.1 Presupuesto de ventas ..................................................................... 199

8.3.2 Presupuesto de costos de producción..................................................... 200

8.3.3 Presupuesto anual de costo de ventas ................................................... 204

8.3.4 Presupuesto de gastos administrativos ................................................ 205

8.3.5 Presupuesto de gastos de ventas....................................................... 205

8.3.6 Resumen: módulo de inversiones, costos y gastos.................................. 206

8.3.7 Resumen de liquidación de IGV ...................................................... 207

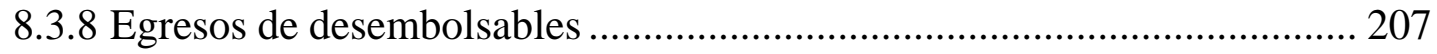

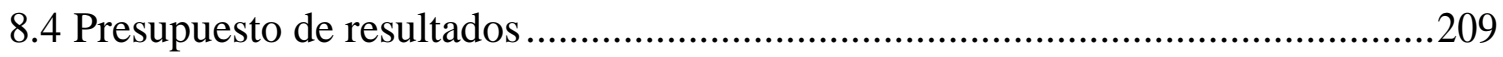

8.4.1 Estado de stuación financiera proyectado............................................ 209

8.4.2 Estado de ganancias y pérdidas proyectado ......................................... 210

8.4.3 Flujo de caja proyectado ............................................................ 210

Capítulo IX .............................................................................................................................. 211

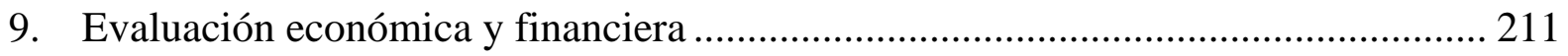

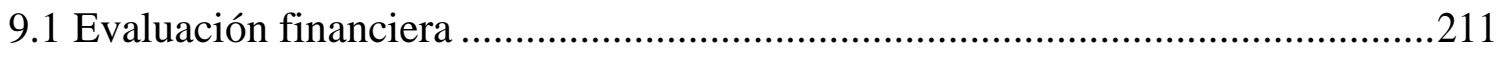

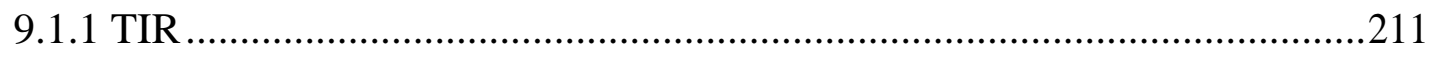

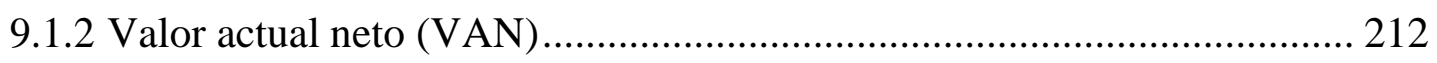

9.1.3 Retorno sobre el patrimonio ......................................................... 212

9.1.4 Período de recuperación descontado.................................................... 213

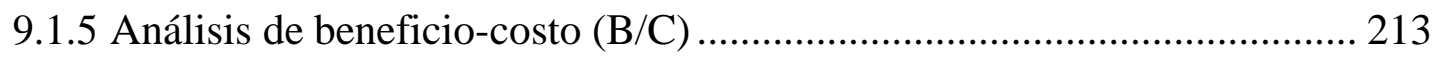

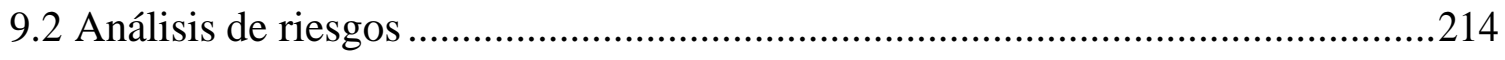

9.2.1 Análisis de punto de equilibrio ......................................................... 214 


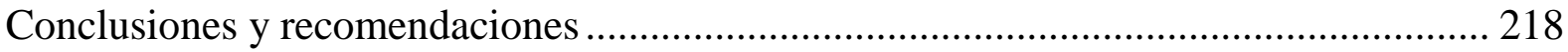

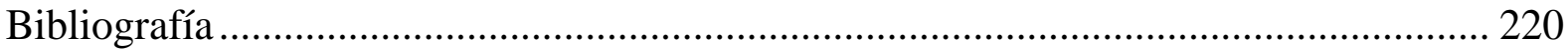

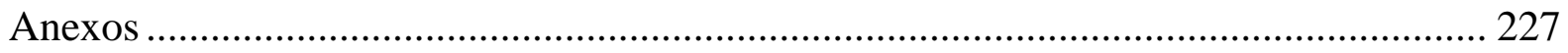

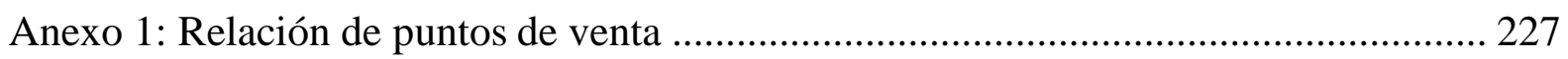

Anexo 2: Transcripciones, entrevistas y focus group ................................................ 230

Anexo 3: Ficha de reclutamiento, ficha técnica, guía de pautas y focus group ..................247

Anexo 4: Encuesta comprobatoria ......................................................................... 283

Anexo 5: Estimación de la población en zona 7 de Lima Metropolitana ........................ 291

Anexo 6: Cálculo de la proporción de la población de la zona 7 de Lima

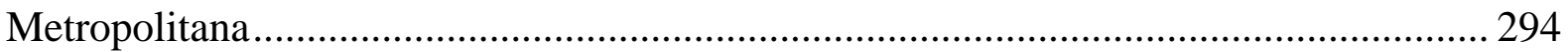

Anexo 7: Tabla de contingencia para el cálculo de la proporción del mercado .............. 295

Anexo 8: Cálculo del COK del inversionista (Modelo CAPM) .................................... 296

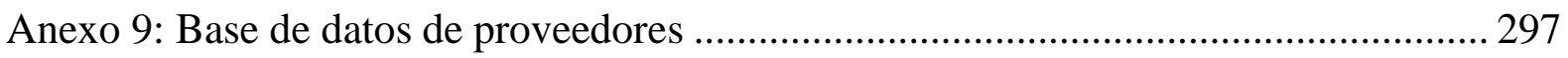

Anexo 10: Formato de costos proveedores nuevo ...................................................... 298

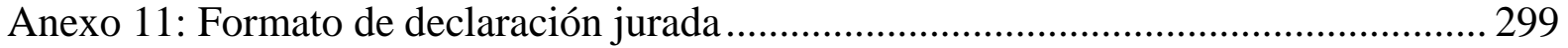

Anexo 12: Formato de Ingreso de productos proveedor nuevo ..................................... 301

Anexo 13: Formato de Ficha Técnica de Alimentos ..................................................... 302

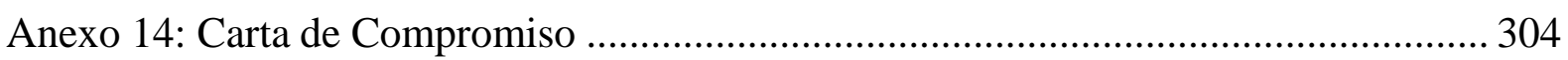




\section{Índice de Tablas}

Página $\mathbf{N}^{\circ}$

Tabla 1. Proyección de ventas "Off Trade” por categorías................................................... 24

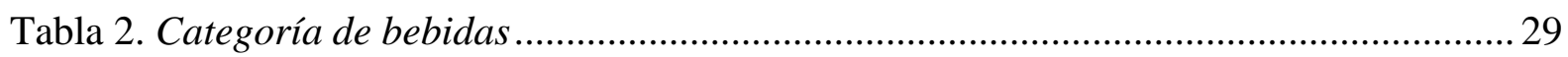

Tabla 3. Producto bruto interno por sectores productivos 2005-2016 (millones de

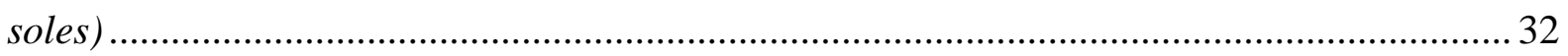

Tabla 4. Participación de mercado de los competidores ......................................................... 40

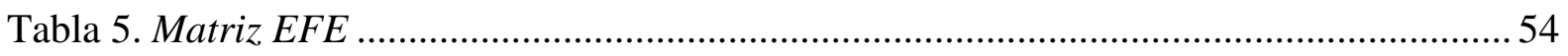

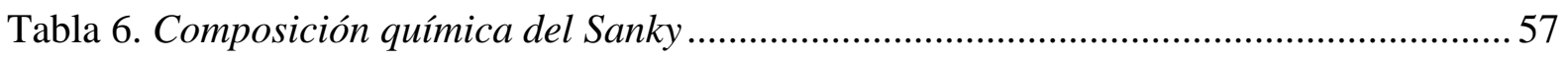

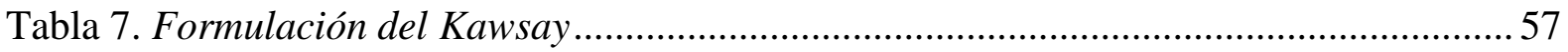

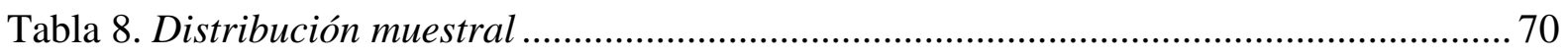

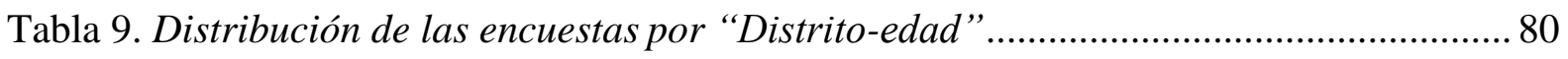

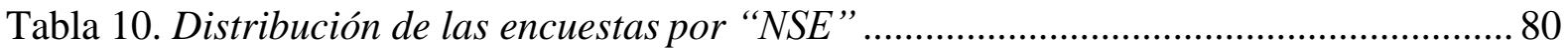

Tabla 11. Análisis de fiabilidad del cuestionario ................................................................. 81

Tabla 12. Resultados de pregunta A según rangos de edad ................................................. 82

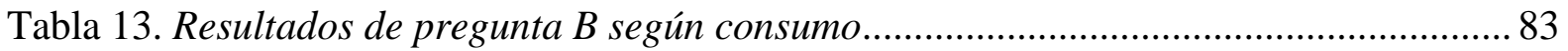

Tabla 14. Resultados de pregunta C según marcas ................................................................ 84

Tabla 15. Resultados de pregunta D según satisfacción ...................................................... 85

Tabla 16. Resultados de pregunta E según textura .................................................................. 86

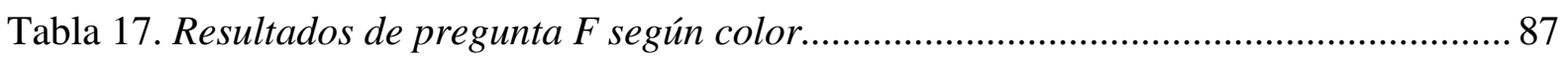

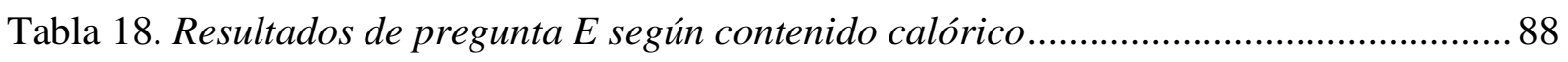

Tabla 19. Resultados de pregunta E según imagen de la marca ............................................. 89

Tabla 20. Resultados de pregunta E según presentación ...................................................... 90

Tabla 21. Resultados de pregunta E según precio.............................................................. 91

Tabla 22. Resultados de pregunta E según propiedades naturales ........................................ 92

Tabla 23. Resultados de pregunta E según tamaño .............................................................. 93

Tabla 24. Resultados de pregunta E según valor nutricional ............................................... 94

Tabla 25. Resultados de pregunta E según variedad de sabores........................................... 95

Tabla 26. Resultados de pregunta F según frecuencia ........................................................ 96 
Tabla 27. Resultados de pregunta G según consumo 97

Tabla 28. Resultados de pregunta H según conocimiento del producto. 98

Tabla 29. Resultados de pregunta I según sabor . 99

Tabla 30. Resultados de pregunta I según color. 100

Tabla 31. Resultados de pregunta I según sabor residual. 101

Tabla 32. Resultados de pregunta I según textura..... 102

Tabla 33. Resultados de pregunta I según satisfacción de aroma. 103

Tabla 34. Resultados de pregunta J según disposición de consumo 104

Tabla 35. Resultados de pregunta K según tipo de envase..... 105

Tabla 36. Resultados de pregunta L según tamaño 106

Tabla 37. Resultados de pregunta M según precio. 107

Tabla 38. Resultados de pregunta $N$ según plaza. 108

Tabla 39. Resultados de pregunta O según nombre del producto 109

Tabla 40. Resultados de pregunta P según difusión

Tabla 41. Población para la zona 7 de Lima Metropolitana 2000-2015

Tabla 42. Población proyectada para la zona 7 Lima Metropolitana 2016-2021 116

Tabla 43. Niveles socioeconómicos en zona 7 Lima Metropolitana (\%).

Tabla 44. Filtro por nivel socioeconómico

Tabla 45. Proporción de población proyectada por edad de 18 á 50 años de la zona 7 de Lima Metropolitana 118

Tabla 46. Mercado potencial (en consumo de personas) 118

Tabla 47. Consumo de bebidas naturales envasadas 119

Tabla 48. Mercado disponible (en número de personas).

Tabla 49. Proporción de población disponible con intención de consumo 120

Tabla 50. Mercado efectivo (en número de personas)..... 120

Tabla 51. Participación de mercado por marca y operador 121

Tabla 52. Mercado objetivo (número de personas) 122

Tabla 53. Frecuencia de compra (al año). 123

Tabla 54. Unidades de compra (número de botellas) 123 
Tabla 55. Demanda proyectada (en número de unidades)........

Tabla 56. Variación de ventas (\%) para el primer año considerando estacionalidad. 124

Tabla 57. Variación de ventas (\%) 145

Tabla 58. Determinación de Capacidad de la Planta...... 146

Tabla 59. Macrolocalización 148

Tabla 60. Factores y ponderación 149

Tabla 61. Estacionalidad de la cosecha de la fruta..... 151

Tabla 62. Perfil del gerente general 171

Tabla 63. Perfil del jefe de producción 172

Tabla 64. Perfil del operario de producción 173

Tabla 65. Modelo de cuantificación de operarios 173

Tabla 66. Perfil del asistente 174

Tabla 67. Cuadro de mano directa . 174

Tabla 68. Cuadro de mano indirecta . 175

Tabla 69. Cuadro de gastos administrativos 176

Tabla 70. Beneficios sociales 177

Tabla 71. Resumen de precios de la competencia según tamaño de envase...... 184

Tabla 72. Costo Unitario del Producto 185

Tabla 73. Fjación de precio a canal de venta y a consumidor final...... 186

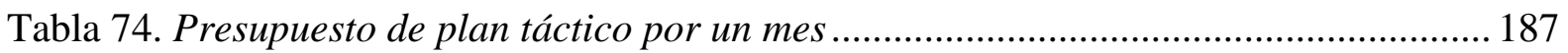

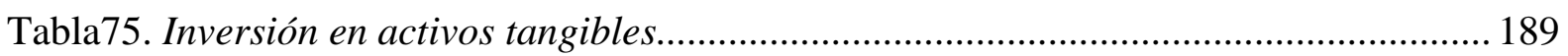

Tabla 76. Inversión en activos fijos operativos ................................................................... 190

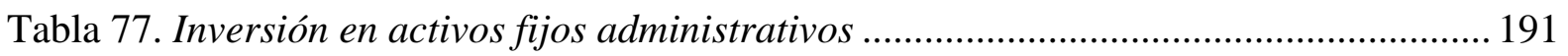

Tabla 78. Equipamiento de seguridad empresa industrial ................................................. 192

Tabla 79. Equipos de protección personal EPS - Planta Industrial ..................................... 192

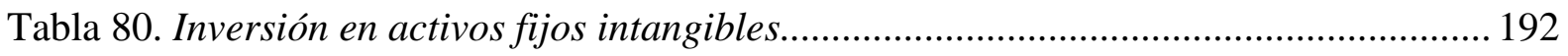

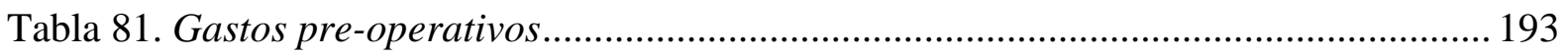

Tabla 82. Implementación de sistemas normativos (certificaciones) .................................... 194

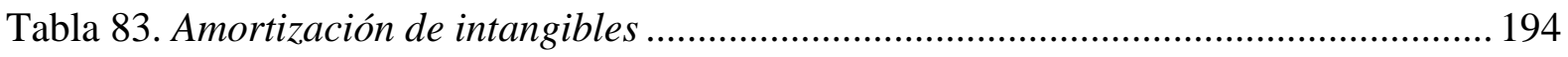


Tabla 84. Capital de trabajo 195

Tabla 85. Flujo de capital de trabajo 196

Tabla 86. Inversión en activos tangibles. 196

Tabla 87. Estructura de inversión. 196

Tabla 88. Costo de operatividad. 198

Tabla 89. Hipótesis sobre primas de riesgo. 198

Tabla 90. Valor de venta y precio de venta del producto 199

Tabla 91. Ingreso anual de ventas 2017-2021 200

Tabla 92. Presupuesto de costo de producción 2017-2021 200

Tabla 93. Presupuesto anual de materia prima. 201

Tabla 94. Beneficios laborales pequeña empresa. 202

Tabla 95. Presupuesto anual de mano de obra directa ..... 202

Tabla 96. Presupuesto anual de costo indirecto de producción y CIF.. 203

Tabla 97. Presupuesto anual de costos de ventas. 204

Tabla 98. Presupuesto anual de costos de ventas. 205

Tabla 99. Presupuesto anual de gastos de ventas. 205

Tabla 100. Resumen de inversiones, costos y gastos 206

Tabla 101. Liquidación de IGV. 207

Tabla 102. Depreciación de activos fijos. 207

Tabla 103. Amortización de intangibles ..... 208

Tabla 104. Estado de situación financiera proyectado o balance general. 209

Tabla 105. Estado de ganancias y pérdidas 210

Tabla 106. Flujo de caja proyectado: inversiones, costos y gastos. 210

Tabla 107. Flujo de caja proyectado 211

Tabla 108. Determinación del período de recuperación descontado 213

Tabla 109. Análisis Beneficio-Costo. 214

Tabla 110. Cálculo del punto de equilibrio (botellas). 215

Tabla 111. Indicadores ante variación de demanda..... 216

Tabla 112. Indicadores ante variación del valor de ventas. 216

Tabla 113. Indicadores ante variación del costo del insumo principal. 


\section{Índice de Figuras}

Página $\mathbf{N}^{\circ}$

Figura 1. Participación de la producción de bebidas ............................................................... 30

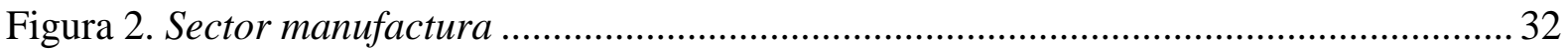

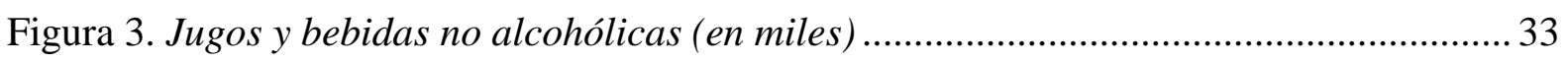

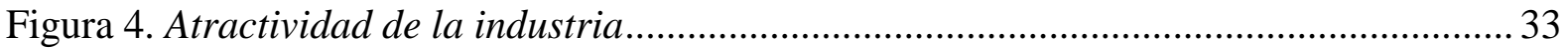

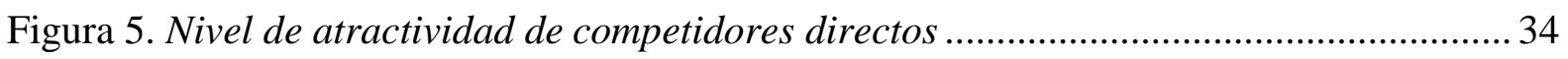

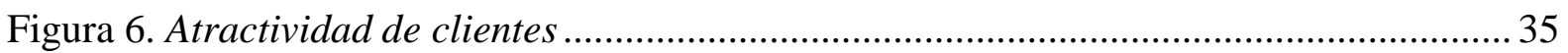

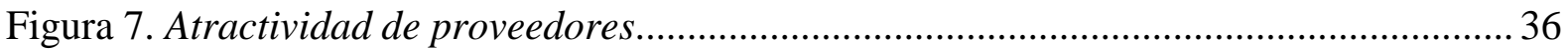

Figura 8. Atractividad de competidores sustitutos ............................................................... 37

Figura 9. Atractividad de competidores potenciales............................................................... 39

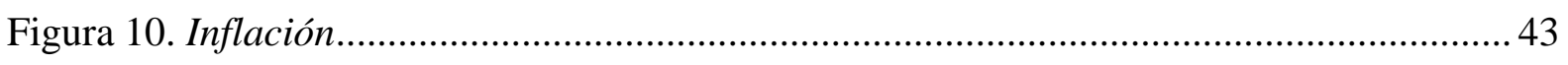

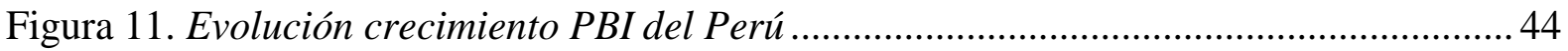

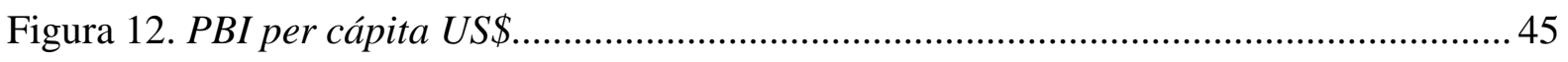

Figura 13. Población de Lima Metropolitana Zona 7 - 2015 ................................................ 59

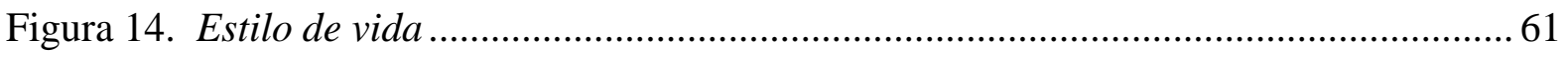

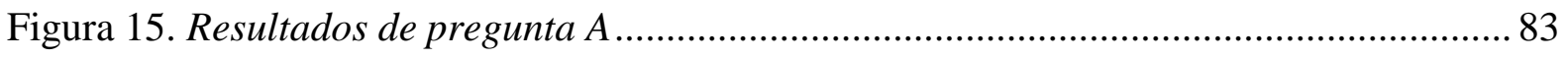

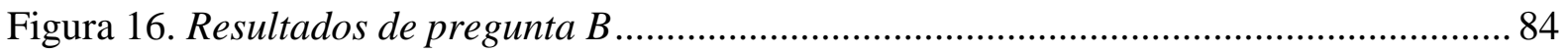

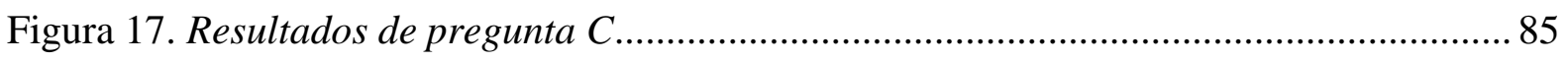

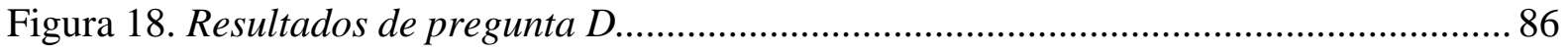

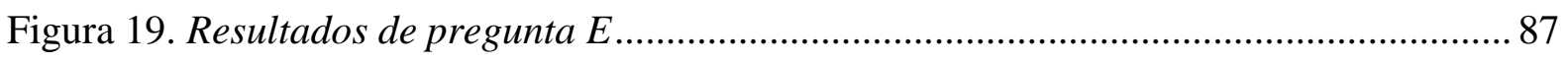

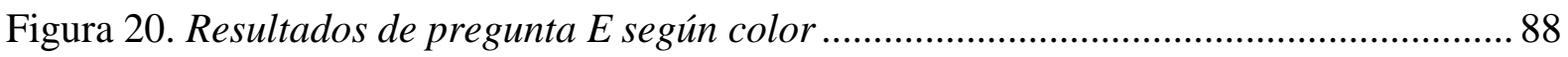

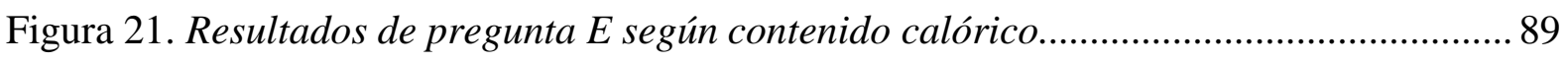

Figura 22. Resultados de pregunta E según imagen de la marca.......................................... 90

Figura 23. Resultados de pregunta E según presentación ...................................................... 91

Figura 24. Resultados de pregunta E según precio .............................................................. 92

Figura 25. Resultados de pregunta E según propiedades naturales....................................... 93

Figura 26. Resultados de pregunta E según tamaño............................................................ 94

Figura 27. Resultados de pregunta E según valor nutricional .............................................. 95

Figura 28. Resultados de pregunta E según variedad de sabores ......................................... 96 
Figura 29. Resultados de pregunta F según frecuencia de consumo..................................... 97

Figura 30. Resultados de pregunta G según número de unidades de consumo....................... 98

Figura 31. Resultados de pregunta H según conoce el Sanky ............................................... 99

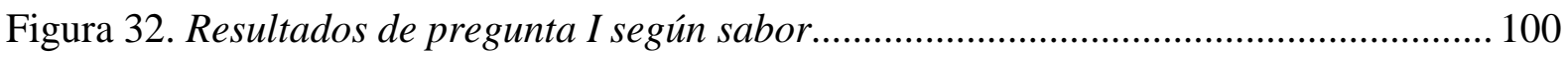

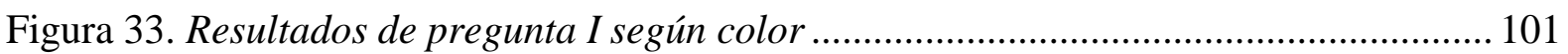

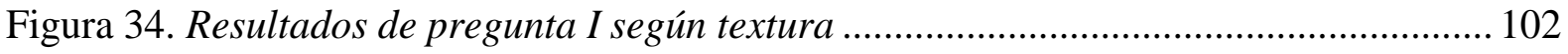

Figura 35. Resultados de pregunta I según sabor residual ................................................ 103

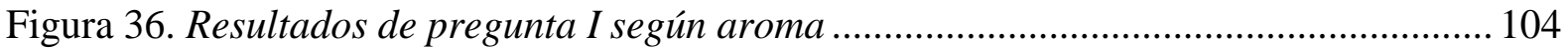

Figura 37. Resultados de pregunta J según disposición de consumo del producto................ 105

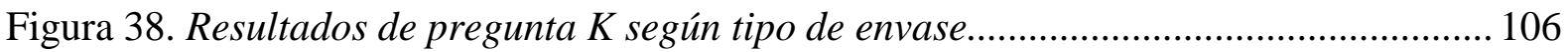

Figura 39. Resultados de pregunta L según tamaño de envase ............................................ 107

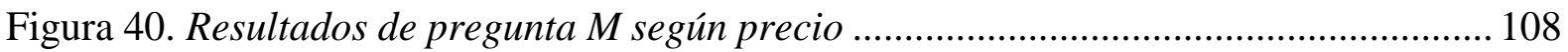

Figura 41. Resultados de pregunta N según plaza............................................................... 109

Figura 42. Resultados de pregunta O según nombre del producto........................................ 110

Figura 43. Resultados de pregunta P según difusión.............................................................. 111

Figura 44. Flujo de procesos de producción (Balance de Materia) ....................................... 130

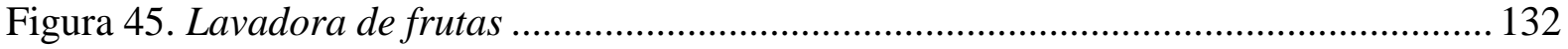

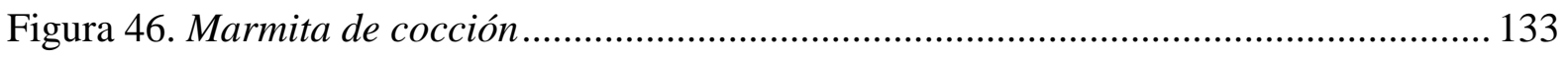

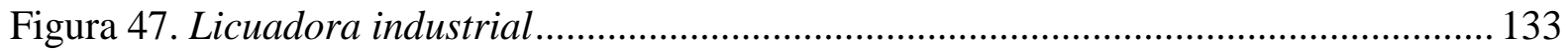

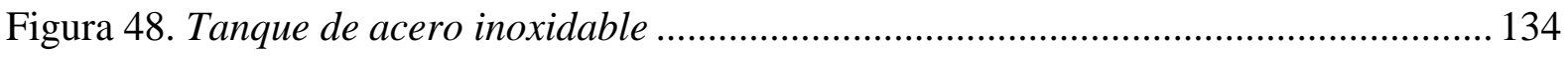

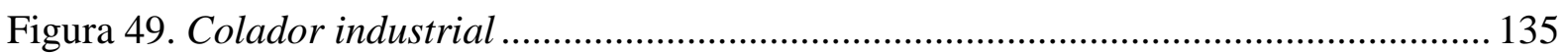

Figura 50. Tanque de agua de acero inoxidable ................................................................. 135

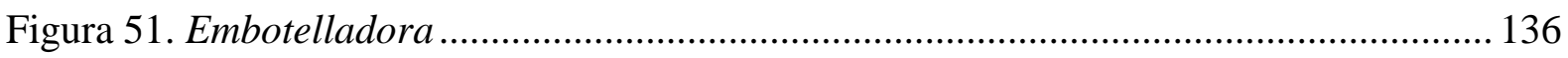

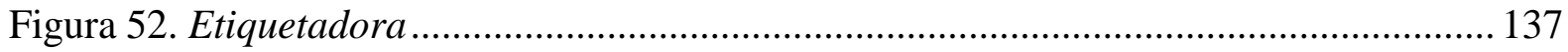

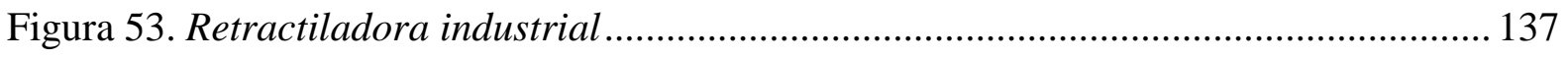

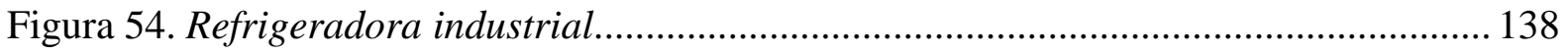

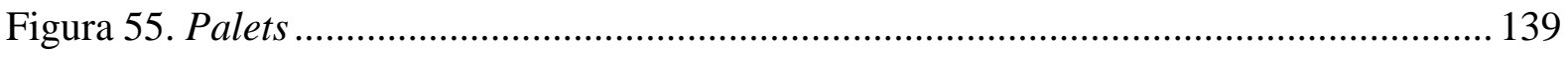

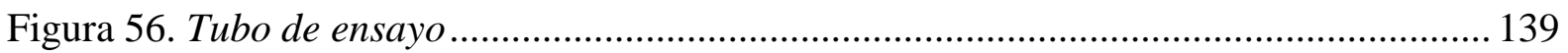

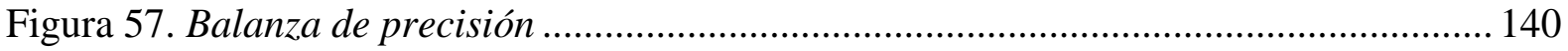

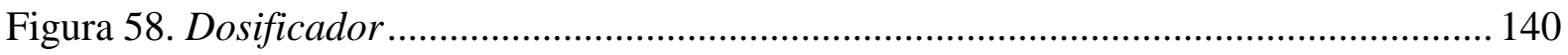




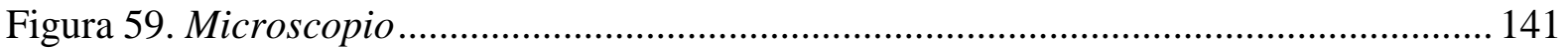

Figura 60. Mesa de trabajo .................................................................................... 141

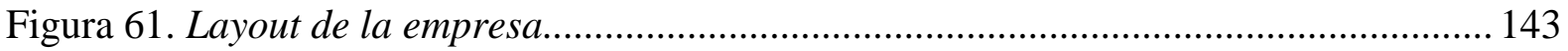

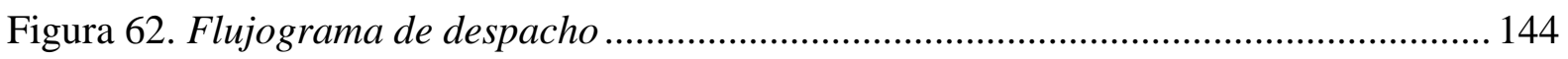

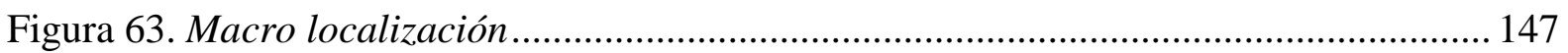

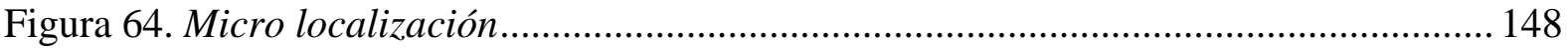

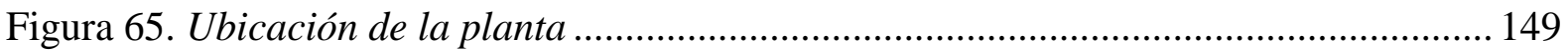

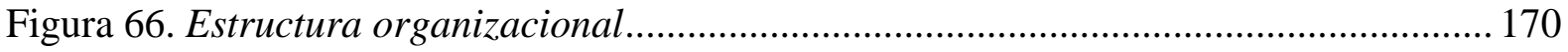

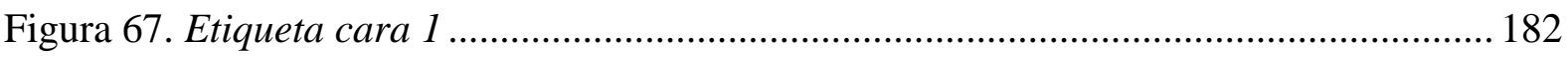

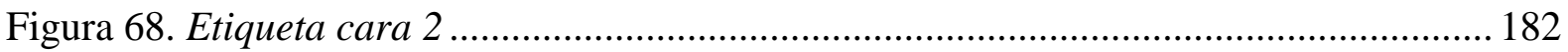

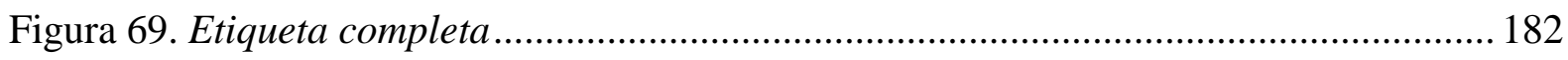

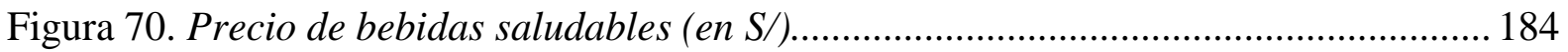




\section{Resumen Ejecutivo}

La razón social del proyecto es FRUTOS NATIVOS DEL SUR SAC, y el nombre comercial es KAWSAY bebida refrescante natural. El código con el que está clasificado el producto es: CIIU 111104 Elaboración de Bebidas No Alcohólicas, Producción de Aguas Minerales y otras aguas embotelladas*.

En esta última década, tanto en el mundo como en el Perú hay una tendencia a la vida saludable; esta tendencia se percibe ante la búsqueda de muchas personas por verse bien y sentirse bien.

Se puede observar que hay una industria del bienestar que se viene desarrollando en forma galopante y cuyos productos podemos verlos en el mercado: batidos nutricionales, bebidas naturales, alimentos con pocos preservantes, etc. Esto representa una oportunidad para introducir al mercado la propuesta de negocio desarrollada.

El perfil del consumidor lo identificamos como personas entre 18 y 50 años, que cuenten con educación superior tecnológica y superior universitaria ya sea en curso o estudios terminados, que tengan además capacidad de compra media-alta, con alta tendencia a verse y sentirse bien y que aprecian la calidad del producto o servicio que adquieren.

El sector industrial relacionado a las bebidas en el Perú es bien dinámico. El resultado obtenido en la matriz resumen de las cinco fuerzas de Porter sobre el análisis de este sector, nos refieren un entorno "atractivo"

La empresa Frutos Nativos del Sur SAC ofrece un producto natural bebible de la fruta andina Sanky aprovechando sus altos contenidos de potasio, fósforo, antioxidantes, calcio, vitamina $\mathrm{C}$ y gomas naturales, beneficioso para atacar el sobrepeso, combatir la hipertensión arterial y sobre todo el cansancio. La presentación de la bebida será en botellas de plástico de 
$250 \mathrm{ml}$ a un precio de S/ 3.32 sin IGV para nuestro canal de venta, que es canal moderno, mediante una estrategia de distribución indirecta.

El costo de la inversión es de S/ 253846.96, el cual será cubierto en su integridad por capital propio.

Se ha contemplado en el plan de negocios el registro de marca y patente que está dentro de la amortización de intangibles.

El punto de equilibrio fue determinado cuando se llegue a la producción 220,141 unidades de botellas al año 1 (2017), donde los Costos Totales sean iguales a los Ingresos Totales $\mathrm{CT}=\mathrm{YT}$.

Respecto a los indicadores de rentabilidad podemos indicar lo siguiente:

\begin{tabular}{cc}
\hline COK & $12.19 \%$ \\
TIR & $27.50 \%$ \\
VAN & S/ 97951.39 \\
ROE & $28.48 \%$ \\
B/C & 1.38 \\
PayBack Descontado & 3 años 2.68 meses \\
\hline
\end{tabular}

Se observa que la tasa interna de retorno es de $27.50 \%$; está por encima del (cok) $12.19 \%$ indicando el retorno anual sobre cada sol invertido; el VAN es del orden de los S/ 97951.39 lo que refleja que el proyecto genera valor para los inversionistas; el retorno sobre el capital (ROE) llega al $28.48 \%$ y el B/C indica que por cada sol colocado en la inversión se producirá 1.38 soles de beneficio. Se considera que la bebida Kawsay Sankyfruit tendrá relativo éxito porque es un producto novedoso, a base de una fruta natural y que cubre una demanda insatisfecha como se ha demostrado en el estudio de mercado. 


\section{Introducción}

En esta última década, tanto en el mundo como en el Perú hay una tendencia a la vida saludable; esta tendencia se percibe ante la búsqueda de muchas personas por verse bien y sentirse bien.

Se puede observar que hay una industria del bienestar que se viene desarrollando en forma galopante y cuyos productos podemos verlos en el mercado: batidos nutricionales, bebidas naturales, alimentos con pocos preservantes, etc.

Es en este contexto en el cual se realiza el presente Plan de Negocios con el que se pretende cubrir en parte la demanda de productos que esta tendencia ha ido generando a través del tiempo.

Este enfoque se centra en la elaboración de un producto correspondiente al rubro de bebidas naturales funcionales y el nombre del producto será "Kawsay-Bebida natural a base de Sanky".

El presente Plan de Negocios, se desarrolla en nueve capítulos. En el Capítulo I se tratan los antecedentes, la determinación de la oportunidad, la justificación del proyecto, el objetivo general y los objetivos específicos, así como también los alcances y limitaciones de la investigación.

En el capítulo II se habla de la estructura económica del sector al cual pertenece, en este caso el sector manufactura, descripción del estado actual de bebidas, segmentación de la industria de bebidas, empresas que la conforman. Tendencias de la industria del sector manufactura. Análisis estructural del sector industrial. Análisis de la competencia. Análisis del contexto actual y esperado, que incluye el análisis político-gubernamental, análisis legal, análisis cultural, análisis tecnológico, análisis ecológico y oportunidades. 
En el capítulo III se analiza el estudio de mercado, la descripción del producto, selección del segmento de mercado mediante los siguientes criterios de segmentación: geográfica, demográfica y psicográfica. Se realiza una investigación cualitativa, proceso de muestreo, siendo esta exploratoria: focus group y entrevistas a profundidad y una investigación cuantitativa mediante encuesta exploratoria y encuesta comprobatoria, el respectivo análisis de la encuesta comprobatoria y las conclusiones y recomendaciones del estudio cualitativo y cuantitativo. Asimismo, se menciona el perfil del consumidor tipo y sus variantes.

En el capítulo IV se analiza la proyección del mercado objetivo, se menciona el ámbito de proyección, se realiza la selección del método de proyección: mercado potencial, mercado disponible, mercado efectivo y finalmente el mercado objetivo. Se determina el pronóstico de ventas utilizando las preguntas de la encuesta y los aspectos críticos que impactan en el pronóstico del mismo.

En el capítulo V, se analiza la ingeniería del proyecto, el estudio de la ingeniería, el modelamiento y selección de los procesos productivos, la selección del equipamiento, layout y distribución de equipos y maquinarias, determinación del tamaño, proyección de crecimiento, recursos, tecnología, flexibilidad, selección del tamaño ideal. También se ve el estudio de la localización, mediante la macro localización y micro localización, determinando con esto la localización óptima. Se mencionan las consideraciones legales y se define el ordenamiento jurídico de la empresa.

En el capítulo VI, se ven los aspectos organizacionales, la visión, misión y los principios en los que se debe de basar la empresa. Formulación de estrategias del negocio, determinación de las ventajas competitivas críticas, el diseño de la estructura organizacional deseada, diseño de los perfiles de puestos clave, remuneraciones, compensaciones e incentivos, política de recursos humanos, régimen laboral y beneficios sociales. 
En el capítulo VII, se tiene el plan de marketing, estrategia del producto, del precio, de distribución, de promoción y publicidad, de ventas. Plan de ventas, políticas de servicio y garantías.

En el capítulo VIII, se trata la planificación financiera, donde se tiene la inversión, la inversión pre-operativa, inversión en capital de trabajo, costo del proyecto, inversiones futuras, financiamiento, endeudamiento y condiciones, capital y costo de oportunidad, costo de capital promedio, presupuesto base, presupuesto de ventas, presupuesto de costo de producción, presupuesto de costo de ventas, presupuesto de gastos administrativos, presupuestos de marketing y ventas, presupuestos de gastos financieros, presupuestos de resultados, y estado de ganancias y pérdidas proyectado, balance proyectado y flujo de caja proyectado.

En el capítulo IX, se realiza la evaluación económica financiera, donde se determina el COK. La evaluación financiera: TIR, VAN, ROE, ratios, análisis de riesgos, análisis de punto de equilibrio, análisis de sensibilidad y análisis de escenarios, finalizando con las conclusiones y recomendaciones. 


\section{Capítulo I}

\section{Generalidades}

\subsection{Antecedentes}

Actualmente se observa una tendencia cada vez más generalizada por el bienestar (verse y sentirse bien) y entre las distintas formas de ver esta tendencia está la del consumo de bebidas saludables. Según el artículo "Producción de bebidas no alcohólicas crecería 8\% para el 2016" se puede leer el resumen de un estudio realizado por "Estudios económicos Scotiabank" donde se menciona que uno de los factores de este crecimiento es la tendencia al consumo de productos naturales, cito: "En ese sentido, prevemos que continúe la tendencia del consumidor de preferir bebidas saludables, sin gas y con menor contenido de azúcar, a lo que se sumaría el lanzamiento de nuevos productos y presentaciones" ${ }^{\text {y }}$ desde otra perspectiva se tiene el estudio de tendencias realizado por Consumer-Truth-Perú donde se manifiesta que las bebidas energéticas también llamadas "Non Stop Drinks" están siendo muy consideradas para sobrellevar rutinas laborales, ritmo académico intenso y rutinas de ejercicios. $^{2}$

Aprovechando este escenario, la presente idea de negocio se basa en la producción y comercialización de una bebida saludable y energética natural, llamada también bebida funcional, con un mínimo de preservantes, alto contenido de antioxidantes y calcio, que contribuye a retardar el proceso de envejecimiento y mantener revitalizados a los clientes.

En el mercado, existen muchas bebidas, como los jugos o néctares de fruta que contienen altos contenidos de saborizantes y preservantes que, en el mediano y largo plazo, dañan el

\footnotetext{
${ }^{1}$ Diario Gestión "Producción de bebidas no alcohólicas crecería 8\% en el 2016 impulsada por aguas envasadas” Mayo 2016 [en línea] PE [citado el 03 de mayo del 2016]. Disponible en https://gestion.pe/economia/produccion-bebidas-alcoholicas-creceria-8-2016-impulsadaaguas-envasadas-119363

2 Consumer Truth, A. (2014) Global Thinking: Las 4 tendencias más importantes en alimentos y bebidas. Recuperado de http://www.consumer-truth.com.pe/global-thinking-las-4-tendencias-mas-importantes-en-alimentos-y-bebidas/
} 
organismo de sus consumidores, por ello se busca ser una alternativa diferente que no sólo atienda las necesidades de saciar la sed de los consumidores, sino que a la vez contribuya a la salud de los mismos.

\subsection{Determinación del Problema u Oportunidad}

A pesar de la desaceleración que se está viendo en el crecimiento económico del país, en los últimos años se sigue percibiendo de gran manera el cambio de estilo de vida optando por invertir recursos en productos naturales que contribuyan a elevar el bienestar de cada persona. Esta situación se puede apreciar en el creciente interés por cuidar la salud e imagen, cambiando los hábitos alimenticios optando por el consumo de productos naturales y orgánicos. Este cambio de conciencia también es demostrado en las constantes realizaciones de actividades deportivas en la ciudad, la proliferación de nuevos gimnasios, spas, centros integrales de cuidado de la salud, yoga, pilates, etc.

En tal sentido, se ha identificado la oportunidad de atender principalmente a los sectores A y B con el perfil mencionado anteriormente, ya que se considera que existe una demanda insatisfecha por productos naturales de calidad.

Se utilizó el B2B para llegar a los consumidores a través de supermercados y mercados saludables de Lima, el estudio se enfoca en los distritos de La Molina, San Borja, San Isidro, Surco, Miraflores, ya que son los sectores de mayor concentración de los NSE A y B.

\section{Justificación del Proyecto}

Basados en la percepción de la demanda y de la rentabilidad que tienen algunas bebidas de este giro (bebidas no alcohólicas) como por ejemplo "Macarena Punch” que, según estudios, 
refleja una rentabilidad de hasta el $25 \%$ al año 3 , y tomando en cuenta la tendencia creciente en la proyección de ventas de bebidas "off-trade" (ver tabla) 4 así como de la industria del bienestar, es que se estima que el proyecto pueda ser viable para atender a aquellas empresas y clientes finales que decidan comercializar y consumir este tipo de bebida funcional.

Tabla 1

Proyección de ventas "Off Trade" por categoría

\begin{tabular}{lcccccc}
\hline \multicolumn{7}{c}{$\begin{array}{l}\text { PROYECCIÓN DE VENTAS CANAL “OF-TRADE” } \\
\text { POR CATEGORÍA }\end{array}$} \\
Categoría & $\mathbf{2 0 1 5}$ & $\mathbf{2 0 1 6}$ & $\mathbf{2 0 1 7}$ & $\mathbf{2 0 1 8}$ & $\mathbf{2 0 1 9}$ & $\mathbf{2 0 2 0}$ \\
\hline Botella de Agua & 1139.8 & 1252 & 1362.4 & 1476.6 & 1595.8 & 1721.3 \\
Carbonatada & 3352.1 & 3399.8 & 3417.6 & 3455.3 & 3508.8 & 3576 \\
Concentrados & 80.5 & 80.7 & 80.6 & 80.7 & 81.2 & 81.9 \\
Jugos & 903.5 & 930.9 & 948.8 & 969.8 & 994 & 1021.4 \\
Café envasado & 0.4 & 0.4 & 0.4 & 0.4 & 0.4 & 0.5 \\
Té envasado & 366.8 & 425.9 & 489.7 & 555.3 & 622.5 & 691.3 \\
Botellas energéticas & 878 & 960.7 & 1043.9 & 1128.7 & 1513.8 & 1598.9 \\
\multicolumn{1}{c}{ Total } & $\mathbf{6 7 2 1 . 1 0}$ & $\mathbf{7 0 5 0 . 4}$ & $\mathbf{7 3 4 3 . 4}$ & $\mathbf{7 6 6 6 . 8}$ & $\mathbf{8 3 1 6 . 5}$ & $\mathbf{8 6 9 1 . 5}$ \\
\hline
\end{tabular}

Fuente: Diario Gestión [publicado el 21 de diciembre 2016]. Disponible en http://abresa.pe/wp-content/uploads/2014/06/Aguas-y-energizantes-seguir\%C3\%A1nrevitalizando-el-mercado-de-bebidas.pdf

\subsection{Información General}

\subsubsection{Nombre de la empresa, Horizonte de evaluación}

Razón social: FRUTOS NATIVOS DEL SUR SAC

Nombre comercial: KAWSAY BEBIDA REFRESCANTE NATURAL

Tipo de empresa: Sociedad Anónima Cerrada

Empresa especializada en la elaboración de bebidas en base a la fruta andina SANKY.

3 Emprendedores tv: Historia de éxito: Jugo natural y energizante [publicado el 29 de setiembre 2016]. Disponible en http://emprendedorestv.pe/historia-de-exito-jugo-natural-y-energizante

4 Diario Gestión [publicado el 21 de diciembre 2016]. Disponible en http://abresa.pe/wp-content/uploads/2014/06/Aguas-y-energizantesseguir\%C3\%A1n-revitalizando-el-mercado-de-bebidas.pdf 
La presente idea de negocio se originó en la iniciativa de un grupo de emprendedores que valora el potencial de suministrar al mercado una bebida elaborada en base a un fruto andino denominado SANKY que posee una serie de componentes naturales que son de beneficio para el organismo humano.

Considerando el esquema de inversión (implementación de una planta de producción) y teniendo en cuenta que el negocio se encuentra dentro de un sector competitivo, se ha establecido que el Horizonte de Evaluación para el presente proyecto sea de 05 años (2017 2021).

\subsubsection{Actividad económica, código CIIU, partida arancelaria}

La actividad económica está ubicada en la industria manufacturera orientada a la producción y comercialización de bebidas No alcohólicas de sabores naturales no tradicionales.

El código con el que está clasificado el producto es: CIIU 111104 Elaboración de Bebidas No Alcohólicas, Producción de Aguas Minerales y otras aguas embotelladas5.

\subsection{Objetivo general y objetivos específicos}

\subsubsection{Objetivo general}

Desarrollar un plan de negocio para la producción y comercialización de una bebida natural elaborada a base de sanky endulzado con yacón, con el fin de satisfacer la necesidad de consumir un producto natural y energizante y que sea de beneficio para el consumo del mercado dirigido (Zona 7 de Lima Metropolitana), en base a sus propiedades naturales.

\footnotetext{
5 Dirección Nacional de Cuentas Nacionales del instituto Nacional de Estadística e Informática. Clasificación Industrial Internacional Uniforme . [en línea]. Lima: INEI, 2010 [citado 15 Setiembre 2017]. Acrobat PDF. Disponible en: https://www.inei.gob.pe/media/MenuRecursivo/publicaciones_digitales/Est/Lib0883/Libro.pdf
} 


\subsubsection{Objetivos Específicos:}

a) Lograr la utilidad esperada, desde el año uno, es decir el 2017 al año cinco o año 2021, de acuerdo al estudio realizado.

b) Lograr que la participación en el mercado se incremente gradualmente a razón de $0.5 \%$ anual desde su lanzamiento el año 2017.

c) Incluir la bebida en la dieta diaria aprovechando las bondades del producto para fidelizar a los clientes, desde su ingreso al mercado el año 2017, de acuerdo a la estrategia de marketing-producto.

\subsection{Alcances y limitaciones de la Investigación}

El plan de negocios presentado incorpora en el mercado una bebida natural que atienda la demanda de las personas con hábitos de consumo relacionados al bienestar. Se realizará en el corto plazo y tendrá un horizonte temporal de cinco años desde el 2017 hasta el 2021.

El producto está dirigido a personas de los niveles socioeconómicos A y B de los distritos que conforman la zona 7 de Lima Metropolitana.

La característica diferenciada que posee el producto está vinculado estrechamente con la fruta andina Sanky o Sancayo que tiene componentes que benefician al organismo (fuente de ácido cítrico, posee propiedades laxantes, tiene propiedades tensor- reguladores y también previene la gastritis así como enfermedades hepáticas) ${ }^{6}$

Por otro lado se identifica como limitación la escasa información estadística específica del sector bebidas en el rubro bebidas naturales sobre todo en lo relacionado a los competidores directos puesto que no existe una bebida que tenga como insumo exclusivo al sanky, razón por la cual el apoyo de información se ha realizado con bebidas naturales cuyo insumo sea

\footnotetext{
${ }^{6}$ Portal UNALM "Sanky cactácea andina de alto valor antioxidante" [en línea] PE. 2018 [citado el 01 de setiembre del 2006] Microsoft HTLM. Disponible en http://www.lamolina.edu.pe/gaceta/edicion2006/notas/nota153.htm.
} 
alguna fruta exótica; esto nos permitirá obtener un resultado más preciso en la proyección de mercados. 


\section{Capítulo II}

\section{Estructura económica del sector manufactura}

La economía peruana creció entre $3.9 \%$ y $4 \%$ en 2016, esto representa un porcentaje mayor al del 2015 que fue de un 3.26\% en la actividad productiva nacional7.

La economía peruana habría crecido $2.5 \%$ el cuarto trimestre del 2016, su menor nivel en siete trimestres, debido a la menor contribución del sector minero, mientras que la inversión pública cayó 17.6\% anual, refirió el Área de Estudios Económicos del BCP.

El sector primario creció $10.8 \%$ anual en noviembre de 2016 y explicó el $71 \%$ de ese mes. Descontando el error de la mina Constancia, el sector minero creció $16.3 \%$ anual, impulsado por el avance de la producción de cobre (26.2\%).

El sector pesca avanzó $23.3 \%$ debido al inicio de la segunda temporada de captura de anchoveta. Por tanto, la manufactura procesadora de recursos primarios creció $18.5 \%$.

Por su parte, el sector hidrocarburos cayó 5.9\% ante la menor producción del petróleo crudo $(-37.8 \%)$ por vigésimo tercer mes consecutivo debido a la rotura del Oleoducto Norperuano. Esto no pudo ser compensado por la mayor extracción de líquidos de gas natural $(4.6 \%)$.

Asimismo, el sector agropecuario creció solo $1.2 \%$ anual.

Los sectores no primarios crecieron $1.2 \%$ anual tras avanzar $0.1 \%$ en octubre de 2016 . El sector construcción se contrajo $8.7 \%$ (tercer mes de caída consecutiva).

La manufactura no primaria cayó $1.5 \%$ por séptimo mes consecutivo de caída y en terreno negativo 30 de los últimos 36 meses. La caída fue menor a la esperada debido al avance de la

\footnotetext{
${ }^{7}$ Perú21. "Fernando Zavala: Economía peruana creció entre 3.9\% y 4 \% en el 2016”. En: Perú21. [en línea]. PE, ene., 2017. [citado 15 setiembre 2017]. Microsoft HTML. Disponible en: http://peru21.pe/economia/zavala-economia-peruana-crecio-entre-39-y-4-2016-2267347
} 
producción orientada a consumo masivo. Esta creció 1.1\% en noviembre de 2016, frente a la caída de $-536 \%$ de octubre.

Asimismo, los sectores comercio $(+0.5 \%)$ y servicios $(+3.5 \%)$ crecieron a su ritmo más bajo desde el 2009 y 2004 , respectivamente. 8

\subsection{Descripción del estado actual de la industria de bebidas}

En general la industria de las bebidas se compone de dos categorías principales y ocho subgrupos. La categoría de las bebidas sin alcohol comprende: la fabricación de jarabes de bebidas refrescantes; el embotellado y enlatado de agua y bebidas refrescantes; embotellado, enlatado y envasado en cajas de zumos de frutas; la industria del café; y la industria del té. La categoría de las bebidas alcohólicas incluye los licores destilados, el vino y la cerveza.9

Según información del INEI, actualmente la industria de bebidas está conformada por las categorías indicadas en la tabla:

Tabla 2

Categoría de bebidas

\begin{tabular}{ll}
\hline$>$ Bebidas Gaseosas & $>$ Piscos \\
$>$ Refrescos (líquidos) & $>$ Cerveza Blanca \\
$>$ Vinos y espumantes & $>$ Aguas \\
$>$ Bebidas Hidratantes & \\
\hline
\end{tabular}

Fuente: INEI y elaboración propia

\footnotetext{
8 Diario Gestión [ Publicado el 23 de enero del 2017]. Disponible en https://gestion.pe/economia/bcp-recuperacion-demanda-internasentira-negocios-segundo-semestre-127172

9 INEI: Fuente: Ministerio de la Producción-Viceministerio de MYPE e Industria. Ministerio de Agricultura-Oficina de Estudios Económicos y Estadísticos. Disponible en http:// www.inei.gob.pe/estadisticas/indice-tematico/sector-statistics/
} 


\subsubsection{Segmentación de la industria de bebidas}

Tomando como referencia el promedio de la producción de cada una de las bebidas mencionadas (entre los años 2012-2016), la participación está segmentada de la siguiente manera:

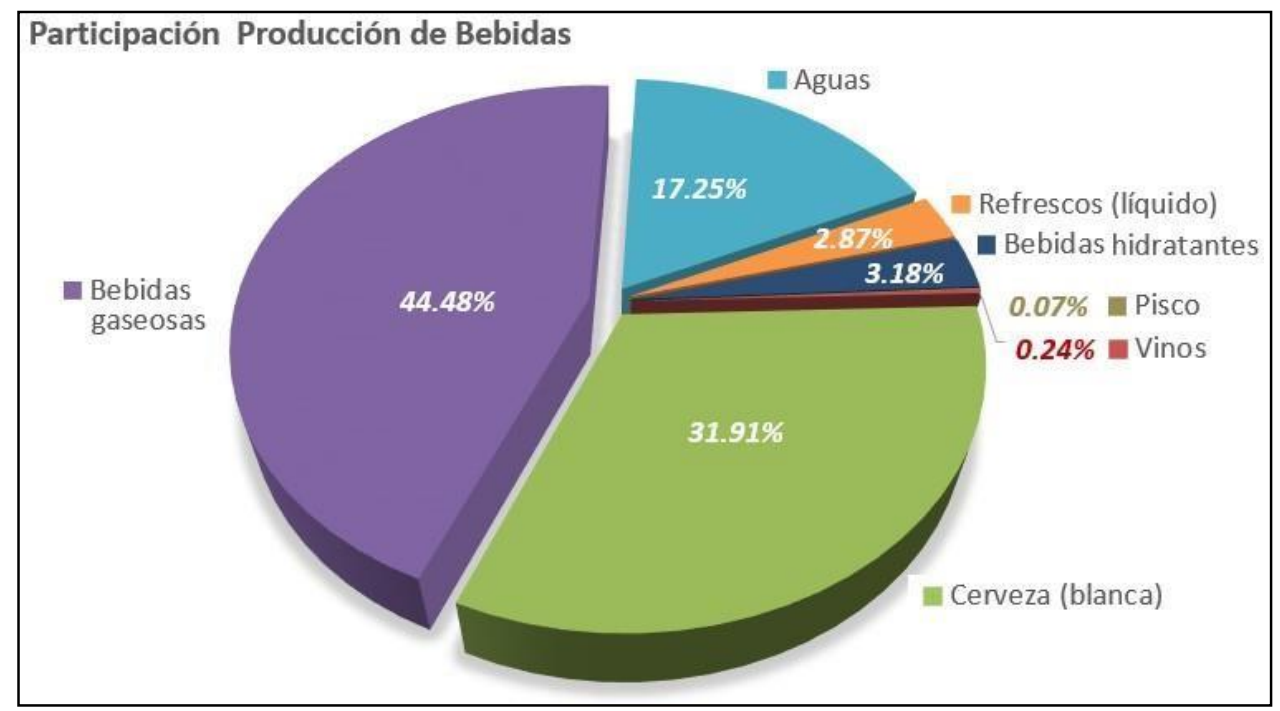

Figura 1. Participación de la Producción de Bebidas

Fuente: INEI y elaboración propia

\subsubsection{Empresas que la conforman. -}

Entre las empresas que conforman la industria de bebidas, tenemos:

a. AJEGROUP en 2015, vendió 3,600 millones de litros de bebidas de todo el mundo. Con 28 años de experiencia; con presencia en más de 23 países; 8 marcas a nivel mundial siendo BIG cola la más emblemática; 32 fábricas y 13000 colaboradores. (fuente:

\section{AJEGROUP)}

b. UCP BACKUS y JHONSTON con un volumen de ventas de S/ 3,846.4 millones distribuidos según sus categorías: S/ 3,495.8, millones en cervezas; S/ 161.6 millones en gaseosas; S/ 143.9 millones en agua; S/ 45.1 millones en maltas. (fuente: Memoria Anual Backus 2015) 
c. CORPORACIÓN JOSÉ R. LINDLEY, con ocho plantas en funcionamiento: Callao, Zárate, Pucusana, Huacho, Trujillo, Arequipa, Cuzco e Iquitos tuvo un volumen de ventas de S/ 2,842 millones de soles consecuencia de una mejor composición del mix del producto. (Fuente: Memoria Anual JR Lindley 2015)

d. GRUPO GLORIA SA, Las ventas netas en el 2015 se incrementaron en 5.2\% respecto al año anterior alcanzando un total de S/ 3519.8 millones. El número de personas empleadas por la empresa a diciembre del 2015 fue de 2002 trabajadores entre funcionarios, empleados y obreros con condición de estables y también de plazo fijo.

e. LAIVE SA, mantiene operando tres unidades de producción ubicadas en Lima, Arequipa y Majes donde elabora productos como yogurt, jugo (además de mantequillas, quesos, manjares y embutidos). El total de trabajadores es de 1110 colaboradores entre administrativos y operativos; cabe señalar que también genera 629 puestos de trabajos a través de terceros en sus áreas de ventas. En el año 2015 las ventas se incrementaron 4.8\% respecto al año anterior alcanzando un total de S/ 495.0 millones.

f. ABT Productos Naturales S.A.C. Empresa enfocada en brindar alimentos y bebidas premium al consumidor final, al día con las últimas tendencias en empaques, procesos e ingredientes naturales. Casa Matriz Calle Daniel Cruz 109 / La Calera de La MercedSurquillo - Lima/ Número de trabajadores: 11 a 50 personas. Ingresos anuales de USD 100,000 a $500,000$.

\subsection{Tendencias de la industria.}

En el Perú -proyectado al 2016- operan más de 1.7 millones de MYPES y este segmento representa el $99.5 \%$ del total de empresas formales en la economía peruana de las cuales el 
$85.6 \%$ realizan actividades de comercio y servicios mientras que el $14.4 \%$ a la actividad productiva (donde se encuentra manufactura).10

La evolución del PBI por sectores productivos se encuentra:

Tabla 3

Producto Bruto Interno por sectores productivos 2005 - 2016 (Millones de Soles)

\begin{tabular}{|c|c|c|c|c|c|c|c|c|c|c|c|c|}
\hline Sector & 2005 & 2006 & 2007 & 2008 & 2009 & 2010 & 2011 & 2012 & 2013 & 2014 & 2015 & 2016 \\
\hline Agropecuario & 16,948 & 18,462 & 19,074 & 20,600 & 20,873 & 21,766 & 22,658 & 23,991 & 24,362 & 24,814 & 25,614 & 26,076 \\
\hline Pesca & 2,086 & 2,163 & 2,364 & 2,436 & 2,352 & 1,891 & 2,892 & 1,960 & 2,445 & 1,762 & 2,042 & 1,836 \\
\hline Minería & 43,236 & 44,058 & 45,892 & 49,599 & 50,076 & 50,714 & 51,043 & 52,473 & 55,035 & 54,554 & 59,715 & 69,442 \\
\hline Manufactura & 44,529 & 47,766 & 52,807 & 57,354 & 53,502 & 59,255 & 64,360 & 65,265 & 68,508 & 66,407 & 65,079 & 64,020 \\
\hline $\begin{array}{c}\text { Electricidad } \\
\text { y agua }\end{array}$ & 4,685 & 5,040 & 5,505 & 5,950 & 6,013 & 6,501 & 6,994 & 7,401 & 7,811 & 8,193 & 8,679 & 9,313 \\
\hline Construcción & 12,168 & 13,994 & 16,317 & 19,061 & 20,360 & 23,993 & 24,848 & 28,779 & 31,353 & 31,956 & 30,097 & 29,151 \\
\hline Comercio & 26,368 & 29,500 & 32,537 & 36,105 & 35,936 & 40,420 & 44,034 & 47,218 & 49,984 & 52,193 & 54,217 & 55,199 \\
\hline Servicios 1/ & 123,951 & 133,615 & 145,197 & 157,818 & 163,472 & 177,840 & 190,253 & 204,186 & 216,868 & 227,756 & 237,366 & 146,585 \\
\hline PBI & 273,971 & 294,598 & 319,693 & 348,923 & 352,584 & 382,380 & 407,052 & 431,273 & 456,366 & 467,276 & 482,809 & 501,622 \\
\hline
\end{tabular}

Fuente: PBI por sectores productivos [en línea]. Lima: Estudios estadísticos-cuadros anuales (BCRP) Gerencia Central de estudios económicos. Disponible en:

www.bcrp.gob.pe/docs/Estadisticas/Cuadros-Anuales/ACuadro_07.xls

Analizando la Figura se observa un crecimiento histórico en el sector Manufactura:

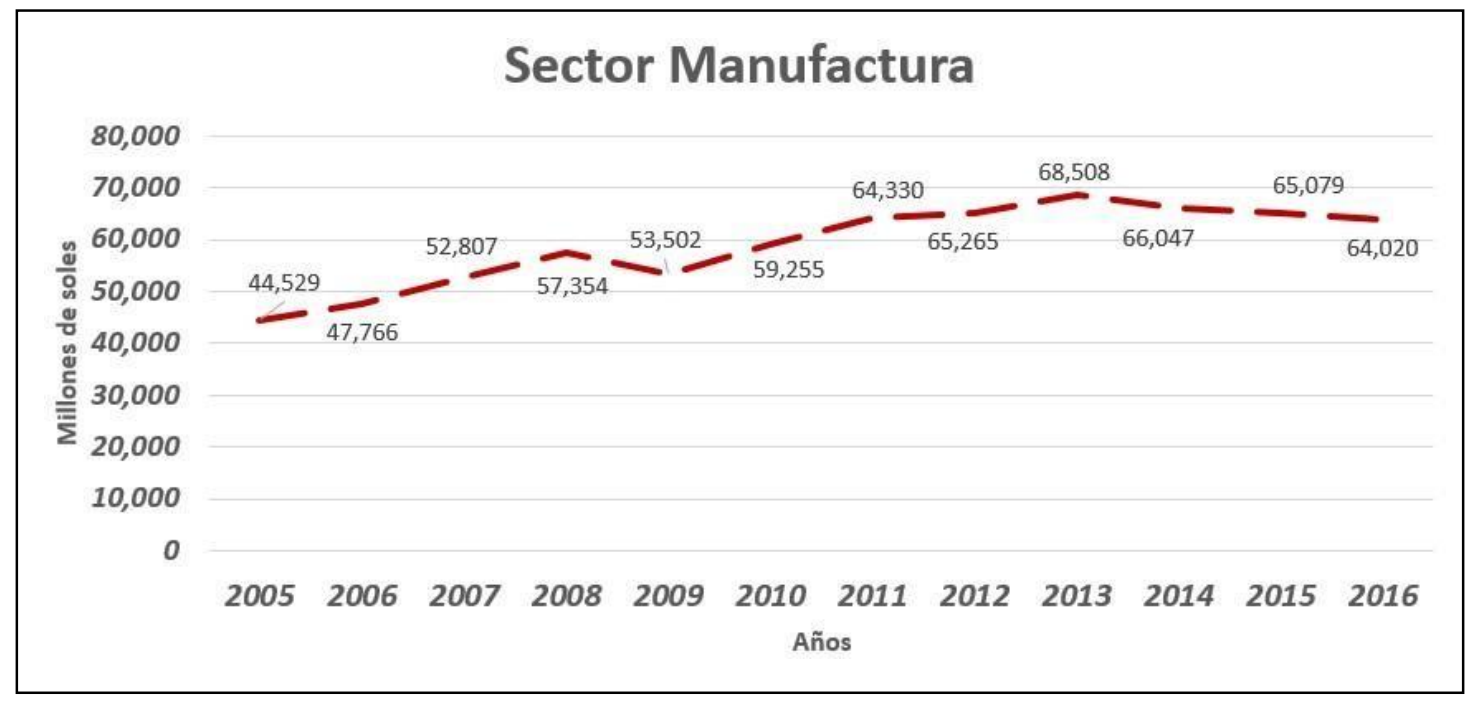

Figura 2. Sector Manufactura.

Fuente: PBI por sectores productivos [en línea]. Lima: Estudios estadísticos-cuadros anuales

(BCRP) Gerencia Central de estudios económicos. Disponible en: www.bcrp.gob.pe/docs/Estadisticas/Cuadros-Anuales/ACuadro_07.xls

\footnotetext{
${ }_{10}$ PRODUCE Micro, Pequeña y Mediana Empresa MIPYME 2016 [en línea] Lima: Ministerio de la Producción Estadísticas MYPE. Estudios abiertos. Disponible en: http://ogeiee.produce.gob.pe/index.php/shortcode/estadistica-oee/estadisticas-mipyme
} 
En cuanto a la industria de bebidas se mostrará el comportamiento histórico que da la pauta de una tendencia de crecimiento.

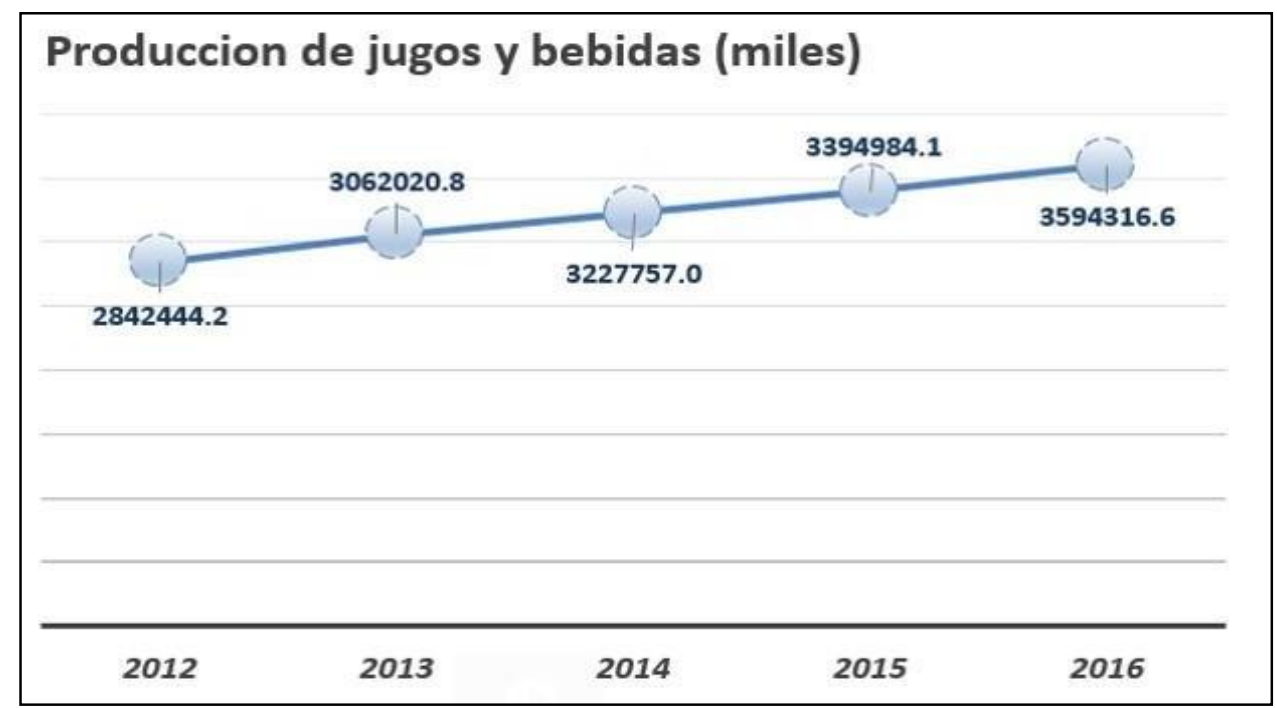

Figura 3. Jugos y Bebidas no Alcohólicas (en miles).

Fuente: Ministerio de la producción - Elaboración propia

\subsection{Análisis estructural del sector industrial}

$1-\underline{2} \underline{3} \underline{4} \underline{5}$

INDUSTRIA

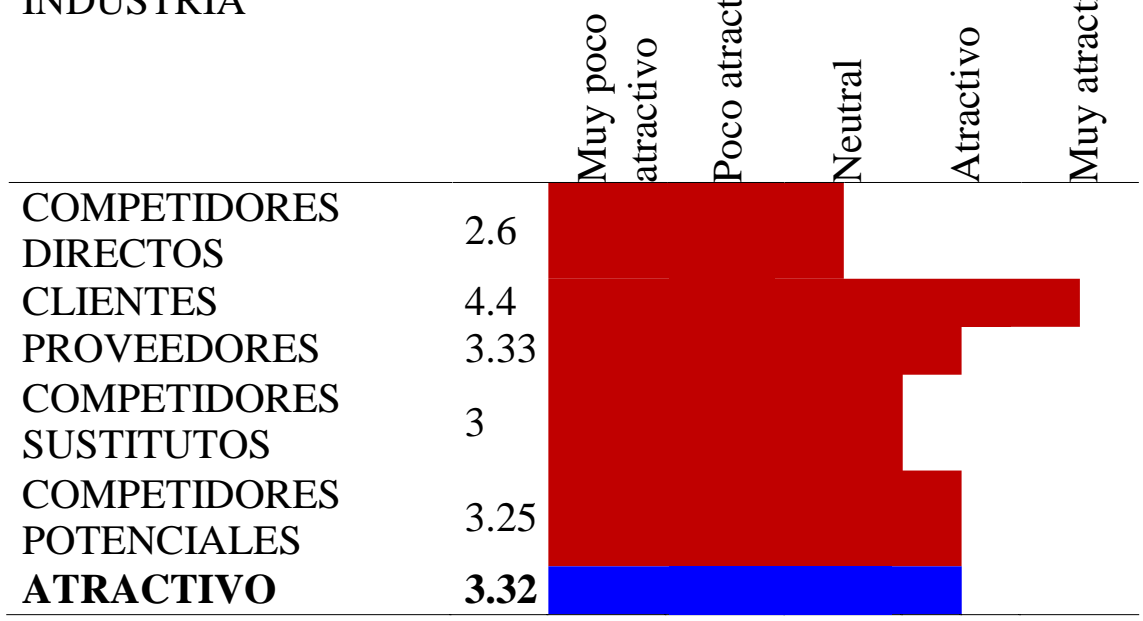

Figura 4. Atractividad de la industria.

Fuente: Elaboración propia 
El sector industrial relacionado a las bebidas en el Perú es bien dinámico lo cual se puede apreciar con la información de la tendencia mostrada en el capítulo anterior. También se puede apreciar que es un mercado atractivo conclusión a la que se llega según el estudio mostrado a continuación:

\subsubsection{Competidores actuales: nivel de competitividad}

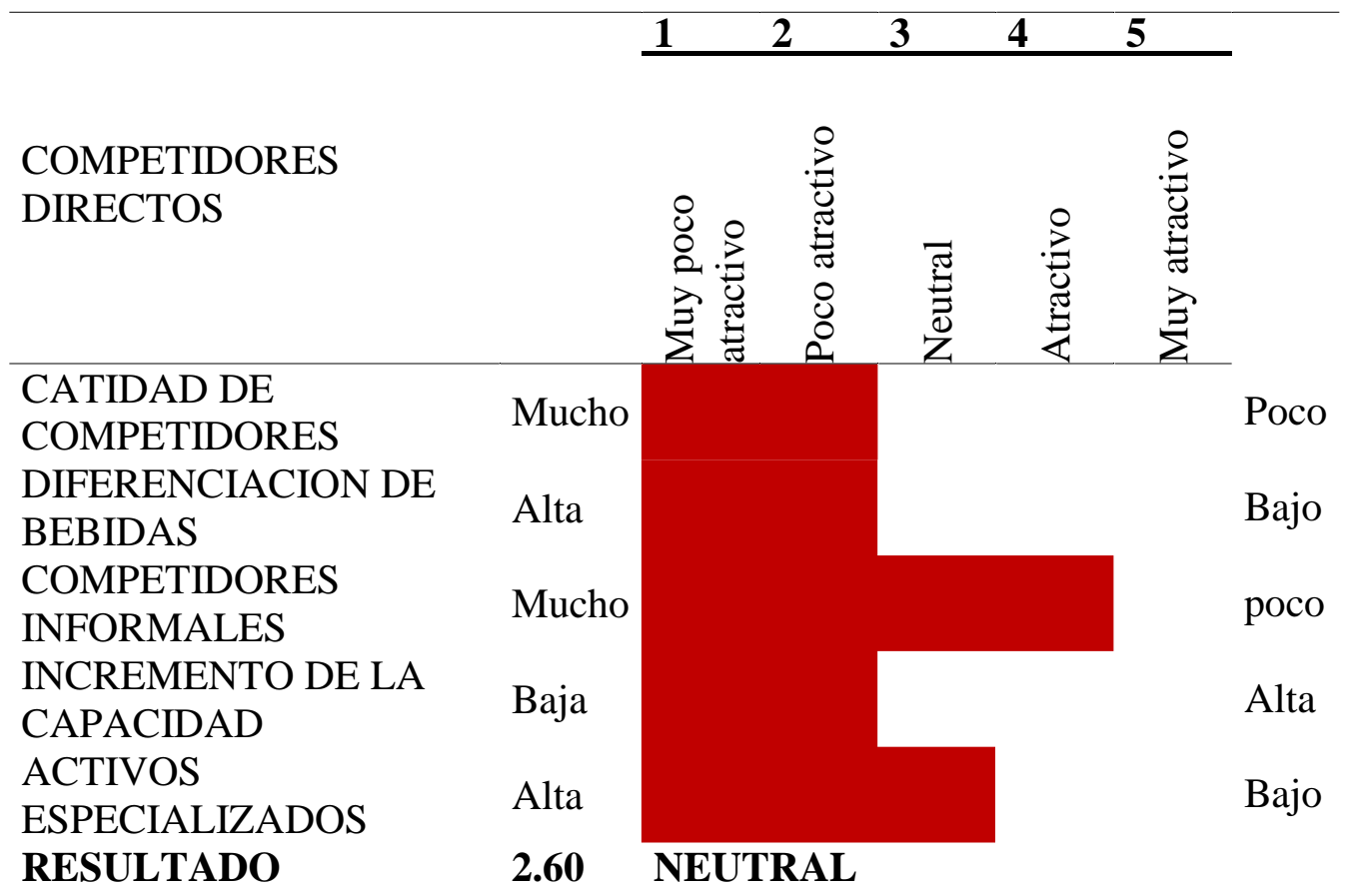

Figura 5. Nivel de atractividad de competidores directos.

Fuente: Elaboración propia

En el mercado existe una variedad de marcas alusivas a bebidas naturales a base de fruta y también bebidas energizantes, pero ninguna que utilice el insumo principal: el fruto formulación. Actualmente hay estudios realizados sobre las cualidades energizantes y medicinales del fruto; algunas empresas como AGRO INKA y Producto Natural que han decidido impulsar estas cualidades ofreciendo presentaciones bajo la forma de sumo para preparación de jugos, cápsulas, cremas, etc. Sin embargo, con el fin de diferenciar la empresa de la competencia, así como también como es el caso de los productos sustitutos 
(néctares, jugos, refrescos), se ofrecerá un producto natural bebible aprovechando los beneficios del Sanky como son sus altos contenidos de potasio, fósforo, antioxidantes, calcio y vitamina $\mathrm{C}$; beneficioso para atacar el sobrepeso, combatir la hipertensión arterial y como ya se mencionó el cansancio.

Dentro de los competidores actuales se tiene a:

Kero, que se destaca por producir jugos de frutas exóticas y naturales.

Infusión, es una bebida herbal que contiene boldo, cola de caballo, manzanilla, linaza, menta.

Chia Cool, En sabores de arándano, frambuesa, maracuyá, pera y chicha morada. Pero cada sabor contiene chia.

Macarena Punch, bebida natural elaborada a base de maca, manzana, zanahoria y maracuyá, endulzado con stevia.

\subsubsection{Fuerza negociadora de los clientes}

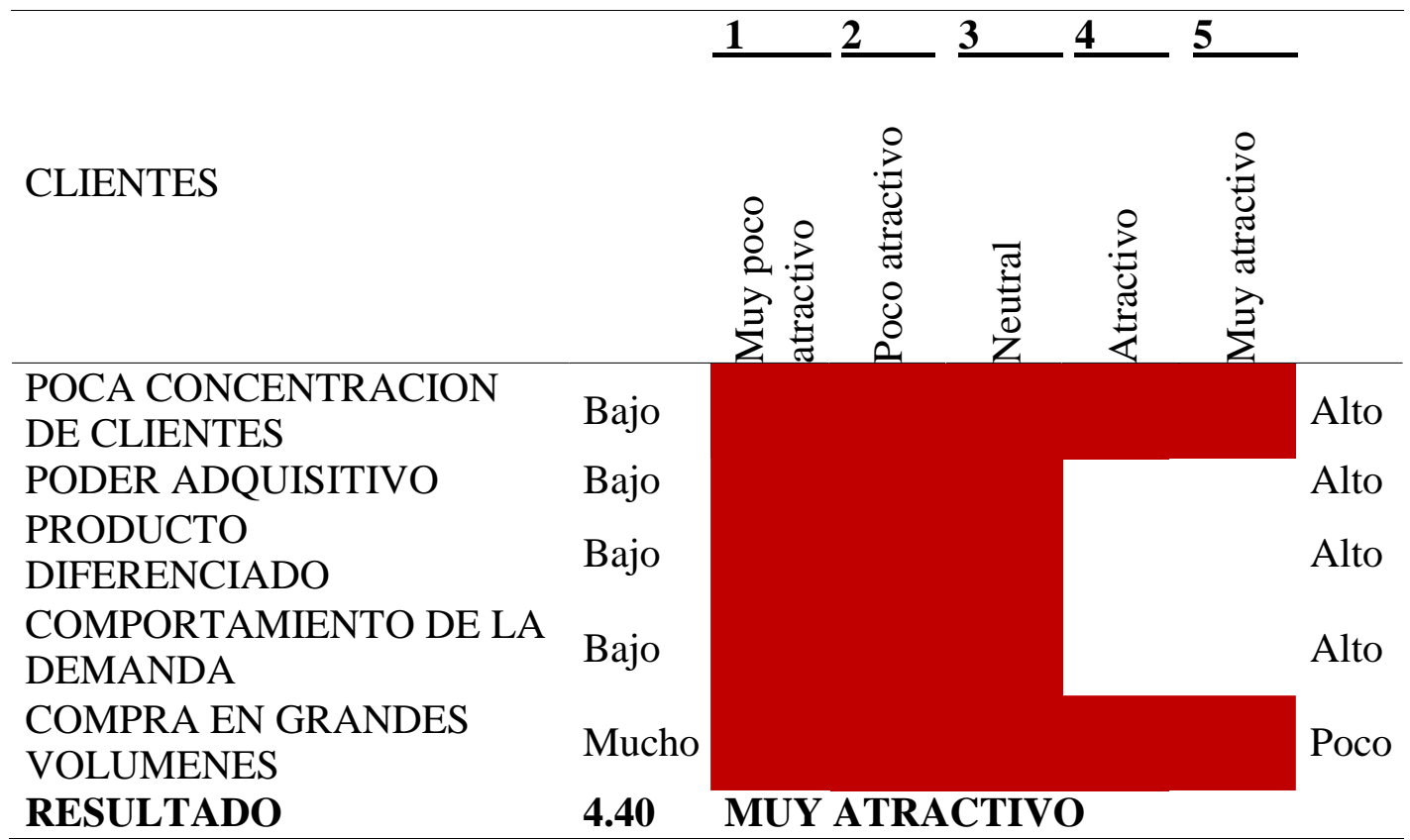

Figura 6. Atractividad de clientes.

Fuente: Elaboración propia 


\section{Grado de Negociación de los Clientes: Alto}

El poder de negociación de los clientes corporativos (B2B) tales como gimnasios y supermercados Premium (como Vivanda y Wong) es alto.

Nivel de concentración de clientes: Poca concentración de clientes, siendo esta atractiva, esto favorece a la colocación de la bebida en diferentes puntos corporativos.

El poder adquisitivo de los clientes finales es alto, siendo atractivo, porque permite ofertar un buen producto con excelentes propiedades.

Es un producto diferenciado, se torna también atractivo, debido a sus propiedades energizantes y siendo un fruto natural y novedoso.

El comportamiento de la demanda se va a tornar atractivo, debido que al sector que se ha orientado es un sector que le gusta verse y sentirse bien.

La compra en grandes volúmenes es poco, pero es muy atractiva, debido a que se oferta a un mercado selecto el cual se proyecta a ser un buen potencial de mercado.

\subsubsection{Fuerza negociadora de los proveedores}

Grado de Negociación de los Proveedores: Alto

\begin{tabular}{lllll}
1 & 2 & 3 & 4 & 5 \\
\hline
\end{tabular}

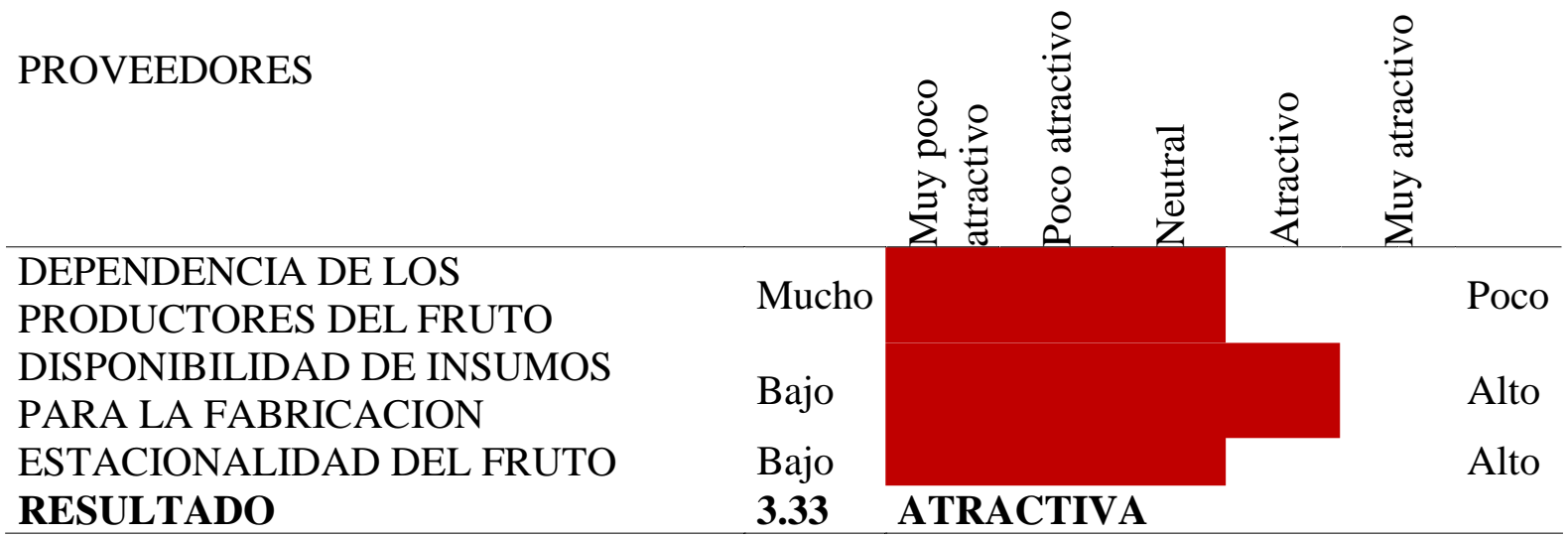

Figura 7 Atractividad de proveedores.

Fuente: Elaboración propia 
Existen comunidades campesinas organizadas que producen la materia prima - el fruto SANKY- en las ciudades de Arequipa, Ayacucho y Huancavelica, esto origina que el poder de negociación que ellos ejercen sobre los comerciantes del mercado de frutas de Lima sea elevado y los favorece para establecer sus condiciones en la comercialización de este fruto al ser traídos a los respectivos mercados de productores de Lima.

\subsubsection{Amenaza de productos sustitutos}

Grado de Amenaza de Productos Sustitutos: Media - Alta

$\underline{1} \underline{2} \underline{3} \underline{4} \underline{5}$

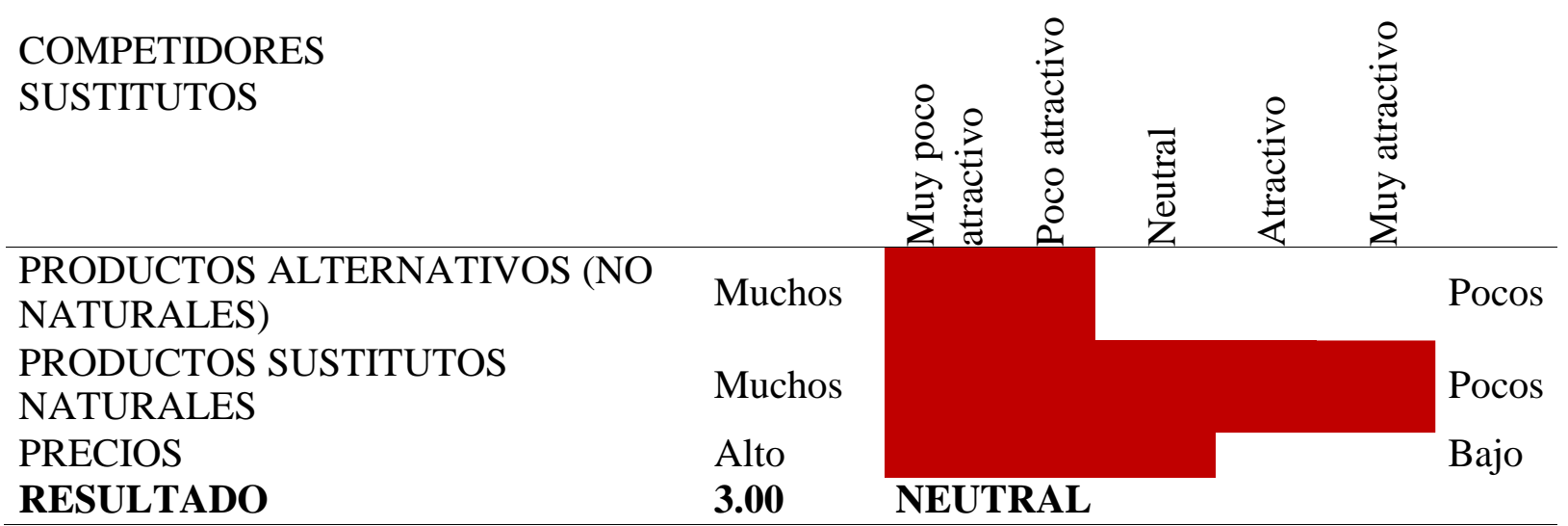

Figura 8. Atractividad de competidores sustitutos.

Fuente: Elaboración propia-

En la actualidad el mercado cuenta con un variado portafolio de bebidas refrescantes que se encuentran respaldadas por firmas reconocidas con amplia participación en el mercado, lo que representa una amenaza media - alta para un producto nuevo como el que ofrecemos.

Como productos sustitutos se puede mencionar: jugos naturales, néctares, gaseosas, refrescos en base a plantas nativas de las principales marcas: 
a. La Unión de Cervecerías Peruanas Backus y Johnston

Maltin Power.- Elaborada en base a malta, busca captar un público objetivo entre los 13 y 20 años que combinen nutrición y diversión.

b. AJE

Free Tea. - Bebida elaborada en base a extracto de té verde, sin cafeína ni preservantes y con todos los antioxidantes necesarios para complementar un estilo de vida fresco y natural.

c. PEPSICO

Lipton Ice Tea. - Refresco de Té verde conocido por ser una bebida hidratante natural. Disponible en varios sabores (Limón, Melocotón y Té verde).

\section{d. LA COSECHA PERUANA}

Beberash Iced Tea. - Refrescante natural, cuenta con 4 diferentes presentaciones: Beberash Iced Tea Natural (el té clásico), Beberash Iced Tea Manzana, Beberash Iced Tea Durazno y Beberash Te Verde.

e. SELVA INDUSTRIAL

Emoliente Selva. Bebida a base de cebada, linaza y limón.

\section{f. CORPORACIÓN AMAZÓNICA LOS MANJARES DE UCAYALI SAC}

Selvida. - Bebida a base de Camu-Camu cuyo valor diferenciado es el de ser rehidratante

\section{g. L' ONDA BEVERAGE COMPANY}

L’onda Beverage, Los productos ofrecidos son jugo de fruta natural, néctares, bebidas de frutas, bebidas carbonatadas y no carbonatadas, energizantes, así como también agua. Entre sus productos resaltan: Jugo de cramberry, de manzana, de naranja, cramberry maracuya, y cramberry uva. 


\subsubsection{Competidores potenciales barreras de entrada}

Grado de Amenaza para competidores potenciales: Alta

$\underline{1} \stackrel{2}{2} \underline{3} \underline{5}$

COMPETIDORES

POTENCIALES

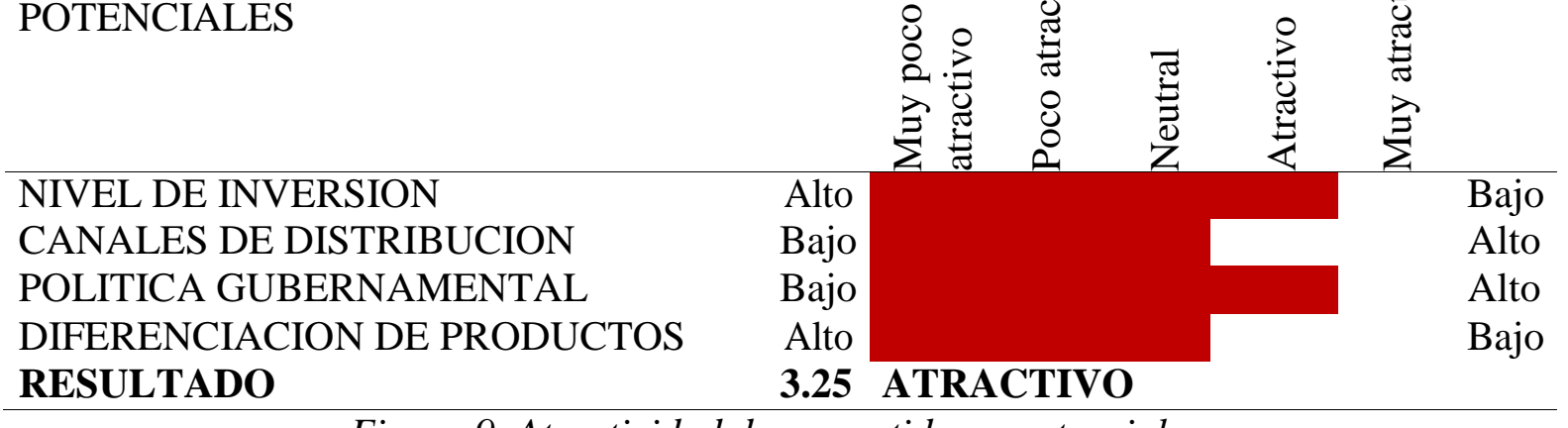

Figura 9. Atractividad de competidores potenciales.

Fuente: Elaboración propia

Existen pocas barreras de entrada debido a que en el sector de elaboración de bebidas, hay empresas que se dedican a la producción de bebidas y tienen la capacidad de producción para elaborar bebidas refrescantes, por lo que pueden incursionar en la producción de una bebida en base a Sanky ya que cuentan con la capacidad instalada y reconocimiento de la marca en el mercado.

\subsection{Análisis de la competencia}

\subsubsection{Empresas que ofrecen el mismo insumo en sus productos (semejanzas y}

\section{diferencias)}

a) Casa naturista LA REINA: ha desarrollado un producto $100 \%$ natural, combinando 3 productos en una sola forma de concentrado bebible, un extracto de noni - sanky graviola.

b) Perú Natural Sanky: vende un concentrado del Sanky para ser combinada con distintas frutas naturales demostrando así varias propiedades curativas y medicinales. 
2.4.2. Empresas que ofrecen bebidas naturales (semejanzas y diferencias)

a) Selva Industrial SA.: desarrollan productos como pulpas, concentrados y jugos a base de una gran variedad de frutas naturales (mango, maracuyá, guanábana, naranja, piña, durazno, fresa, papaya, carambola y Camú Camú).

b) Corporación Amazónica Los Manjares de Ucayali SAC.: desarrolla productos a base de Camú Camú (mermelada y jugo) con el nombre comercial Selvida.

\subsubsection{Participación de mercado de cada uno de ellos}

Contando con información de Euromonitor Internacional se puede ver la participación de mercado de los competidores:

Tabla 4

Participación de mercado de los competidores

\begin{tabular}{lll}
\hline Marca & Operador Global & Partcipación \\
\hline Frugos & The Coca Cola Co & $25 \%$ \\
Cifrut & Aje Group & $16.20 \%$ \\
Pulp & Aje Group & $13.60 \%$ \\
Gloria & Grupo Gloria S.A & \\
Laive & Laive S.A & \\
& Houchens Industries & \\
Tampico & INC & \\
Kris & Industrias San Miguel \\
Watts & Watts S.A & $26.00 \%$ \\
Ecofresh & Food Pack SAC & \\
Aruba & Grupo Gloria S.A & \\
Pura Vida & Grupo Gloria S.A & \\
Huanchuy & P\&D Andina Alimentos \\
Selvida & Manjares del Ucayali & $0.65 \%$ \\
Selva & P\&D Andina Alimentos & $1.09 \%$ \\
Otros & & $17.46 \%$ \\
TOTAL & & $\mathbf{1 0 0 . 0 \%}$ \\
\hline
\end{tabular}

Fuente: Euromonitor Internacional 
Se puede apreciar que P\&D Andina Alimentos con su producto SELVA alcanza el 1.09\% de participación de mercado; mientras que Manjares del Ucayali a través de su producto SELVIDA alcanza una participación del $0.65 \%$.

\subsection{Análisis del contexto actual y esperado}

\subsubsection{Análisis Político-Gubernamental}

El presidente de la Sociedad Nacional de Industrias (SNI), Andreas Von Wedemeyer, aseguró que hay una predisposición muy interesante hacia el nuevo gobierno (2016-2021) por parte de los inversionistas, lo que tendría como consecuencia promover el crecimiento del PBI en los siguientes años. 11

Por otro lado, el gobierno de Pedro Pablo Kuczynski ha planteado en su plan de gobierno diferentes propuestas que promoverán el desarrollo de nuevas empresas.

Los pilares del gobierno serán el crecimiento sostenido de la economía, la inversión y la formalización. Para ello propone:

$>$ Otorgar a las pequeñas y medianas empresas una gestión tributaria especial, reduciendo el IGV en tres tramos hasta el 15\%. El objetivo del gobierno con esta medida es de disminuir el porcentaje de informalidad en el país.

Promover la inversión privada tanto de las grandes empresas como de las medianas y pequeñas empresas, para ello se otorgará facilidades que permitirán que las medianas y pequeñas empresas puedan desarrollarse de manera óptima.

$>$ Implementar un nuevo régimen tributario, el cual propone que las empresas que facturen 2,300 UIT's o menos por 10 años tengan acceso a una amnistía tributaria para sus deudas fiscales pasadas. 12

\footnotetext{
${ }^{11}$ Gestión: SNI: inversionistas tienen una predisposición interesante para este Gobierno [citado el 13 de junio del 2016] Disponible en https://gestion.pe/economia/sni-inversionistas-predisposicion-interesante-gobierno-146510

12 Gestión: PPK: 15 puntos de su plan económico que debe conocer [citado el 16 de junio del 2016] Diponible en https://gestion.pe/economia/ppk-15-puntos-plan-economico-debe-conocer-146449
} 
Con toda esta información detallada anteriormente, se puede concluir que el Perú es un país atractivo para los inversionistas, lo cual es favorable para nuestro Plan de Negocios.

\subsubsection{Análisis Económico}

\section{Inflación}

En la década del 1980 el Perú atravesó un cuadro de Híper inflación, sin embargo, esta etapa ya ha sido superada y se demuestra por que el rango de la inflación va del 1.5\% hasta 5.8\% para el periodo 2005 - 2016, este es un largo periodo de estabilidad económica que favorece a la población y le da confianza para gastar en nuevos y novedosos productos.

La inflación del 2016 finalizó en 3.23\% lo cual estuvo por debajo del 2015 pero similar al 2014. El rubro de alimentos y bebidas registro la mayor alza (3.54\% todo el año), ya que aporto el 44\% al crecimiento del año 2016.13

Ante una demanda en crecimiento de productos y una producción que no crece al mismo ritmo que aquella, se generaría una demanda insatisfecha lo que llevaría a un posible aumento de precios en las bebidas.

Desde otro punto de vista si el factor gustos y preferencias por bebidas saludables (factor distinto al precio) se incrementa, la curva de la demanda se desplazaría a la derecha lo que originaría incremento en la misma y debido a ello se esperaría un incremento en el precio14.

\footnotetext{
${ }^{13}$ INEI: Inflación en Lima Metropolitana llegó a 3.23\% en 2016. [citado el 01 de enero del 2017] Disponible en https://andina.pe/agencia/noticia-inei-inflacion-lima-metropolitana-llego-a-323-2016-647487.aspx

${ }^{14}$ Economía Aplicada: Juan León Mendoza, Callao-UNAC, 2010- 236p. Disponible en

http://economia.unmsm.edu.pe/org/arch doc/JLeonM/publ/Interiores Economia Aplicada.pdf
} 


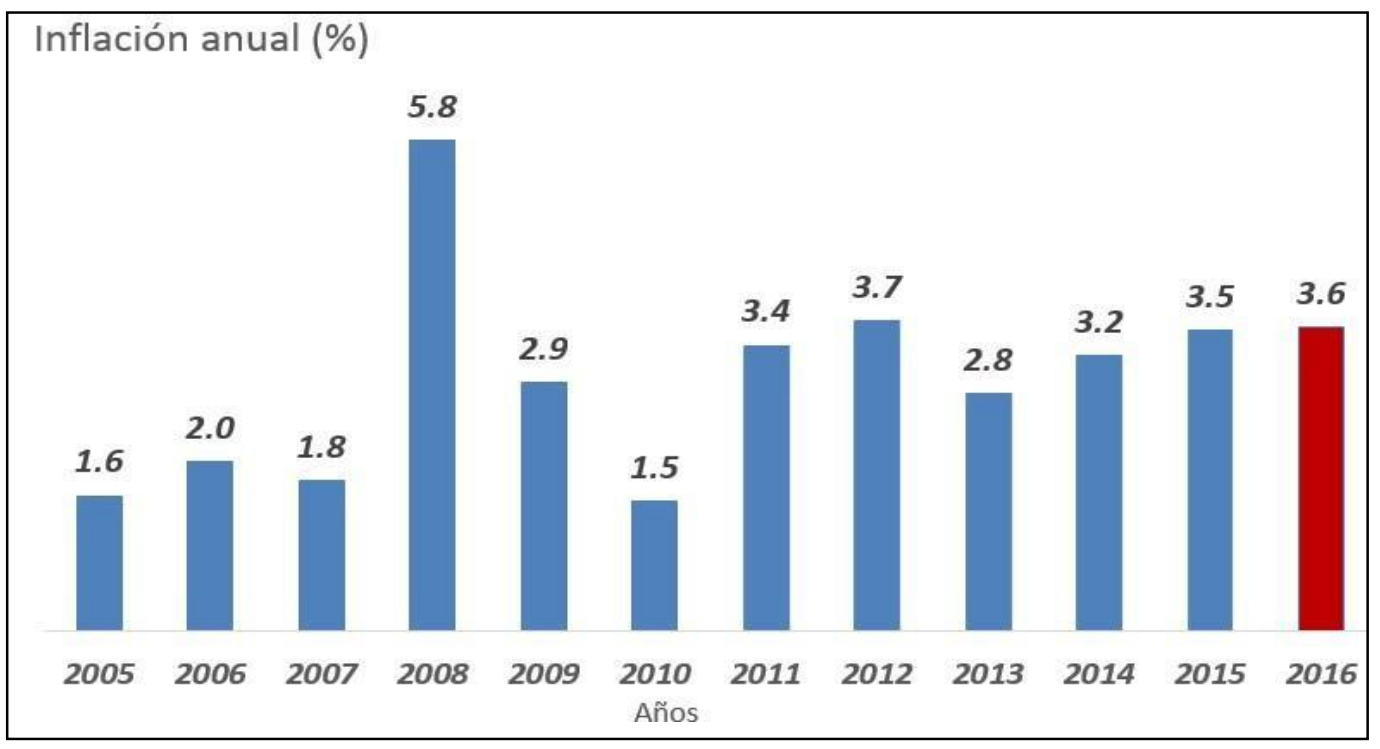

Figura 10. Inflación.

Fuente: BCRP / Elaboración propia. Disponible en http://www.bcrp.gob.pe/estadisticas/cuadros-anuales-historicos.html

\section{Tipo de Cambio}

La moneda peruana mostró una leve recuperación luego de tres años de bajas consecutivas.

En la última sesión del año, el tipo de cambio alcanzó S/ 3.3570, lo que representó una caída de $1.67 \%$ en todo el 2016, según datos de Bloomberg.

En el día, el tipo de cambio osciló entre un mínimo de 3.3492 y un máximo de 3.3625. El mínimo representó el piso de las últimas 14 semanas (22 de setiembre, cerró en S/ 3.440).

En el año, el tipo de cambio tocó un pico de S/ 3.5291, el 24 de febrero.

El sol peruano mostró una leve recuperación luego de tres años de bajas consecutivas, en medio de un apetito por mercados emergentes y una recuperación de los precios de los metales, informa Reuters. 
La moneda de Perú, uno de los mayores productores de cobre en el mundo, retomó sus ganancias anuales tras retroceder un $14.56 \%$ en el 2015 ; un $6.43 \%$ en el 2014 y un $9.72 \%$ en el 2013.15

\section{PBI y Consumo Interno}

El FMI estima un crecimiento del PBI de 4.3\% para el 2017 ubicando al Perú en top de la economía de América del Sur.

Se espera este crecimiento por:

1. La mayor producción de cobre unido al alza del precio. Esto se origina por la mayor demanda de China debido a su crecimiento de viviendas e infraestructura.

2. Un alza del gasto público.

3. Mayor dinamismo del consumo.16

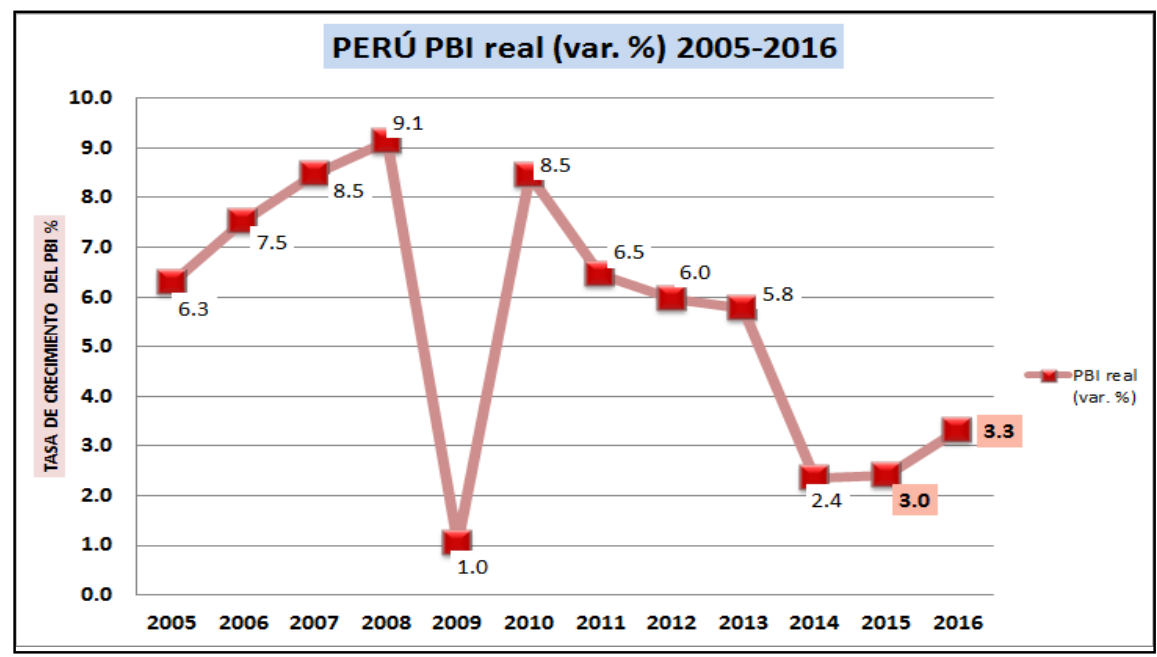

Figura 11. Evolución Crecimiento PBI del Perú.

Fuente: BCR- FMI. Disponible en http://wenssilvestre.blogspot.com/2015/10/a-donde-va-laeconomia-peruana.html

\footnotetext{
${ }^{15}$ Gestión: Tipo de cambio cerró con una caída de 1.7\% en todo el 2016 [citado el 30 de diciembre del 2016]. Disponible en https://gestion.pe/economia/tipo-cambio-cerro-caida-1-7-2016-125628

${ }^{16}$ Perú 21: Perú liderará crecimiento ecoómico para el 2017 [citado el 24 de enero del 2017]. Disponible en https://peru21.pe/economia/peru-liderara-crecimiento-economico-2017-62887
} 
El PBI per cápita a nivel de paridad de compra ha sido el de mayor expansión en los últimos años en la región, creciendo del \$7.4 (2006) al \$12.2 (2015)

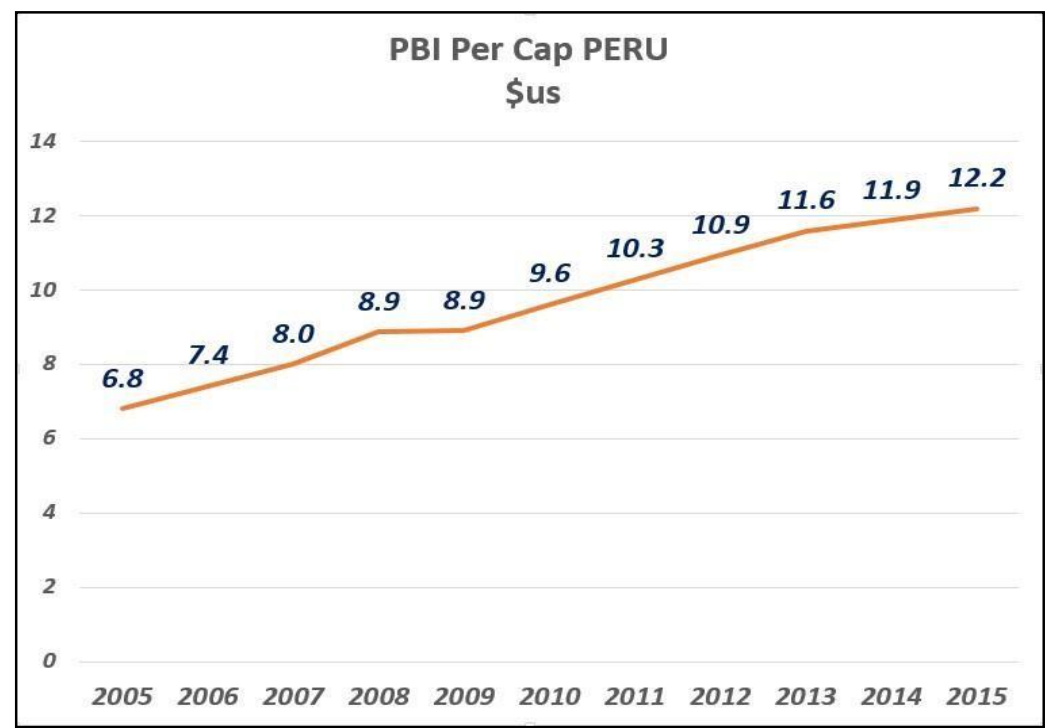

Figura 12. PBI Per Cápita US\$.

Fuente: INEI / Elaboración propia. Disponible en

http://desarrolloperuano.blogspot.com/2016/05/comparando-nuestro-pbi-ppa-per-capita.html

Con todo lo expuesto anteriormente se puede concluir que la situación económica del entorno es favorable para el desarrollo del plan de negocio, ya que se visualiza un escenario económico creciente e inflación y tipo de cambio estable para el futuro.

\subsubsection{Análisis Legal.}

En el 2014 se realizaron cambios legislativos para mejorar la inversión como la reducción progresiva de la tasa del impuesto a la renta para las empresas.

El artículo $3^{\circ}$ del D. Leg. 1261, modifica la tasa aplicable a la distribución de Dividendos y otras formas de distribución de utilidades que se adopten o se pongan a disposición en efectivo o en especie, y esto entro en vigencia, a partir del 01 de enero de 2017; así la tasa a partir del ejercicio 2017 se ha fijado en $5 \% .17$

\footnotetext{
${ }^{17}$ Boletín Empresarial Tribiutario: Archivo de la etiqueta: tasa de dividendos 2017 [ citado el 12 de diciembre del 2017]. Disponible en http://www.asesormype.com/etiqueta/tasa-dividendos-2017/
} 
Se tiene las leyes y reglamentos que norman y ayudan a la pues ta en marcha de una empresa de bebida natural en el Perú:

a. R.M.449-2006-MINSA. Norma sanitaria sobre el procedimiento para la aplicación del sistema HACCP en la fabricación de alimentos y bebidas.

b. Ley 29571 - Código de Protección y Defensa del Consumidor. El presente código establece las normas de protección y defensa de los consumidores, instituyendo como un principio rector de la política social y económica del Estado la protección de los derechos de los consumidores.

Tiene como finalidad que los consumidores accedan a productos y servicios idóneos y que gocen de los derechos y los mecanismos efectivos para su protección, previniendo o eliminando las conductas y prácticas que afecten sus legítimos intereses.

\section{c. Ley 26842 - Ley General de Salud: Reglamento sobre Vigilancia y Control Sanitario de Alimentos.}

Tiene la finalidad de normar las condiciones, requisitos y procedimientos higiénicosanitarios a que debe sujetarse la producción, el transporte, la fabricación, el almacenamiento, el fraccionamiento, la elaboración y el expendio de alimentos y bebidas de consumo humano.

\section{d. Ley 28015 - Ley de Promoción y Formalización de la Micro y Pequeña Empresa (Ley} 28851)

Tiene por objeto la promoción de la competitividad, formalización y desarrollo de las micro y pequeñas empresas para incrementar el empleo sostenible, su productividad y rentabilidad, su contribución al Producto Bruto Interno, la ampliación del mercado interno y las exportaciones y su contribución a la recaudación tributaria.

\section{e. Ley 29783 - Ley de Seguridad y Salud en el Trabajo}

Tiene como finalidad promover una cultura de prevención de riesgos laborales en el país. Para ello, cuenta con el deber de prevención de los empleadores, el rol de fiscalización y 
control del Estado y la participación de los trabajadores y sus organizaciones sindicales quienes, a través del diálogo social, velan por la promoción, difusión y cumplimiento de la normativa.

\section{f. Licencia de Funcionamiento Municipal}

La licencia de funcionamiento es otorgada por el municipio en donde se encontrarán las instalaciones del negocio. El municipio cobra una tasa dependiendo del giro de la actividad y el área que ocupará el inmueble.

La Municipalidad Distrital o Provincial, según corresponda, no podrá cobrar tasas por concepto de renovación, fiscalización o control y actualización de datos de la misma, ni otro referido a este trámite, con excepción de los casos de cambio de uso, de acuerdo a lo que establece el Decreto Legislativo No 776, Ley de Tributación Municipal y sus modificatorias.

Requisitos para licencia de funcionamiento definitiva:

$>$ Solicitud de licencia de funcionamiento definitiva

$>$ Certificado de Zonificación y Compatibilidad de Uso

$>$ Copia del RUC

> Copia del Título de Propiedad o documento equivalente que acredite la propiedad o Copia del Contrato de alquiler.

$>$ Copia de la Escritura Pública de Constitución.

Informe favorable de Defensa Civil.

$>$ Pago por derecho de trámite.

$>$ En el caso de autorizaciones sectoriales, copia de la autorización y/o certificación del sector competente según actividad.

Algún otro documento requerido por la Municipalidad 18

\footnotetext{
${ }^{18}$ Portal Municipalidad Distrital de Chorrillos: Requisitos y trámites para obtener uan licencia de funcionamiento-Ordenanza $\mathrm{N}^{\circ} 124$ MDCH adecuada a la Ley $N^{\circ}$ 28976. Disponible en http://www.munichorrillos.gob.pe/home/modernizamuni.php
} 


\section{Registro Sanitario}

DIGESA es la entidad que regula el buen control y mantenimiento de los alimentos para que una empresa pueda comercializarlos, de modo tal que estos estén aptos para la salud y consumo humano. Esto involucra a las condiciones en las que se elaboran, cuidado e higiene del personal y los insumos que se utilizan.

Requisitos:

$\checkmark$ Formato dirigido al Director Ejecutivo de Higiene Alimentaria y Zoonosis, con carácter de Declaración Jurada, que contenga $\mathrm{N}^{\mathrm{o}}$ de RUC, firmada por el Representante Legal. (Ver formato para productos nacionales o para productos importados).

Resultado de los análisis físicos, químicos y microbiológicos del producto terminado, confirmando su aptitud de acuerdo a la normatividad sanitaria vigente, otorgado por un laboratorio acreditado o del laboratorio de control de calidad de la fábrica.

$\checkmark$ Certificado de Libre Comercialización o similar o Certificado Sanitario emitido por la Autoridad Competente del país de origen, en original o copia refrendado por el consulado respectivo, cuando el alimento o bebida sea importado.

Rotulado de los productos etiquetados.

Los Alimentos y Bebidas de regímenes especiales, deberán señalar sus propiedades nutricionales, acompañando los correspondientes análisis bromatológicos practicados por laboratorio acreditado por INDECOPI.

$\checkmark$ Declaración Jurada de ser MYPE, cuando corresponda.

Certificado de Validación de recurso y producto natural, para su uso en salud otorgado por CENSI. (Requisito Eliminado).

$\checkmark$ Comprobante de Pago de Derecho de Trámite, 405 Nuevos Soles. (10\% UIT, UIT $2017=$ 4050)

Norma Técnica Peruana - Indecopi. 
Según la clasificación indicada por Indecopi, el producto deberá ceñirse a la norma NTP 203.110:2009, la cual da la pauta sobre las características que deberá tener el producto para ser comercializado dentro del mercado nacional, de manera que sea confiable y transparente para los consumidores. En ella se indican puntos como:

Etiquetado

Nombre del alimento

Lista de ingredientes.

\subsubsection{Análisis Cultural}

Los gustos del consumidor de bebidas han variado.

El mercado de bebidas energizantes creció un 9,8\% el año 2014 acumulando US\$31 mil millones de ventas a nivel mundial, según informa Euromonitor.

En los últimos años las bebidas energizantes se han ido apoderando del mercado de bebidas hasta comprender un gran sector de las ventas totales de bebidas a nivel mundial. Aunque las gaseosas y bebidas azucaradas son las líderes indiscutibles en ventas gracias a su antigüedad y ubicuidad en todos los tipos de mercado, lo cierto es que las bebidas energizantes son las que más ha crecido el último año.

Las bebidas energéticas o hipertónicas son bebidas sin alcohol y con algunas virtudes estimulantes que desde hace más de una década han salido al mercado mundial ofreciendo al consumidor virtudes regeneradoras de la fatiga y el agotamiento, además de aumentar la habilidad mental y desintoxicar el cuerpo. Aunque llevan ya algún tiempo en el mercado, recién en los últimos años ha visto su despegue. Esto debido a un cambio en el posicionamiento de estas bebidas. Mientras que antes iban dirigidas a un mercado reducido compuesto de atletas de alto rango, hoy en día este mercado se ha expandido dirigiéndose a todo aquel que trabaje o estudie durante largas horas. La necesidad de energía y de mayor 
concentración no es solo buscada por los deportistas sino por el trabajador que desea una mejor performance no en el deporte, sino en la vida diaria. De ahí el crecimiento masivo de este tipo de bebidas.

En el caso de las bebidas rehidratantes como Gatorade, Powerade y otros, han logrado posicionarse gracias a una abundante y masiva campaña publicitaria desde hace mucho tiempo. Hoy en día, el que menos sabe que luego de realizar ejercicio físico tiene que rehidratarse. Sin embargo, en los últimos años, y debido a una moda por los productos naturales, esta forma de rehidratación se busca mediante el agua embotellada y no tanto por las bebidas hidratantes. Esto explica el auge del agua embotellada no solo a nivel local sino a nivel mundial.

Finalmente, las ventas combinadas de bebidas energéticas y deportivas alcanzaron los US\$ 50 mil millones en 2014.19.

\subsubsection{Análisis Tecnológico.}

La ley 30309, Ley que promueve la investigación científica, desarrollo tecnológico, e innovación tecnológica, favorece a la inversión en innovación y desarrollo, por parte de la empresa para poder acceder a los beneficios tributarios 20 .

La maquinaria y equipo a utilizar en el proyecto para el proceso productivo es de tipo industrial, y será adquirida para la implementación de la planta, que constará de lo siguiente: lavadora de frutas (sistema de lavado de inmersión y aspersión, elaborada en acero inoxidable, con una banda transportadora de 1.70 m), marmita de cocción (capacidad aproximada de 100 lts. y con un consumo máximo de $1242 \mathrm{gr} / \mathrm{h}$ ), licuadora industrial (bajo consuno de amperaje para menor consumo de corriente), tanque de acero inoxidable

\footnotetext{
${ }^{19}$ Proexpansión*: ¿Por qué el mercado de las bebidas energizantes ha crecido tanto? [citado 09 febrero 2015]. Disponible en http://proexpansion.com/es/articles/1138

${ }^{20}$ MINISTERIO DE LA PRODUCCION. Ley de Promoción de la Investigación Científica, Desarrollo Tecnológico e Innovación Tecnológica. [en línea]. Lima: PRODUCE, 2016 [citado 20 setiembre 2017]. Acrobat PDF. Disponible en: http://www.innovateperu.gob.pe/landings/incentivo-tributario/
} 
mezclador (de enfriamiento y calentamiento, está diseñado con una cubierta de respiración sanitaria contra moscas e insectos, lo que garantiza altos estándares de higiene), tanque de agua de acero inoxidable (de almacenamiento), embotelladora (capacidad de 900 lts. / hr.), etiquetadora (con un diseño que se adapta muy bien a las pequeñas producciones, teniendo una frecuencia de 20 etiquetas/ minuto), retractiladora industrial (envolvedora retráctil semiautomática).

El estudio tecnológico se analizará considerando tres enfoques: los clientes, los competidores y la evolución tecnológica.

La empresa debe estar en la capacidad de generar respuestas rápidas y eficientes ante cualquier cambio que impacte en la tecnología de modo que la repercusión de estos cambios sea mínima, es por ello que se debe considerar:

Detectar anticipadamente los cambios tecnológicos: alertas sobre cambios o amenazas generadas en el mismo sector, por ejemplo.

Minimizar los riesgos al momento de detectar la amenaza: por ejemplo, realizar un estudio de los competidores para saber si están copiando el know-how de la empresa.

Al identificar algún desfase tecnológico, se debe también identificar oportunidades de inversión y comercialización.

Dar lugar de relevancia a la generación de ideas para implementar nuevas soluciones tecnológicas, por ejemplo, tomar la decisión sobre nuevos productos, su programación, estrategias, etc.

Actuar estratégicamente con nuevos socios tecnológicos de modo que se impulse desarrollos mancomunados o facilitar la incorporación de nuevos avances tecnológicos a los propios productos. 


\subsubsection{Análisis Ecológico.}

Dentro de la Ley General del Ambiente $N^{\circ} 28611$, la empresa se compromete a cumplir con los derechos y deberes de la misma.21

Cuando se tenga que comprar el Sanky a los proveedores del mercado de frutas $n^{\circ} 2$, se les pedirá que le haga llegar al productor, que este sea producto de un trabajo bien organizado y no de una depredación de los terrenos en los cuales se cultiva, siendo este un requisito indispensable.

En la empresa se regulará el consumo de energía, siendo la necesaria en el proceso productivo, asimismo dentro de las políticas de la empresa se hará tomar conciencia del prendido y apagado de luces, pc's y otros que originen un inadecuado uso de los mismos.

Las botellas de plástico del kawsay llevaran información donde se mencionará que es reciclable.

La empresa tendrá una preocupación por el calentamiento global, será socialmente responsable y tendrá la certificación ISO 14000.

\subsection{Matriz de Evaluación de Factores Externos}

Esta matriz permite resumir y evaluar información económica, social, demográfica, ambiental, cultural, gubernamental, jurídica y tecnológica. En el proyecto se han determinado factores críticos o determinantes para el éxito expresados en oportunidades y amenazas. Estos factores son ponderados asignando valores que van desde 0 (no es importante) a 1 (muy importante) y se califican con una puntuación del 1 (amenaza mayor) al 4 (oportunidad mayor).

El peso adjudicado a un factor dado indica la importancia relativa del mismo para alcanzar el éxito del proyecto dentro de la industria de bebidas.

${ }^{21}$ MINISTERIO DEL AMBIENTE. Ley General de Ambiente N² 28611. Disponible en: http://www.minam.gob.pe/wpcontent/uploads/2013/06/ley-general-del-ambiente.pdf 
Con la calificación asignada permite ubicar amenazas mayor; amenaza menor;

oportunidad menor y oportunidad mayor que tendría la empresa encargada del proyecto.

De esta manera la ponderación nos permite hacer un análisis de la industria mientras que la calificación permite un análisis de la empresa. ${ }^{22}$

$\overline{22}$ Disponible en: http://planeacionestrategica.blogspot.es/1243897868/matriz-efe-efi/ 
Tabla 5

Matriz EFE

\begin{tabular}{lllll}
\hline & Oportunidades & Ponderación & Calificación & Puntaje \\
\hline $\mathbf{1}$ & $\begin{array}{l}\text { Crecimiento económico del país en el } \\
2016\end{array}$ & 0.06 & 3 & 0.18 \\
\hline $\begin{array}{l}\text { Tendencia en aumento de un mejor estilo } \\
\text { de vida donde el consumidor está } \\
\text { optando por invertir recursos en } \\
\text { productos naturales que contribuyan a } \\
\text { elevar el bienestar de cada persona. }\end{array}$ & 0.2 & 4 & 0.8 \\
\hline $\mathbf{3} \quad \begin{array}{l}\text { Creciente interés por cuidar la salud e } \\
\text { imagen }\end{array}$ & 0.12 & 3 & 0.36 \\
\hline $\mathbf{4} \quad \begin{array}{l}\text { Cambio en los hábitos alimenticios } \\
\text { optando por el consumo de productos }\end{array}$ & 0.15 & 4 & 0.6 \\
\hline & $\begin{array}{l}\text { Crecimiento de actividades deportivas en } \\
\text { la ciudad, la proliferación de nuevos } \\
\text { gimnasios, spas, centros integrales de } \\
\text { cuidado de la salud, yoga, pilates, etc }\end{array}$ & 0.09 & 4 & 0.36 \\
\hline $\mathbf{6} \quad \begin{array}{l}\text { Demanda insatisfecha por productos } \\
\text { naturales de calidad. }\end{array}$ & 0.05 & 3 & 0.15 \\
\hline
\end{tabular}

\begin{tabular}{lllll}
\hline & Amenazas & Ponderación & Calificación & Puntaje \\
\hline $1 \quad \begin{array}{l}\text { Riesgo que el producto ofrecido sea } \\
\text { fabricado por una empresa ya en marcha } \\
\text { y con reconocimiento en el mercado. }\end{array}$ & 0.3 & 1 & 0.3 \\
\hline $\begin{array}{l}\text { Posible confusión del mercado objetivo } \\
\text { en distinguir los tipos de bebidas que } \\
\text { hay en el mercado, tales como los shots } \\
\text { energéticos, las bebidas deportivas, las } \\
\text { aguas funcionales, las bebidas a base de } \\
\text { té o café y finalmente smothies de frutas } \\
\text { o vegetales. }\end{array}$ & 0.02 & 2 & 0.04 \\
\hline $3 \quad \begin{array}{l}\text { Cambios inesperados de las políticas del } \\
\text { gobierno de turno }\end{array}$ & 0.01 & 2 & 0.02 \\
\hline RESULTADO & $\mathbf{1}$ & $\mathbf{2 . 8 1}$
\end{tabular}

CALIFICACIÓN: 1. Amenaza mayor 2. Amenaza menor 3. Oportunidad menor 4.

Oportunidad mayor

Fuente: Elaboración propia 
Con una calificación 2.81 (siendo el mayor puntaje 4) significa que dentro de las estrategias de la empresa, esta está preparada aprovechar las oportunidades y menguar las amenazas del sector. 


\section{Capítulo III}

\section{Estudio de Mercado}

Se realizará el estudio de mercado para recoger toda la información relevante que nos permita establecer el perfil del consumidor, aceptación del producto, preferencias sobre acceso al producto y el mercado objetivo. Este estudio se realizó con la asesoría de la empresa Asesorías Integrales, expertos en temas de estudio de mercado.

\subsection{Descripción del producto}

El Sanky pertenece a la familia de las Cactáceas, su nombre científico es corryocactus brevistylus. Esta planta tiene frutos redondos de color verde y de un tamaño promedio de 12 centímetros de diámetro. El Sanky tiene un gran contenido de calcio, fósforo y potasio. Adicionalmente regula la sensación de hambre y sed.

Es un fruto andino que crece entre los 2,500 y 3,000 msn y se da en las zonas altas de Arequipa, Ayacucho y Huancavelica.

Se considera un $2 \%$ de mermas asociadas a la perecibilidad del fruto, daños en la manipulación, transporte del sanky y una merma del 22\% debido a la cáscara del sanky.

\section{Propiedades del Sanky}

Ayuda a reducir el colesterol y triglicéridos, también ayuda a disminuir los problemas cardíacos y coronarios.

Las gomas naturales del Sanky ayudan a reducir la acidez del estómago, así como reducir la gastritis. 
Tabla 6

Composición química del Sanky

\begin{tabular}{llll}
\hline $\mathrm{N}^{\circ}$ & Componente & Pulpa & Cáscara \\
\hline 1 & Calorías $(\mathrm{kcal})$ & 17.6 & 28 \\
2 & Humedad $(\mathrm{g} / 100 \mathrm{~g})$ & 95.2 & 91.6 \\
3 & Carbohidratos $(\mathrm{g} / 100 \mathrm{gr})$ & 3.1 & 5.6 \\
4 & Cenizas $(\mathrm{g} / 100 \mathrm{gr})$ & 0.4 & 1.4 \\
5 & Fibras $(\mathrm{g} / 100 \mathrm{gr})$ & 0.9 & 1.7 \\
6 & Proteínas $(\mathrm{g} / 100 \mathrm{gr})$ & 1.3 & 1.4 \\
7 & Calcio $(\mathrm{ppm})$ & 104.5 & 752 \\
8 & Potasio $(\mathrm{ppm})$ & 5566.4 & 1743.9 \\
9 & Fósforo $(\mathrm{mg} / 100 \mathrm{~g})$ & 12.8 & 6.7 \\
10 & Vitamina C (mg/100g) & 51.1 & 2.5 \\
\hline
\end{tabular}

Fuente: http://www.lamolina.edu.pe/gaceta/edicion2006/notas/nota153.htm

\section{Formulación del producto}

El producto que se ofrecerá se llamará Kawsay Sankyfruit (término que significa vida en quechua), bebida hecha a base del fruto andino Sanky; natural; de color verde limón; presentada en envase de botella de plástico de $250 \mathrm{ml}$ y sellado al vacío; con etiquetas plastificadas con la información nutricional y las propiedades principales. Contiene edulcorante natural (yacón). No contiene alcohol, ni cafeína, uso mínimo de preservantes, ni azúcar.

Tabla 7

Formulación del Kawsay

(preparación de la bebida v envió a expertos para valor nutricional)

\section{FORMULACIÓN DE KAWSAY} $250 \mathrm{ml}$

Agua $175 \mathrm{ml}$

Yacón en polvo $6 \mathrm{gr}$

Sanky (pulpa) 75gr

Sorbato de Potasio $1.25 \mathrm{ml}$

Fuente: Elaboración propia 


\subsection{Selección del segmento de mercado}

\section{Criterios de Segmentación:}

\subsubsection{Geográfica:}

Información geográfica de segmentación:

a. País: Perú

b. Población:

El Perú finalizó el año 2016 con una población de 31.488.625 habitantes, un aumento de

337.00 personas respecto a 2015.23

c. Ciudad: Lima Metropolitana

La Población de Lima Metropolitana al 2015 fue de 9.752 .000 habitantes

d. Distritos: Los distritos que se consideran en el proyecto son: San Isidro, Miraflores, San Borja, La Molina y Santiago de Surco que según APEIM pertenecen a la Zona 7 de Lima Metropolitana y representa el área geográfica con población de mayores recursos económicos. $\stackrel{24}{ }$

\footnotetext{
${ }^{23}$ Fuente INEI. [publicado el 11 de julio del 2016] Disponible en: https://www.inei.gob.pe/prensa/noticias/el-peru-tiene-una-poblacionde-31-millones-488-mil-625-habitantes-9196/.

${ }^{24}$ Fuente: INEI. Disponible en: http://proyectos.inei.gob.pe/web/biblioineipub/bancopub/Est/Lib1010/index.htm
} 


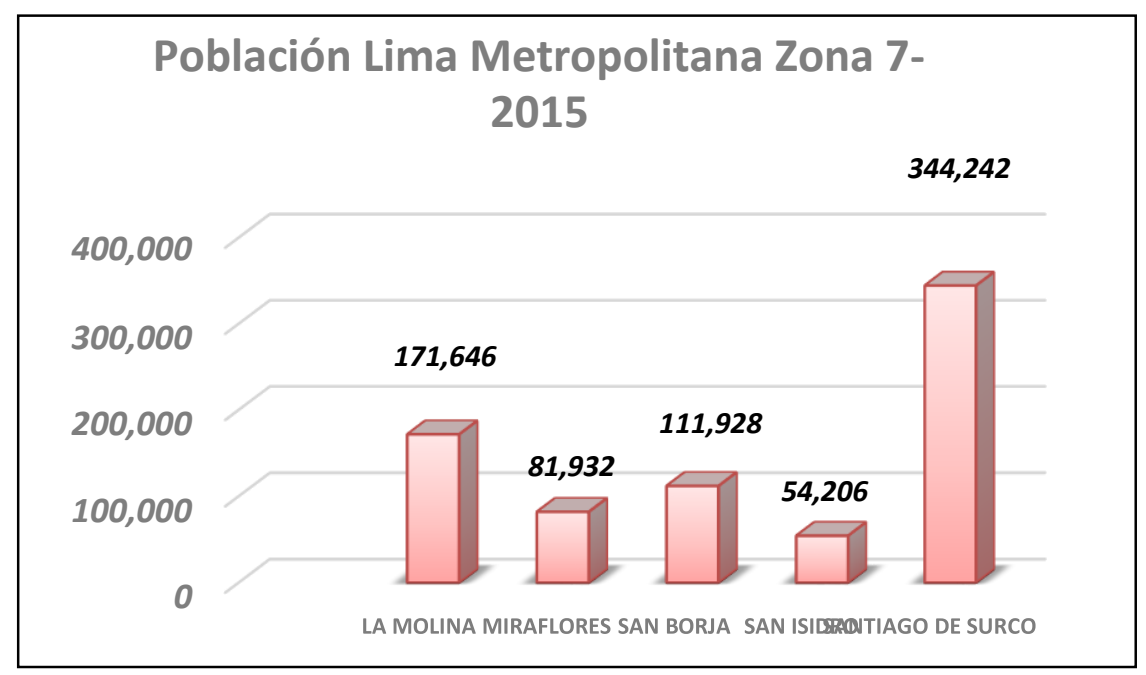

Figura 13. Población Lima Metropolitana Zona 7 - 2015.

Fuente: https://www.inei.gob.pe (Población proyectada)

\subsubsection{Demográfica}

a. Edad: Personas en el rango de edad de 18 a 50 años.

b. Género: ambos sexos (masculino y femenino)

c. Educación: preferentemente personas con estudios y que gustan de informarse sobre temas de bienestar.

d. Ocupación: Indistinta con cierta incidencia en algunas personas como los deportistas, nutricionistas, y personas vinculadas a la industria del bienestar.

e. Religión: indistinto.

f. Raza: Indistinta.

\subsubsection{Psicográfica}

Nivel socioeconómico: Analizando el NSE, el objetivo es orientarse a los niveles socioeconómicos A y B de la Zona 7 de Lima Metropolitana, conformada por los distritos de Miraflores; San Isidro; San Borja; Santiago de Surco y La Molina. 


\subsubsection{Segmentación Conductual}

Se menciona esta segmentación sólo para reforzar la tendencia al bienestar como consecuencia del estilo de vida que las personas actualmente cultivan y no necesariamente tomarla como un filtro. Dentro de la Zona 7 de Lima metropolitana encontramos una población con alta inclinación por aprovechar los beneficios de los productos naturales (Beneficios) así como también el uso de bebidas naturales con propiedades energizantes al momento de realizar sus ejercicios físicos (Ocasión).

Estilo de vida: En 1996, Arellano Marketing realizó un estudio en el que identificó nueve estilos de vida de los peruanos. En el 2005 actualizó dichos estudios, y definió seis estilos de vida entre las cuales se encuentra distribuida la población peruana: los afortunados, los progresistas, las modernas, los adaptados, las conservadoras y los modestos. Posteriormente en el año 2009 realizó una pequeña modificación en dos nomenclaturas: la de afortunados por el de Sofisticados y el de modestos por Resignados; agrupando los tres primeros estilos como de Vida Proactiva y a los tres últimos estilos como de Vida Reactiva.

En el año 2010 complementaron el estudio enfocando entre otras las siguientes preguntas: 1. ¿Cómo son?

2. ¿Qué desean los consumidores?

Los Sofisticados: En este grupo se encuentran hombres y mujeres jóvenes y de mediana edad, luchadores por naturaleza, los más instruidos y con ingresos medianos-altos, pertenecen a los NSE A, B y C y serían los que valorarían el producto.

Las características de este grupo son: Se aventuran por probar novedades; son sensibles a las modas y tendencias; el "cambio constante" es un valor en sí mismo; las marcas son importantes pues representan símbolos de diferenciación; toman el precio como un indicador de la realidad. En resumen, se puede decir que:

a. Buscan disfrutar del dinero que han ganado 
b. Invierten mucho en su cuidado personal.

c. Evalúan el ambiente del punto de venta (PDV) y el servicio.

d. Buscan productos de alta calidad.

Las Modernas: Este grupo conformado por mujeres de carácter pujante, trabajadoras, con un modo de pensar moderno y que ven con optimismo el futuro, también forma parte de la segmentación, pertenecen a este grupo mujeres de los NSE B/C/D/E y la empresa también se enfocaría en una parte de este mercado.

Las características de este grupo son: Usan marcas como referentes de calidad y valor social; integran sus distintas facetas en el consumo; interesadas en su apariencia; abiertas al mundo. En resumen, se puede decir que:

a. Compran productos light o saludables.

b. Visitan malls y tiendas por departamento.

c. Valoran la experiencia en el punto de venta (PDV).

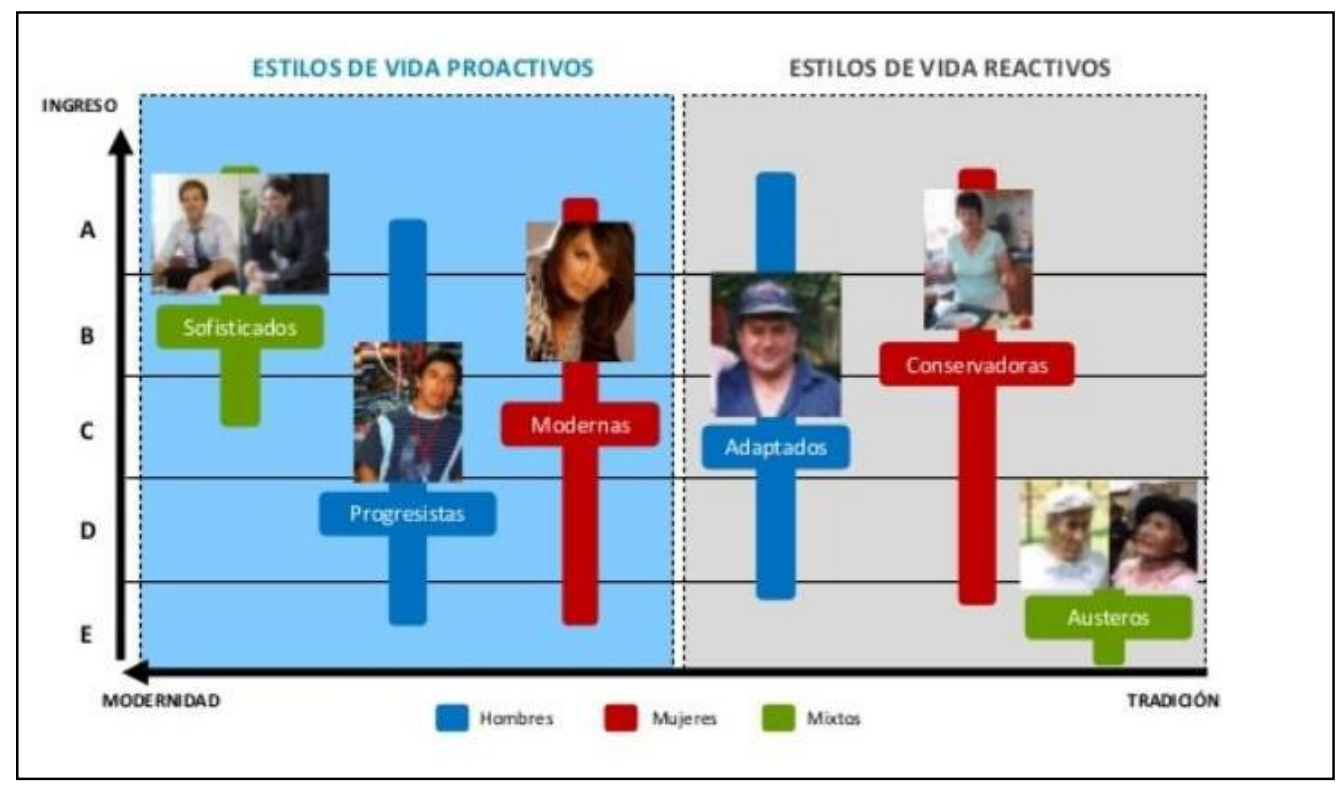

Figura 14. Estilo de Vida

Fuente: Arellano Marketing. [Lima 2013] Disponible en: https://es.slideshare.net/ArellanoMarketing/estilos-de-vida-arellanomarketing?next_slideshow $=1$ 


\subsection{Investigación Cualitativa}

En la investigación cualitativa se utilizarán tanto la técnica de Entrevista de Profundidad como también la técnica del Focus Group.

\subsubsection{Técnica Cualitativa: Entrevista de profundidad}

Permitirá obtener información relevante de expertos tanto en el sector fabril (en cuanto a producción) como en el sector retail (ingreso de mercadería nueva en puntos de venta).

De acuerdo al sector al que pertenece nuestro plan de negocios. Se ha entrevistado a dos ingenieras de industrias alimentarias para ver la composición química del producto de modo que resulte lo más natural posible; satisfaga la necesidad de las personas que consumen bebidas naturales; tenga los componentes nutricionales en las medidas correctas y esté alineado con la tendencia de la industria del bienestar. Asimismo, se ha entrevistado a dos especialistas en ingresos de productos en el mercado retail.

Expertos:

Ingeniera de industrias alimentarias

Ingeniera de industrias alimentarias (con estudios en nutrición)

Gerente Comercial abarrotes comestibles Supermercados Peruanos S.A.

Jefe de categoría de bebidas Cencosud S.A.

La información de esta investigación se encuentra en el Anexo $\mathrm{N}^{\circ} 2$

\section{a. Conclusiones de la Primera Entrevista a Profundidad Ingeniero de Industrias}

\section{Alimentarias}

El Sector de bebidas envasadas se encuentra en crecimiento, por lo que sí sería posible el ingreso de la bebida en el mercado, esta tendencia de crecimiento no sólo se encuentra en el país, sino también en países como Chile. 
Respecto de la calidad, las bebidas que se encuentran en el mercado, todas tienen un alto nivel de calidad, ya que necesariamente han pasado todas las pruebas reglamentarias, como son las normas fisicoquímicas, organolépticas, microbiológicas, ISO 9000, ISO 22000, ISO 9001, Sistema de Análisis de Peligros y de los Puntos Críticos de Control (Sistema HACCP).

Dada la consistencia y naturaleza del fruto, se sugiere se fabrique de néctar sin descartar la elaboración de un refresco.

$\checkmark$ El uso de preservantes debe darse de acuerdo a lo indicado por las normas de la OMS, dicho preservante ayudará a conservar el producto durante un aproximado de 6 meses después de su elaboración y no altera las propiedades naturales ni el sabor del fruto.

Dados los cuatro meses del año en el que se puede extraer el fruto, la técnica de conservación de la pulpa es la refrigeración, que permitirá conservar el fruto en buen estado un tiempo aproximado de mes y medio.

Las bebidas envasadas más consumidas en el mercado son las de tipo bebible (más líquidas, más contenido de agua que fruta), esto debido a la tendencia de cuidado de imagen y salud que existe en los sectores hacia los que está dirigido, sin embargo, apelando a los beneficios adicionales que tiene el producto si podría calzar dentro de esta tendencia, sumado a que no existe en el mercado un producto similar.

Para una óptima producción, es esencial que se cuide el tema de la temperatura, desde el momento del transporte hasta la etapa misma de la producción.

Es importante que se cuente con personal capacitado en todo el proceso, desde la extracción, el transporte y producción, para que se evite tiempos muertos y por ende pérdidas monetarias.

$\checkmark$ El transporte del fruto debe ser refrigerado, en javas esterilizadas de acuerdo a la norma, las cuales se apilarán y se transportarán a su destino. 
Los profesionales necesarios para la empresa son, un administrador, uno o dos ingenieros alimentarios, un laboratorista (sin embargo, esta función puede tercerizarse), tres técnicos en producción que conozcan el manejo de las maquinarias y unos ocho auxiliares.

La temperatura necesaria para todo el proceso son 5 grados Celsius.

El margen de ganancia aplicable para este tipo de productos es aproximadamente un $70 \%$. Para la planta se debe de contar mínimamente, con una máquina envasadora y una cocina industrial, considerando que los envases se comprarían ya esterilizados.

$\checkmark$ Es viable que se cuente con un local alquilado para la implementación de la planta.

$\checkmark$ El uso adecuado de la temperatura ayudará al cuidado del PH del producto, lo que es indispensable conservar para que se mantenga los beneficios del fruto.

\section{b. Conclusiones de la Segunda Entrevista a Profundidad de Ingeniero de Industrias}

\section{Alimentarias.}

En cuanto al sector de refrescos envasados a base de este tipo de frutos (con propiedades alimenticias), es poco explotado. Existe actualmente una difusión de productos elaborados a base de fruta, pero con un proceso de producción donde se pierden muchas de estas propiedades, lo que da como resultado una bebida con sabor a fruta, pero con pocos nutrientes.

Para la dosificación de pulpa de fruta, agua y otros insumos que se utilizará en la producción, es necesario que se haga una evaluación sensorial y otra de costos. La primera consiste en la elaboración de distintas formulaciones o propuestas (con diferentes dosificaciones) y hacer que participe un panel considerable de personas en la degustación para que se pueda recibir su opinión. Luego de ser recolectada la información se procesará estadísticamente para obtener la dosificación más conveniente para la utilización de pulpa.

El Sanky es un fruto perecible y sensible, esto último hace referencia a su cáscara blanda lo que en un escenario de transporte se convertiría en un alto riesgo para que el insumo 
pierda su calidad. Se sugiere que la planta procesadora para el producto esté muy cerca del proveedor para evitar la pérdida del insumo que se reflejaría en el costo de producción. En el caso que la planta no estuviera cerca de los proveedores sería necesario la habilitación de un transporte de adecuada refrigeración para que el producto llegue en las mejores condiciones al lugar de procesamiento.

La estacionalidad es uno de los problemas vitales a los que se tendría que hacer frente, el fruto no crece todo el año de modo que se tendría que extraer la pulpa del fruto y envasarlas al vacío para que se mantenga en las mejores condiciones de refrigeración de modo que dure el mayor tiempo posible (con buenas técnicas se puede lograr una vida de 5 meses sin que la fruta pierda sus propiedades).

El otro problema que se puede avizorar es la competencia por parte de las grandes empresas elaboradoras de bebidas quienes cuentan con la infraestructura adecuada y canales de comercialización.

$\checkmark$ El equipo más importante es el de pasteurización (ya que el tratado artesanal en olla no logra el mismo efecto) UHT, máquinas de envasado, máquinas de sellado, cámaras para mantener en condiciones adecuadas los insumos y ambientes adecuados para el almacenamiento del producto final.

$\checkmark$ Es tal vez oportuno, al ser una empresa nueva en el mercado, se maquile la producción para que se evite costos excesivos iniciales esto es hasta que se cuente con equipos propios.

Una de las limitaciones que se ve con frecuencia es la gradual baja de calidad en los productos terminados a través del tiempo, esto muchas veces es originado porque no se tiene una adecuada estrategia de costos. Lamentablemente esta tendencia se hace para seguir logrando ganancias. Lo recomendable es que se mantenga siempre la calidad con la se cautivó al cliente. 
La calidad higiénica también es fundamental al punto que, si se quisiera en un mediano plazo exportar el producto, previamente se tendrían que cumplir con normas de control de calidad como el HACCP (necesaria para poder ser exportador).

Se recomienda: Buenas prácticas de manufactura más aún que en la actualidad el cliente es conocedor de este tema lo que lo ha convertido en más exigente. En este caso más aún al tratar de cubrirse parte del NSE A y B; Valor nutricional en el producto; El ISO 9000 asegura una gestión empresarial más eficiente.

$\checkmark$ Por la forma de procesar el producto sin sacrificar la mayor parte de los nutrientes es oportuno y adecuado dirigirse al segmento A y B. Se debe asegurar que el cliente pueda asociar el precio con las propiedades nutricionales del fruto.

\section{c. Conclusiones de la tercera entrevista de profundidad de Gerente Comercial} abarrotes comestibles Supermercados Peruanos S.A.

Para poder ser proveedor en un supermercado, debe de ser una empresa formal, con RUC vigente y una cuenta corriente.

Para la calificación de nuevos productos, deben de ser codificados y para esto se debe de llenar los respectivos formatos de precio, de datos logísticos y el pago de indicado en el acuerdo comercial vigente por nuevo producto o en su defecto el monto de S/ $300.00+$ IGV por ítem codificado.

$\checkmark$ Con respecto a la calidad se necesita presentar la siguiente documentación respectivamente llenada: solicitud de incorporación regular de nuevos productos-nuevos proveedores, registro sanitario, muestra del producto.

Por ser nuevo proveedor, se debe de pasar la auditoria sanitaria de su almacén o planta de producción de ser el caso o informe de auditoría realizada por la entidad acreditada el mismo año de la postulación (con calificativo aprobado) 
Además de los registros mencionados anteriormente, el producto debe de tener su etiqueta, empaque y código de barras.

$\checkmark$ En el formato de costos para producto nuevo, hay hasta 3 descuentos que deben ser llenados por parte del proveedor en $\%$, es decir hay: $\%$ Descuento 1, \% Descuento 2, \% Descuento 3, lo cual dará un P.V. P. sugerido nuevo con IGV y se verá el margen.

El posicionamiento en la categoría en las tiendas sería a la par de quienes se colocan, es decir de "tu competidor".

$\checkmark$ Nuestro plan de inversión en el canal respectivo debe ser de la siguiente manera:

$\checkmark$ En el punto de venta debe den haber impulso y degustación y en las redes sociales en Facebook y e-commerce.

El producto al ser dirigidos al NSE de la zona 7 de Lima Metropolitana, es decir a los distritos de Miraflores, San Borja, San Isidro, Santiago de Surco y Las Molina, pueden ser colocados en los supermercados de los distritos en mención sin ningún tipo de restricción tanto de Vivanda y Plaza Vea.

El pago a proveedores se hace a 60 días.

\section{d. Conclusiones de la tercera entrevista de profundidad al Jefe de Categorías Bebidas}

\section{Cencosud S.A.}

$\checkmark$ Para poder ingresar el producto debe de tener la aprobación del jefe de categoría y la aprobación de calidad.

$\checkmark$ Para el proceso de calificación de nuevos productos se necesita la ficha técnica del producto, estructura de costos, presentación del producto en formato PPT y degustación del producto a ingresar.

$\checkmark$ Con respecto a la calidad se necesita la ficha técnica del producto, registro sanitario del producto (número) DIGESA, análisis microbiológico y fisicoquímico, estudio de 
vida útil del producto, etiqueta del producto, informe de inspección de planta y carta de compromiso firmado.

$\checkmark$ En caso de ser proveedor nuevo no hay ningún otro requisito adicional a los mencionados anteriormente.

$\checkmark$ Antes de la colocación del costo final se debe de tener en cuenta los siguientes descuentos: desarrollo comercial (18\% en promedio), tasa logística entre 2 y $4 \%$ y uso de plataformas $\mathrm{b} 2 \mathrm{~b}$ de $0.2 \%$

$\checkmark$ Con respecto al posicionamiento en la categoría en las tiendas esto depende de la marca, no del retail. Debe de ir a la par de los posibles competidores.

$\checkmark$ El plan de inversión en el canal por lanzamiento de productos de baja rotación como Jugos premium dentro de la cadena debería ser alrededor de S/ 5,000 a S/ 10,000 en los primeros 3 meses, esto solo contabilizando el uso de espacios, no se considera la inversión por fuera.

$\checkmark$ El producto al ser dirigidos al NSE de la zona 7 de Lima Metropolitana, es decir a los distritos de Miraflores, San Borja, San Isidro, Santiago de Surco y Las Molina, pueden ser colocados en los supermercados de los distritos en mención sin ningún tipo de restricción en los supermercados de Wong.

$\checkmark$ El pago a proveedores se hace a 60 días.

\subsubsection{Técnica Cualitativa de Focus Group}

Para el presente estudio cualitativo se utilizó la técnica de "Focus Group", que consiste en dinámicas de grupo efectuadas con 24 personas distribuidas en tres segmentos con características homogéneas cada uno de ellos, dirigida por el psicólogo Julius Silva Vicuña. Las sesiones se desarrollaron sobre la base de una guía de pautas donde se cubrían los principales objetivos del presente estudio. 
Las dinámicas de grupo se realizaron el día 28 de setiembre del presente año en el distrito de San Isidro.

Las ficha técnica y hoja de reclutamiento del Focus Group se encuentran disponibles en el Anexo $\mathrm{N}^{\circ} 3$

a. Los objetivos de la investigación son:

Consumos de bebidas.

Percepción y preferencias sobre bebidas naturales.

Percepción y preferencias por tipos de envases.

Opinión por degustación de producto.

Valoración del producto (¿cuánto pagarían?)

Opinión sobre el nombre comercial.

Opinión sobre difusión.

b. Proceso de muestreo, tamaño de muestra y selección de elementos de muestra: La dinámica se realizó en tres sesiones donde se reunió a 24 personas, hombres y mujeres de edades comprendidas entre los siguientes intervalos: 18 a 25; 26 a 35 y 36 a 50 años, pertenecientes a los NSE A y B que domicilien en los distritos comprendidos en la zona 7 de Lima Metropolitana.

Para los tres Focus Group se utilizó el método de contacto por recomendación en cadena. Se realizó comunicación con personas según segmentos y se hizo una lista inicial de posibles participantes considerando el cumplimiento de las condiciones muestrales establecidas además de las pautas generales para elegir a los participantes más idóneos.

Se confirmó luego la disposición y finalmente se hizo la invitación a la sesión principal. 
Tabla 8

Distribución Muestral

\begin{tabular}{|c|c|c|c|c|}
\hline $\begin{array}{l}\text { Focus } \\
\text { Group }\end{array}$ & NSE & $\begin{array}{l}\text { Condición Muestral } \\
1\end{array}$ & $\begin{array}{l}\text { Condición Muestral } \\
2\end{array}$ & Condición muestral 3 \\
\hline 1 & A y B & $\begin{array}{l}\text { Personas que residen } \\
\text { en la Zona } 7 \text { de Lima } \\
\text { Metropolitana }\end{array}$ & De 18 a 25 años & $\begin{array}{l}\text { Estudiantes y público } \\
\text { que consumen bebidas } \\
\text { naturales como parte } \\
\text { de su dieta diaria }\end{array}$ \\
\hline 2 & A y B & $\begin{array}{l}\text { Personas que residen } \\
\text { en la Zona } 7 \text { de Lima } \\
\text { Metropolitana }\end{array}$ & De 26 a 35 años & $\begin{array}{l}\text { Personas que } \\
\text { consumen bebidas } \\
\text { naturales como parte } \\
\text { de su dieta diaria }\end{array}$ \\
\hline 3 & A y B & $\begin{array}{l}\text { Personas que residen } \\
\text { en la Zona } 7 \text { de Lima } \\
\text { Metropolitana }\end{array}$ & De 36 a 50 años & $\begin{array}{l}\text { Personas que } \\
\text { consumen bebidas } \\
\text { naturales como parte } \\
\text { de su dieta diaria }\end{array}$ \\
\hline
\end{tabular}

Fuente: Elaboración propia

\section{c. Recolección de datos:}

Diseño del instrumento: En función a los requerimientos mencionados en los objetivos, se desarrolló la guía de pautas e indagación a emplearse en los Focus Group; esta guía está disponible en el Anexo $\mathrm{N}^{\circ} 4$

Trabajo de Campo: El trabajo de campo consistió en lo siguiente:

Focus Group $\mathbf{N}^{\circ} \mathbf{1}$ : Estudiantes y jóvenes comprendidos en el rango de 18 a 25 años

- Tamaño del grupo: 8 personas

- Moderador: 1 persona.

- Duración: 1 h 45,

- Registro: Audio y vídeo

- Fecha de ejecución: 29 de setiembre del 2018

- Hora:10 am- 11:45 am

Focus Group N²: Personas comprendidos en el rango de 26 a 35 años.

- Tamaño del grupo: 8 personas 
- Moderador: 1 persona.

- Duración: 1 h 30’

- Registro: Audio y vídeo

- Fecha de ejecución: 29 de setiembre del 2018

- Hora: $12: 30$ pm-2:00 pm

Focus Group N³: Personas comprendidos en el rango de 36 a 50 años.

- Tamaño del grupo: 8 personas

- Moderador: 1 persona.

- Duración: 1h 50'

- Registro: Audio y vídeo

- Fecha de ejecución: 29 de setiembre del 2018

- Hora: 02: 30 pm-03:20 pm

\section{d. Procesamiento de datos:}

\section{Primer Focus Group (18 a 25 años)}

La mayoría de los participantes indican que consumen diferentes bebidas para refrescarse o aplacar la sed como: gaseosas, agua, jugo de naranja, jugo verde, té verde. Algunos de los participantes relacionan a los refrescos naturales con hierbas aromáticas, como el cedrón, hierba luisa, pero con bajo nivel de azúcar o algún tipo de edulcorante tipo stevia.

Mayormente estos son consumidos en la mañana o al mediodía. En las mañanas como parte del desayuno y a mediodía como para refrescarse o hidratarse.

La mayoría de los presentes manifestó que cuando buscan una bebida natural prefieren que esta sea de color claro o que represente el color de la fruta que se está vendiendo, que sea bajo de azúcar, si está endulzado con stevia mejor, jarabe de algarrobo, miel de abejas, cero 
de preservantes. Asimismo, mencionaron que les gustaría que tenga un sabor ácido porque este sabor lo relacionan con naturaleza.

Por otro lado, estos desearían que el producto tenga beneficios para la salud y lo podrían consumir en la mañana, mediodía o en la noche, estos beneficios deberán de estar especificados en el envase.

Con respecto al envase, la gran mayoría manifestó que este sea de transparente e incoloro, en donde se muestre claramente el color de la bebida, además que tenga una etiqueta como la de los refrescos marca Selva. Se les presentó algunos productos de la competencia y los participantes coincidieron en el color de la bebida es muy importante y que este debería ser muy parecido al color de la fruta en su estado natural: Por ejemplo. bebidas de chía, guanábana o quinua con manzana.

Cuando se les hizo degustar la bebida en estudio, estos mencionaron que tiene un sabor muy parecido a manzana, pitahaya con camu camu. En general, indicaron que el producto tenía muy buen sabor, que no tiene azúcar y que tiene buena consistencia, aunque el color de este no estaba muy bien definido, muy transparente, sugieren que sería mejor si lo envasan en una botella de color.

A los participantes se les mostró una serie de tamaños de envases y la gran mayoría manifestó que le gustaría la presentación de entre 250 a 300 ml debido a que esta capacidad es lo que están acostumbrados a consumir para este tipo de bebidas. Una capacidad mayor a las mencionadas no las consumiría.

Con respecto a la disposición a pagar por este tipo de bebida sería entre 2 a 3 soles. Así mismo, se pudo observar que el consumo de estas bebidas es muy disperso. Muchos de los participantes solo consumen agua. Este tipo de producto lo consumirían un par de veces a la semana o semanalmente. 
En cuanto a la disposición de pago por una bebida natural entre $250 \mathrm{ml}$ o 300ml estarían dispuestos a pagar entre 2 o 3 soles que es lo que normalmente pagan por productos similares.

En cuanto a la prueba de nombre, los participantes mencionaron que el nombre Kawsay no les llama la atención, desconocen su significado, el nombre no les dice nada, la gran mayoría prefieren que la bebida tenga un nombre relacionado al sabor de la fruta como Pitafruit o Pitafrush, si son varias frutas podría ser una combinación de los nombres de estas.

En cuanto al lugar donde prefieren que esta bebida natural se venda, la totalidad de los participantes manifestaron que la prefieren en los supermercados. Así también mencionaron que las bebidas naturales que actualmente conocen y consumen son: bebidas de aloe vera, zuma, bebida sana, te vida de Perú Kola, entre las más importantes.

Finalmente, en cuanto a la forma de publicidad para promocionar esta bebida, los participantes sugirieron realizarlo a través de las redes sociales, pues estos interactúan diariamente en esta plataforma y tiene mucha influencia de decisión en el público objetivo.

\section{Segundo Focus Group (26 a 35 años)}

Los lugares de compra más comunes de bebidas envasadas son los supermercados, bodegas, market de grifos y kioskos, el lugar que resulte más cercano de acuerdo a donde la persona se encuentre.

Las marcas más recurrentes que tienen los consumidores en mente son: Frugos, Gloria, Watts, Laive, Selva, Pulp, Kero, Free Tea, Aquarius, Cifrut, Tampico, Gatorade, Sporade, Powered, Coca Cola, Fanta y San Mateo.

Las marcas con las que se identifican los participantes son: Kero, Frugos, Watts, Gloria, Free Tea, Aquarius y Cifrut. 
Las expectativas respecto de un refresco natural son: que no se sientan los químicos que utiliza la bebida sino el sabor propio de la fruta, que tenga textura q simule la fruta misma, que tenga vitaminas, que presente un nivel moderado de azúcar que permita saciar la sed.

Respecto del color, prefieren los de color natural (propio de la fruta) o que tengan menor cantidad de colorante, prefieren el sabor antes que el color, acompañado de un buen aspecto.

La mayoría prefiere los envases de vidrio debido a que según la percepción de los participantes conserva mejor el sabor natural de la fruta y es más higiénico.

La mayoría de los participantes prefiere una presentación que contenga más de $400 \mathrm{ml}$, pero menos de 1lt (por considerarlo poco práctico para el traslado), la presentación del envase calza en ese rango.

Sobre el sabor, a la mayoría le agradó. El punto de azúcar y acidez es el adecuado; indicaron que se siente el sabor de la fruta, lo que demuestra que se trata de un producto muy natural.

Respecto de la textura, les agradó, sin embargo, indicaron que no lo consumirían para saciar la sed, dado que la consistencia no es tan líquida, sugirieron que se aligere un poco más.

Respecto del color (verde), les pareció adecuado para apoyar la onda natural del producto (libre de colorantes), sin embargo, prefieren que sea un verde claro.

Los participantes, indicaron que esperan encontrar el producto en supermercados, market's, bodegas y sugirieron que debería colocarse en tiendas naturistas.

Respecto del precio, indicaron que estarían dispuestos a pagar entre S/ 4.50 a S/ 6.50. tomado como referencia los precios con características "similares” según su percepción.

Respecto de las cualidades que benefician a la salud del consumidor, resaltaron los beneficios que tiene en el sistema gastrointestinal, dado que la gastritis es un mal común en 
nuestra sociedad. Indicaron que les parece una bebida completa dado su valor nutricional y la función refrescante que cumple.

Sugirieron que en la etiqueta se describa todos los beneficios que tiene el producto.

Indicaron que la estrategia de marketing debería ir dirigida a los beneficios del

producto, haciendo notar la marcada diferencia en relación a los otros productos del mercado, sumado a la difusión de las bondades del fruto mismo, a través de los medios de comunicación.

Indicaron que sería un producto muy adecuado para los deportistas, dada la cantidad de fibra que contiene.

Sugirieron el uso de impulsadoras para poder difundir los beneficios entre los potenciales clientes.

Al ser consultados sobre el nombre Kawsay, no conocían el término, sin embargo, al explicarle que es una palabra en quechua que significa "vida plena" consensuaron que era un nombre apropiado y muy peruano pero que se le tenía que hacer difusión.

\section{Tercer Focus Group (36 a 50 años)}

La mayoría de los participantes indican que toman agua, jugos, gaseosas, infusiones, para saciar la sed.

Algunos de los participantes conocen las bebidas naturales y las relacionan con aloe vera, chía, jugo de naranja de Wong, camu camu, free tea, jugos de casa, pero con bajos niveles de azúcar. Asimismo, mencionaron que mayormente estos jugos naturales lo consumen una vez a la semana.

La mayoría de los presentes manifestó que prefieren comprar jugos de frutas exóticas, porque son saludables y comprarlos en los supermercados resulta más práctico. Consideran que es importante una buena presentación del producto y que sea un empaque ecológico. 
Con respecto al sabor, la mayoría indicó que puede ser amargo o que tenga el sabor de la fruta, bajo en azúcar o que se endulce con un producto natural. Sobre el color de la bebida indicaron que se muestre en un envase transparente.

La mayoría de los participantes mencionaron que muchas de las bebidas naturales lo han tomado en restaurantes.

A los presentes se les mostró una serie de tamaños y modelos de envases de la competencia y la gran mayoría manifestó que le gustaría una presentación de 300 ml y que se muestren en unas botellas como tienen los jugos de: aloe vera, jugo Selva, chía y de quinua con manzana.

Asimismo, indicaron que les gustaría encontrar este producto en los grifos o supermercados.

Con respecto a la disposición a pagar por este tipo de bebida, mencionaron que sería entre 3.50 a S/5.00 soles como máximo.

Cuando se les hizo degustar la bebida en estudio, estos mencionaron que tiene un sabor muy agradable, les gustó la acidez de este, pero lo prefieren tomar más frio.

Cuando se les consultó sobre el nombre Kawsay, indicaron que no sabían el significado de este y sugirieron que en la etiqueta del producto debería indicar el nombre del producto y su significado.

Para el producto en investigación, los participantes recomendaron que se muestre en un envase similar a la bebida de chía y que tenga la etiqueta de la bebida de quinua con manzana.

Finalmente, en cuanto a la forma de publicidad para promocionar esta bebida, los participantes sugirieron realizarlo a través de la televisión. 


\subsection{Investigación Cuantitativa}

\subsubsection{Finalidad y Objetivos}

\section{a. Finalidad}

Conocer la demanda proyectada de una nueva bebida natural elaborada con un fruto denominado Sanky en la zona 7 de Lima Metropolitana según APEIM. Esta zona está conformada por los distritos de Santiago de Surco, La Molina, San Borja, San Isidro y Miraflores.

\section{b. Objetivo General}

Conocer la demanda en número de botellas de esta nueva bebida para los años de 2017 al 2021, periodo en que dure este proyecto.

\section{c. Objetivos Específicos}

Determinar el mercado potencial del proyecto que está compuesto por aquellas personas que residen en los distritos mencionados, cuyas edades fluctúan entre 18 y 50 años y cuyo Nivel Socioeconómico sea A o B.

Determinar el mercado disponible que está compuesto por aquellas personas que pertenecen al mercado potencial y además consumen algún tipo de bebida natural envasada.

$\checkmark$ Determinar el mercado disponible del proyecto, que está compuesto por aquellos que actualmente consumen alguna bebida natural envasada de otra marca, pero por las características superiores de la bebida natural elaborada con Sanky consumirían dicho producto.

Determinar el mercado objetivo del proyecto, que representa la participación de mercado de este producto con respecto al mercado total de bebidas naturales envasadas.

$\checkmark$ Establecer los factores de importancia que el consumidor espera de una bebida natural envasada. 
Determinar el tamaño de envase más idóneo para la comercialización del producto.

Determinar los principales puntos de comercialización.

Determinar la frecuencia de compra de compra de bebidas naturales envasadas, así como la cantidad de unidades por compra.

Determinar la disponibilidad a pagar del público objetivo por dicho producto.

Conocer la aceptación del producto en cuanto a sabor, textura, aroma, color de la bebida, etc.

\subsubsection{Característica de la encuesta}

Método de entrevista: Se empleó el método de entrevista personal, realizada por un equipo de encuestadores contratados por los miembros del grupo, quienes se instalaron visitando diferentes zonas de los distritos en mención.

Se capacito al equipo de encuestadores para que definieran a las personas a encuestar el concepto de bebida natural, que sería elaborada a base del fruto andino sanky, edulcorante natural (yacón), agua, con un mínimo de preservantes, que no contiene alcohol, ni azúcar, ni cafeína que se elaborara de manera industrial y será envasada.

\subsubsection{Unidad de Investigación}

La unidad de investigación son aquellas personas que consumen generalmente algún tipo de bebida natural envasada.

\subsubsection{Diseño Muestral}

Población objetivo: La población objetivo está compuesta por aquellas personas que cuentan con las características deseadas para consumir el producto que se está evaluando en el presente proyecto. 
Elemento: Se considera a las personas que residen en alguno de los distritos de la zona 7 de Lima Metropolitana (según APEIM), cuyas edades fluctúen entre los 18 a 50 años y consuman bebidas naturales envasadas.

Unidad de muestreo: Son aquellas personas que residen en los distritos que conforman la Zona 7 de Lima Metropolitana (según APEIM) que son los distritos de Santiago de Surco, La Molina, San Borja, Miraflores, San Isidro y San Borja.

$\checkmark$ Técnica de muestreo: Para la presente investigación se ha considerado la técnica de muestro aleatorio sistemático, por el cual se consultaba a los transeúntes, que cumplían con el filtro inicial. Es decir, se procedía a realizar la encuesta al décimo peatón y así sucesivamente.

Tiempo: El trabajo de campo fue realizado entre los días del 05 al 08 de octubre del 2018.

Tamaño de la muestra: Para la presente investigación se ha considerado 385 encuestas, para ello se ha considerado la siguiente ecuación:

$$
N=\frac{Z^{2} \cdot p \cdot q}{E^{2}} \Rightarrow N=\frac{(1.96)^{2}(0.5)(0.5)}{(0.05)^{2}}=384.16
$$

Donde $\mathrm{n}$ representa el tamaño de la muestra, $\mathrm{Z}$ es el nivel de confianza que para el presente proyecto es de 95\%, P es la proporción favorable y Q es la proporción desfavorable, mientras que d es el error permitido que para este caso es de 5\%. Es importante mencionar que como se desconoce los valores de P y Q se considera para ambos 50\% debido a que estos valores maximizan el valor del tamaño de la muestra. De esta forma, las 385 encuestas necesarias para el presente proyecto de inversión estarían distribuidas considerando tanto el distrito de su residencia, así como al nivel socio económico al cual pertenece. 
Tabla 9

Distribución de las encuestas por "Distrito-edad"

\begin{tabular}{lllll}
\hline Distrito & $\begin{array}{l}\mathbf{N}^{\circ} \text { de personas } \\
\text { encuestadas }\end{array}$ & $\begin{array}{l}\text { Edad } \\
\mathbf{1 8 - 2 5}\end{array}$ & $\mathbf{2 6 - 3 5}$ & $\mathbf{3 6 - 5 0}$ \\
\hline San Isidro & 27 & 12 & 9 & 6 \\
Santiago de Surco & 175 & 81 & 87 & 7 \\
San Borja & 55 & 23 & 26 & 6 \\
La Molina & 87 & 38 & 43 & 6 \\
Miraflores & 41 & 15 & 19 & 7 \\
Total & $\mathbf{3 8 5}$ & $\mathbf{1 6 9 ( 4 3 . 9 0 \% )}$ & $\mathbf{1 8 4}$ & $\mathbf{3 2}(\mathbf{8 . 3 1 \% )}$ \\
\hline
\end{tabular}

Fuente: Elaboración Propia

Tabla 10

Distribución de las encuestas por "NSE"

\begin{tabular}{llll}
\hline Distrito & \multicolumn{2}{l}{ Nivel Socio Económico } & $\begin{array}{l}\mathbf{N}^{\circ} \text { de personas } \\
\text { encuestadas }\end{array}$ \\
\hline San Isidro & A & B & 27 \\
Santiago de Surco & 75 & 15 & 27 \\
San Borja & 24 & 99 & 175 \\
La Molina & 38 & 32 & 55 \\
Miraflores & 18 & 49 & 87 \\
Total & $\mathbf{1 6 6}$ & 23 & 41 \\
\hline
\end{tabular}

Fuente: INEI y APEIM

\subsubsection{Recolección de Datos}

Para este estudio se empleó una encuesta la cual incluye diversos controles a fin de garantizar que las respuestas sean consistentes y para que el encuestador pueda recoger información relevante de las personas encuestadas.

\section{a. Diseño del instrumento}

Encuesta directa-estructurada de tipo personal.

Se determinó el contenido y estructura de preguntas 
Se estableció secuencia y se revisó redacción.

Se definió la característica física del cuestionario que comprende 29 preguntas de las cuales 14 son de control para asegurar que pertenecen a la población a quien se dirige el producto.

Se realizaron ensayos para estimar el tiempo de aplicación de la encuesta y también para evaluar la idoneidad del instrumento.

El cuestionario se encuentra en el Anexo $\mathrm{N}^{\circ} 5$.

\section{b. Trabajo de campo}

$\checkmark$ El método de la encuesta, en base a su aplicación, fue de tipo personal, con el soporte de un cuestionario impreso y el llenado a lapicero.

Para medir la fiabilidad del cuestionario aplicado, se ha realizado la prueba denominada Alfa de Cronbach. Este análisis mide la correlación entre los ítems del constructo. El constructo será fiable, cuando el índice supera el 0.6.

Por tal motivo, se demuestra que el instrumento utilizado para el presente proyecto es fiable.

Tabla 11

Análisis de fiabilidad del cuestionario

\begin{tabular}{ll}
\hline Estadísticos de fiabilidad \\
\hline Alfa de Cronbach & $\mathrm{N}$ de elementos \\
, 780 & 15 \\
\hline
\end{tabular}

Fuente: Elaboración propia

Los cuestionarios fueron aplicados desde el 05 hasta el 09 de octubre del 2018 en sectores seleccionados de la Zona Lima 7.

Para la ejecución de los cuestionarios, estos fueron asesorados por la consultora Asesores Integrales especializada en estudio de mercado, quienes asesoraron en el proceso inicial de trabajo de campo, entendido como: selección y designación de los encuestadores, 
capacitación respecto al cuestionario elaborado, así como la supervisión del trabajo. Los integrantes del grupo se encargaron de verificar en campo la presencia de los encuestadores y la ejecución de las actividades, acorde a lo planificado con la consultora.

\subsubsection{Procesamiento $y$ análisis de datos:}

Con el total de los cuestionarios en físico se procedió a trasladar las respuestas a un archivo de Excel. Se elaboró un cuadro de consolidación de resultados que comprendía el total de los cuestionarios.

En su mayoría, el análisis estadístico se realizó por cada pregunta. La tabulación de los datos obtenidos para cada una de ellas permitió construir una distribución de frecuencias, organizando los valores en cada clase y expresando su frecuencia relativa. Esta información la presentamos en forma tabular y además gráfica en forma de diagramas.

A continuación, indicamos los resultados obtenidos en la encuesta y el análisis realizado por pregunta:

\section{Pregunta A: ¿Qué edad tiene usted?}

Tabla 12

Resultados de pregunta A

\begin{tabular}{lcc}
\hline $\begin{array}{l}\text { Rangos de } \\
\text { Edad }\end{array}$ & Encuestados & Porcentajes \\
\hline $18-25$ & 169 & $43.90 \%$ \\
$26-35$ & 184 & $47.79 \%$ \\
$36-50$ & 32 & $8.31 \%$ \\
TOTAL & $\mathbf{3 8 5}$ & $\mathbf{1 0 0 \%}$ \\
\hline
\end{tabular}

Fuente: Elaboración Propia 


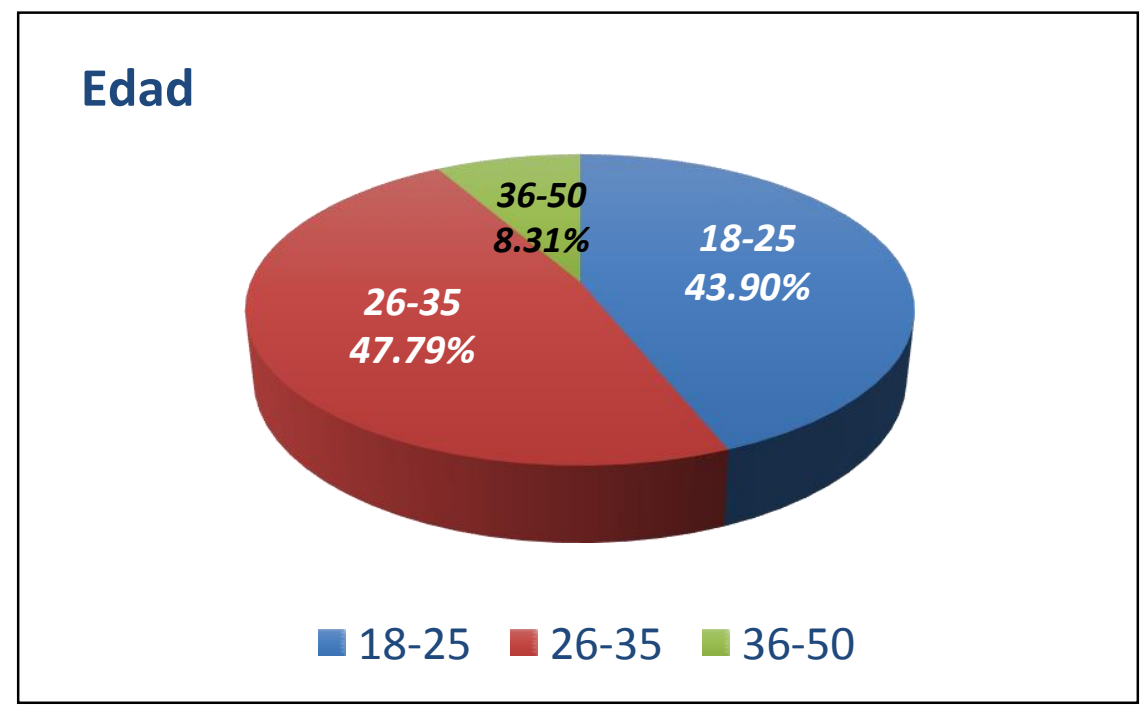

Figura 15. Resultados de pregunta A.

Fuente: Elaboración Propia

Se puede concluir que el $43.90 \%$ de las personas encuestadas están entre los 18 y 25 años; el $47.79 \%$, entre los 26 y 35 y el $8.31 \%$ entre 36 y 50 años.

Pregunta B: ¿Consume bebidas naturales?

Tabla 13

Resultados de pregunta B

\begin{tabular}{lcc}
\hline Conducta & Encuestados & Porcentajes \\
\hline No consume & 2 & $0.52 \%$ \\
Si Consume & 383 & $99.48 \%$ \\
TOTAL & $\mathbf{3 8 5}$ & $\mathbf{1 0 0 \%}$ \\
\hline
\end{tabular}

Fuente: Elaboración Propia 


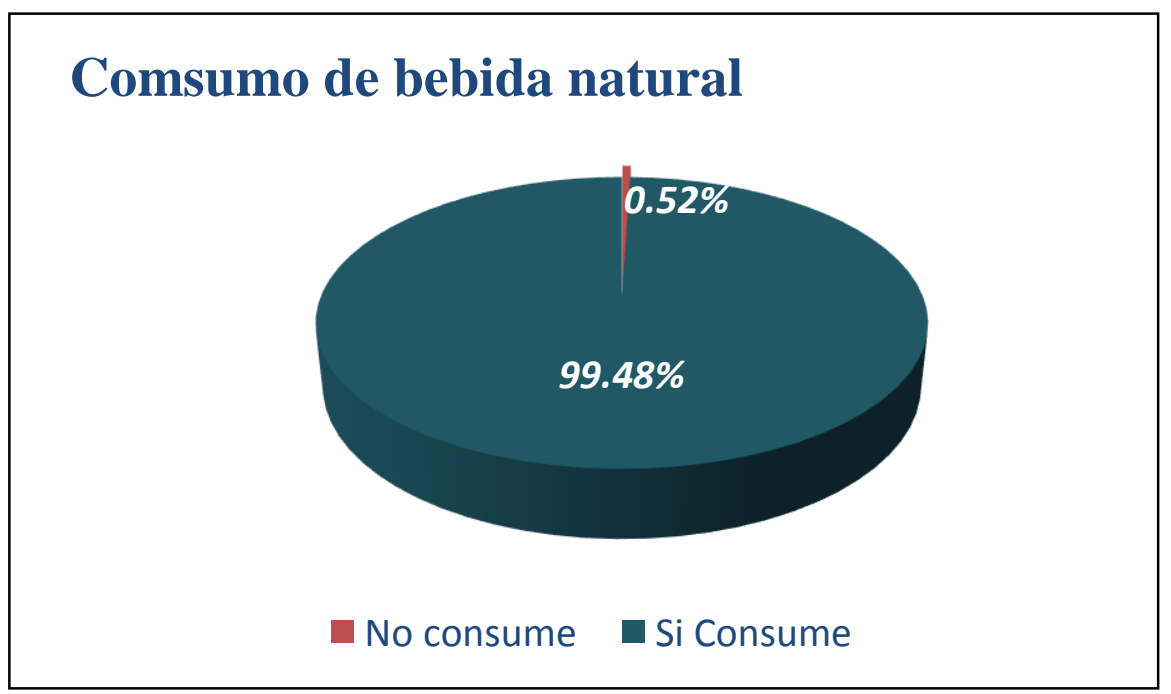

Figura 16. Resultados de pregunta B.

Fuente: Elaboración Propia

Al realizar la pregunta de campo se hizo énfasis en las características que tiene toda bebida natural que se produce a nivel industrial, luego de la precisión, los encuestados indicaron que el $99.48 \%$ consumen bebidas naturales y el $0.52 \%$ no lo hacen. Esta respuesta es muy favorable para los objetivos del proyecto pues casi el 100\% de los encuestados consumen bebidas naturales envasadas.

Pregunta C: ¿Cuáles de estas marcas de bebidas naturales usted conoce?

Tabla 14

Resultados de pregunta $C$

\begin{tabular}{lcc}
\hline Marcas & Encuestados & Porcentajes \\
\hline Chía & 0 & $0.00 \%$ \\
Frumas & 0 & $0.00 \%$ \\
Jugos Selva & 115 & $29.87 \%$ \\
Petit & 0 & $0.00 \%$ \\
Free Tea & 50 & $12.99 \%$ \\
Kero & 0 & $0.00 \%$ \\
Aloe Vera & 220 & $57.14 \%$ \\
TOTAL & $\mathbf{3 8 5}$ & $\mathbf{1 0 0 \%}$ \\
\hline
\end{tabular}

Fuente: Elaboración propia 


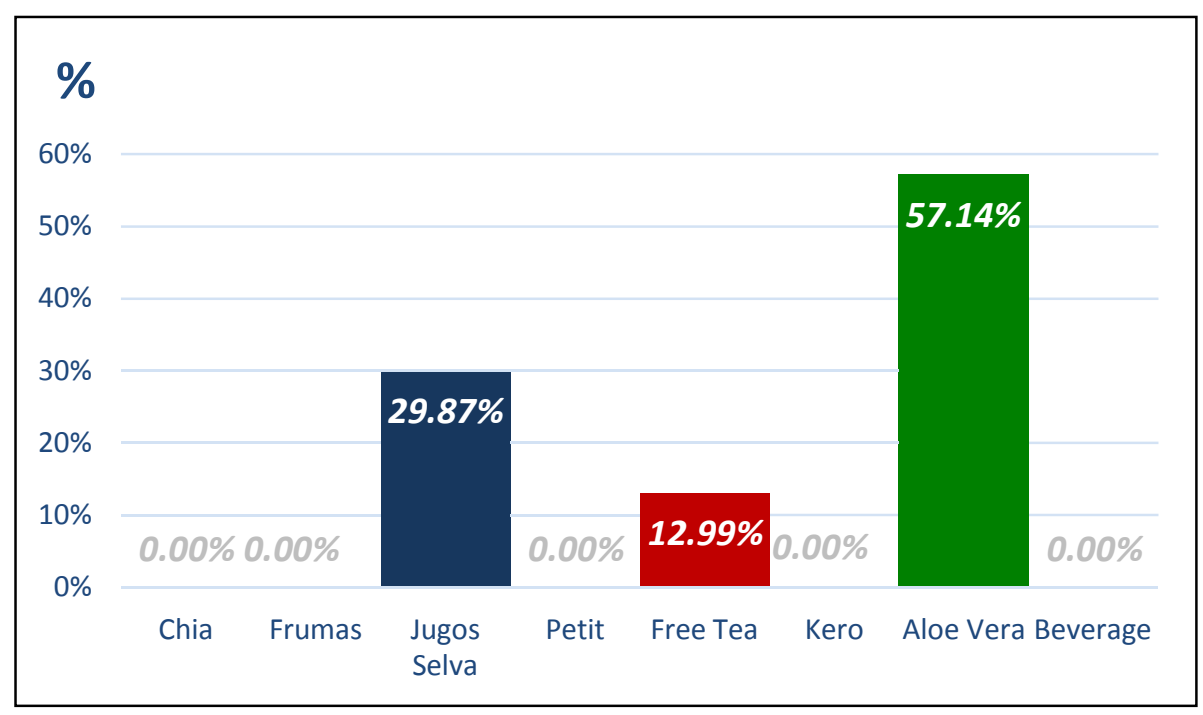

Figura 17. Resultados de pregunta $C$

Fuente: Elaboración Propia

En esta Figura se puede observar que el $56.92 \%$ conoce la bebida Aloe Vera, el $30.03 \%$ jugos selva y el $13.05 \%$ Free Tea. Esta respuesta es coherente con lo observado en el Focus Group donde se indicaba la gran preferencia de esta bebida entre los participantes.

Pregunta D: ¿Considera usted que las características de la bebida natural que más consume, es todo lo que usted necesita?

Tabla 15

Resultados de pregunta D

\begin{tabular}{lcc}
\hline Satisfacción & Encuestados & Porcentajes \\
\hline Totalmente de acuerdo & 216 & $\mathbf{5 6 . 1 4 \%}$ \\
De acuerdo & 169 & $\mathbf{4 3 . 8 6 \%}$ \\
TOTAL & $\mathbf{3 8 5}$ & $\mathbf{1 0 0 \%}$ \\
\hline
\end{tabular}

Fuente: Elaboración Propia 


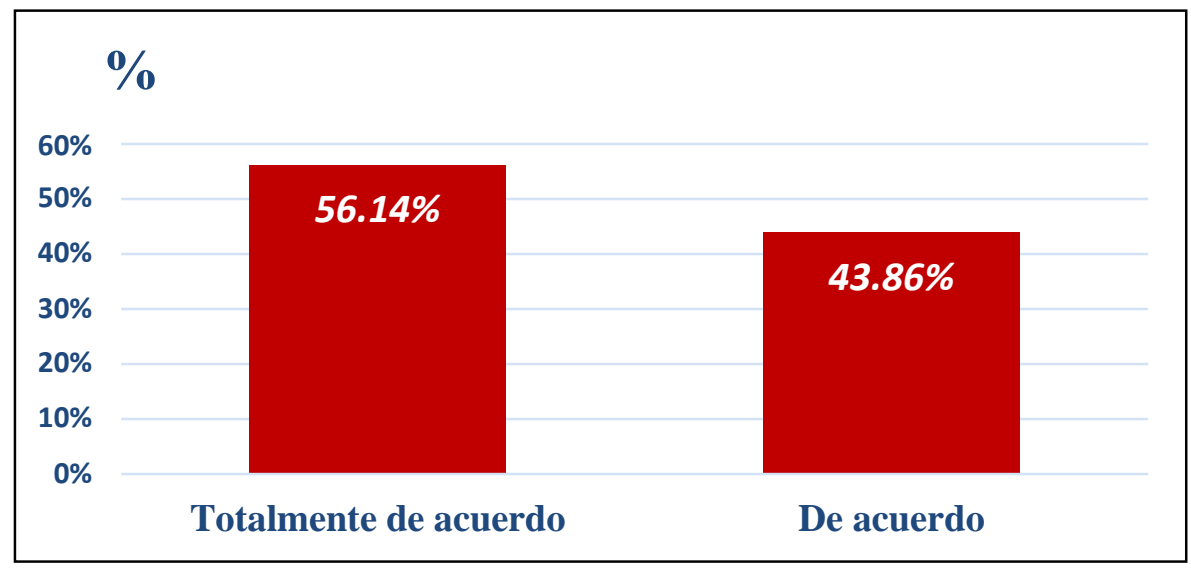

Figura 18. Resultados de pregunta D.

Fuente: Elaboración Propia

El 56.14\% de las personas encuestadas están totalmente de acuerdo que la bebida natural que consume es de su agrado y el $43.86 \%$ están de acuerdo de lo que se menciona anteriormente. Es decir, el 100\% de los encuestados afirman que la bebida natural envasada que consumen es de agrado.

Pregunta E: ¿Identifique el nivel de importancia con respecto a los siguientes atributos que usted busca en las bebidas naturales?

Tabla 16

Resultados de pregunta E Textura

\begin{tabular}{lcc}
\hline Sobre la Textura & Encuestados & Porcentajes \\
\hline Poco Importante & 1 & $0.26 \%$ \\
Medianamente importante & 53 & $13.84 \%$ \\
Importante & 259 & $67.36 \%$ \\
Muy importante & 71 & $18.54 \%$ \\
TOTAL & $\mathbf{3 8 5}$ & $\mathbf{1 0 0 \%}$ \\
\hline
\end{tabular}

Fuente: Elaboración Propia 


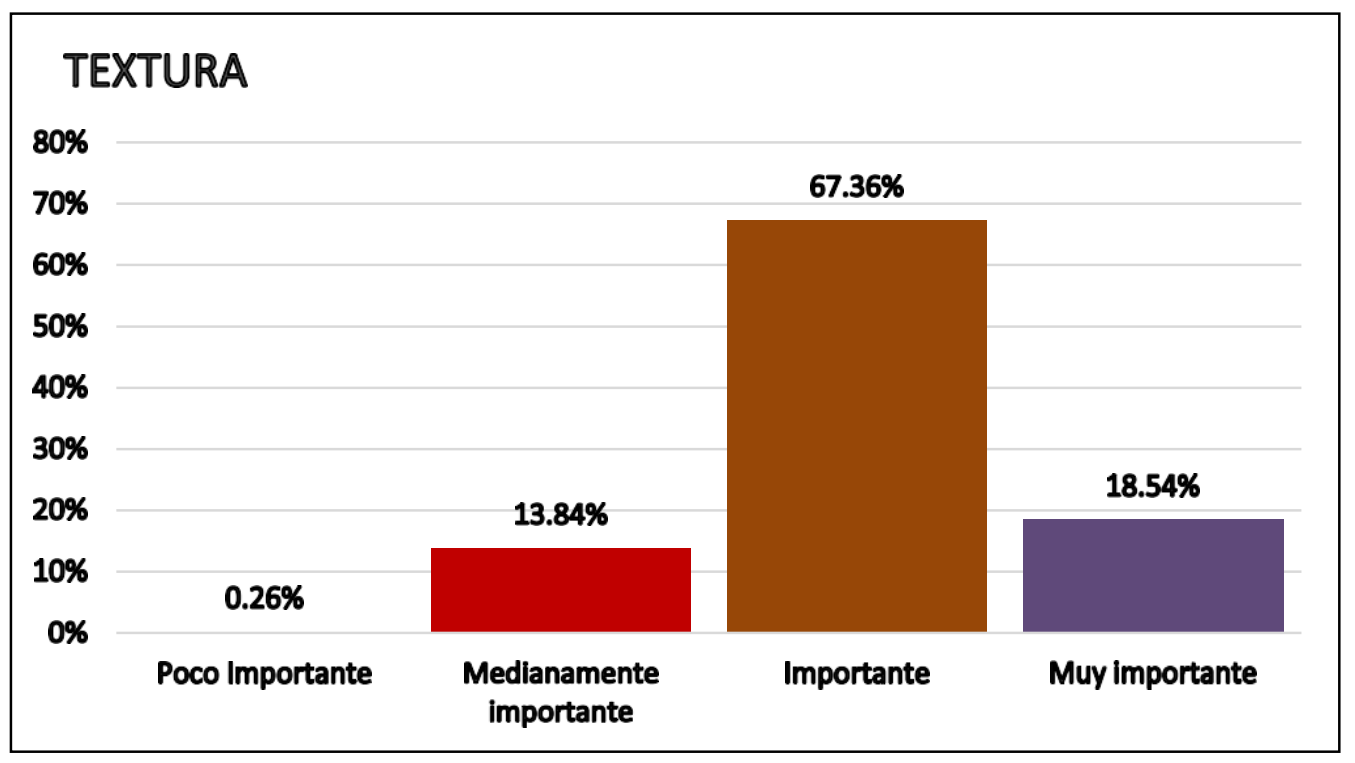

Figura 19. Resultados de pregunta E Textura.

Fuente: Elaboración Propia

El $67.36 \%$ de los encuestados consideran importante la textura de la bebida natural, el

$18.54 \%$ lo considera muy importante, el $13.84 \%$ medianamente importante, y el $0.26 \%$ poco importante. Es decir, casi el $86 \%$ de los encuestados afirman que la textura de la bebida es importante. Es decir, la gran mayoría de los encuestados prefieren las bebidas algo espesas, pues según el estudio cualitativo, mientras más espeso mejor.

\section{Tabla 17}

Resultados de pregunta E Color

\begin{tabular}{lcc}
\hline Sobre el color & Encuestados & Porcentajes \\
Medianamente importante & 41 & $10.70 \%$ \\
Importante & 266 & $69.19 \%$ \\
Muy importante & 77 & $20.10 \%$ \\
TOTAL & $\mathbf{3 8 5}$ & $\mathbf{1 0 0 \%}$ \\
\hline
\end{tabular}

Fuente: Elaboración Propia 


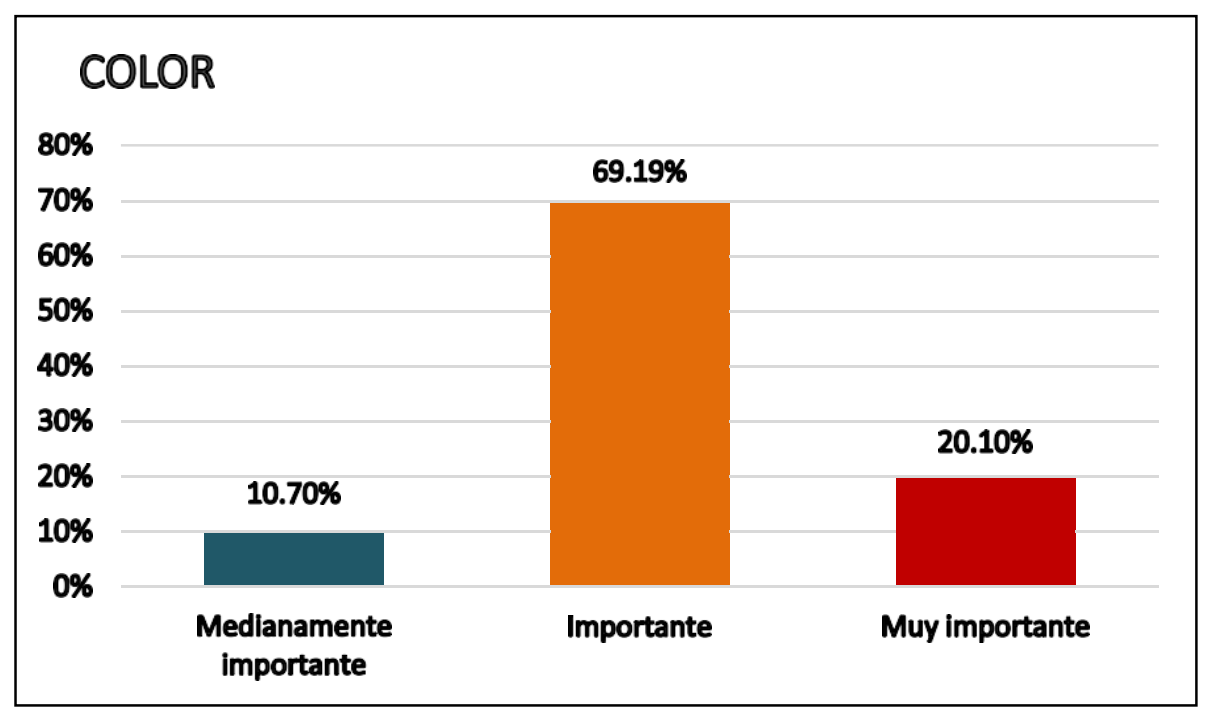

Figura 20. Resultados de pregunta E Color.

Fuente: Elaboración Propia

El 69.19\% de los participantes consideran que el color es un atributo importante, el

$20.10 \%$ muy importante y el $10.70 \%$ medianamente importante. Casi el $90 \%$ de los encuestados afirma que el color de la bebida es muy importante.

Tabla 18

Resultados de pregunta F Contenido Calórico

\begin{tabular}{lcc}
\hline Sobre el contenido calórico & Encuestados & Porcentajes \\
\hline Poco Importante & 1 & $0.26 \%$ \\
Medianamente importante & 24 & $6.27 \%$ \\
Importante & 301 & $78.07 \%$ \\
Muy importante & 59 & $15.40 \%$ \\
$\quad$ TOTAL & $\mathbf{3 8 5}$ & $\mathbf{1 0 0 \%}$ \\
\hline
\end{tabular}

Fuente: Elaboración Propia 


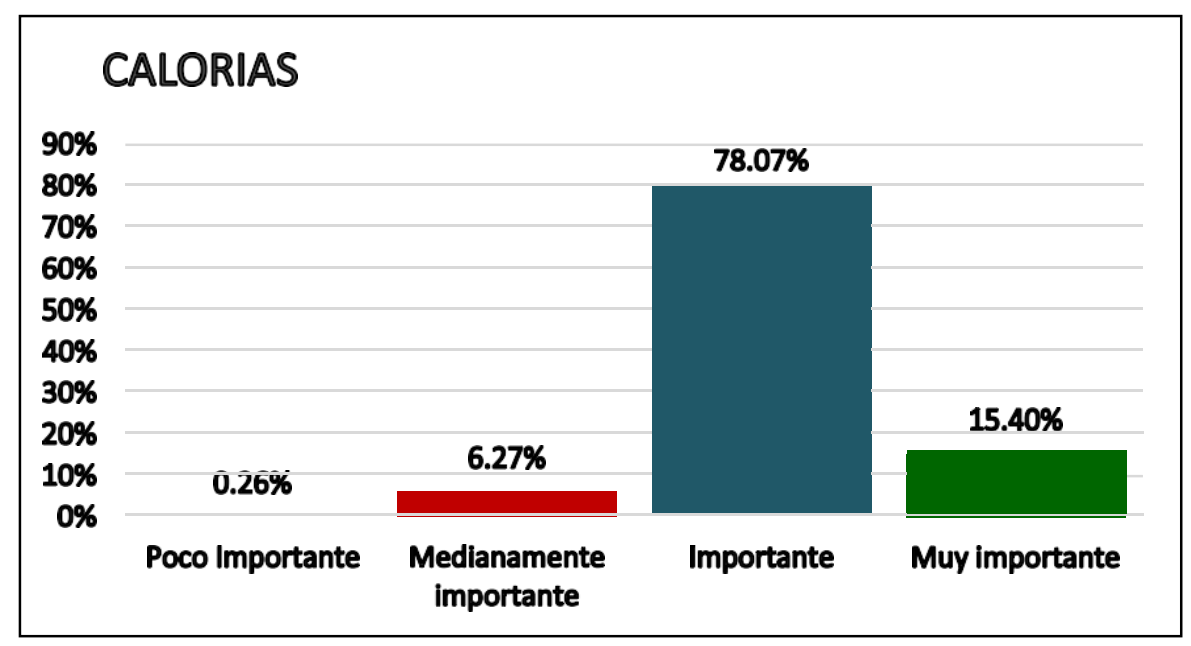

Figura 21. Resultados de pregunta E Contenido Calórico.

Fuente: Elaboración propia

Los encuestados indicaron que el $78.07 \%$ es importante el contenido calórico, el $15.40 \%$ lo consideran muy importante, el $6.27 \%$ medianamente importante, el $0.26 \%$ poco importante. Es decir, casi el 94\% de los encuestados consideran que el contenido calórico de las bebidas naturales envasadas es importante.

Tabla 19

Resultados de pregunta E Imagen de la Marca

\begin{tabular}{lcl}
\hline Imagen Marca & Encuestados & Porcentajes \\
\hline Poco Importante & 1 & $0.26 \%$ \\
Medianamente importante & 3 & $0.78 \%$ \\
Importante & 302 & $78.33 \%$ \\
Muy importante & 79 & $20.63 \%$ \\
$\quad$ TOTAL & $\mathbf{3 8 5}$ & $\mathbf{1 0 0 \%}$ \\
\hline
\end{tabular}

Fuente: Elaboración Propia 


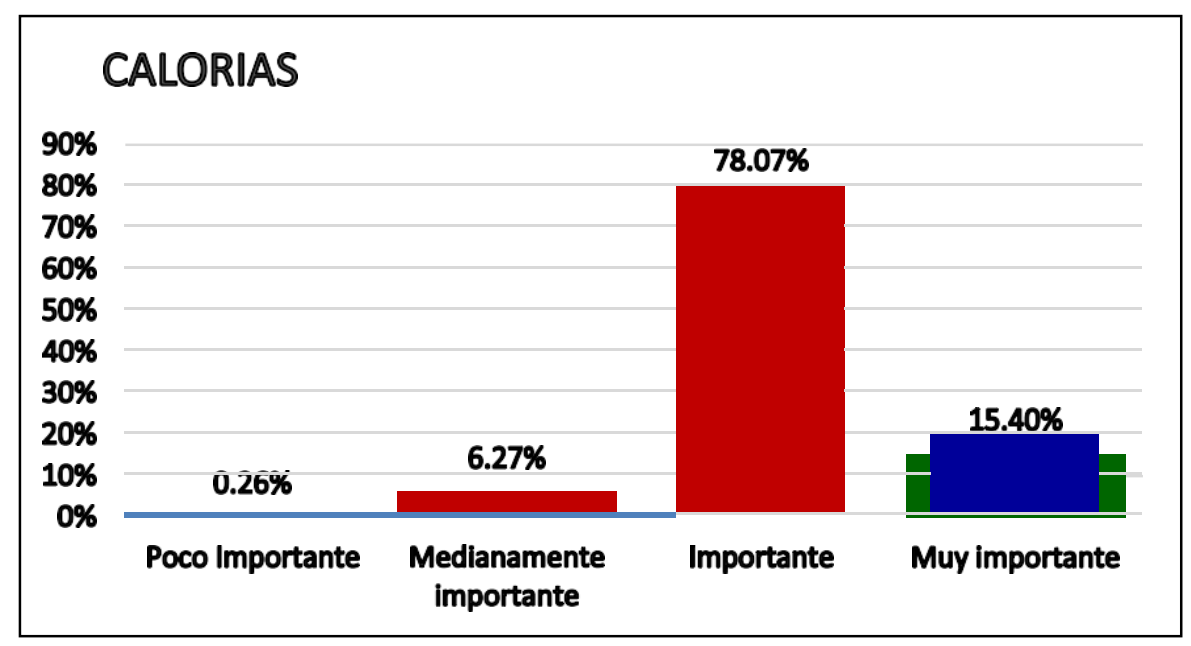

Figura 22. Resultados de pregunta E Imagen de la Marca.

Fuente: Elaboración propia

El 78.33\% consideran importante la imagen de la marca, el $20.63 \%$ muy importante, el $0.78 \%$ medianamente importante y el $0.26 \%$ poco importante. Es decir, casi el $99 \%$ de los encuestados consideran que la marca del producto es muy importante. Este punto es muy desfavorable para los objetivos del presente proyecto, debido a que una marca en este sector demasiado atomizado deberá de realizar estrategias de posicionamiento de marca para generar confianza dentro de los consumidores.

Tabla 20

Resultados de pregunta E Presentación

\begin{tabular}{lcc}
\hline Presentación & Encuestados & Porcentajes \\
\hline Importante & 332 & $86.16 \%$ \\
Muy importante & 53 & $13.84 \%$ \\
TOTAL & $\mathbf{3 8 5}$ & $\mathbf{1 0 0 \%}$ \\
\hline
\end{tabular}

Fuente: Elaboración propia 


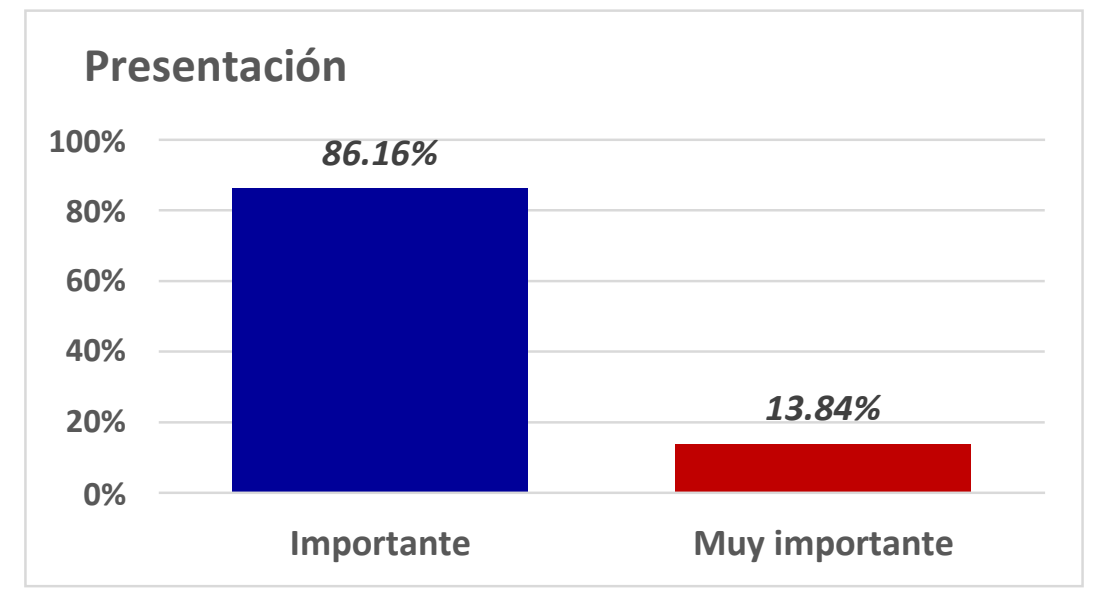

Figura 23, Resultados de pregunta E Presentación.

Fuente: Elaboración propia

El $86.16 \%$ considera importante la presentación de las bebidas naturales y el 13.84\% muy importante. Es decir, el 100\% de los encuestados manifiestan que la presentación es importante y por lo tanto deberá de tenerse en cuenta para la comercialización del producto.

Tabla 21

Resultados de pregunta E Precio

\begin{tabular}{lcl}
\hline Precio & Encuestados & Porcentajes \\
\hline Poco Importante & 6 & $1.56 \%$ \\
Medianamente importante & 2 & $0.52 \%$ \\
Importante & 341 & $88.57 \%$ \\
Muy importante & 36 & $9.35 \%$ \\
$\quad$ TOTAL & $\mathbf{3 8 5}$ & $\mathbf{1 0 0 \%}$ \\
\hline
\end{tabular}

Fuente: Elaboración propia 


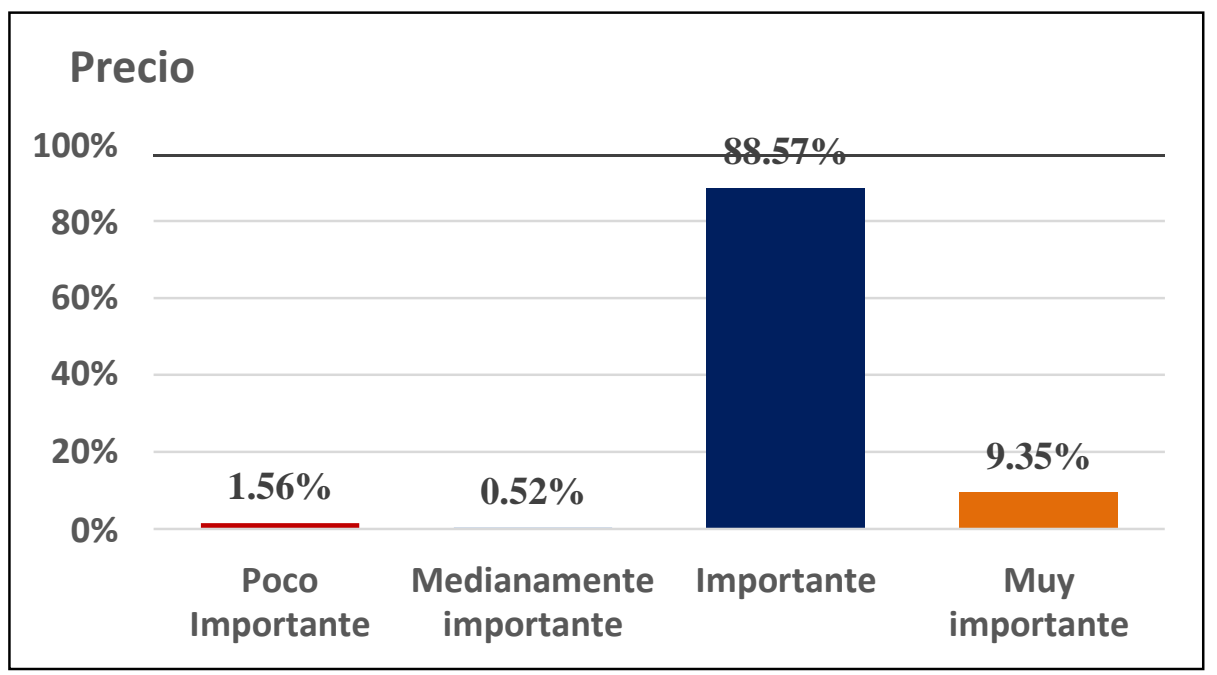

Figura 24. Resultados de pregunta E Precio.

Fuente: Elaboración propia

El 88.57\%consideran que el atributo "Precio" es importante, el 9.35\% muy importante, el $1.56 \%$ poco importante, el $0.52 \%$ medianamente importante. Casi el $98 \%$ de los encuestados manifiestan que el precio es importante para la decisión de compra. Esta respuesta manifiesta que es muy probable que la elasticidad del precio con la demanda de este producto sea muy alta. Así también, es coherente con atomización del producto, debido a que la oferta de productos sustitutos es muy amplia.

Tabla 22

Resultados de pregunta E Propiedades Naturales

\begin{tabular}{lcc}
\hline Propiedades Naturales & Encuestados & Porcentajes \\
\hline Poco Importante & 23 & $5.97 \%$ \\
Medianamente importante & 15 & $3.90 \%$ \\
Importante & 290 & $75.32 \%$ \\
Muy importante & 57 & $14.81 \%$ \\
$\quad$ TOTAL & $\mathbf{3 8 5}$ & $\mathbf{1 0 0 \%}$ \\
\hline
\end{tabular}

Fuente: Elaboración propia 


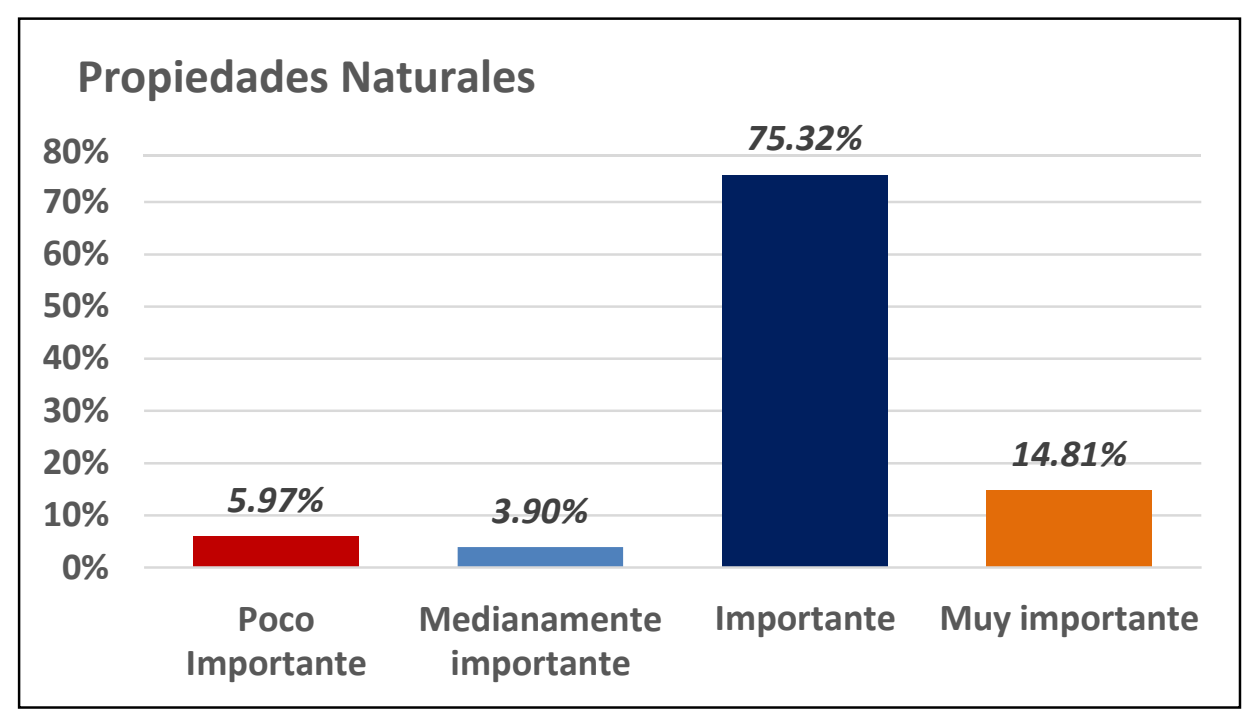

Figura 25. Resultados de pregunta E Propiedades Naturales.

Fuente: Elaboración propia

El atributo "propiedades naturales" es considerado por el $75.32 \%$ como importante, el $14.81 \%$ muy importante, el $5.97 \%$ poco importante y el $3.90 \%$ medianamente importante. Es decir, más del $90 \%$ de los encuestados afirman que las propiedades naturales de la fruta son muy importantes. Por tal motivo, es necesario que dentro de las estrategias de marketing es la de comunicar al público objetivo las propiedades naturales de la fruta.

\section{Tabla 23}

Resultados de pregunta E Tamaño

\begin{tabular}{lcc} 
Tamaño & Encuestados & Porcentaje \\
\hline Medianamente importante & 29 & $7.57 \%$ \\
Importante & 315 & $81.72 \%$ \\
Muy importante & 41 & $10.70 \%$ \\
$\quad$ TOTAL & $\mathbf{3 8 5}$ & $\mathbf{1 0 0 \%}$ \\
\hline
\end{tabular}

Fuente: Elaboración propia 


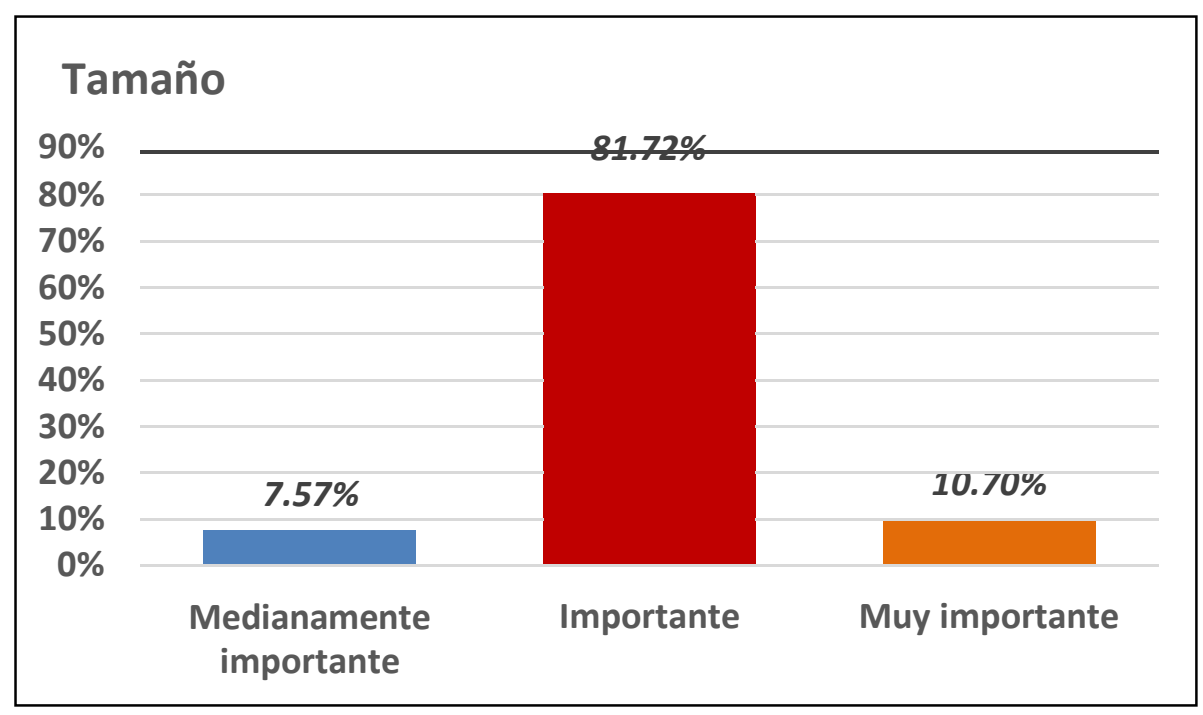

Figura 26. Resultados de pregunta E Tamaño.

Fuente: Elaboración propia

El $81.72 \%$ de los encuestados consideran importante al atributo "tamaño", el 10.70\% muy importante, $7.57 \%$ medianamente importante

Tabla 24

Resultados de pregunta E Valor Nutricional

\begin{tabular}{lcc}
\hline Valor Nutricional & Encuestados & Porcentajes \\
\hline Importante & 350 & $90.86 \%$ \\
Muy importante & 35 & $9.14 \%$ \\
$\quad$ TOTAL & $\mathbf{3 8 5}$ & $\mathbf{1 0 0 \%}$ \\
\hline
\end{tabular}

Fuente: Elaboración propia 


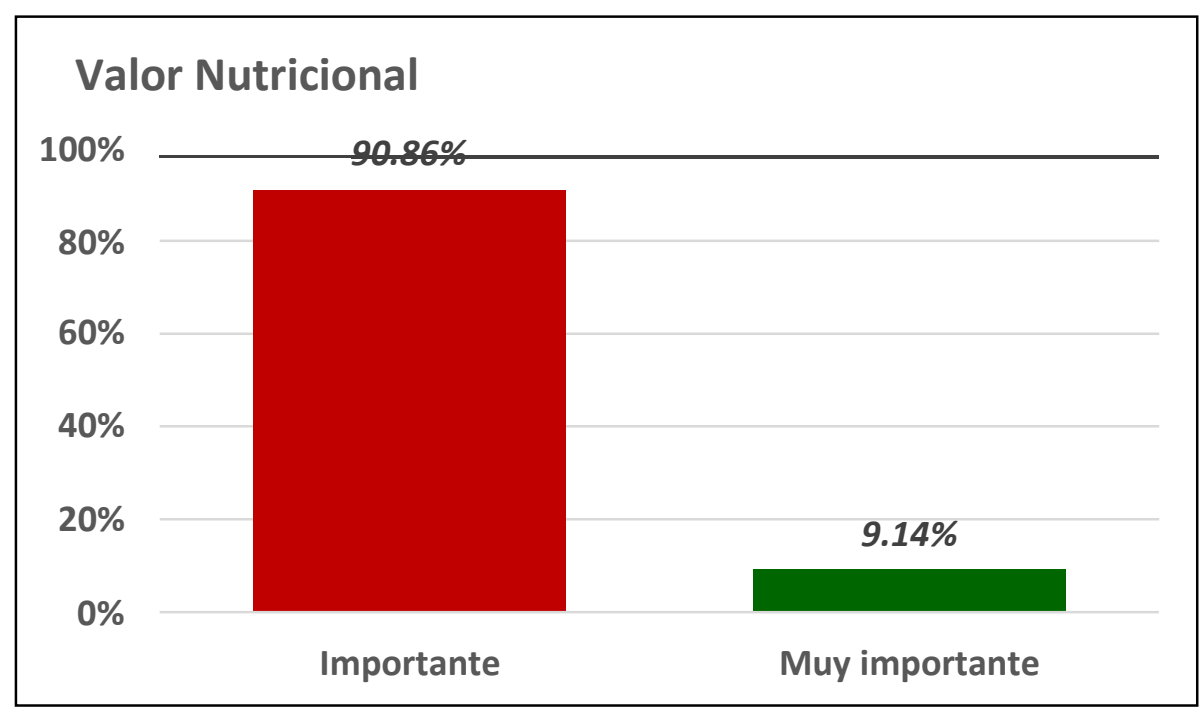

Figura 27. Resultados de pregunta E Valor Nutricional,

Fuente: Elaboración propia

El 90.86\% consideran el valor nutricional como importante y el $9.14 \%$ muy importante. Es decir, el $100 \%$ de los encuestados afirman que es muy importante conocer el valor nutricional de la bebida que consumen.

En tal sentido, será un objetivo de la estrategia de marketing el comunicar el valor nutricional de la bebida al público objetivo.

Tabla 25

Resultados de pregunta E Variedad de sabores

\begin{tabular}{lll}
\hline Variedad de Sabores & Encuestados & \\
\hline Poco Importante & 57 & $14.86 \%$ \\
Medianamente importante & 115 & $29.77 \%$ \\
Importante & 189 & $49.09 \%$ \\
Muy importante & 24 & $6.27 \%$ \\
$\quad$ TOTAL & $\mathbf{3 8 5}$ & $\mathbf{1 0 0 \%}$ \\
\hline
\end{tabular}

Fuente: Elaboración propia 


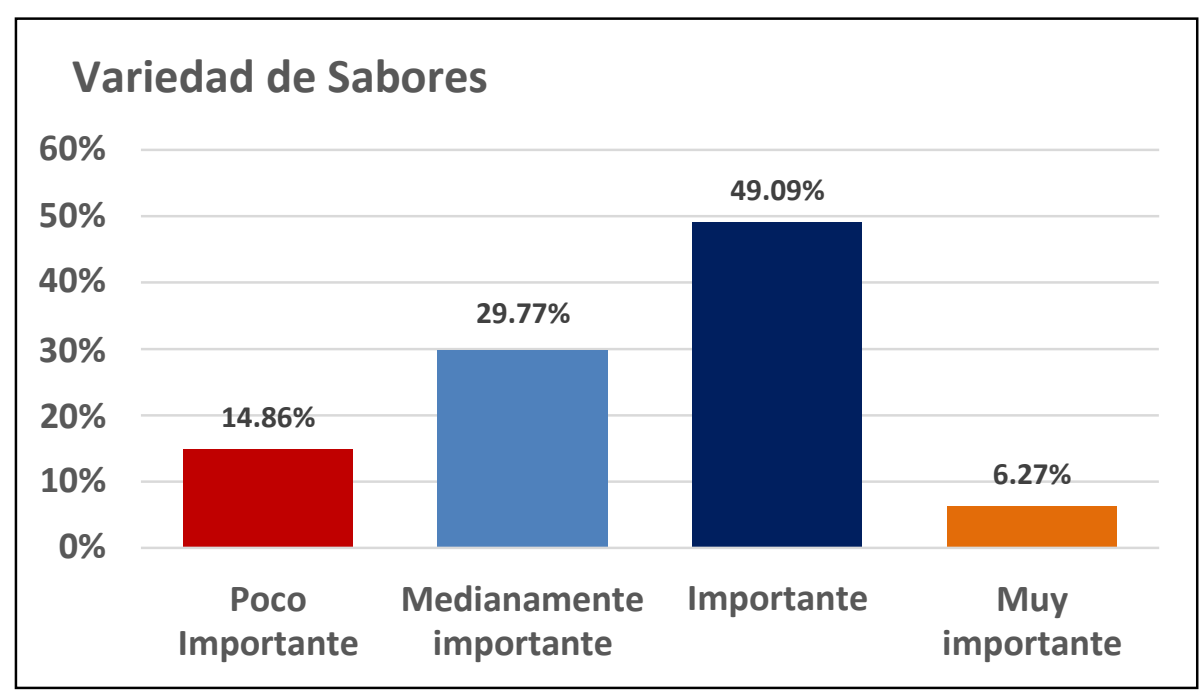

Figura 28. Resultados de pregunta E Variedad de Sabores,

Fuente: Elaboración propia

El 49.09\% de los encuestados considera el atributo de "variedad de sabores" como importante, el $29.77 \%$ medianamente importante, el $14.88 \%$ poco importante y el $6.27 \%$ muy importante. En este sentido, este es un problema para los objetivos del proyecto, debido a que solo se comercializará un tipo de bebida.

\section{Pregunta $\mathbf{F}$ ¿Con qué frecuencia consume bebidas naturales?}

Tabla 26

Resultados de pregunta $F$

\begin{tabular}{lcl}
\hline Frecuencia & Encuestados & Porcentajes \\
Diariamente & 10 & $2.61 \%$ \\
Dos veces por semana & 243 & $63.19 \%$ \\
Semanalmente & 51 & $13.32 \%$ \\
Quincenalmente & 80 & $20.89 \%$ \\
$\quad$ TOTAL & $\mathbf{3 8 5}$ & $\mathbf{1 0 0 \%}$ \\
\hline
\end{tabular}

Fuente: Elaboración propia 


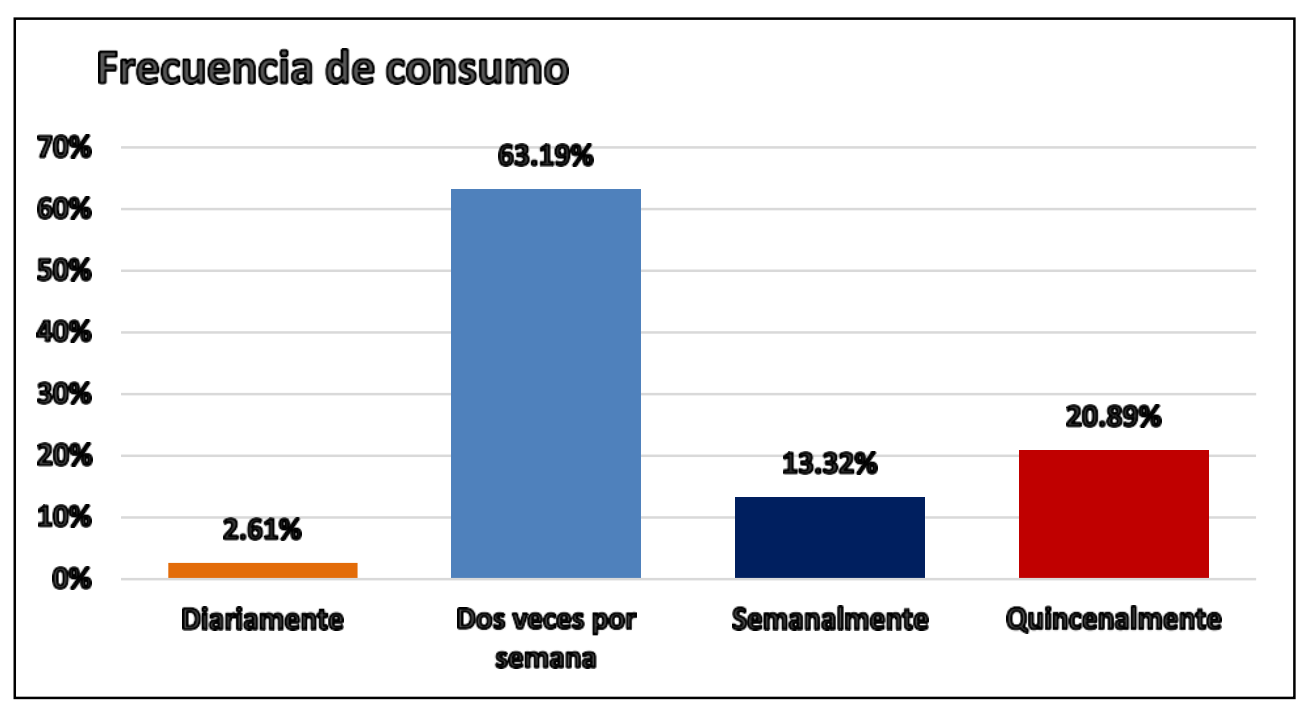

Figura 29. Resultados de pregunta F.

Fuente: Elaboración propia

El 63.19\% de participantes indican que consumen bebidas naturales dos veces por semana, el $20.89 \%$ lo hacen quincenalmente, el $13.32 \%$ semanalmente y el $2.61 \%$ diariamente. Esta respuesta es favorable para los fines del proyecto debido a que una frecuencia alta de compra mejorará los pronósticos de la demanda.

Pregunta G ¿Cuántas unidades de este tipo de bebida compra cada vez que se acerca al punto de venta para realizar la compra?

Tabla 27

Resultados de pregunta $G$

\begin{tabular}{lcc}
\hline Consumo & Encuestados & Porcentajes \\
Una Unidad & 271 & $70.50 \%$ \\
Entre 2 a 3 unidades & 114 & $29.50 \%$ \\
$\quad$ TOTAL & $\mathbf{3 8 5}$ & $\mathbf{1 0 0 \%}$ \\
\hline
\end{tabular}

Fuente: Elaboración propia 


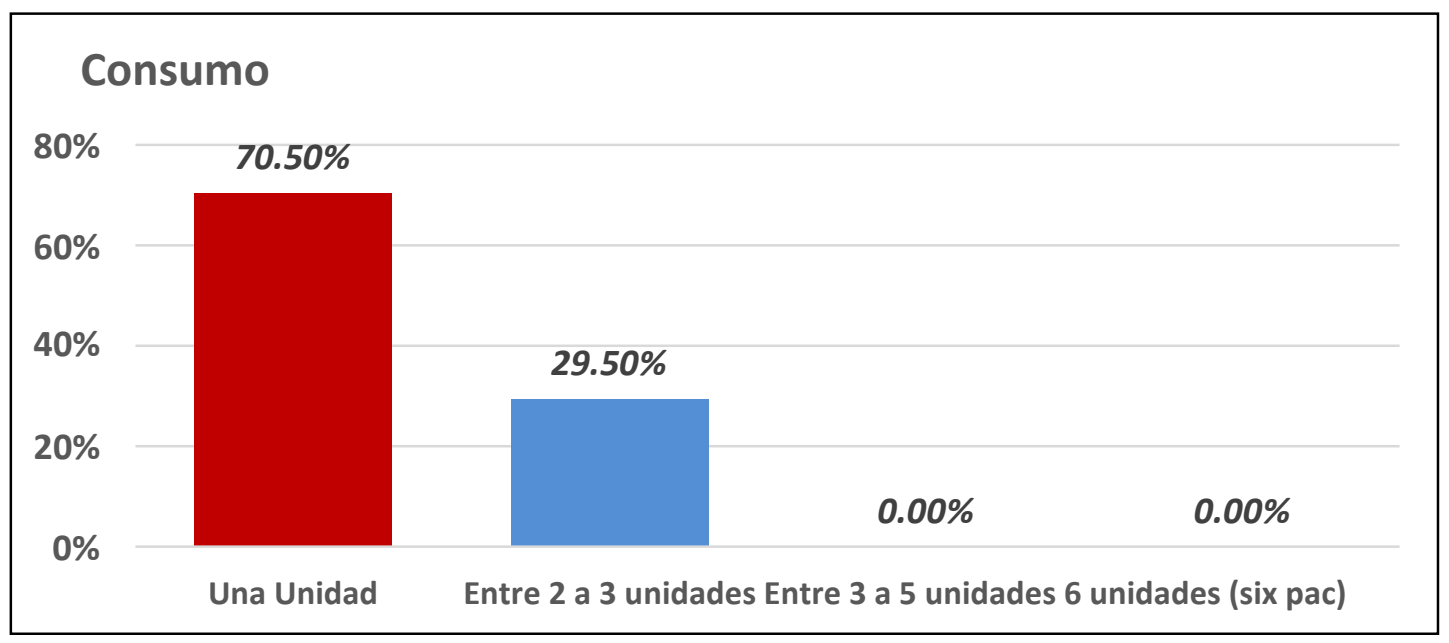

Figura 30. Resultados de pregunta $G$.

Fuente: Elaboración propia

El $70.50 \%$ consume una unidad de esta bebida natural y el $29.5 \%$ entre dos a tres

unidades. Esta respuesta nos indica que la mayoría de los encuestados solo compra una

unidad, además es importante pues muestra la forma de comercializar en el punto de venta.

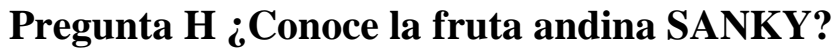

Tabla 28

Resultados de pregunta $H$

\begin{tabular}{lcc}
\hline $\begin{array}{l}\text { Conocimiento de la fruta } \\
\text { andina SANKY }\end{array}$ & \multicolumn{2}{c}{ Encuestados Porcentajes } \\
$\mathrm{Si}$ & 81 & $21.04 \%$ \\
$\mathrm{No}$ & 301 & $78.18 \%$ \\
Perdidos & 3 & $0.78 \%$ \\
TOTAL & 385 & $100.00 \%$ \\
\hline
\end{tabular}

Fuente; Elaboración propia 


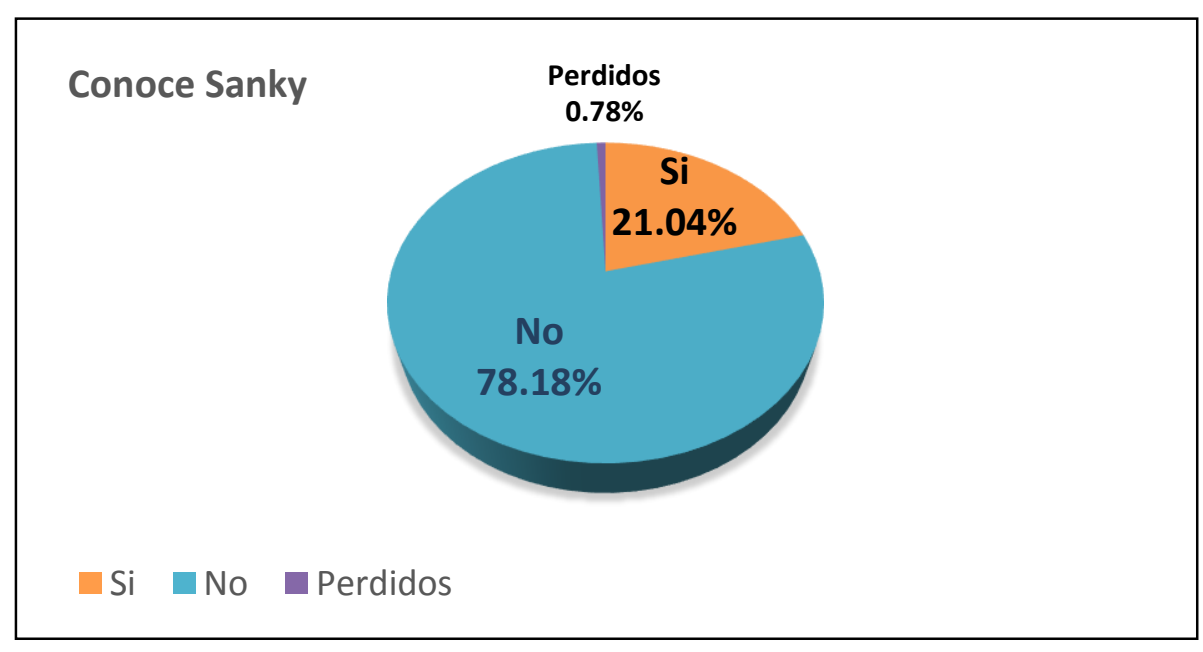

Figura 31. Resultados de pregunta $H$.

Fuente: Elaboración propia

El 78.18\% de los encuestados no conocen la fruta Sanky, el 21.04\% indica que si lo conoce. Esta respuesta es desfavorable para los efectos del problema, debido a que la gran mayoría dijo desconocer la fruta en mención. En consecuencia, dentro de los planes de marketing es necesario realizar estrategias de sampling en los principales puntos de venta para que el público deguste y conozca el sabor y propiedades del producto.

Pregunta I ¿Qué tan satisfecho está con los siguientes atributos del producto que acaba de probar? Sabor

Tabla 29

Resultados de pregunta I: Sabor

\begin{tabular}{lcc}
\hline Satisfacción Sabor & Encuestados & Porcentajes \\
\hline Muy Satisfecho & 184 & $47.78 \%$ \\
Satisfecho & 201 & $52.22 \%$ \\
$\quad$ TOTAL & $\mathbf{3 8 5}$ & $\mathbf{1 0 0 \%}$ \\
\hline
\end{tabular}

Fuente: Elaboración propia 


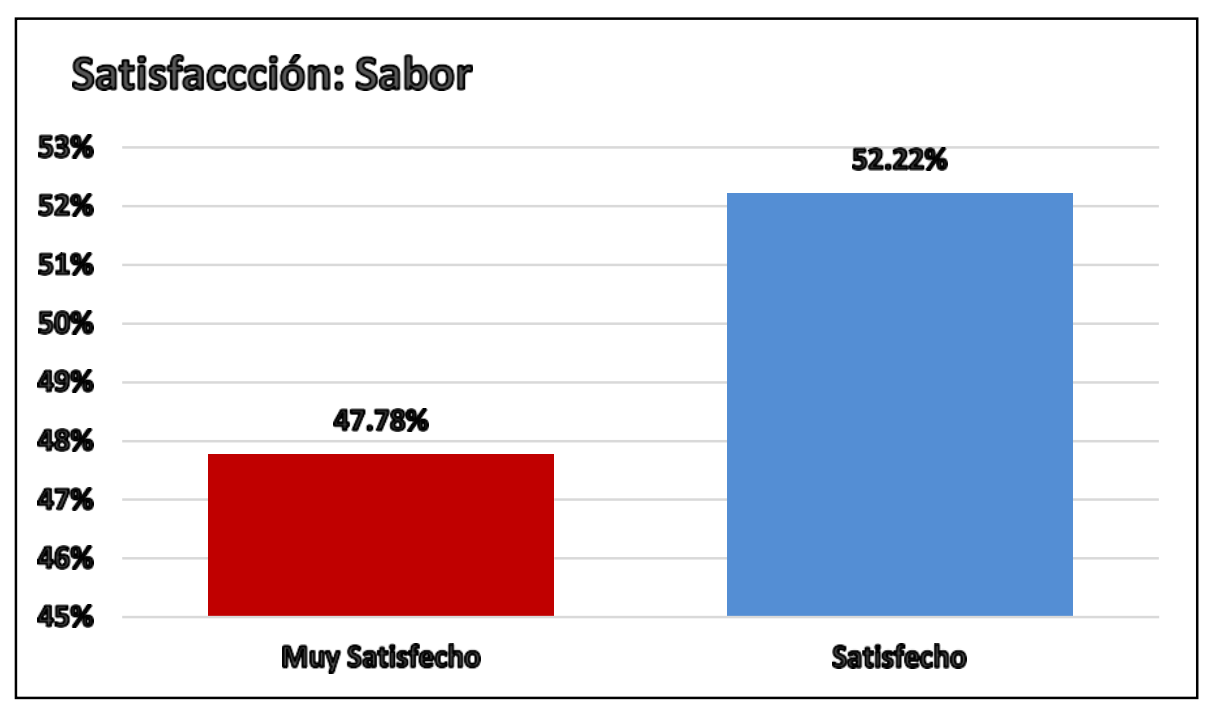

Figura 32. Resultados de pregunta I: Sabor.

Fuente: Elaboración propia

Después de la degustación el 52.22\% de los encuestados indicaron que se sentían satisfechos con el sabor, el $47.78 \%$ se sintieron muy satisfechos. Esta respuesta es muy favorable pues al 100\% de los encuestados le agradó el sabor de la bebida elaborada con Sanky.

Pregunta I ¿Qué tan satisfecho está con los siguientes atributos del producto que acaba de probar? Color

Tabla 30

Resultados de pregunta I: Color

\begin{tabular}{lcl}
\hline Satisfacción Sabor & Encuestados & Porcentajes \\
\hline Muy Satisfecho & 198 & $51.44 \%$ \\
Satisfecho & 185 & $48.04 \%$ \\
No precisa & 2 & $0.52 \%$ \\
$\quad$ TOTAL & $\mathbf{3 8 5}$ & $\mathbf{1 0 0 . 0 0 \%}$ \\
\hline
\end{tabular}

Fuente: Elaboración propia 


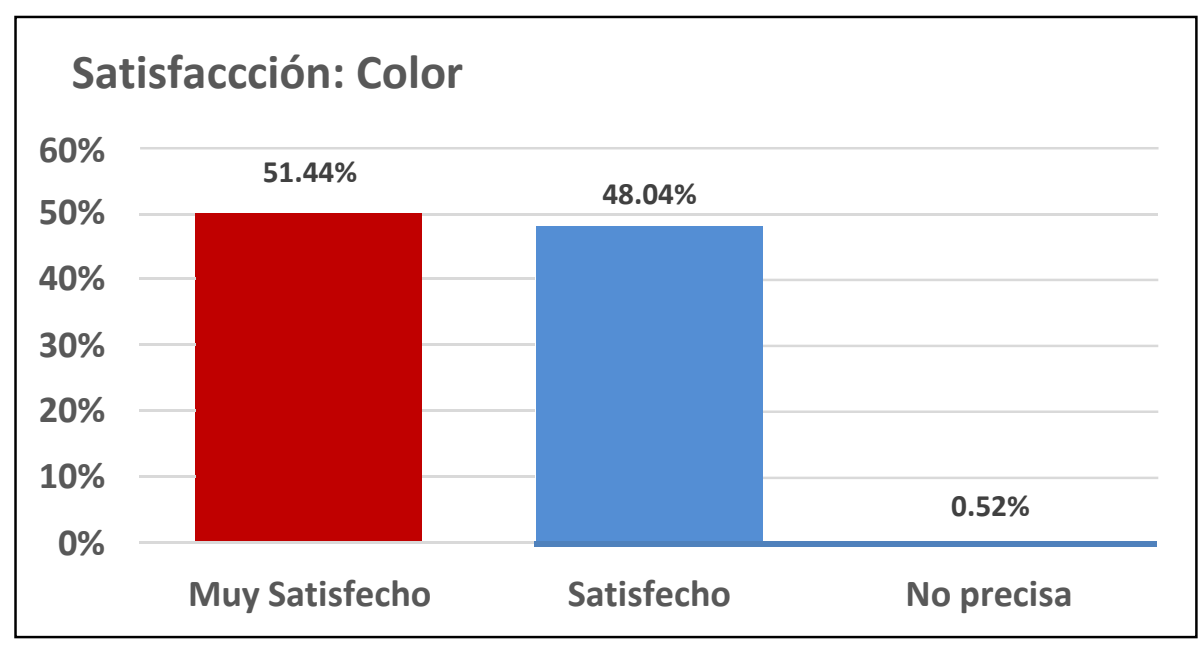

Figura 33. Resultados de pregunta I: Color.

Fuente: Elaboración propia

El 51.44\% de los participantes indicaron que se sintieron muy satisfechos con el color de la bebida natural, el $48.04 \%$ satisfecho y el $0.52 \%$ no precisa. Así mismo, casi el $100 \%$ de los encuestados quedaron conformes con el color de la bebida.

Pregunta I ¿Qué tan satisfecho está con los siguientes atributos del producto que acaba de probar? Textura

Tabla 31

Resultados de pregunta I: Textura

\begin{tabular}{lcc}
\hline Satisfacción Textura & Encuestados & Porcentajes \\
\hline Muy Satisfecho & 263 & $68.41 \%$ \\
Satisfecho & 60 & $15.67 \%$ \\
No precisa & 61 & $15.93 \%$ \\
$\quad$ TOTAL & $\mathbf{3 8 5}$ & $\mathbf{1 0 0 \%}$ \\
\hline
\end{tabular}

Fuente: Elaboración propia 


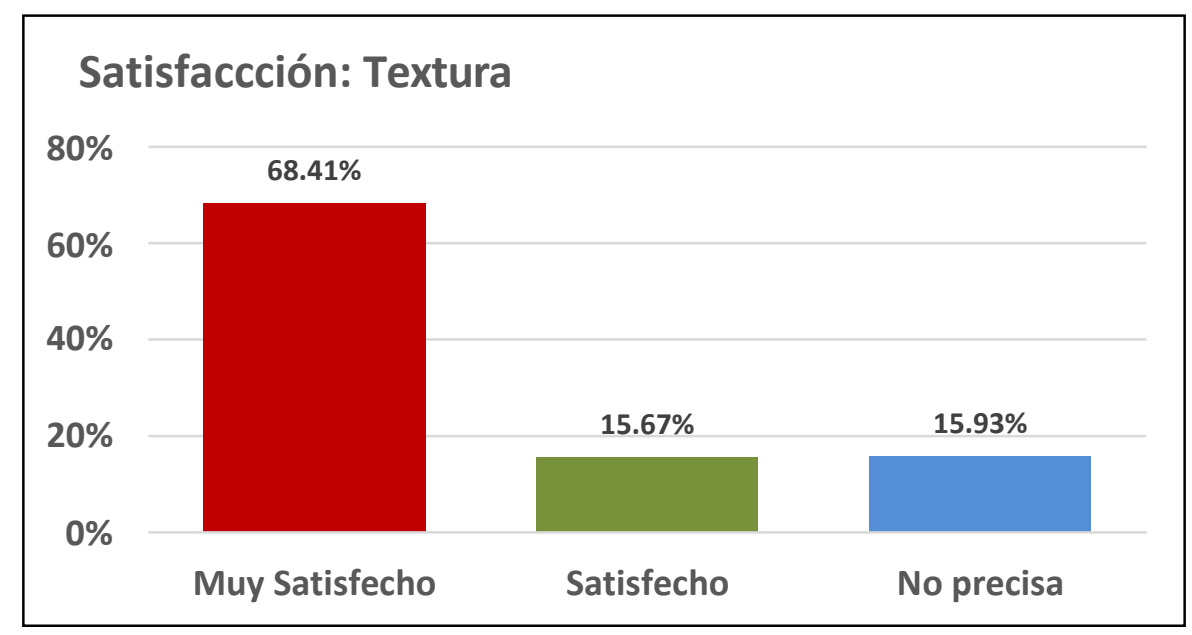

Figura 34. Resultados de pregunta I: Textura.

Fuente: Elaboración propia

Acerca de la textura de la bebida natural, el $68.41 \%$ se sintió muy satisfecho, el $15.67 \%$ satisfecho y el $15.93 \%$ no precisa. Es decir, casi el $85 \%$ de los encuestados consideraron que la textura de la bebida degustada era de su agrado.

Pregunta I ¿Qué tan satisfecho está con los siguientes atributos del producto que acaba de probar? Sabor Residual

Tabla 32

Resultados de pregunta I: Sabor Residual

\begin{tabular}{lcc}
\hline Satisfacción Sabor Residual & Encuestados & Porcentajes \\
\hline Muy Satisfecho & 247 & $64.23 \%$ \\
Satisfecho & 133 & $34.46 \%$ \\
No precisa & 5 & $1.31 \%$ \\
TOTAL & $\mathbf{3 8 5}$ & $\mathbf{1 0 0 \%}$ \\
\hline
\end{tabular}

Fuente: Elaboración propia 


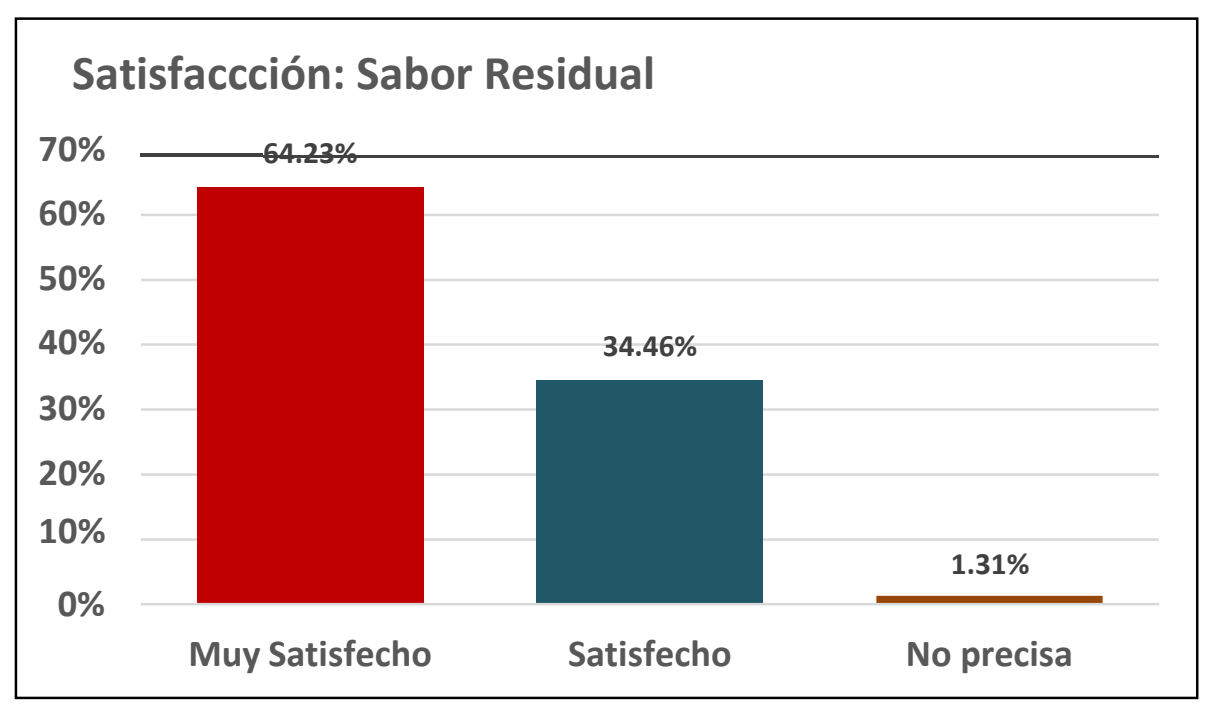

Figura 35. Resultados de pregunta I: Sabor Residual.

Fuente: Elaboración propia

Acerca del atributo "sabor residual" en la bebida natural, el 64.23\% se sintieron muy satisfechos, el $34.46 \%$ satisfecho y el $1.31 \%$ No precisa. Casi el $100 \%$ de los encuestados indicaron que el sabor residual después del consumo estaba agradable.

Pregunta I ¿Qué tan satisfecho está con los siguientes atributos del producto que acaba de probar? Aroma

Tabla 33

Resultados de pregunta I: Satisfacción de Aroma

\begin{tabular}{lcc}
\hline Satisfacción Aroma & Encuestados & Porcentajes \\
\hline Muy Satisfecho & 266 & $69.19 \%$ \\
Satisfecho & 115 & $29.77 \%$ \\
No precisa & 4 & $1.04 \%$ \\
TOTAL & $\mathbf{3 8 5}$ & $\mathbf{1 0 0 \%}$ \\
\hline
\end{tabular}

Fuente: Elaboración propia 


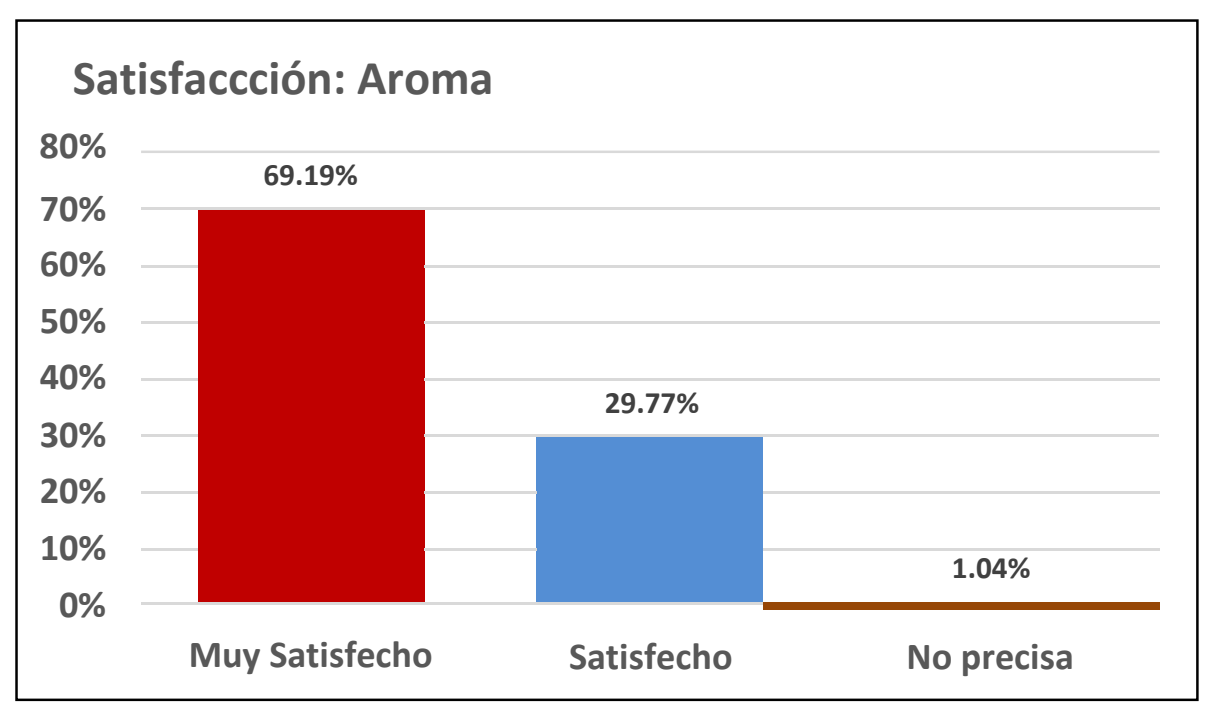

Figura 36. Resultados de pregunta I: Aroma.

Fuente: Elaboración propia

El aroma, es otro atributo importante en la bebida natural, el 69.19\% de los encuestados se sintieron muy satisfechos, el $29.77 \%$ satisfechos y el $1.04 \%$ no precisa. Es decir, casi el $100 \%$ de los encuestados manifestaron estar satisfechos con el aroma de la bebida.

\section{Pregunta $\mathbf{J}$ ¿Estarías dispuesto a consumir esta nueva bebida natural?}

Tabla 34

Resultados de pregunta J: Disposición de Consumo

\begin{tabular}{lcc}
\hline Disposición Consumo & Encuestados & Porcentajes \\
\hline En desacuerdo & 28 & $7.31 \%$ \\
No precisa & 63 & $16.45 \%$ \\
De acuerdo & 30 & $7.83 \%$ \\
Totalmente de acuerdo & 263 & $68.41 \%$ \\
$\quad$ TOTAL & $\mathbf{3 8 5}$ & $\mathbf{1 0 0 \%}$ \\
\hline
\end{tabular}

Fuente: Elaboración propia 


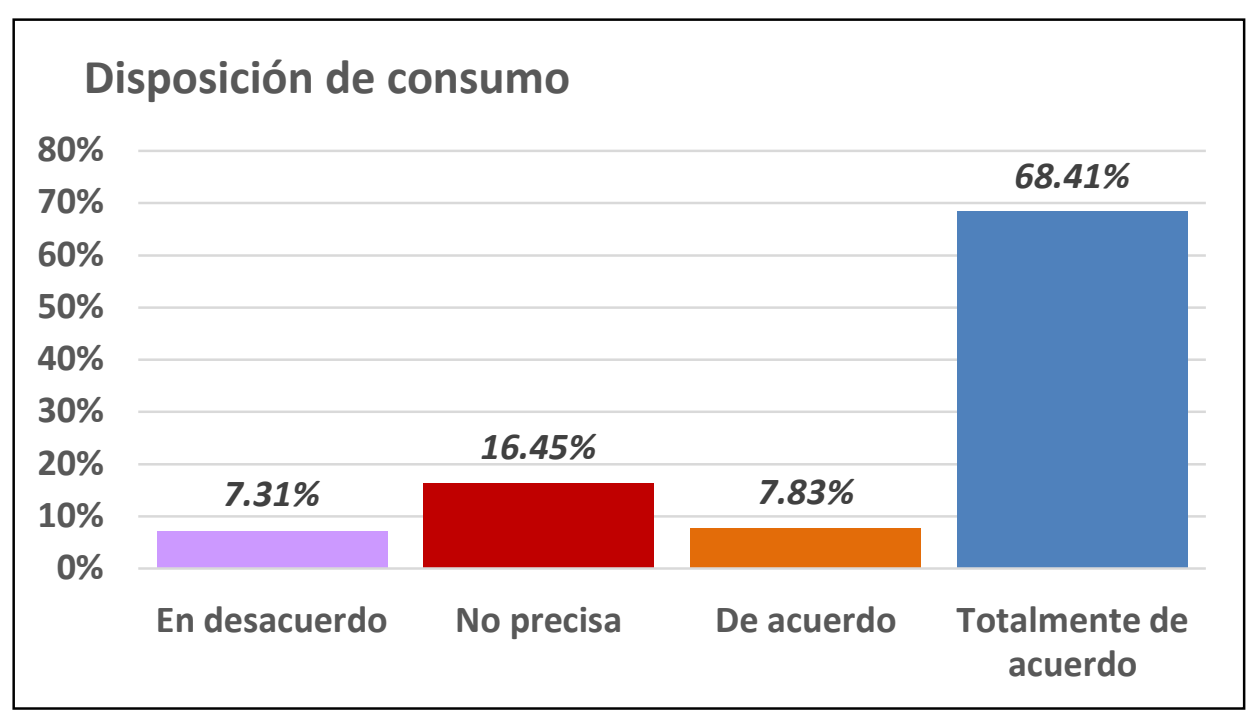

Figura 37. Resultados de pregunta J: Disposición de consumo del producto.

Fuente: Elaboración propia

El $68.41 \%$ de los encuestados indicaron que estarían totalmente de acuerdo en consumir la bebida natural elaborada a base de Sanky, el $16.45 \%$ no precisa, el $7.83 \%$ está de acuerdo y el 7.31\% no lo consumiría. Esta pregunta es muy favorable para el proyecto pues nos indica que en promedio casi el $70 \%$ de los encuestados estaría dispuesto a dejar la bebida que consume por esta nueva bebida.

\section{Pregunta K ¿Qué tipo de envase prefiere para el producto?}

Tabla 35

Resultados de pregunta $K$

\begin{tabular}{lcc}
\hline \multicolumn{1}{c}{ Tipo de envase } & Encuestados & Porcentajes \\
\hline Lata & 5 & $1.31 \%$ \\
Plástico & 214 & $55.61 \%$ \\
Tetrapack & 14 & $3.66 \%$ \\
Vidrio & 119 & $30.81 \%$ \\
Le es indiferente & 33 & $8.62 \%$ \\
\multicolumn{1}{c}{ TOTAL } & $\mathbf{3 8 5}$ & $\mathbf{1 0 0 \%}$ \\
\hline
\end{tabular}

Fuente: Elaboración propia 


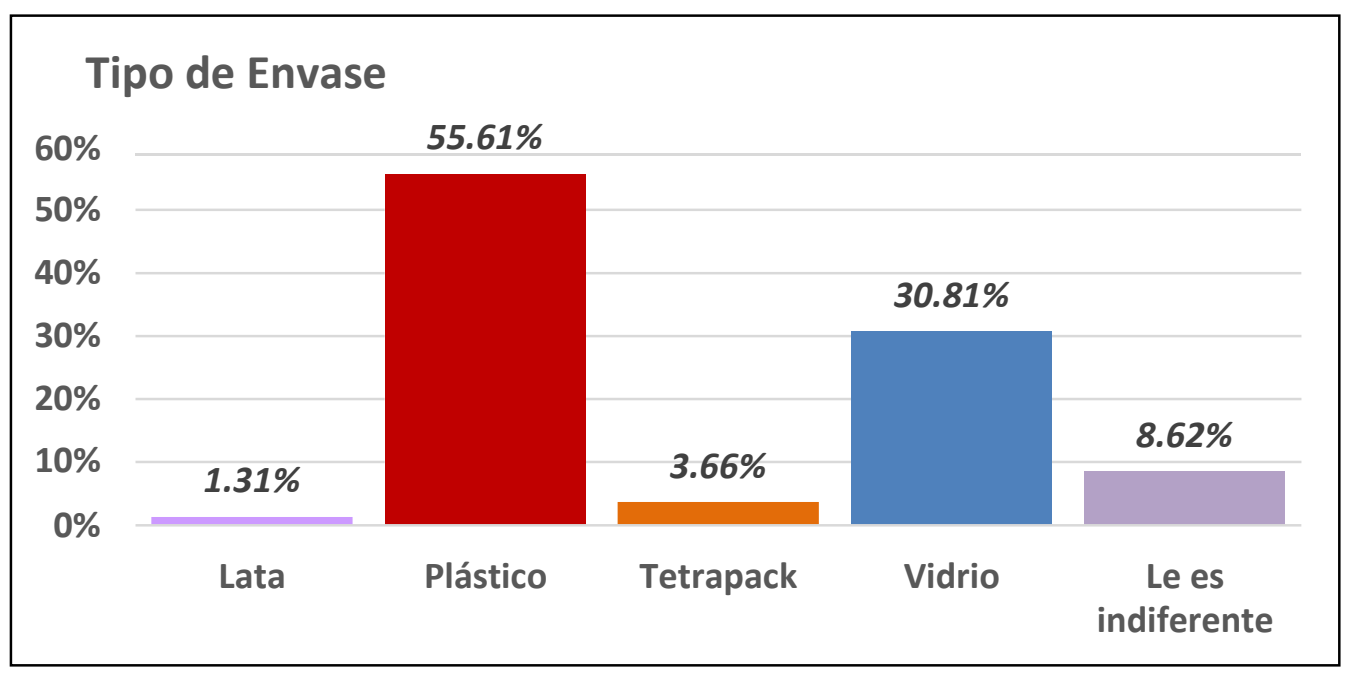

Figura 38. Resultados de pregunta K: Tipo de envase.

Fuente: Elaboración propia

El $55.61 \%$ de encuestados indicaron que prefieren que el envase de la bebida natural sea de plástico, el $30.81 \%$ lo prefiere en vidrio, el $8.62 \%$ le es indiferente, el 3.66\% en Tetrapak y el $1.31 \%$ en lata. Se tomará la decisión apoyándonos también en otras tendencias como los materiales biodegradables y la higiene.

\section{Pregunta $L$ ¿En qué tamaño le gustaría que se venda el producto?}

Tabla 36

Resultados de pregunta L

\begin{tabular}{lcc}
\hline Tamaño & Encuestados & Porcentajes \\
\hline Envase de $250 \mathrm{ml}$ & 162 & $42.04 \%$ \\
Envase de $300 \mathrm{ml}$ & 44 & $11.49 \%$ \\
Envase de $450 \mathrm{ml}$ & 109 & $28.20 \%$ \\
Envase de $600 \mathrm{ml}$ & 70 & $18.28 \%$ \\
TOTAL & $\mathbf{3 8 5}$ & $\mathbf{1 0 0 \%}$ \\
\hline
\end{tabular}

Fuente: Elaboración propia 


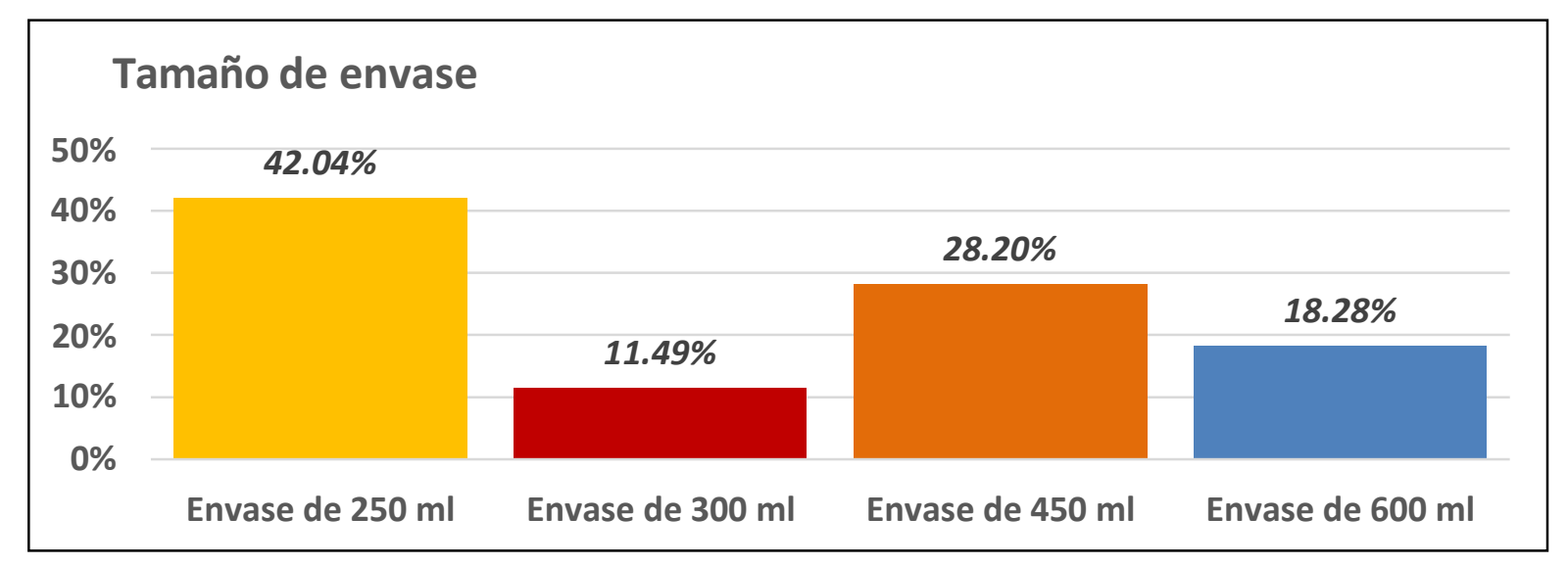

Figura 39. Resultados de pregunta L.

Fuente: Elaboración propia

El $42.04 \%$ de los encuestados prefieren que la bebida natural se venda en un envase de $250 \mathrm{ml}$, el $28.20 \%$ en envase de $450 \mathrm{ml}$, el $18.28 \%$ en envase de $600 \mathrm{ml}$, el $11.49 \%$ en envase de $300 \mathrm{ml}$. Es decir, la mayoría de los encuestados prefieren el envase de $250 \mathrm{ml}$. Cabe mencionar que en el desarrollo de la encuesta se le mostró a los encuestados, el tamaño del envase en forma real.

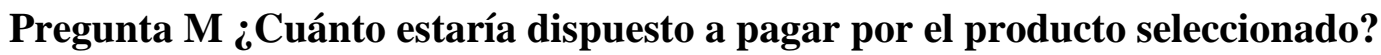

Tabla 37

Resultados de pregunta $M$

\begin{tabular}{lcc}
\hline Precio & Encuestados & Porcentajes \\
\hline S/2.00 - S/2.50 & 83 & $21.56 \%$ \\
S/3.00 - S/3.50 & 87 & $22.60 \%$ \\
S $/ 4.00-$ S $/ 4.50$ & 50 & $12.99 \%$ \\
S $/ 5.00-$ S $/ 5.50$ & 107 & $27.79 \%$ \\
S/6.00-S/6.50 & 58 & $15.06 \%$ \\
TOTAL & $\mathbf{3 8 5}$ & $\mathbf{1 0 0 \%}$ \\
\hline
\end{tabular}

Fuente: Elaboración propia 


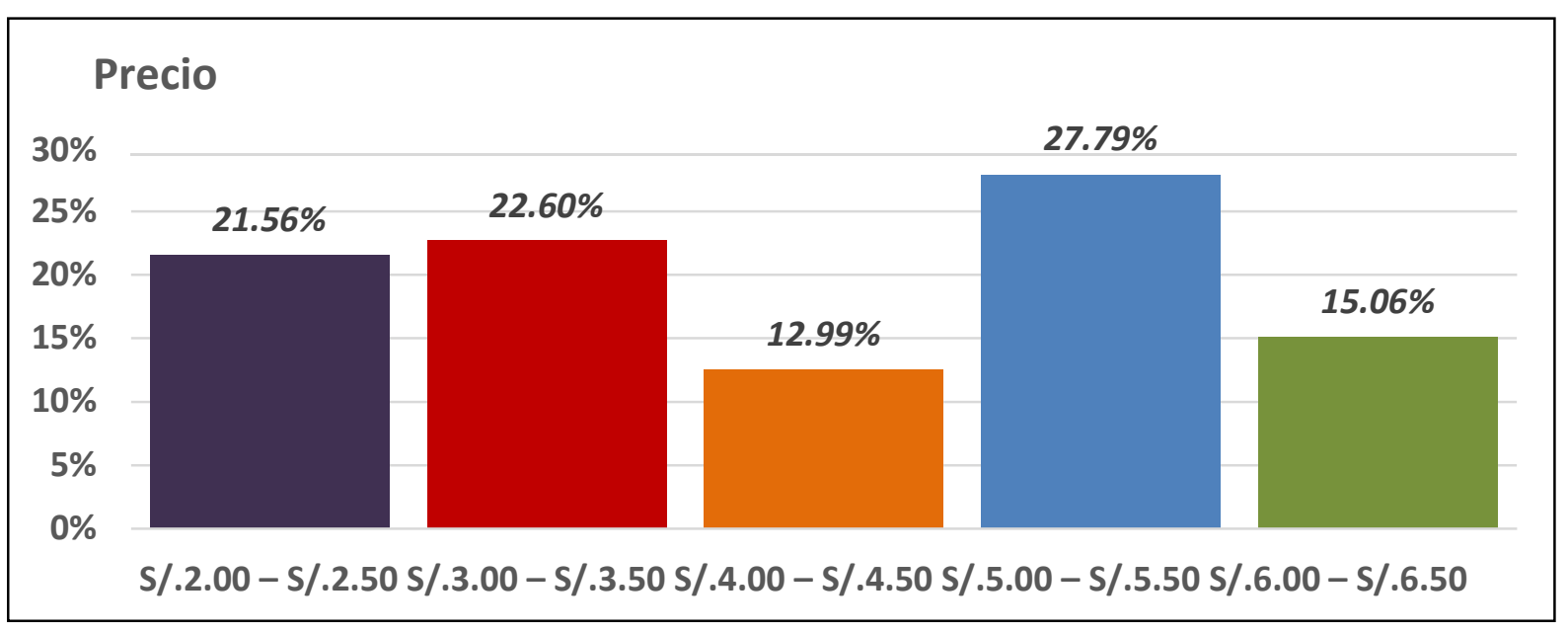

Figura 40. Resultados de pregunta $M$.

Fuente: Elaboración propia

El 21,56\% de los encuestados estaría dispuesto a pagar como máximo S/ 2.50; sin embargo, el 78.44\% tiene intención de pagar como mínimo S/ 3.00 por el producto natural hecho a base de Sanky. Se considerará además el precio del mercado para bebidas de tipo natural, para establecer el precio.

Pregunta $\mathbf{N}$ ¿Dónde le gustaría encontrar esta nueva bebida natural?

Tabla 38

Resultados de pregunta $N$

\begin{tabular}{lcc}
\hline Plaza & Encuestados & Porcentajes \\
Bodegas & 5 & $1.37 \%$ \\
Gimnasios & 73 & $19.06 \%$ \\
Grifos & 85 & $22.19 \%$ \\
Mercados & 75 & $19.58 \%$ \\
Saludables & & $37.80 \%$ \\
Supermercados & 146 & $\mathbf{1 0 0 \%}$ \\
\hline
\end{tabular}

Fuente: Elaboración propia 


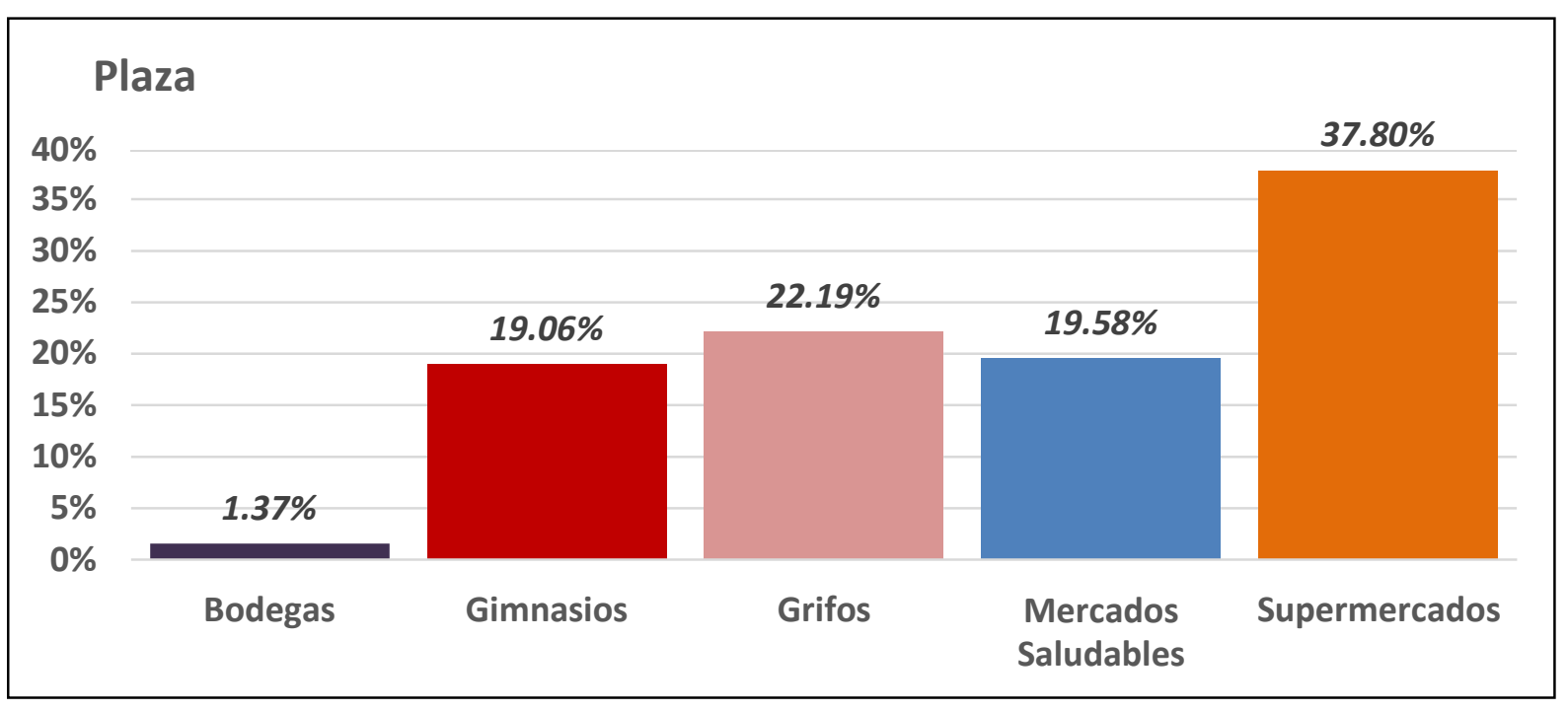

Figura 41. Resultados de pregunta $N$.

Fuente: Elaboración propia

El $37.80 \%$ de los encuestados desean encontrar esta nueva bebida en Supermercados, el $22.19 \%$ en grifos, el $19.58 \%$ en mercados saludables, el $19.06 \%$ en gimnasios y el $1.4 \%$ en bodegas.

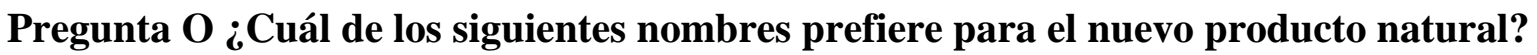

Tabla 39

Resultados de pregunta $O$

\begin{tabular}{lcc}
\hline $\begin{array}{l}\text { Nombre del } \\
\text { producto }\end{array}$ & Encuestados & Porcentajes \\
\hline Sankyfruit & 366 & $95.04 \%$ \\
Sanky Natural & 3 & $0.78 \%$ \\
otro & 16 & $4.18 \%$ \\
$\quad$ TOTAL & $\mathbf{3 8 5}$ & $\mathbf{1 0 0 . 0 0 \%}$ \\
\hline
\end{tabular}

Fuente: Elaboración propia 


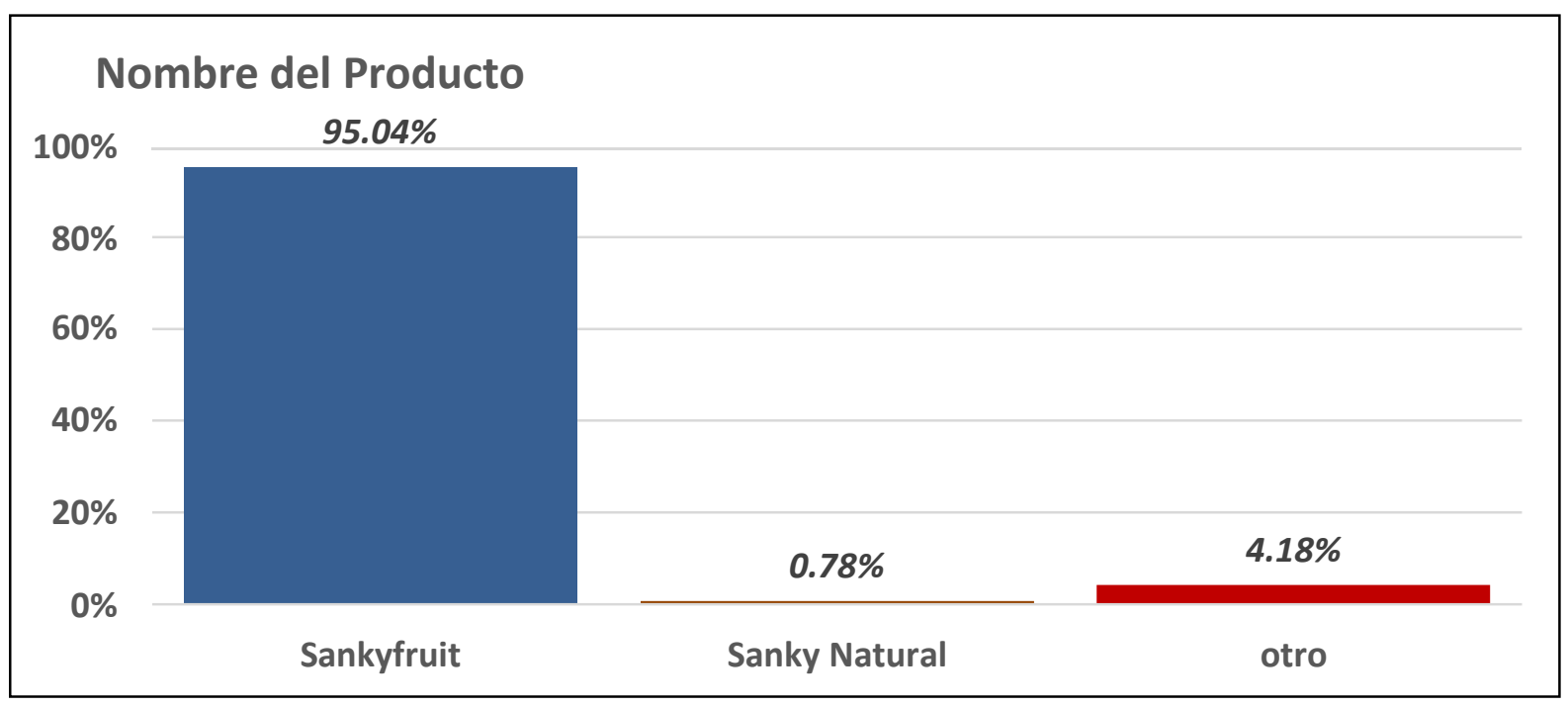

Figura 42. Resultados de pregunta $O$.

Fuente: Elaboración propia

La mayoría de los encuestados, representados por el 95.04\% prefiere que la bebida natural lleve por nombre Sankyfruit.

Pregunta $\mathbf{P}$ ¿Por cuál de los medios desearía conocer sobre esta nueva bebida natural?

Tabla 40

Resultados de pregunta $P$

\begin{tabular}{lcc}
\hline Difusión & Encuestados & Porcentajes \\
\hline Redes Sociales & 335 & $86.91 \%$ \\
Paneles Publicitarios & 50 & $13.09 \%$ \\
$\quad$ TOTAL & $\mathbf{3 8 5}$ & $\mathbf{1 0 0 . 0 0 \%}$ \\
\hline
\end{tabular}

Fuente: Elaboración propia 


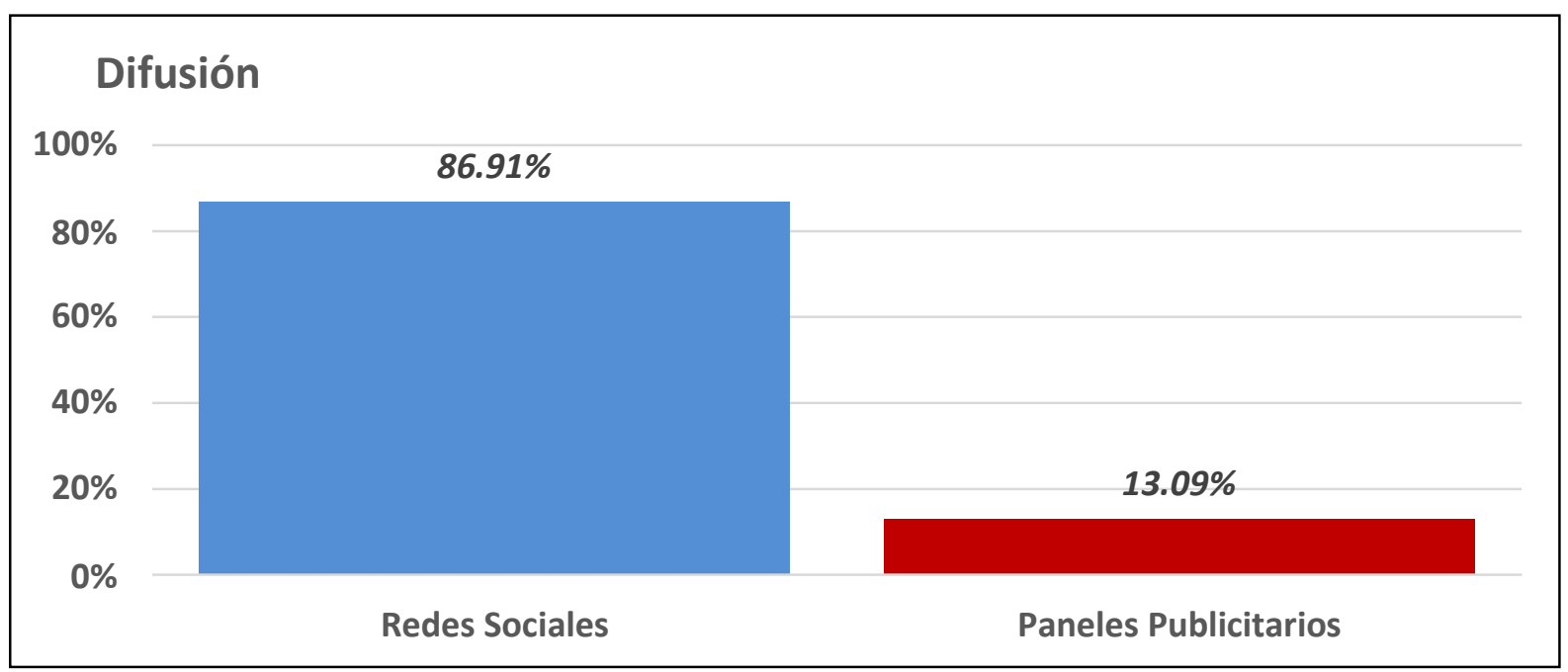

Figura 43. Resultados de pregunta $P$.

Fuente: Elaboración propia

El $86.91 \%$ de los encuestados prefiere conocer el producto por medio de las redes sociales y el $13.09 \%$ por paneles publicitarios. En consecuencia, dentro de las estrategias de marketing se debe poner énfasis en el marketing digital.

\subsubsection{Resultados y conclusiones}

Luego de analizar los resultados de la encuesta se puede decir:

\section{Objetivo: Establecer los factores de importancia que el consumidor espera de una}

bebida natural envasada. Los factores que el cliente considera importante se corroboraron al responder la pregunta sobre las características del producto en cuanto a Textura con el $86 \%$ de encuestados que lo consideran importante; en cuanto al color de la bebida, el $90 \%$ de encuestados afirma que es muy importante.

Más del 93\% de los encuestados consideran que el contenido calórico de las bebidas naturales envasadas es importante; casi el 99\% de los encuestados consideran que la marca del producto es muy importante, lo cual fuerza elaborar una propuesta de estrategia para el posicionamiento de la nueva marca. 
El 100\% de los encuestados manifiestan que la presentación es importante y por lo tanto deberá de tenerse en cuenta para la comercialización del producto.

Más del 90\% de los encuestados afirman que las propiedades naturales de la fruta son muy importantes; el $90.86 \%$ de los encuestados consideran el valor nutricional como importante.

El 100\% de los encuestados afirman que es muy importante conocer el valor nutricional de la bebida que consumen.

Objetivo: Determinar el tamaño de envase más idóneo para la comercialización del producto. El $42.04 \%$ de los encuestados prefieren que la bebida natural se venda en un envase de $250 \mathrm{ml}$, el $28.20 \%$ en envase de $450 \mathrm{ml}$, el $18.28 \%$ en envase de $600 \mathrm{ml}$, el $11.49 \%$ en envase de $300 \mathrm{ml}$. Es decir, la mayoría de los encuestados prefieren el envase de $250 \mathrm{ml}$.

Objetivo: Determinar los principales puntos de comercialización.

El $37.60 \%$ de los encuestados desean encontrar esta nueva bebida en Supermercados, y el $19.58 \%$ en mercados saludables, totalizando el $57.18 \%$. Se entiende que se debe hacer un esfuerzo adicional para influir en el lugar de compras del público objetivo.

Objetivo: Determinar la frecuencia de compra de compra de bebidas naturales envasadas, así como la cantidad de unidades por compra.

Es favorable para los fines del proyecto debido a que el $63.19 \%$ de participantes indican que consumen bebidas naturales dos veces por semana y el $20.89 \%$, quincenalmente.

Objetivo: Determinar la disponibilidad a pagar del público objetivo por dicho producto. (precio)

El $88.51 \%$ de los encuestados consideran que el atributo precio es importante y un $78.29 \%$ de encuestados tienen la intención de pagar como mínimo S/ 3.00 por el producto natural hecho a base de Sanky que fue degustado. 


\section{Conclusiones:}

1. La gran mayoría de los encuestados consumen bebidas naturales envasadas. Esto favorece a los objetivos del estudio debido a que es un producto de consumo masivo.

2. Las marcas preferidas en el mercado de bebidas naturales son: Aloe vera, Jugos Selva, Free Tea.

3. Queda demostrado que todos los atributos consultados son importantes para los encuestados. Sin embargo, los de mayor importancia son: Valor nutricional y el precio. Esto demostraría que existiría una alta elasticidad precio-demanda.

4. En el presente estudio se demuestra que la mayoría de los encuestados consume solamente una unidad de bebida natural envasada.

5. La mayoría de encuestados no conoce la fruta Sanky. Esto representa un aspecto negativo para el desarrollo del proyecto. Para ello se deberá de comunicar al público objetivo las propiedades de la fruta en mención. Asimismo, se deberá realizar una estrategia de sampling en el punto de venta con el objetivo de que aprecien los atributos analizados anteriormente.

6. Con respecto a la prueba del producto, la gran mayoría de los encuestados manifestaron su conformidad con las propiedades de la bebida en cuanto al sabor, color, textura, aroma, etc. Por tal motivo, es recomendable realizar estrategias pull con el objetivo de motivar la compra.

7. El posicionamiento de la marca es muy importante en la decisión de compra por parte del consumidor. Por esta razón, es necesario que la empresa desarrolle una estrategia de posicionamiento y recordación de marca con el objetivo de generar confianza en la bebida natural. 
8. La mayoría de los encuestados está dispuesto a consumir la nueva bebida natural envasada, siendo un aspecto positivo para el proyecto, pues amplifica el mercado efectivo.

9. La mayoría de los encuestados prefiere los envases de plástico con una capacidad de 250 $\mathrm{ml}$.

10. En cuanto al precio, la gran mayoría de los participantes tienen una disposición de pago entre $\mathrm{S} / 3.00$ a $\mathrm{S} / 5.50$.

11. La gran mayoría de los encuestados prefieren que esta bebida natural envasada se comercialice en los supermercados y en menor proporción en los mercados saludables/ecológicos.

12. Con respecto al posible nombre del producto, la mayoría de los encuestados sugiere como nombre "Sankyfruit", por tanto, se modificó el nombre original considerando esta recomendación.

13. Finalmente, la gran mayoría prefiere que la comunicación entre la empresa y el público objetivo se realice a través de las redes sociales.

La encuesta nos permitió conocer que, para nuestro público objetivo, el producto Kawsay bebida natural, es favorable, lo que permite realizar el proyecto con una buena probabilidad de acogida. Sin embargo, se deben considerar estrategias adicionales en algunos aspectos como la plaza y el posicionamiento de la marca. En términos generales con los resultados obtenidos procederemos a cuantificar la demanda tomando en cuenta todos los filtros que sean convenientes y necesarios. 


\section{Capítulo IV}

\section{PROYECCIÓN DEL MERCADO OBJETIVO}

\subsection{El ámbito de la proyección.}

La demarcación geográfica considerada corresponde a los distritos La Molina, Miraflores, San Borja, San Isidro y Santiago de Surco. La población registrada disponible en los distritos de interés para los años “2000-2015” se presentan en la siguiente tabla.

Tabla 41

Población para la zona 7 de Lima Metropolitana 2000-2015

(en número de personas)

\begin{tabular}{cccccc}
\hline \multirow{2}{*}{ ANOS } & $\begin{array}{c}\text { LA } \\
\text { MOLINA }\end{array}$ & MIRAFLORES & $\begin{array}{c}\text { SAN } \\
\text { BORJA }\end{array}$ & $\begin{array}{c}\text { SAN } \\
\text { ISIDRO }\end{array}$ & $\begin{array}{c}\text { SANTIAGO } \\
\text { DE SURCO }\end{array}$ \\
\hline 2000 & 108,227 & 92,093 & 109,543 & 64,741 & 256,761 \\
2001 & 112,179 & 91,848 & 109,886 & 64,309 & 263,165 \\
2002 & 116,170 & 91,522 & 110,179 & 63,822 & 269,488 \\
2003 & 120,194 & 91,114 & 110,418 & 63,280 & 275,711 \\
2004 & 124,243 & 90,623 & 110,602 & 62,685 & 281,817 \\
2005 & 128,306 & 90,049 & 110,728 & 62,037 & 287,788 \\
2006 & 132,343 & 89,371 & 110,848 & 61,321 & 293,534 \\
2007 & 136,350 & 88,596 & 110,968 & 60,544 & 299,054 \\
2008 & 140,381 & 87,767 & 111,088 & 59,735 & 304,466 \\
2009 & 144,491 & 86,920 & 111,208 & 58,920 & 309,889 \\
2010 & 148,738 & 86,091 & 111,328 & 58,123 & 315,447 \\
2011 & 153,133 & 85,284 & 111,448 & 57,345 & 321,157 \\
2012 & 157,638 & 84,473 & 111,568 & 56,570 & 326,928 \\
2013 & 162,237 & 83,649 & 111,688 & 55,792 & 332,725 \\
2014 & 166,912 & 82,805 & 111,808 & 55,006 & 338,509 \\
2015 & 171,646 & 81,932 & 111,928 & 54,206 & 344,242 \\
\hline
\end{tabular}

Fuente: INEI. Elaboración propia 


\subsection{Método de Proyección}

Para proyectar la población de la zona 7 de Lima Metropolitana para el periodo 2016-2021 se utilizó el método de regresión lineal considerando como punto de partida el histórico de población desde el año 2000, hasta el año 2015 (disponible en INEI) para cada distrito.

La población proyectada para los años 2016-2021 resultó:

Tabla 42

Población proyectada para la zona 7 de Lima Metropolitana 2016-2021

\begin{tabular}{lccccc}
\hline & LA & MIRAFLORES & $\begin{array}{c}\text { SAN } \\
\text { BORJA }\end{array}$ & $\begin{array}{c}\text { SAN } \\
\text { ISIDRO }\end{array}$ & SURCO \\
\hline $\mathbf{2 0 1 6}$ & 174,592 & 81,737 & 112,175 & 53,744 & 350,248 \\
$\mathbf{2 0 1 7}$ & 178,785 & 81,029 & 112,319 & 53,020 & 356,007 \\
$\mathbf{2 0 1 8}$ & 182,978 & 80,321 & 112,463 & 52,295 & 361,766 \\
$\mathbf{2 0 1 9}$ & 187,172 & 79,612 & 112,607 & 51,571 & 367,526 \\
$\mathbf{2 0 2 0}$ & 191,365 & 78,904 & 112,751 & 50,846 & 373,285 \\
$\mathbf{2 0 2 1}$ & 195,558 & 78,196 & 112,895 & 50,122 & 379,045 \\
\hline
\end{tabular}

Fuente: Elaboración Propia

El procedimiento realizado está disponible en el Anexo 5

\subsubsection{Mercado Potencial}

El mercado potencial está formado por el conjunto de consumidores que podría necesitar el producto, y que cumple con los criterios de segmentación definidos.

a. Geográfica: Población de la Zona 7 de Lima Metropolitana

b. Nivel Socioeconómico (NSE): segmentos A y B

c. Demográfica: Pobladores entre los 18 y 50 años.

De APEIM (Asociación Peruana de Empresas de Investigación de Mercado) se tiene la Distribución del NSE por zonas siendo el objetivo: NSE A y B de la ZONA 7 (Miraflores, 
San Isidro, San Borja, Surco, La Molina). Se observa que en los distritos mencionados más del 80\% del nivel socioeconómico está distribuido en los niveles A y B. (Filtro APEIM)

Tabla 43

Niveles Socioeconómicos en Zona 7 de Lima Metropolitana (\%)

\begin{tabular}{|c|c|c|c|c|c|c|}
\hline \multicolumn{7}{|c|}{ Distribución de Niveles por Zonas APEIM 2017 - Metropolitana } \\
\hline $\begin{array}{l}\text { Personas - \% Horizontales } \\
\text { Zona }\end{array}$ & TOTAL & NSE A & NSE B & NSE C & NSE D & NSE E \\
\hline 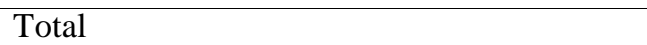 & 100 & 4.4 & 24.5 & 42.2 & 23.0 & 5.9 \\
\hline Zona 1 (Puente Piedra, Comas, Carabayllo) & 100 & 0.0 & 13.6 & 46.4 & 30.7 & 9.3 \\
\hline Zona 2 (Independencia, Los Olivos, SMP) & 100 & 2.5 & 28.3 & 49.8 & 18.9 & 0.5 \\
\hline Zona 3 (San Juan de Lurigancho) & 100 & 1.2 & 16.1 & 43.5 & 31.5 & 7.7 \\
\hline Zona 4 (Cercado, Rímac, Breña, La Victoria) & 100 & 2.8 & 31.0 & 43.6 & 20.1 & 2.5 \\
\hline $\begin{array}{l}\text { Zona } 5 \text { (Ate, Chaclacayo, Lurigancho, Santa } \\
\text { Anita, San Luis, El Agustino) }\end{array}$ & 100 & 1.0 & 17.0 & 47.3 & 27.3 & 7.4 \\
\hline $\begin{array}{l}\text { Zona } 6 \text { (Jesús María, Lince, Pueblo Libre, } \\
\text { Magdalena, San Miguel) }\end{array}$ & 100 & 14.0 & 59.3 & 19.8 & 5.9 & 0.1 \\
\hline $\begin{array}{l}\text { Zona } 7 \text { (Miraflores, San Isidro, San Borja, } \\
\text { Surco, La Molina) }\end{array}$ & 100 & 34.9 & 46.0 & 11.4 & 6.2 & 1.5 \\
\hline $\begin{array}{l}\text { Zona } 8 \text { (Surquillo, Barranco, Chorrillos, San } \\
\text { Juan de Miraflores) }\end{array}$ & 100 & 2.7 & 31.3 & 42.3 & 19.1 & 4.6 \\
\hline $\begin{array}{l}\text { Zona } 9 \text { (Villa El Salvador, Villa María del } \\
\text { Triunfo, Lurín, Pachacamac) }\end{array}$ & 100 & 0.0 & 10.4 & 48.4 & 30.4 & 10.8 \\
\hline $\begin{array}{l}\text { Zona } 10 \text { (Callao, Bellavista, La Perla, La } \\
\text { Punta, Carmen de la Legua, Ventanilla) }\end{array}$ & 100 & 1.6 & 21.5 & 45.6 & 22.0 & 9.3 \\
\hline Otros & 100 & 0.0 & 10.3 & 32.3 & 37.9 & 19.5 \\
\hline
\end{tabular}

Fuente: APEIM 2017 Data ENAHO 2016

Del cuadro se pudo ver que, para la Zona 7 de Lima Metropolitana se tiene NSE $(\mathrm{A})=$ $34.9 \%$ y NSE $(B)=46 \%$ de lo que resultó un total de $80.9 \%$, información que se presenta en el siguiente cuadro:

Tabla 44

Filtro por Nivel Socioeconómico

\begin{tabular}{lll}
\hline NSE A & NSE B & Total \\
\hline $34.9 \%$ & $46.0 \%$ & $\underline{80.9 \%}$ \\
\hline
\end{tabular}

Fuente: Elaboración propia 
De INEI se obtuvo la proporción de la población comprendida entre el rango de edades desde 18 hasta 50 años. (Filtro edad). El cálculo de esta información se encuentra en el Anexo 6.

Tabla 45

Proporción de población proyectada por edad de 18 a 50 años de la Zona 7 de Lima Metropolitana

\begin{tabular}{llllll}
\hline & LA & MIRAFLORES & SAN & SAN & SURCO \\
Distrito & MOLINA & BORJA & ISIDRO & SÚn \\
Proporción & $62.29 \%$ & $60.20 \%$ & $58.04 \%$ & $62.63 \%$ & $67.93 \%$ \\
\hline
\end{tabular}

Fuente: Elaboración Propia

Finalmente, el cálculo para encontrar el MERCADO POTENCIAL fue:

Mercado Potencial $=$ Población $*$ Filtro APEIM * Filtro Edad

Tabla 46

Mercado Potencial (en número de personas)

\begin{tabular}{lllllll}
\hline Año & $\begin{array}{c}\text { LA } \\
\text { MOLINA }\end{array}$ & MIRAFLORES & SAN BORJA & $\begin{array}{c}\text { SAN } \\
\text { ISIDRO }\end{array}$ & SURCO & Total \\
\hline $\mathbf{2 0 1 6}$ & 87,986 & 39,807 & 52,668 & 27,230 & 192,476 & $\mathbf{4 0 0 , 1 6 7}$ \\
$\mathbf{2 0 1 7}$ & 90,099 & 39,462 & 52,735 & 26,863 & 195,641 & $\mathbf{4 0 4 , 8 0 0}$ \\
$\mathbf{2 0 1 8}$ & 92,212 & 39,117 & 52,803 & 26,496 & 198,806 & $\mathbf{4 0 9 , 4 3 4}$ \\
$\mathbf{2 0 1 9}$ & 94,325 & 38,772 & 52,870 & 26,128 & 201,972 & $\mathbf{4 1 4 , 0 6 8}$ \\
$\mathbf{2 0 2 0}$ & 96,439 & 38,427 & 52,938 & 25,761 & 205,137 & $\mathbf{4 1 8 , 7 0 2}$ \\
$\mathbf{2 0 2 1}$ & 98,552 & 38,082 & 53,005 & 25,394 & 208,302 & $\mathbf{4 2 3 , 3 3 5}$ \\
\hline
\end{tabular}

Fuente: Elaboración propia

\subsubsection{Mercado Disponible}

El Mercado Disponible es la parte del mercado potencial que tiene la característica de interés por el producto (el acceso y la capacidad de compra ya se filtró en el mercado potencial). Para determinarlo utilizamos la pregunta filtro C. ¿consumen bebidas naturales envasadas? 
Tabla 47

Consumo de bebidas naturales envasadas

\begin{tabular}{ll}
$\mathrm{Si}$ & $99.80 \%$ \\
\hline
\end{tabular}

Fuente: Elaboración Propia

El cálculo para encontrar el MERCADO DISPONIBLE fue:

Mercado Disponible $=$ Mercado Potencial * \%Respuesta "SI"

Tabla 48

Mercado Disponible (en número de personas)

\begin{tabular}{llllllc}
\hline \multirow{2}{*}{ Año } & $\begin{array}{c}\text { LA } \\
\text { MOLINA }\end{array}$ & \multirow{2}{*}{ MIRAFLORES } & SAN BORJA & $\begin{array}{c}\text { SAN } \\
\text { ISIDRO }\end{array}$ & SURCO & Total \\
\hline $\mathbf{2 0 1 6}$ & 87,810 & 39,728 & 52,562 & 27,175 & 192,091 & 399,366 \\
$\mathbf{2 0 1 7}$ & 89,919 & 39,383 & 52,630 & 26,809 & 195,250 & 403,991 \\
$\mathbf{2 0 1 8}$ & 92,028 & 39,039 & 52,697 & 26,443 & 198,409 & 408,615 \\
$\mathbf{2 0 1 9}$ & 94,137 & 38,695 & 52,765 & 26,076 & 201,568 & 413,240 \\
$\mathbf{2 0 2 0}$ & 96,246 & 38,350 & 52,832 & 25,710 & 204,726 & 417,864 \\
$\mathbf{2 0 2 1}$ & 98,355 & 38,006 & 52,899 & 25,344 & 207,885 & 422,489 \\
\hline
\end{tabular}

Fuente: Elaboración propia

\subsubsection{Mercado Efectivo}

El Mercado Efectivo es la parte del mercado disponible que muestra la firme intención de adquirir el producto. Para determinarlo utilizamos los filtros J. ¿Estarías dispuesto a consumir esta nueva bebida natural?; R. ¿Cuál es tu distrito de residencia?; $\mathrm{M}_{\text {¿Cuánto }}$ estaría dispuesto a pagar por el producto seleccionado? y el principio de Jeffrey Pope comentado en la página 160 de su libro Investigación de Mercados donde trata el análisis de 
los resultados donde menciona que sólo las tres cuartas partes $(0.75)$ de aquellos que

aseguran el consumo realmente lo harán. ${ }^{25}$

El resultado es:

Tabla 49

Proporción de población disponible con intención de consumo

\begin{tabular}{lccccc}
\hline & LA & \multirow{2}{*}{ MIRAFLORES } & $\begin{array}{c}\text { SAN } \\
\text { BORJA }\end{array}$ & $\begin{array}{c}\text { SAN } \\
\text { ISIDRO }\end{array}$ & SURCO \\
\hline Distrito & $27.14 \%$ & $27.04 \%$ & $15.84 \%$ & $22.54 \%$ & $24.94 \%$ \\
Precio & $44.16 \%$ & $44.16 \%$ & $44.16 \%$ & $44.16 \%$ & $44.16 \%$ \\
Proporción & $71.30 \%$ & $71.20 \%$ & $60.00 \%$ & $66.70 \%$ & $69.10 \%$ \\
\hline
\end{tabular}

Fuente: Elaboración propia

La tabla de contingencia de donde se obtienen estos resultados se encuentra en el Anexo

El cálculo para encontrar el MERCADO EFECTIVO es:

Mercado Efectivo $=$ Mercado Disponible * \% Intención de consumo* Factor Pope (0.75)

Tabla 50

Mercado Efectivo (en número de personas)

\begin{tabular}{llllllc}
\hline \multirow{2}{*}{ Año } & $\begin{array}{c}\text { LA } \\
\text { MOLINA }\end{array}$ & MIRAFLORES & $\begin{array}{c}\text { SAN } \\
\text { BORJA }\end{array}$ & $\begin{array}{c}\text { SAN } \\
\text { ISIDRO }\end{array}$ & SURCO & Total \\
\hline $\mathbf{2 0 1 6}$ & 46,956 & 21,215 & 23,653 & 13,594 & 99,551 & 204,970 \\
$\mathbf{2 0 1 7}$ & 48,084 & 21,031 & 23,683 & 13,411 & 101,188 & 207,398 \\
$\mathbf{2 0 1 8}$ & 49,212 & 20,847 & 23,714 & 13,228 & 102,825 & 209,826 \\
$\mathbf{2 0 1 9}$ & 50,340 & 20,663 & 23,744 & 13,045 & 104,462 & 212,254 \\
$\mathbf{2 0 2 0}$ & 51,467 & 20,479 & 23,774 & 12,861 & 106,099 & 214,682 \\
$\mathbf{2 0 2 1}$ & 52,595 & 20,295 & 23,805 & 12,678 & 107,736 & 217,110 \\
\hline
\end{tabular}

Fuente: Elaboración propia

25 Fuente: https://es.scribd.com/doc/33841301/Pope-Jeffrey-Investigacion-de-Mercados 


\subsubsection{Mercado Objetivo}

El mercado objetivo se obtuvo considerando tres elementos para poder fijar la proporción del mercado efectivo a la que podamos llegar:

a) La participación de mercado de los competidores: Selva y Selvida es del 1.74\% que juntamente con otros (17.46\%) resulta un porcentaje de $13.05 \%$

b) Entrevista de profundidad a especialista que indicó que por ser empresa nueva se podría acceder a un $2 \%$ (entrevista de profundidad a experto) del mercado efectivo e ir incrementando medio punto porcentual por año debido a que el rubro de bebidas era bien dinámico.

c) Información de participación de mercado por Euromonitor Internacional, cuyo cuadro mostramos a continuación:

Tabla 51

Participación de Mercado por Marca y Operador

\begin{tabular}{lll}
\hline Marca & Operador Global & Participación \\
\hline Frugos & The Coca Cola Co & $25 \%$ \\
Cifrut & Aje Group & $16.20 \%$ \\
Pulp & Aje Group & $13.60 \%$ \\
Gloria & Grupo Gloria S.A & \\
Laive & Laive S.A & \\
& Houchens Industries & \\
Tampico & INC & \\
Kris & Industrias San Miguel & \\
Watts & Watts S.A & $26.00 \%$ \\
Ecofresh & Food Pack SAC & \\
Aruba & Grupo Gloria S.A & \\
Pura Vida & Grupo Gloria S.A & \\
Huanchuy & P\&D Andina Alimentos \\
Selvida & Manjares del Ucayali & $0.65 \%$ \\
Selva & P\&D Andina Alimentos & $1.09 \%$ \\
Otros & & $17.46 \%$ \\
Total & & $100.0 \%$ \\
\hline
\end{tabular}

Fuente: Euromonitor International 
Se observa que hay varias empresas "menores" (aproximadamente veinte) que se reparten el $18.70 \%$ esto quiere decir, en promedio el $0.93 \%$. del total del mercado.

Con toda la información analizada se decidió utilizar un 0.9\% de participación de mercado para los cinco años de vida que se muestran en el proyecto y con la posibilidad de incrementar este valor en la medida que se vayan viendo resultados favorables.

El MERCADO OBJETIVO se encontró así:

$$
\text { Mercado Objetivo }=\text { Mercado Efectivo } * 0.9 \%
$$

Tabla 52

Mercado Objetivo (número de personas)

\begin{tabular}{lcccccc}
\hline Año & $\begin{array}{c}\text { LA } \\
\text { MOLINA }\end{array}$ & MIRAFLORES & $\begin{array}{c}\text { SAN } \\
\text { BORJA }\end{array}$ & $\begin{array}{c}\text { SAN } \\
\text { ISIDRO }\end{array}$ & SURCO & Total \\
\hline $\mathbf{2 0 1 6}$ & 423 & 191 & 213 & 122 & 896 & 1,845 \\
$\mathbf{2 0 1 7}$ & 433 & 189 & 213 & 121 & 911 & 1,867 \\
$\mathbf{2 0 1 8}$ & 443 & 188 & 213 & 119 & 925 & 1,888 \\
$\mathbf{2 0 1 9}$ & 453 & 186 & 214 & 117 & 940 & 1,910 \\
$\mathbf{2 0 2 0}$ & 463 & 184 & 214 & 116 & 955 & 1,932 \\
$\mathbf{2 0 2 1}$ & 473 & 183 & 214 & 114 & 970 & 1,954 \\
\hline
\end{tabular}

Fuente: Elaboración Propia

\subsection{Pronóstico de Ventas}

Con el mercado objetivo ya establecido se procedió a determinar la demanda proyectada; para esto se utilizó la información obtenida en la encuesta a través de las preguntas:

$F$. ¿Con qué frecuencia consume bebidas naturales?

G. ¿Cuántas unidades de este tipo de bebida compra cada vez que se acerca al punto de venta para realizar la compra?

Los resultados se muestran en los siguientes cuadros: 
Tabla 53

Frecuencia de compra (al año)

\begin{tabular}{lccc}
\hline \multicolumn{1}{c}{ Frecuencia } & $\%$ & Veces x año & Factor \\
\hline Diariamente & $2.61 \%$ & 365 & 9.53 \\
Dos veces por & & & \\
semana & $63.19 \%$ & 104 & 65.72 \\
Semanalmente & $13.32 \%$ & 52 & 6.93 \\
Mensualmente & $20.89 \%$ & 12 & 2.51 \\
\hline
\end{tabular}

Fuente: Elaboración Propia

Tabla 54

Unidades de compra (número de botellas)

\begin{tabular}{lccc}
\hline \multicolumn{1}{c}{ Unidades } & $\mathbf{N}^{\circ}$ & \% & Factor \\
\hline 1 unidad & 1 & $70.50 \%$ & 0.71 \\
De 2 a 3 unidades & 2.5 & $29.50 \%$ & 0.74 \\
Entre 3 a 5 unidades & 4 & $0.00 \%$ & 0.00
\end{tabular}

Fuente: Elaboración Propia

Demanda proyectada $=$ Mercado objetivo $*$ factor frecuencia $*$ factor unidades/compra

Tabla 55

Demanda Proyectada (en número de unidades)

\begin{tabular}{llllllc}
\hline Año & $\begin{array}{c}\text { LA } \\
\text { MOLINA }\end{array}$ & MIRAFLORES & $\begin{array}{c}\text { SAN } \\
\text { BORJA }\end{array}$ & $\begin{array}{c}\text { SAN } \\
\text { ISIDRO }\end{array}$ & SURCO & Total \\
\hline $\mathbf{2 0 1 6}$ & 51,620 & 23,322 & 26,002 & 14,945 & 109,439 & 225,328 \\
$\mathbf{2 0 1 7}$ & 52,860 & 23,120 & 26,036 & 14,743 & 111,239 & 227,997 \\
$\mathbf{2 0 1 8}$ & 54,100 & 22,917 & 26,069 & 14,542 & 113,038 & 230,666 \\
$\mathbf{2 0 1 9}$ & 55,339 & 22,715 & 26,102 & 14,340 & 114,838 & 233,335 \\
$\mathbf{2 0 2 0}$ & 56,579 & 22,5134 & 26,136 & 14,139 & 116,638 & 236,005 \\
$\mathbf{2 0 2 1}$ & 57,819 & 22,311 & 26,169 & 13,937 & 118,437 & 238,674 \\
\hline
\end{tabular}

Fuente: Elaboración propia 


\subsection{Aspectos críticos que impactan el pronóstico de ventas}

\subsubsection{Factor climatológico}

El pronóstico de ventas se puede ver afectado por adversidades como el fenómeno del niño y también como la estacionalidad de nuestro insumo principal (Sanky) ambos dependientes del clima. En el caso del consumo debido a las estaciones del año habría una reducción, pero no como las bebidas refrescantes ya que el producto es natural.

Tabla 56

Volumen de ventas para el primer año considerando estacionalidad (en número de unidades)

\begin{tabular}{lcccc}
\hline & & & $\begin{array}{c}\text { Valor } \\
\text { Venta }\end{array}$ \\
& & Estacionalidad & Ventas (un) & 3.32 soles \\
\hline Enero & \multirow{2}{*}{ Alto } & $10 \%$ & 22,800 & 75,695 \\
Febrero & $12 \%$ & 27,360 & 90,834 \\
Marzo & $10 \%$ & 22,800 & 75,695 \\
Abril & & $6 \%$ & 13,680 & 45,417 \\
Mayo & & $6 \%$ & 13,680 & 45,417 \\
Junio & \multirow{2}{*}{ Bajo } & $6 \%$ & 13,680 & 45,417 \\
Julio & & $8 \%$ & 13,680 & 45,417 \\
Agosto & & $8 \%$ & 18,240 & 60,556 \\
Setiembre & & $8 \%$ & 18,240 & 60,556 \\
Octubre & & $10 \%$ & 22,800 & 60,556 \\
Noviembre & Alto & $10 \%$ & 22,800 & 75,695 \\
Diciembre & & $100 \%$ & 227,997 & \\
& & & & \\
\hline
\end{tabular}

Fuente: Elaboración propia

\subsubsection{Empresas existentes}

Existen empresas que se dedican al rubro de la fabricación de bebidas con productos y líneas diversas, quienes podrían interesarse en un producto similar a base del insumo que nosotros también utilizamos, al contar con la tecnología de fabricación y el respaldo de una 
marca conocida les sería más sencillo penetrar en el mercado con algún nuevo producto con las mismas características que el presentado en este proyecto.

\subsubsection{Factores internos}

Dentro de los factores internos se tiene como aspectos importantes los ajustes que se debe realizar como consecuencia de las variaciones estimadas que no se presenten en la dimensión esperada.

También se debe revisar constantemente la estrategia de comercialización y mercadeo ya que al ser una empresa nueva y necesariamente se debe adaptar al ritmo económico y comercial del sector. 


\section{Capítulo V}

\section{INGENIERÍA DEL PROYECTO}

\subsection{Estudio de ingeniería}

El objetivo general del estudio de ingeniería del proyecto es resolver todo lo concerniente a la instalación y el funcionamiento de la planta. Desde la adquisición de equipo y maquinaria, proceso productivo y la distribución óptima de la planta.

Se deben determinar los procesos, equipos, recursos humanos, mobiliario, equipo de oficina, terrenos, distribución de equipo, y obras civiles. Esto se tocará de manera más amplia en los siguientes puntos 26 .

Asimismo, la implementación de sistema normativos, como el ISO 9000, ISO 9001, HACCP e ISO 14000.

Según la demanda proyectada y la capacidad de producción se proyecta producir solo un día y medio o dos a la semana en un proceso por lotes reducidos de no más de 3000 botellas diarias.

\subsubsection{Modelamiento y selección de procesos productivos}

Para producir la bebida a base de Sanky se tienen las siguientes etapas dentro del proceso productivo:

a. Preparación del fruto y envase final.

b. Preparación del agua potable.

c. Preparación del edulcorante.

d. Preparación de las botellas y tapas

26 Disponible en Aula Fácil: http://www.aulafacil.com/cursos/119693/empresa/organizacion/gestion-de-proyectos/ingenieria-del-proyecto 
De estas, la etapa "a" es la más importante, siendo las demás etapas de apoyo. A continuación de describen los pasos de cada etapa.

El principal proceso productivo es la elaboración de una bebida a base de Sanky, fruto de color verde, de aspecto similar a la tuna, con pulpa gomosa.

La fruta Sanky deberá estar almacenada en jabas esterilizadas dentro del almacén.

La producción de un lote de bebida Sanky está compuesto por

a. Pesado

Lo primero que se hará, será pesar la fruta hasta que coincida con la cantidad requerida por el lote.

\section{b. Selección}

Se separan los frutos que no son adecuados para la elaboración de la bebida, una buena selección permitirá el buen aprovechamiento de la fruta, lo que contribuirá al proceso, debido a sus características organolépticas. El peso desechado se reemplaza por nuevas frutas seleccionadas.

\section{c. Lavado}

Se procede al lavado de la fruta con agua potable a temperatura ambiente, a la cual se le agrega un desinfectante. En esta etapa se observa que la fruta flota, por lo que se recomienda remojarla agitándola constantemente. Luego de la inmersión, se enjuaga los frutos una vez más con agua potable para así eliminar cualquier residuo del germicida o suciedad.

\section{d. Corte y pelado}

Se procede al corte y extracción de la pulpa gomosa que será insumo principal de la bebida. 
e. Pesado

Una vez obtenida toda la pulpa, se coloca en recipientes de acero inoxidable y se procede al pesado de la misma y futura conservación para ser utilizada en el siguiente paso.

\section{f. Licuado y filtrado}

Una vez obtenida la pulpa se procede a agregarle agua y edulcorante. Una vez agregados estos productos se continúa con el licuado de la mezcla para luego pasar al colado con el fin de retirar todos los residuos producto de las pepas que contiene la pulpa.

\section{g. Embotellado}

Luego de filtrado el producto, se introduce el líquido en los envases con el producto caliente, a no menos de $85^{\circ} \mathrm{C}$, para lograr el envasado al vacío.

h. Sellado / Enroscado

Se realiza inmediatamente después de rellenar los recipientes con las tapas adquiridas.

\section{i. Etiquetado}

Luego de que las botellas se encuentran correctamente selladas, se procede a la colocación de la etiqueta, que contendrá toda la información resaltante del producto.

\section{j. Control de calidad}

Una vez culminado el proceso detallado anteriormente, se realizará una elección aleatoria de las botellas para comprobar si el producto cumple o no con todas las exigencias requeridas antes de su salida al mercado. 
k. Empaquetado y almacenamiento

Se procederá a empaquetar por doce unidades para su posterior almacenamiento, en lugares secos a temperatura ambiente. 


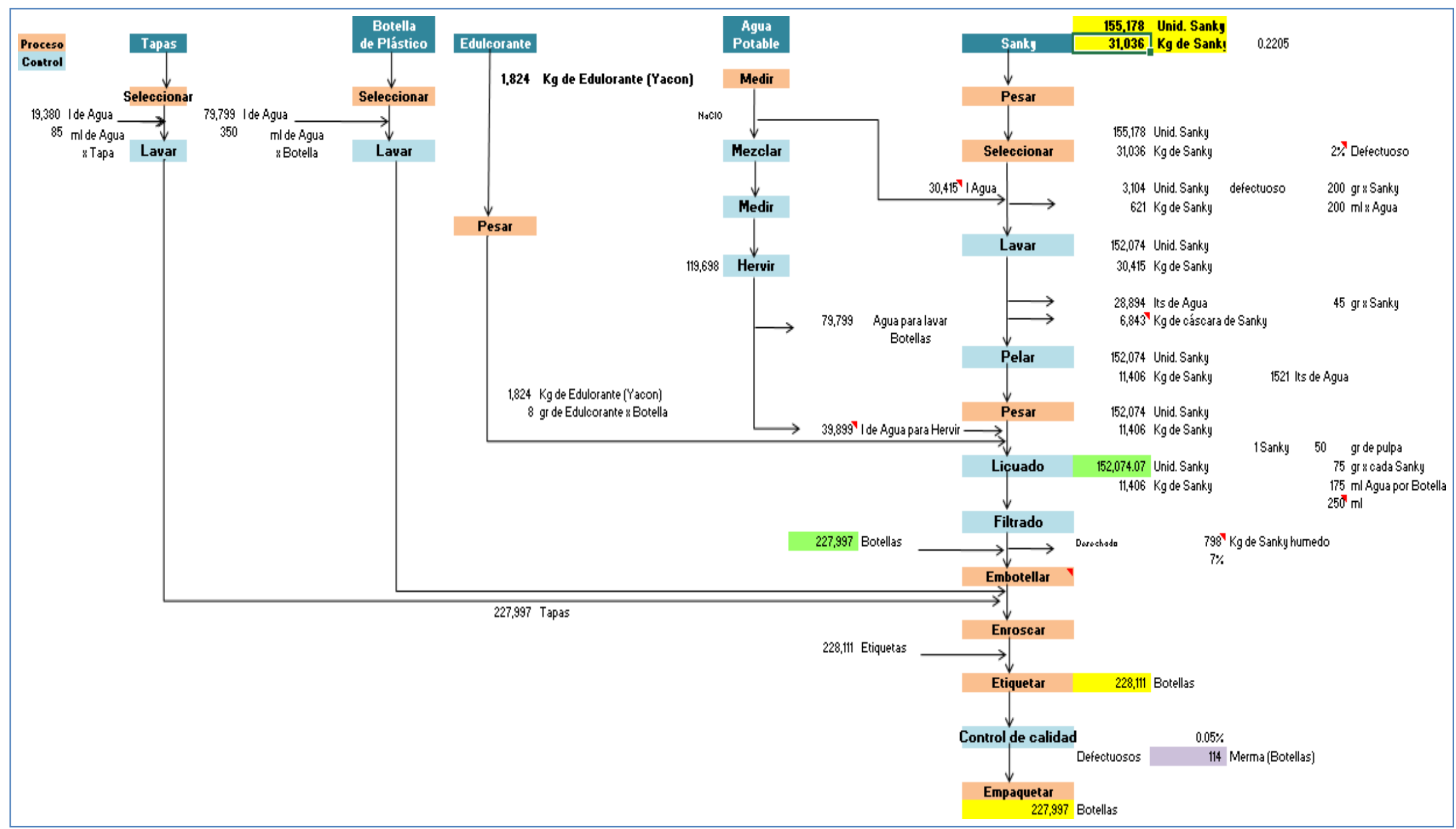

Figura 44. Flujo de Procesos de Producción (Balance de Materia).

Fuente: Elaboración propia. 
En el flujo de proceso de producción se puede apreciar que en el proceso de selección del sanky, luego del pesado hay una merma del 2\% debido a los daños en la manipulación, transporte y perecibilidad del mismo producto (cada vez que se lo utilice para el proceso de producción, que está incluido dentro de ese $2 \%$, es decir $621 \mathrm{Kg}$. de sanky).

Se puede apreciar en el flujo que, en el proceso de pelado, aparece una merma del $22 \%$ es decir $6,843 \mathrm{Kg}$. de cáscara de sanky, la cual será vendida por parte de la empresa para que se prepare abono orgánico, de acuerdo a la norma ISO 14000 como eliminación de residuos sólidos, la cual se encuentra detallada en la parte correspondiente a la implementación de sistemas normativos.

Luego del proceso de licuado y filtrado habrá una merma de 7\% de sanky húmedo, es decir $798 \mathrm{Kg}$. que también será vendido para que se prepare abono orgánico, cumpliendo con la norma técnica mencionada anteriormente.

Luego de los procesos de embotellado, enroscado y etiquetado, se realiza el respectivo control de calidad en el cual hay una merma del $0.05 \%$ de botellas, es decir 114 unidades defectuosas, las cuales serán desechadas y colocadas en bolsas amarillas para ser entregadas al área de reciclaje de la municipalidad, de acuerdo a la norma ISO 14000.

\subsubsection{Selección del equipamiento}

A continuación, se detalla la maquinaria empleada en el proceso de producción, la cual es en su totalidad de tipo industrial.

\section{Lavadora de Frutas:}

Sistema de lavado de inmersión y aspersión, elaborada en acero inoxidable.

Garantía: 1 año

Motor: italiano, importado de Selle 
Hermético exclusivo

Banda transportadora: $1.70 \mathrm{mts}$. Aprox.

Dimensiones: 65 x 45 x 475 m3

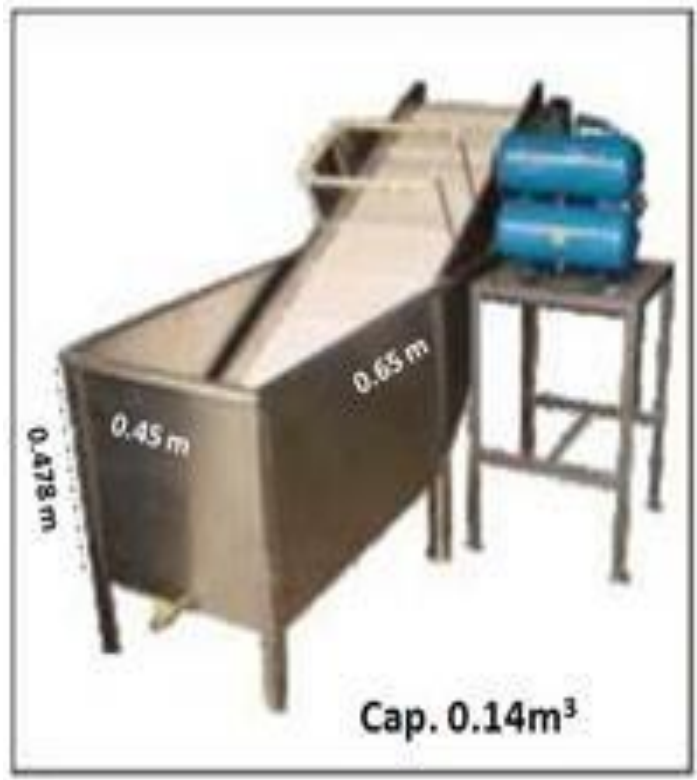

Figura 45. Lavadora de Frutas.

Fuente: http://maquinasempacadoras.com

\section{Marmita de Cocción:}

Modelo: MFD107 100

Capacidad (aproximada): 100 litros.

Funciona con propano.

Consumo máximo: 1242 gr/h.

Presión de trabajo. $37 \mathrm{gr} \mathrm{x} \mathrm{cm².}$

Medidas exteriores: 85 x 90 x $85 \mathrm{~cm}$.

Medidas interiores: altura 450mm, diámetro 550mm. 


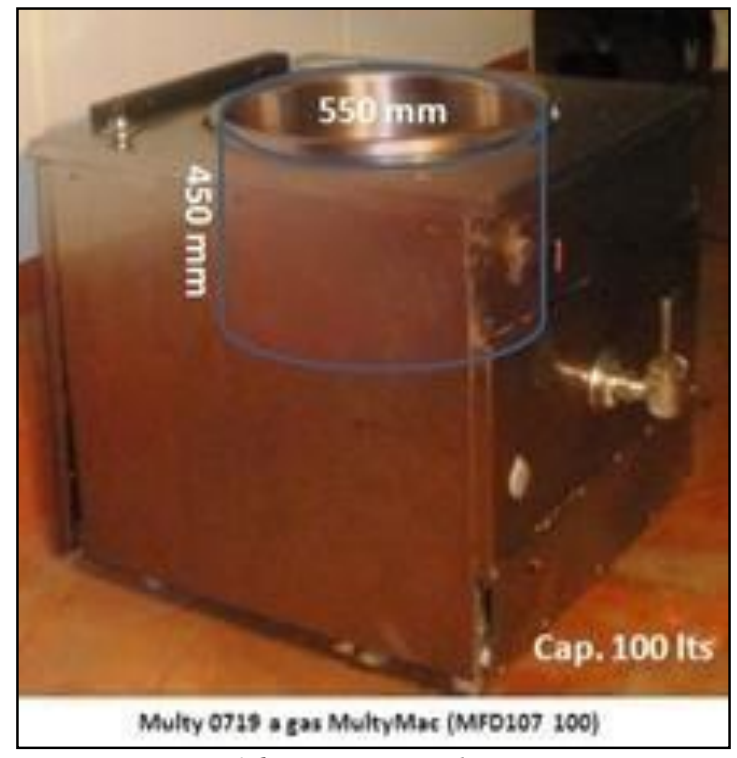

Figura 46. Marmita de Cocción-

Fuente: https://www.multymaq.com/ocasion/marmita-multymaq-amulty-0719/

\section{Licuadora Industrial:}

Sistema volcable. Motor de 2HP de alta revolución. Vaso de 15,25 y 50 litros.

Cuchilla de 6 aspas para mayor rendimiento.

Cable de $2 * 12$ rencauchutado con polo a tierra

Dos velocidades para mejor triturado.

Fabricado en Acero inoxidable.

Bajo consumo de Amperaje para menor consumo de corriente

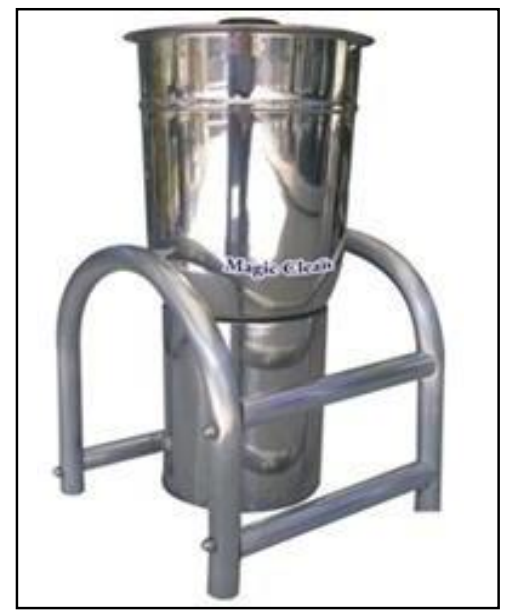

Figura 47. Licuadora Industrial.

Fuente: https://www.electromero.com/licuadoras 


\section{Tanque de Acero Inoxidable Mezclador:}

Enfriamiento y calentamiento en tres capas.

Boca de inspección de rápida abertura

Este tanque de enfriamiento y calentamiento está diseñado con una cubierta de respiración sanitaria contra moscas e insectos, lo que garantiza altos estándares de higiene.

Trípode ajustable

Materiales desmontables del tubo de alimentación

Termómetro (De acuerdo con los requisitos de cliente)

Escalera (De acuerdo con los requisitos de cliente)

Licuadora lateral

Camisa (Tabla Miller, camisa hueca o camisa de tubo de bobinas están disponibles según los requisitos de cliente.)

Medidor de nivel de líquido y regulador de nivel

Placa anti-vórtice

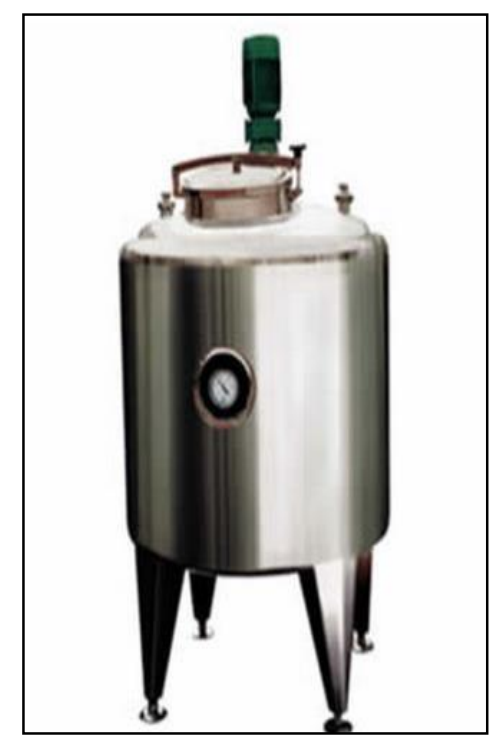

Figura 48. Tanque de Acero Inoxidable.

Fuente: http://inoxidablesmt.blogspot.pe/html 


\section{Colador Industrial:}

Elaborado en acero inoxidable

Medidas: $40 \mathrm{~cm}$. de diámetro aprox.

Asas laterales para facilitar el trabajo

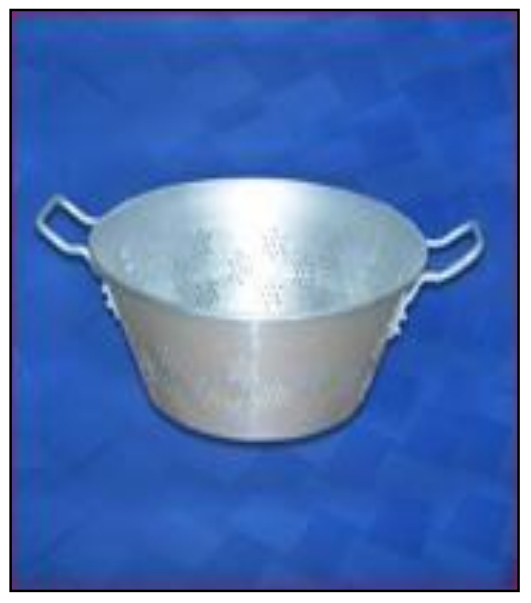

Figura 49. Colador Industrial.

Fuente: https://listado.mercadolibre.com.pe/colador-industrial-grande_DisplayType_G

\section{Tanque de Agua de Acero Inoxidable:}

Tanque de almacenamiento de acero inoxidable.

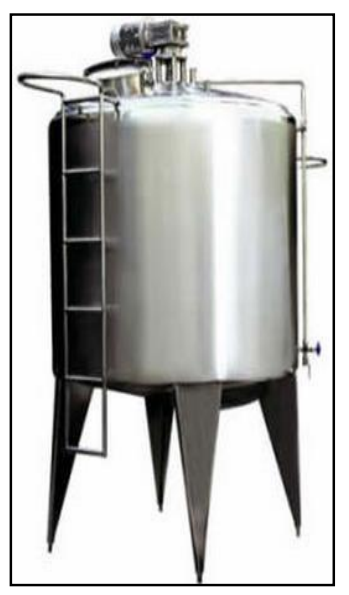

Figura 50. Tanque de Agua de Acero Inoxidable.

Fuente: http://www.gemlsa.com/productos/calderas/equipos-complementarios/tanque-deagua-caliente 


\section{Embotelladora:}

\section{Equitek Serie DN-M}

Capacidad: 900 litros/hr

2 o 4 en línea, de 13,16, 19 o 25 mm. de diámetro, actuadas neumáticamente.

De 25 a 160 mm. De diámetro y de 70 a 320 mm. de altura

Transportador:

De $3 \mathrm{mt}$. de largo en transportador activo, velocidad fija de $11 \mathrm{mt}$. por minuto.

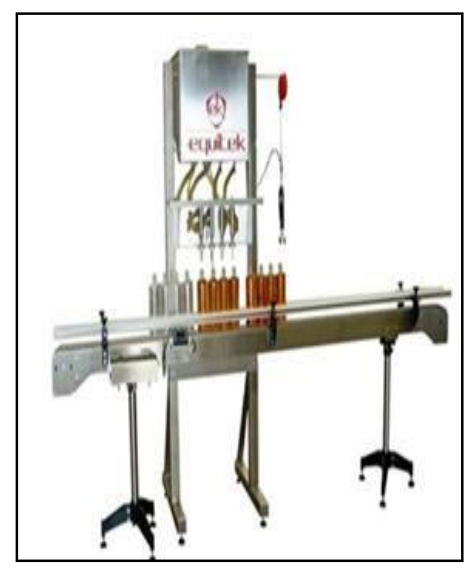

Figura 51. Embotelladora.

Fuente: http//www.maquinariamac.galeon.com-Fuente de Internet

\section{Etiquetadora:}

Esta etiquetadora tiene un diseño que se adapta muy bien a las pequeñas producciones teniendo una frecuencia de 20 etiquetas por minuto. Funciona en envases cilíndricos con etiquetas auto adhesivas.

Las etiquetas pueden ser de $25 \mathrm{~mm}$ de altura hasta los $125 \mathrm{~mm}$ de altura y de $30 \mathrm{~mm}$ de largo hasta $350 \mathrm{~mm}$.

Los envases pueden ser de 25 a 160mm de diámetro y de 70 a 320mm de altura. 


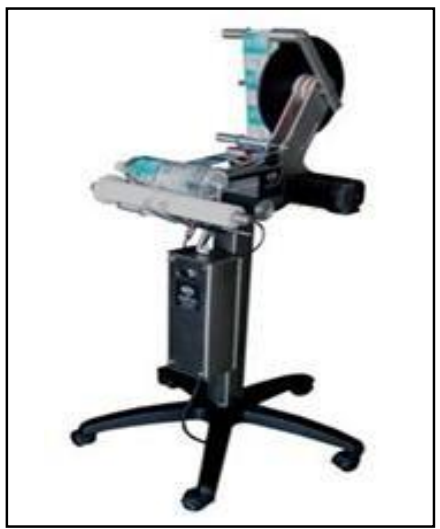

Figura 52. Etiquetadora,

Fuente: *http//www.maquinariamac.galeon.com-Fuente de Internet

\section{Retractiladora Industrial:}

Envolvedora retráctil semiautomática ST-6040:

Esta envolvedora semiautomática junta las funciones de transporte, alimentación, sellado y cortado. La máquina se usa para envolver los productos (latas, botellas...) con la bandeja, y después, pone las películas retráctiles PE o PVC y realiza la envoltura.

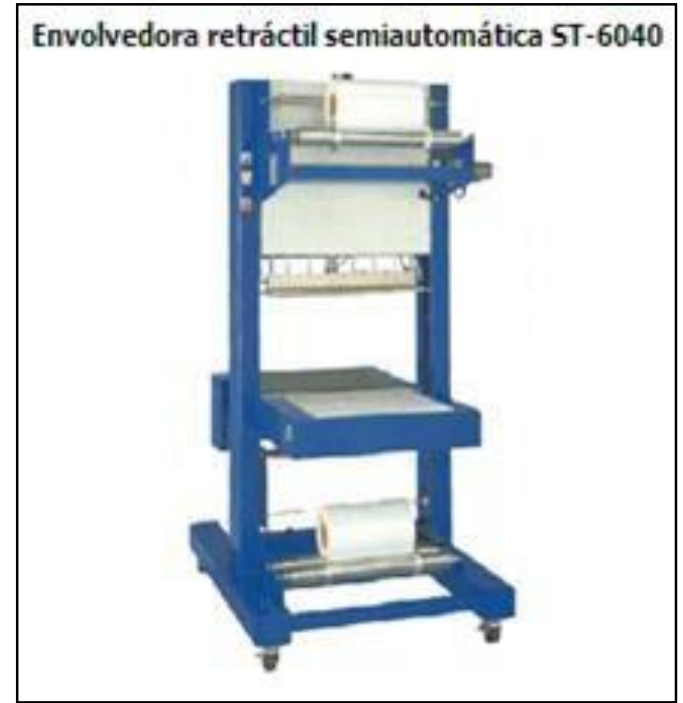

Figura 53. Retractiladora Industrial.

Fuente: http://beverage-machinery.es/shrink_packaging.html 


\section{Refrigeradora Industrial:}

Capacidad: 42 pies cúbicos.

Control inteligente de temperatura.

Ahorrador de Energía. Cuatro puertas.

Además de la selección del equipamiento, también se tienen herramientas que ayudarán en el proceso de producción:

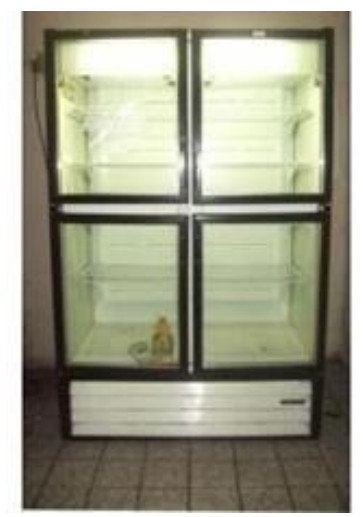

Figura 54. Refrigeradora Industrial.

Fuente: https://listado.mercadolibre.com.pe/refrigeradora-industrial

\section{Pallets:}

Medidas: 1000 x $1200 \mathrm{~mm}$

Peso: Aproximadamente $25 \mathrm{Kg}$.

Carga dinámica: $1500 \mathrm{Kg}$.

Carga estática: $2000 \mathrm{Kg}$.

Carga en estanterías: $1300 \mathrm{~kg}$

Entradas transpaleta: 2 entradas. 


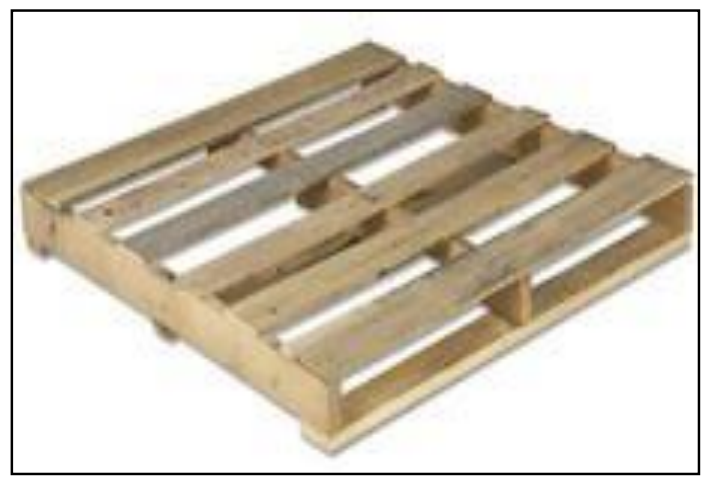

Figura 55. Pallets.

Fuente: http://www.paletsguadiana.pe/que-ofrecemos.html

Cubierta superior cerrada.

\section{Tubos de ensavo}

Recipiente de vidrio, de volumen variable, para hacer pequeños ensayos en el laboratorio

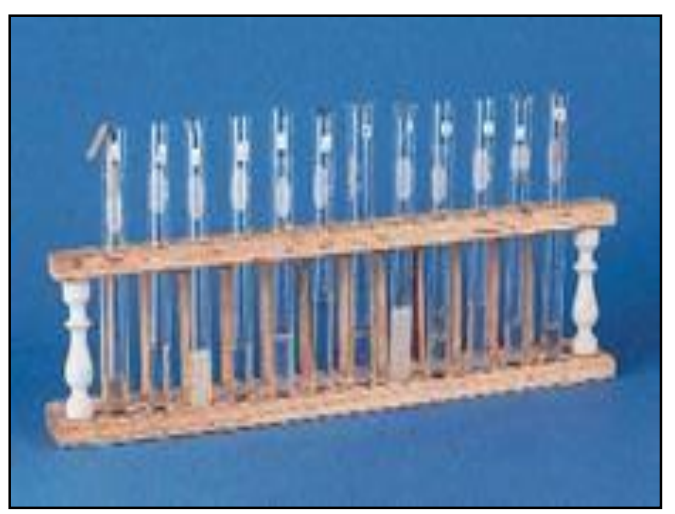

Figura 56. Tubo de Ensayo.

Fuente: http://www.marienfeld-superior.com/index.php/343/articles/tubos-de-ensayo-contapa-rosca.html

\section{Balanza de Precisión}

De capacidad hasta $30 \mathrm{~kg}$.

Digital, para exactitud en las medidas aplicadas a la producción. 


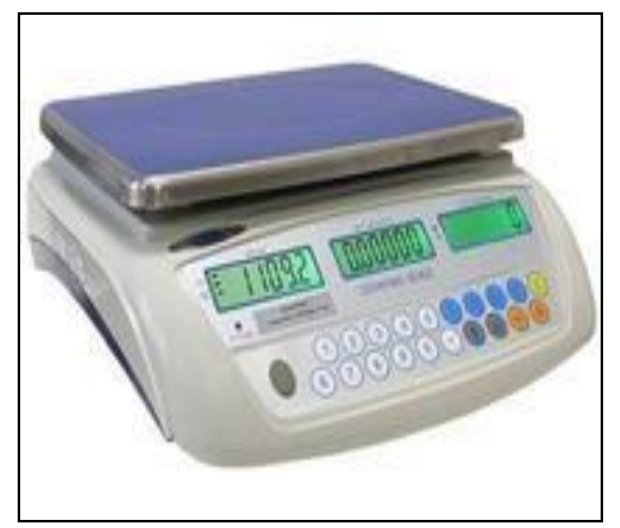

Figura 57. Balanza de Precisión

Fuente: http://balanzasprecisur.com/balanzaselectronicas/balanzas-electronicas-deprecision/balanzas-precision-ohaus.html

\section{Dosificador}

Dosificador de líquidos, utilizado para el llenado y preparación.

Hecho en acero inoxidable, para garantizar la higiene.

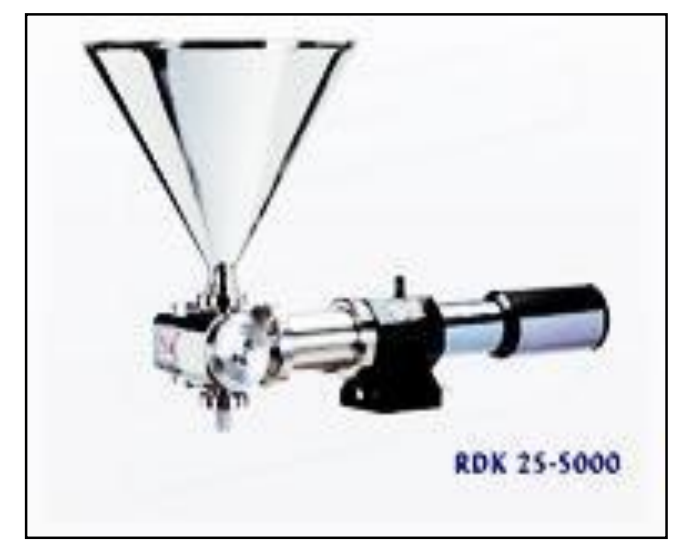

Figura 58. Dosificador.

Fuente: http://jef.es/dosificador.php?idioma=cas

\section{Microscopio:}

Utilizado para las pruebas de laboratorio realizadas antes de la mezcla y control de calidad. 


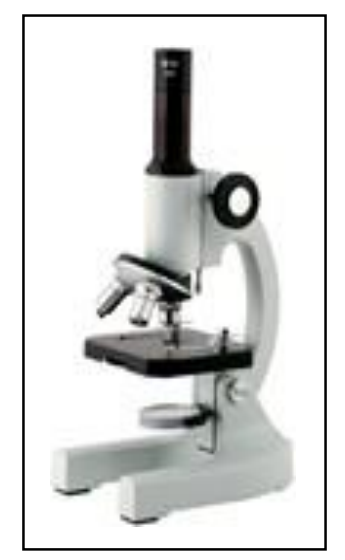

Figura 59. Microscopio.

Fuente: https://pe.all.biz/microscopios-bgg1057093

\section{Mesa de Trabajo:}

Mesa de Trabajo Tipo Isla. Fabricada en Acero Inoxidable Cal. 18 y 20

Modelo: MTIE-140 1.40 x 0.70 x 0.90 m.

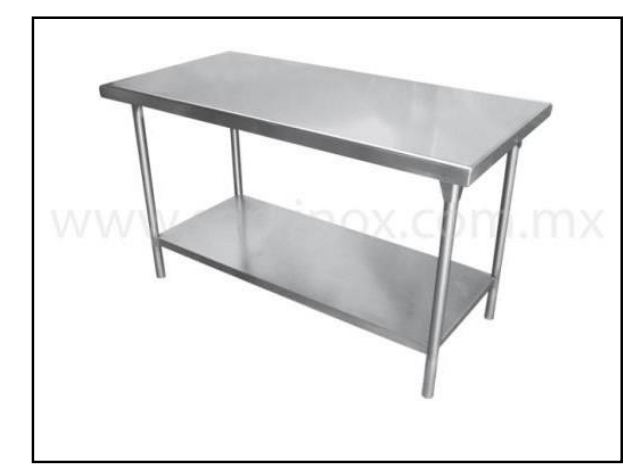

Figura 60. Mesa de Trabajo.

Fuente: https://listado.mercadolibre.com.pe/mesas-de-trabajo-para-taller

\subsubsection{Layout y Distribución de equipos y maquinarias}

El centro de operaciones se ubicará en Chorrillos, específicamente en la zona industrial, denominada "La Campiña", en este local que cuenta con un aproximado de 350 metros cuadrados, donde se desarrollarán actividades tanto administrativas, operativas y de almacenaje, por lo que el total de nuestro personal se ubicará en esta planta. 
El local, contará con dos áreas, una administrativa y otra de producción; tendrá estacionamiento y servicios completos. 


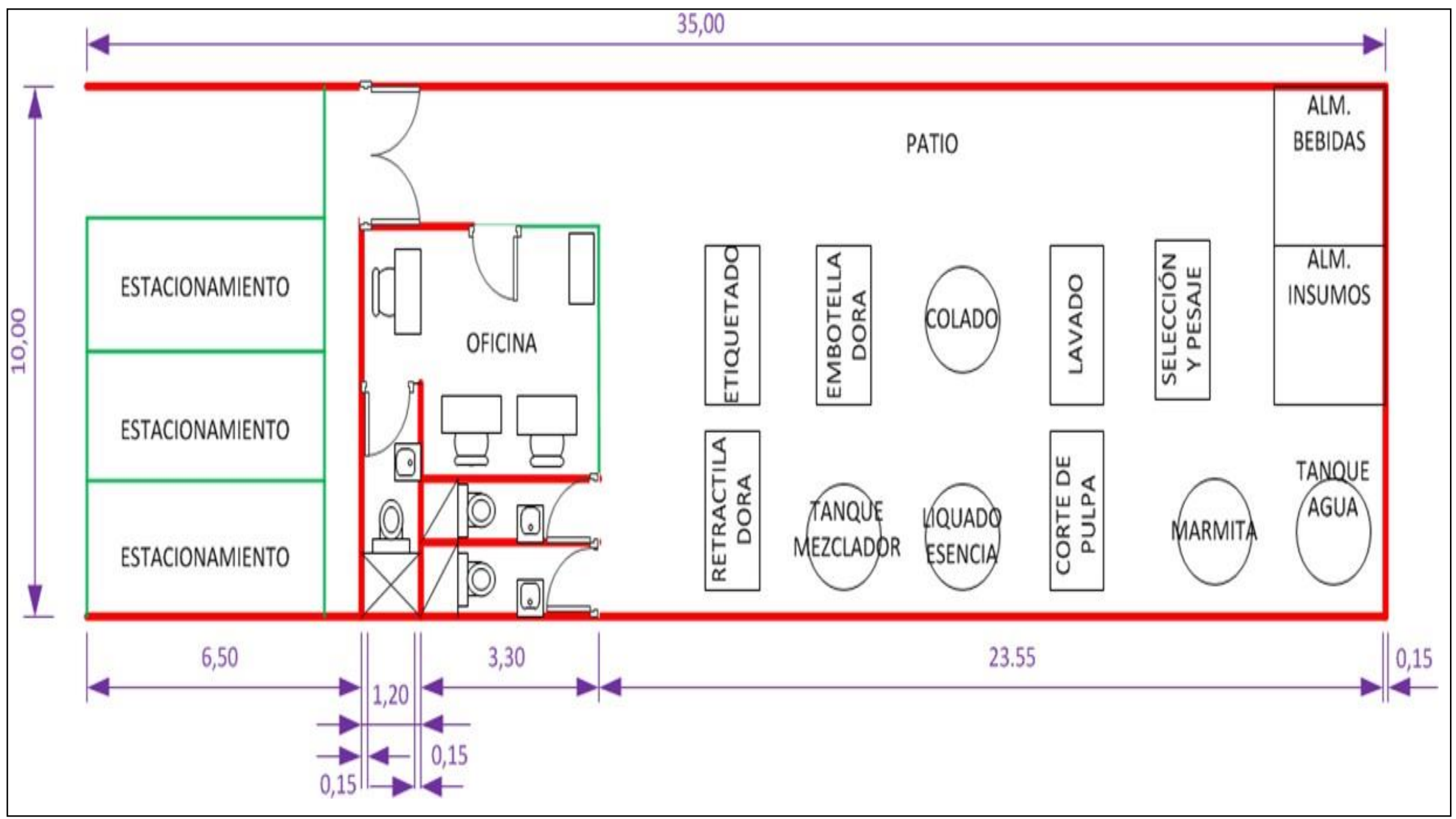

Figura 61, Layout de la Empresa,

Fuente: Elaboración propia. 


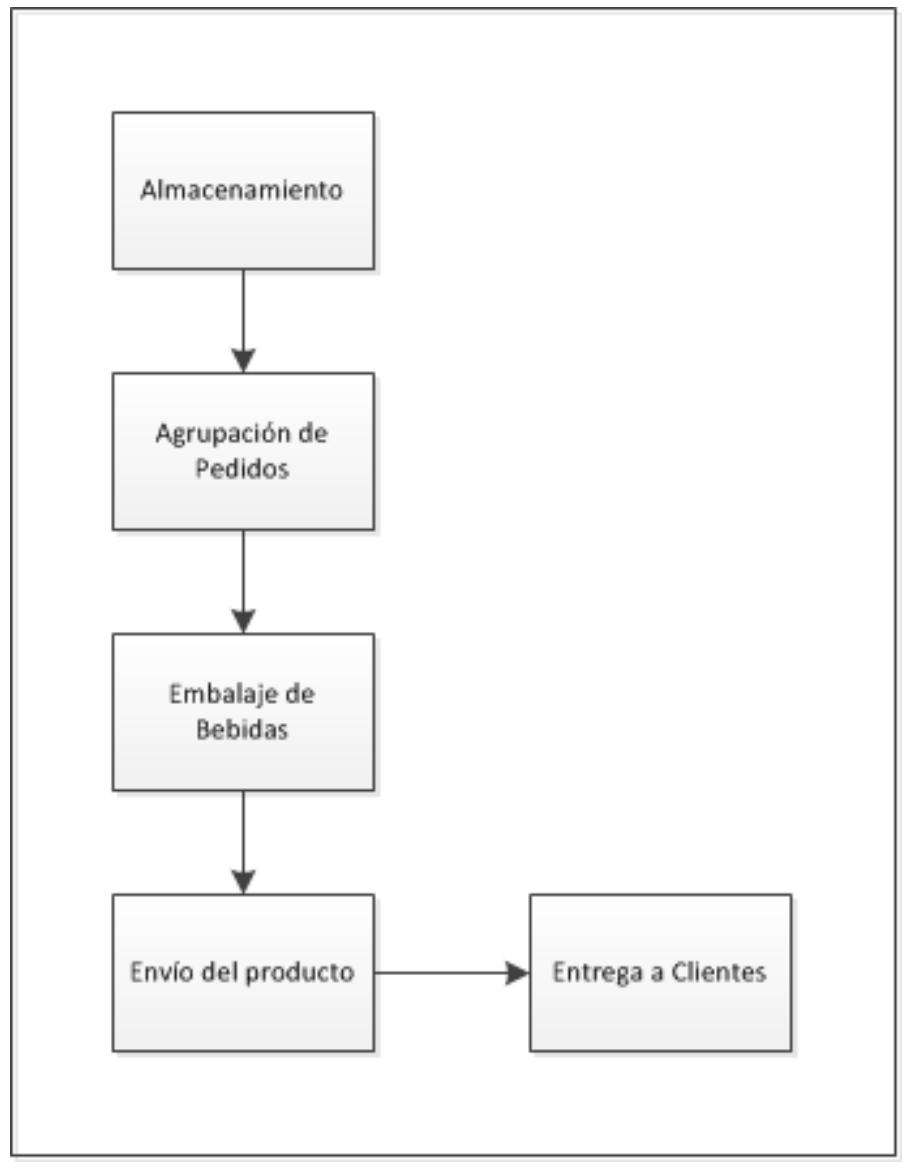

Figura 62. Flujograma de Despacho.

Fuente: Elaboración propia. 


\subsection{Determinación del Tamaño}

\subsubsection{Proyección de crecimiento}

El crecimiento de ventas se determinó con la variación porcentual anual según la demanda proyectada tal como se ve en el siguiente cuadro

Tabla 57

Variación de Ventas (\%)

\begin{tabular}{cc}
\hline Años & $\begin{array}{c}\text { Variación de } \\
\text { ventas }\end{array}$ \\
\cline { 2 - 2 } 2017 & - \\
2018 & $1.171 \%$ \\
2019 & $1.157 \%$ \\
2020 & $1.144 \%$ \\
2021 & $1.131 \%$ \\
\hline Fuente: & Elaboración Propia
\end{tabular}

\subsubsection{Recursos}

Dentro de los recursos considerados, se tiene que el fruto del Sanky será trasladado del mercado mayorista $\mathrm{N}^{\circ} 2$ de frutas, distrito de La Victoria a nuestras instalaciones ubicado en Chorrillos a tempranas horas del día con lo que se evitará la pérdida de tiempo en tránsito de la ciudad.

\subsubsection{Tecnología}

La planta usará agua del servicio público que será hervida y luego se le aplicará hipoclorito de sodio según una formulación inocua para el ser humano. Este proceso mejorará la calidad del agua con respecto a un proceso de filtrado.

Luego de la mezcla del agua con la pulpa y los demás ingredientes, la bebida pasará por un proceso de pasteurización. 


\subsubsection{Flexibilidad}

La planta producirá a un $9.71 \%$ de su capacidad instalada por lo que se podrá aumentar la producción en caso la demanda tenga un crecimiento mayor al planificado. También se podrá realizar la producción de bebidas de otras empresas (maquila), esto se diseñará en una siguiente etapa del proyecto.

\subsubsection{Selección del tamaño ideal}

La capacidad instalada en maquinarias y equipos (tamaño normal y máximo) se presenta en la siguiente tabla, así como también el porcentaje de utilización.

\section{Tabla 58}

Determinación Capacidad de la Planta

\begin{tabular}{|c|c|c|c|c|c|}
\hline $\begin{array}{l}\text { Tanque de Lavado } 0.25 \mathrm{HP}(65 * 45 * 47.8 \\
\mathrm{cm} 3)\end{array}$ & 0.28 & $\operatorname{tn} / \mathrm{hr}$ & & $6720 \mathrm{~kg}$ & $2419200 \mathrm{~kg}$ \\
\hline Marmita de Cocción & 100 & 1 & $1.5 \times \mathrm{hr}$ & 3600 litros & 1296000 litros \\
\hline Licuadora Industrial & 50 & 1 & $5.0 \times \mathrm{hr}$ & 6000 litros & 2160000 litros \\
\hline Colador industrial ac. Inox & 45 & $\mathrm{Kg}$ & $3.0 \times \mathrm{hr}$ & 3240 litros & 1166400 litros \\
\hline Tanque acero Inox. (Mezclado) & 1000 & 1 & $2.0 \times \mathrm{hr}$ & $\begin{array}{l}48000 \\
\text { litros }\end{array}$ & 17280000 litros \\
\hline Embotelladora, Selladora & 900 & $1 / \mathrm{hr}$ & $900.0 \times \mathrm{hr}$ & $\begin{array}{l}21600 \\
\text { litros }\end{array}$ & 7776000 litros \\
\hline Etiquetadora & 20 & $\mathrm{bot} / \mathrm{min}$ & $1200.0 \times \mathrm{hr}$ & $\begin{array}{l}13680 \\
\text { litros }\end{array}$ & 4924800 litros \\
\hline Retractiladora industrial (empaque $\mathrm{x}$ doc) & 8 & packs/min & & $\begin{array}{l}65664 \\
\text { litros }\end{array}$ & 23639040 litros \\
\hline Refrigeradora (x2) & 2.36 & $\mathrm{~m} 3$ & $\begin{array}{l}1.0 \text { x día } \\
\text { Cap.Max. }\end{array}$ & $\begin{array}{l}2360 \text { litros } \\
2360 \text { litros } \\
\end{array}$ & $\begin{array}{l}849600 \text { litros } \\
849600 \text { litros }\end{array}$ \\
\hline Capacidad Máxima (Especif. Técnicas) & 849,600 & 849,600 & 849,600 & 849,600 & 849,600 \\
\hline $\begin{array}{l}\text { Capacidad Normal (19.5 hrs diarias x } 6 \\
\text { días sem } x 52 \mathrm{sem})\end{array}$ & 598,260 & 598,260 & 598,260 & 598,260 & 598,260 \\
\hline $\begin{array}{l}\text { Demanda Real (Según Programa de } \\
\text { Ventas) }\end{array}$ & 56,999 & 57,667 & 58,334 & 59,001 & 59,668 \\
\hline $\begin{array}{l}\text { Porcentaje de utilización de la capacidad } \\
\text { instalada }\end{array}$ & $9.53 \%$ & $9.64 \%$ & $9.75 \%$ & $9.86 \%$ & $9.97 \%$ \\
\hline
\end{tabular}

Fuente: Elaboración Propia 
Se puede observar que el uso de la capacidad instalada corresponde al 10\% de la capacidad total durante el plazo; esto nos permitiría poder atender una inesperada alza en la demanda del producto por parte del consumidor final. Así mismo se podría hacer trabajos de maquilación a otras pequeñas empresas.

\subsection{Estudio de localización}

\subsubsection{Macro Localización}

Existen factores muy importantes que se debe tener en cuenta para la ubicación de la planta, que contribuirán o dificultarán el desenvolvimiento de las actividades. Se ha considerado tres posibles provincias para la ubicación de la planta, teniendo en consideración el mercado objetivo evaluado y los lugares de producción del insumo base del producto, dando como resultado las provincias de Lima, Huancavelica y Ayacucho. Aplicando una metodología de factores, se tiene los siguientes resultados.

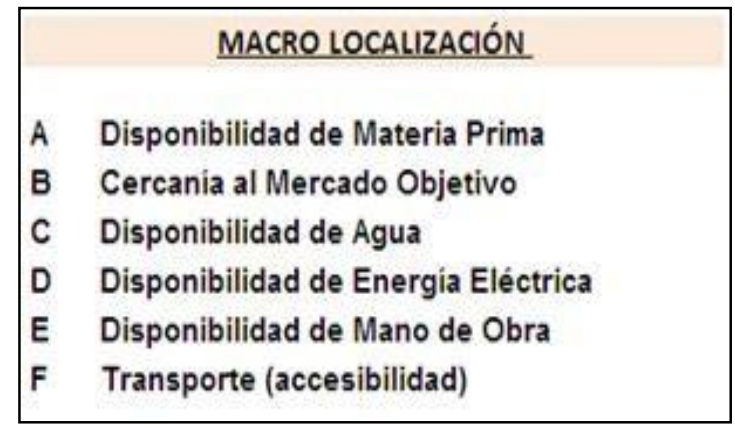

Figura 63. Macro Localización.

Fuente: Elaboración propia

Estos factores han sido ponderados de acuerdo al impacto que tienen en el funcionamiento de la planta. Considerando las provincias de Lima, Huancavelica y Ayacucho, se tiene el siguiente resultado, siendo Lima la provincia con mayor puntaje, por tanto, la mejor opción para la ubicación de la planta. 
Tabla 59

Macro Localización

\begin{tabular}{cccccccc}
\hline \multirow{2}{*}{ Factores } & \multirow{2}{*}{ Ponderación } & \multicolumn{2}{c}{ Lima } & \multicolumn{2}{c}{ Huancavelica } & \multicolumn{2}{c}{ Ayacucho } \\
& & Calificación & Puntaje & Calificación & Puntaje & Calificación & Puntaje \\
\hline A & $25 \%$ & 6 & 1.50 & 10 & 2.50 & 10 & 2.50 \\
B & $20 \%$ & 10 & 2.00 & 2 & 0.40 & 4 & 1.80 \\
C & $18 \%$ & 10 & 1.80 & 6 & 1.08 & 8 & 1.44 \\
D & $18 \%$ & 10 & 1.80 & 4 & 0.72 & 8 & 1.44 \\
E & $10 \%$ & 10 & 1.00 & 6 & 0.60 & 8 & 0.80 \\
F & $9 \%$ & 6 & 0.54 & 8 & 0.72 & 8 & 0.72 \\
& $100 \%$ & & 8.64 & & 6.02 & & 7.70 \\
\hline
\end{tabular}

Fuente: Elaboración Propia

\subsubsection{Micro Localización}

Respecto del distrito donde será ubicada la planta dentro de la provincia de Lima, se ha evaluado tres opciones, considerando la cercanía al mercado objetivo, a la adquisición de insumos, costos de alquiler de local, entre otros. Al igual que en la macro localización, se ha puntualizado algunos factores que influyen en la elección, lo mismos que han sido ponderados, logrando los siguientes resultados.

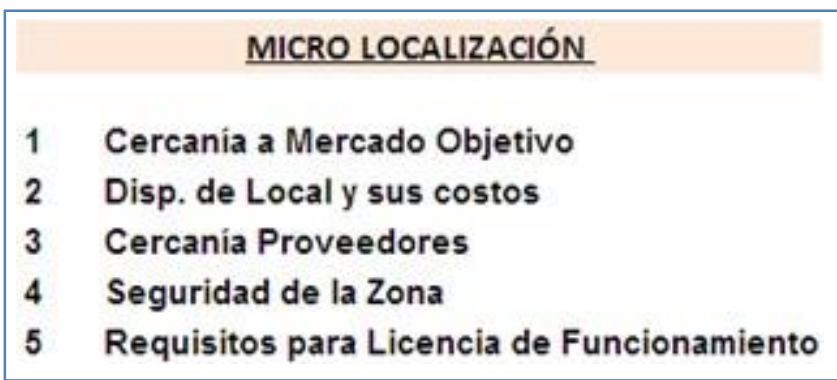

Figura 64. Micro Localización.

Fuente: Elaboración propia

Los distritos que se han considerado para la evaluación son Ate, Huachipa y Chorrillos, resultando Chorrillos la mejor opción para la ubicación de la planta. 
Tabla 60

Factores y Ponderación

\begin{tabular}{cccccccc}
\hline \multirow{2}{*}{ Factores } & \multirow{2}{*}{ Ponderación } & \multicolumn{2}{c}{ Ate } & \multicolumn{2}{c}{ Huachipa } & \multicolumn{2}{c}{ Chorrillos } \\
& & Calificación & Puntaje & Calificación & Puntaje & Calificación & Puntaje \\
\hline 1 & $25 \%$ & 6 & 1.50 & 4 & 1.00 & 8 & 2.00 \\
2 & $25 \%$ & 6 & 1.50 & 6 & 1.50 & 10 & 2.50 \\
3 & $25 \%$ & 8 & 2.00 & 6 & 1.50 & 6 & 1.50 \\
4 & $10 \%$ & 6 & 0.60 & 6 & 0.60 & 6 & 0.60 \\
5 & $15 \%$ & 6 & 0.90 & 6 & 0.90 & 8 & 1.20 \\
& $100 \%$ & & 6.50 & & 5.50 & & 7.80 \\
\hline
\end{tabular}

Fuente: Elaboración Propia

La ubicación específica es en Av. Los Gorriones Mz. A Lote 28 B La Campiña -

Chorrillos.

\subsubsection{Ubicación de la Planta}

En la siguiente Figura se muestra la ubicación de la planta en el distrito de Chorrillos.

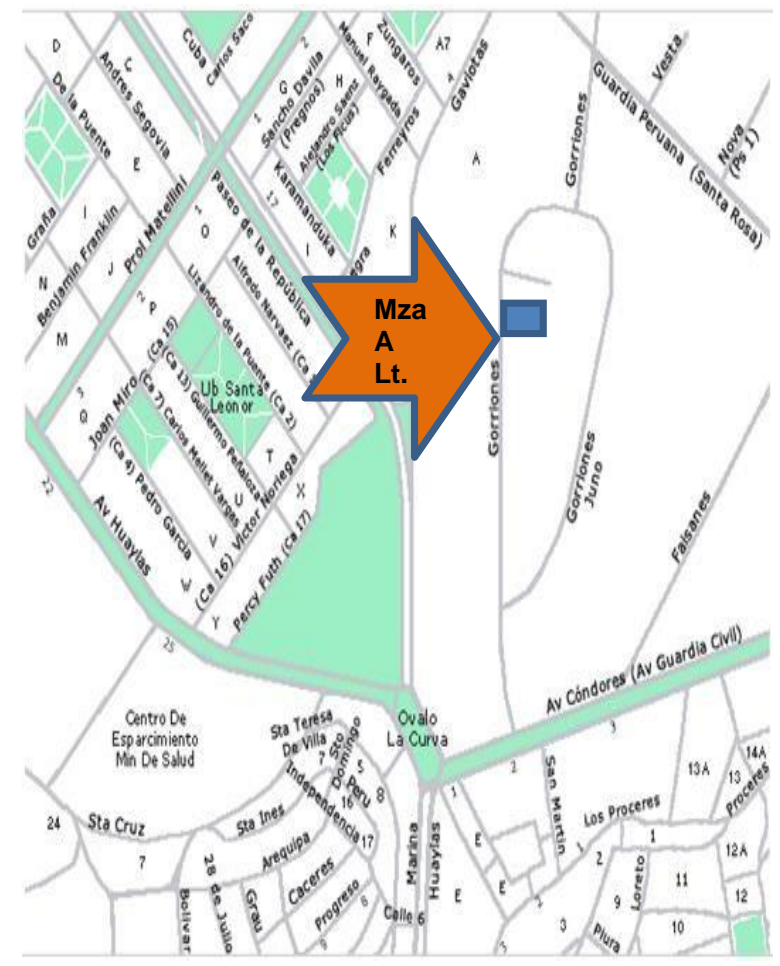

Figura 65. Ubicación de la Planta.

Fuente: Elaboración propia. 


\subsubsection{Determinación de la localización óptima.}

Según los cuadros de Macro y Micro localización se establece el distrito de Chorrillos como la localización óptima de la planta de producción de bebida Sanky.

\subsection{Proceso Logístico de Compra}

En el proceso de logística de compra el principal producto a comprar es la fruta SANKY la misma que se comprará en el mercado mayorista $\mathrm{N}^{\circ} 2$ de frutas, situado en Antonio Alarco $\mathrm{N}^{\circ}$ 403-Lima.

Los principales proveedores de la fruta sanky, son los siguientes:

1. Proveedor: Apolin Fernández, Moisés

RUC: 10224498018

Dirección: Antonio Alarco Nº 403 -Lima/ Puesto 741- Mercado Mayorista N² de Frutas.

2. Proveedor: Risco Pashanasi, Milagros

RUC: 10431781201

Dirección: Antonio Alarco N 403 -Lima/ Puesto 747- Mercado Mayorista N² de Frutas.

3. Proveedor: Agroindustrias Verónica S.A.C.

RUC: 20392495534

Dirección: Av. Nicolas Arriola cdra. S/N-La Victoria/ Puesto A-20- Mercado Mayorista N² de Frutas.

Las conversaciones sostenidas con uno de los proveedores se encuentran en el anexo 2. Por la estacionalidad de la fruta la mayor producción se da entre mayo y octubre sin embargo hay cosecha durante casi todo el año, como se puede apreciar en la siguiente tabla: 
Tabla 61

Estacionalidad de la coseha de la fruta

\begin{tabular}{|l|l|l|l|l|l|l|l|l|l|l|l|l|}
\hline ITEM & ENE & FEB & MAR & ABR & MAY & JUN & JUL & AGO & SET & OCT & NOV & DIC \\
\hline Ayacucho & & & & & & & & & & & & \\
\hline Arequipa & & & & & & & & & & & & \\
\hline Huancavelica & & & & & & & & & & & & \\
\hline
\end{tabular}

Fuente: https://edoc.pub/hope-energy-jugo-de-sanky-pdf-free.html y elaboración propia

La compra de los equipos, insumos y accesorios se realizará a los diversos proveedores que están listados en el anexo 9.

\subsection{Implementación de sistemas normativos}

Se implementarán los sistemas normativos ISO 9000, ISO 9001, HACCP e ISO 14000 de acuerdo a lo solicitado por el MINSA, así como sugeridas por las dos especialistas en industrias alimentarias en las entrevistas a profundidad realizadas en la investigación cualitativa y para minimizar el impacto frente al medio ambiente y asumir un compromiso frente a la gestión ambiental.

\subsubsection{ISO 9000}

Las normas ISO -9000 son un sistema para aseguramiento de la calidad. Las normas de aseguramiento de la calidad más modernas tienen su origen en las relaciones contractuales entre fabricantes y suministradores de algunos sectores en los que se requería la mayor fiabilidad: construcción de centrales nucleares y defensa principalmente.

Además, son un paquete de normas para la gestión de la calidad (administración) y del aseguramiento de la calidad, publicadas por ISO (International Organization Standaritation). Los sistemas de calidad no solo se aplican a las grandes empresas industriales. Las empresas productoras de alimentos pueden y deben implantar un sistema de gestión basado en la 
calidad. En consecuencia, la implantación del sistema es independiente del tamaño de la empresa. Lo importante es llevarlo a la práctica con eficacia, que será diseñado y ajustándolo a las necesidades concretas de la empresa.

Adoptar un sistema de aseguramiento de la calidad de acuerdo al ISO 9000, permitirá: tener un marco adecuado para una gestión efectiva, optimizando la estructura organizativa de la empresa, definiendo claramente las responsabilidades, mejorando las comunicaciones y por lo tanto mejorando la relación con los clientes; tener un medio para poder mejorar el control de la calidad a través de un sistema formal y consistente; incrementar la rentabilidad, disminuyendo errores y trabajos repetitivos, mejorando la utilización del tiempo y los recursos y una ventaja en el marketing de la empresa.

\subsubsection{ISO 9001}

Toda organización sacara beneficio de la implantación de la ISO 9001, puesto que sus requisitos están basados en los siguientes ocho principios de gestión:

$>$ Principio 1: Organización centrada en el cliente

$>$ Principio 2: Liderazgo

$>$ Principio 3: Compromiso de las personas

$>$ Principio 4: Enfoque a los procesos

Principio 5: Enfoque hacia la gestión del sistema

$>$ Principio 6: Mejora continua

$>$ Principio 7: Enfoque objetivo para la toma de decisiones

Principio 8: Relaciones con el suministrador mutuamente beneficiosas.

\section{Los beneficios de la certificación:}

A nivel interno: 
$\checkmark$ Satisfacción del cliente-mediante la entrega de productos y/o servicios que cumplan sistemáticamente con los requisitos del cliente.

$\checkmark$ Reducción de costos de operación-mediante la mejora continua de procesos y su resultado en eficiencia operacional.

$\checkmark$ Mejorar las relaciones entre partes interesadas-incluyendo trabajadores, clientes y proveedores.

$\checkmark$ Cumplimiento de la legislación-entendiendo el impacto de los requisitos legales en la organización y en sus clientes.

$\checkmark$ Mejorar la gestión de riesgo-mediante mayor regularidad y trazabilidad de productos y servicios.

$\checkmark$ Demostrar sus credenciales-gracias a una auditoría independiente según estándares reconocidos.

$\checkmark$ Posibilidad de conseguir más negocio-especialmente cuando la certificación sea un requisito para ser proveedor.

A nivel externo:

$\checkmark$ Facilita el acceso a los mercados externos, aportando credenciales de calidad para la empresa y aumentando las credenciales de sus productos.

$\checkmark$ Es un buen argumento publicitario en folletos o catálogos, con una escala de reconocimiento a nivel global y local.

\subsubsection{Aplicación del sistema ISO 9000 en una planta procesadora de bebidas naturales}

\section{$>$ Manual de calidad}

Elementos del sistema de calidad

\section{Buenas prácticas de manufactura}

El personal que trabajará requiere cumplir con lo siguiente: 
1. Higiene personal: el baño diario y el lavado frecuente de cabello reduce las probabilidades de contaminación de los productos con bacterias que normalmente se encuentran en el cuerpo debido a la contaminación ambiental.

2. Uniforme limpio y completo: se debe de ingresar a la zona de producción con los siguientes accesorios: guardapolvo, camisa, pantalón, mandil (de plástico), gorro, protector naso-bucal, guantes y botas. No se debe de usar ropa de vestir (chompas, casacas) sobre el uniforme.

3. Uñas cortas: se debe de mantener uñas cortas, limpias y recortadas porque albergan gran número de bacterias que pueden pasar al producto y pueden ser nocivas para la salud. Está prohibido el uso de esmalte de uñas, estos pueden descascararse y caer sobre el producto.

4. Manos limpias: las manos son portadoras de bacterias que pueden contaminar los productos. Deben de lavarse las manos inmediatamente después de usar los servicios higiénicos, antes de ingresar al área de trabajo, cada vez que se ensucien, además de usar soluciones desinfectantes.

5. Bolsillos: no se debe de guardar nada en los bolsillos de la camisa o guardapolvos como lapiceros, aretes, relojes, peines que puedan caer accidentalmente al producto.

6. Joyas y accesorios: no ingresar a la zona de producción con anillos, aretes, collares, cadenas, pulseras, etc.

7. Uso de guantes: mantener los guantes limpios, lavarlos antes de iniciar el trabajo diario, cada vez que se ensucien y cuando termine la jornada de trabajo. Se pueden utilizar soluciones desinfectantes.

8. Evitar malos hábitos: pueden originar contaminación del producto, tales como: rascarse la cabeza o agarrarse el cabello. Colocarse el dedo en la nariz, oreja o boca. Toser o estornudar sobre los productos, maquinas o utensilios. Secarse la frente con las manos o 
brazos. Secarse o limpiarse las manos con el uniforme. Apoyarse sobre las paredes, máquinas, equipos y productos. Limpiarse las manos con trapos sucios.

9. Buena salud: notificar al jefe inmediato si algún operario tiene alguna enfermedad contagiosa e infecciosa (respiratoria y de la piel). No se debe de permitir el ingreso al área de producción a los operarios que tienen contacto directo con el producto hasta que la situación haya sido superada.

10. No fumar: está prohibido fumar dentro del área de producción y en el área de almacén.

11. Alimentos y bebidas: no se debe de ingresar alimentos a las áreas de producción y de almacén.

12. Vidrios y Waype: está prohibido ingresar materiales de vidrio a la zona de producción, ya que pueden quebrarse y caer al producto. Materiales como el waype, trapos, yutes, pitas pueden originar contaminación accidental en el producto. Evitar su uso.

13. Maquinaria y equipos: se debe de realizar una limpieza y desinfección de la maquinaria y/o equipos antes y después del proceso de producción. ${ }^{27}$

\subsubsection{HACCP (Análisis de peligros y puntos críticos de control)}

El análisis de peligros y de puntos críticos de control (HACCP) es un sistema de gestión destinado a garantizar la inocuidad de los alimentos que goza de gran aceptación. El servicio de calidad de alimentos y normas alimentarias (ESNS), del programa de la FAO de apoyo a los países para fortalecer sus sistemas de producción y garantizar la inocuidad del suministro de alimentos, ha colaborado con organismos gubernamentales y con la industria alimentaria en la aplicación del HACCP. Una parte importante de este programa ha sido la creación de instrumentos y la realización de cursos de capacitación en los países miembros, a fin de

\footnotetext{
${ }^{27}$ Fuente: file:///G:/PGA/TESIS\%20VARIAS-\%20GUIAS/69.0361.AL.pdf y elaboración propia
} 
fortalecer la capacidad nacional para la aplicación y auditoría del HACCP. El programa de curso de capacitación contiene elementos de capacitación, buenas prácticas de higiene y para la creación del sistema de HACCP. El objetivo del curso de capacitación es promover buenas prácticas de higiene y el sistema HACPP a través de la higiene alimentaria.

Los materiales de capacitación y una explicación de los requisitos generales (higiene de los alimentos) Figuran en el manual "Sistemas de calidad e inocuidad de los alimentos" y "Manual de capacitación sobre higiene de los alimentos y sobre el sistema de análisis

\section{HACCP”}

Este manual es una referencia para los promotores y para los responsables de la elaboración del plan de HACCP. El trabajo va dirigido, entre otros, a los funcionarios de control de alimentos, al personal de la industria alimentaria y a los promotores.

El HACCP es compatible con otros sistemas de control de calidad. Esto significa que la inocuidad, la calidad y la productividad pueden ser manejadas juntas con los beneficios de una mayor confianza por parte de los consumidores, más rentabilidad para las empresas y mejores relaciones entre los que trabajan por el objetivo común de garantizar la inocuidad y calidad de alimentos.

\section{$>$ Clasificación de peligros:}

1. Peligros biológicos: se incluyen aquí las bacterias, virus y parásitos patógenos, toxinas naturales, toxinas microbianas, metabólicos tóxicos de origen microbiano.

2. Peligros químicos: pesticidas, herbicidas, contaminantes inorgánicos tóxicos, antibióticos, promotores de crecimiento (hormonas), aditivos alimentarios tóxicos, lubricantes y tintas. Se produce una contaminación directa del alimento con substancias químicas prohibidas o ciertos metales como mercurio o productos químicos que pueden causar intoxicación aguda en cantidad elevada o que pueda causar daños y perjuicios a consumidores más sensibles. 
3. Peligros físicos: fragmentos de vidrio, metal y madera u otros objetos que puedan causar daño físico al consumidor. Se produce cuando objetos extraños y fragmentos causan lesiones o daños al consumidor, como piedras, vidrios, agujas, metales y objetos cortantes, constituyendo un riesgo a la vida del consumidor.

\section{$>$ Principios del HACCP}

Para aplicar correctamente el sistema HACCP es muy importante conocer las definiciones y el significado exacto de los principios del HACCP.

Principio 1: Conducción del análisis de peligros. Consiste en la preparación de una lista de todas las etapas del proceso donde ocurran peligros significativos (biológicos, químicos y físicos) y la descripción de las medidas preventivas, de esta forma controlar si los peligros pueden eliminarse o reducirse a los niveles aceptables para la producción de alimentos inocuos. Los peligros de baja probabilidad y baja severidad de ocurrencia no deben de ser manejados por el sistema HACCP, sino a través de las prácticas de manufactura.

Principio 2: Determinación de los puntos críticos de control (PCC). Se define un punto crítico de control (PCC) como "la etapa en la que puede aplicarse un control y que es esencial para prevenir o eliminar un peligro relacionado con la inocuidad de los alimentos y reducirlo hasta un nivel aceptable”. Si se identifica un peligro en una etapa en la que el control es necesario para mantener la inocuidad y no existe ninguna medida de control que pueda adoptarse en esta etapa o en cualquier otra, el producto o el proceso deberá modificarse en esta etapa, o en cualquier etapa anterior o posterior, para incluir en una medida de control.

Principio 3: Definición de los límites críticos. Para cada punto crítico de control (PCC) deben de establecerse y especificarse límites críticos. Se definen límites críticos como criterios de control que separa lo aceptable de lo inaceptable. Un límite crítico representa los valores absolutos que se usan para juzgar si la operación suministra productos seguros. Pueden ponerse límites críticos para los parámetros tales como temperatura, tiempo, 
dimensiones físicas, actividad de agua, nivel de humedad, etc. Estos parámetros, si se mantienen dentro de los límites, confirmarán la inocuidad del producto.

Principio 4: Establecer un sistema de vigilancia para el control de los PCC. La vigilancia es la medida programada de observación de un PCC, para determinar si están respetándose los límites críticos. Los procedimientos supervisados deben de determinar la pérdida de control del PCC a tiempo, para prevenir la producción de un alimento no apto o retenerlo. Debe de especificarse totalmente cómo, cuándo y por quién se realizarán los controles.

Principio 5: Establecer las acciones correctivas que han de adoptarse cuando la vigilancia indica que un determinado PCC no está controlado. La pérdida de control es considerada como una desviación del límite crítico de un PCC. Los procedimientos de corrección son un conjunto predeterminado y documentado de acciones que deben de llevarse a cabo cuando una desviación ocurre. Todas las desviaciones deben de ser controladas mediante acciones establecidas para controlar el producto no-conforme y corregir la causa de la desviación.

Principio 6: Establecer procedimientos de verificación para confirmar que el sistema HACCP funciona eficazmente. Consiste en aplicación de métodos, procedimientos, pruebas, análisis y otras evaluaciones, las cuales además de vigilar, sirven para determinar si el sistema HACCP está trabajando correctamente.

Principio 7: Establecer un sistema de documentación sobre todos los procedimientos y los registros apropiados para estos principios y su aplicación. Un registro muestra la historia del proceso, los controles, las desviaciones y las acciones correctivas (incluso la disposición del producto) que ocurrieron al PCC identificado. Ellos son esenciales para verificar la suficiencia del plan y la adhesión del sistema HACCP al plan.

\section{HACCP ofrece un número de ventajas sobre el sistema actual}

1. Es un planteamiento sistemático para la identificación, valoración y control de los riesgos. 
2. Evita múltiples debilidades inherentes al enfoque de la mera inspección y los inconvenientes que presenta la confianza en el análisis microbiológico.

3. Ayuda a establecer prioridades.

4. Permite planificar como evitar problemas en vez de esperar que ocurran para controlarlos.

5. Elimina el empleo inútil de recursos en consideraciones extrañas y superfluas, al dirigir directamente la atención al control de los factores claves que intervienen en la sanidad y en la calidad en toda cadena alimentaria, resultando más favorables las relaciones costo/ beneficio.

6. Por esta misma razón:

a. Los inspectores gubernamentales, el productor, el fabricante y el consumidor final del alimento pueden estar seguros de que se alcanzan y se mantienen en los niveles deseados de sanidad y calidad.

b. La administración puede dirigir sus esfuerzos hacia otros artículos y operaciones sobre los que no ejerce un control adecuado, con la economía que ello supone.

7. El sistema es aplicable a todos los eslabones de la cadena alimentaria, desde la producción, pasando por el procesado, transporte y comercialización, hasta la utilización final en los establecimientos dedicados a la alimentación o en los propios hogares.

8. A las compañías de los alimentos les ayuda a competir con más eficacia en el mercado mundial.

\subsubsection{Evaluación del plan HACCP en el proceso de elaboración de una bebida natural a base de sanky:}

1. Recepción y almacenamiento de insumos: se deberá evitar golpear los insumos, ya que fácilmente se pueden estropear por la zona del golpe si estuviesen almacenadas algunos 
días. El almacenamiento de los insumos debe de hacerse en un lugar fresco, de humedad media, y de forma que no gravite mucho peso sobre el insumo.

El almacenamiento no debe de prolongarse más de quince días, en condiciones normales: deberá realizarse en jabas esterilizadas dentro del almacén de insumos.

2. Pesado, selección y transporte al área de lavado: se deberá pesar la fruta que coincida con la cantidad requerida por el lote. Se separarán los frutos que no son adecuados para la elaboración de la bebida, ya que una selección óptima permitirá el buen aprovechamiento de la fruta, lo que contribuirá beneficiosamente al proceso debido a sus características organolépticas. El peso desechado será reemplazado por nuevas frutas seleccionadas y será llevado al área de lavado.

3. Lavado: Se procederá al lavado de la fruta con agua potable a temperatura ambiente, a la cual se le agregará un desinfectante. En esta etapa se observará que la fruta flota, por lo que se recomienda remojarla agitándola constantemente. Luego de la inmersión, se enjuaga los frutos una vez más con agua potable para así eliminar cualquier residuo del germicida o suciedad.

4. Corte y pelado: Se procederá al corte y extracción de la pulpa gomosa, que será insumo principal de la bebida.

5. Pesado: Una vez obtenida toda la pulpa, se colocará en recipientes de acero inoxidable, y se procederá al pesado y futura conservación de la misma, para ser utilizada en el siguiente paso.

6. Licuado y filtrado: Una vez obtenida la pulpa, se procederá a agregarle agua y edulcorante. Una vez agregados estos productos, se continúa con el licuado de la mezcla para luego pasar al colado con el fin de retirar todos los residuos, producto de las pepas que contiene la pulpa. 
7. Embotellado: Posteriormente al filtrado el producto, se introducirá el líquido en los envases con el producto caliente, a no menos de $85^{\circ} \mathrm{C}$, para lograr el envasado al vacío.

8. Sellado / Enroscado: Se realizará inmediatamente después de rellenar los recipientes con las tapas adquiridas.

9. Etiquetado: Luego de que las botellas se encuentran correctamente selladas, se procede a la colocación de la etiqueta, que contendrá toda la información resaltante del producto.

\section{Control de calidad}

Una vez culminado el proceso detallado anteriormente, se realizará una elección aleatoria de las botellas para comprobar si el producto cumple o no con todas las exigencias requeridas antes de su salida al mercado.

\section{Empaquetado y almacenamiento}

Se procederá a empaquetar por doce unidades para su posterior almacenamiento, en lugares secos a temperatura ambiente ${ }^{28}$.

\subsubsection{ISO 14000}

Las normas ISO 14000 son una familia de normas que persiguen establecer herramientas sistemas para la administración de numerosas obligaciones ambientales de una organización sin prescribir que metas debe de alcanzar.

Se debe de tener presente que las normas estipuladas por ISO 14000 no fijan metas ambientales para la prevención de la contaminación, ni tampoco se involucran en el desempeño ambiental a nivel mundial; sino que, establecen herramientas de sistemas enfocadas a los procesos de producción al interior de una empresa u organización y de los efectos o externalidades que de estos deriven al medio ambiente.

\footnotetext{
${ }^{28}$ Fuente: file:///G:/PGA/TESIS\%20VARIAS-\%20GUIAS/69.0361.AL.pdf y elaboración propia
} 
ISO 14000 se ocupa de la manera en que la empresa desarrolla sus actividades, y no se ocupa, al menos de manera directa, del resultado de dichas actividades. Es decir, se involucra con los procesos y no con los productos de la empresa. Indudablemente, la manera en que la empresa gestiona sus procesos afectará el producto final. En este contexto, el sistema de gestión ambiental permitirá asegurar que se ha hecho todo lo necesario para minimizar el impacto adverso sobre el medio ambiente al tomar consideración de la incidencia sobre los recursos naturales y la contaminación ambiental durante los procesos productivos y el ciclo de vida del producto, incluyendo su destino final.

Las normas ISO 14000 son normas voluntarias y genéricas, pues la empresa decide libremente sobre su adopción y se aplican a cualquier organización, grande o pequeña, cualquiera sea su producto o servicio, en cualquier sector de la actividad y tanto si se trata de una empresa privada, como de la administración pública.

Muchas empresas toman conciencia, unas más que otras, del impacto frente al medio ambiente, por lo que asumen un compromiso frente a la gestión ambiental. El éxito de esto en una organización requiere dos factores imprescindibles: en primer lugar, el compromiso de todo el personal de la organización, desde el nivel más alto. En segundo lugar, disponer de una herramienta de gestión sistemática que interactue dentro del modelo de gestión empresarial de la gestión empresarial de la organización: por ejemplo, la norma ISO 14001

\subsubsection{ISO 14001}

El documento ISO 14001 llamado también sistema de administración ambientalEspecificación con guía para uso A, es el de mayor importancia en la serie ISO 14000, dado que esta norma establece los elementos del SGA (Sistema de Gestión Ambiental) exigidos para que las organizaciones cumplan a fin de lograr su registro o certificación después de pasar una auditoría de un tercero debidamente registrado. En otras palabras, si una 
organización desea certificar o registrarse bajo la norma ISO 14000 es indispensable que dé cumplimiento a lo estipulado en ISO 14001.

Se debe de tener en cuenta que el sistema de gestión ambiental (SGA) forma parte de la administración general de una empresa, en ese sentido el SGA debe incluir:

En primer lugar, los elementos del sistema de control los describe la norma como:

-Compromiso de la dirección y política ambiental.

-Metas y objetivos ambientales.

-Programa de control ambiental, integrado por procesos, prácticas, procedimientos y líneas de responsabilidad.

En segundo lugar, auditoría y acción correctiva, cuya función radica en la entrega de información periódica (registros) que permite la realización de revisiones administrativas y asegurar que el SGA funcione correctamente.

Por último, revisión administrativa, que es la función ejecutada por la gerencia con el objeto de determinar la efectividad del SGA. Mejoría constante, esta etapa permite asegurar que la organización cumple sus obligaciones ambientales y protege el medio ambiente. Por lo tanto se puede concluir que las ISO 14001 tienen aplicación en cualquier tipo de organización, independiente de su tamaño, rubro y ubicación geográfica.

\section{Principales beneficios de la ISO 14000:}

$\checkmark$ Mejora de la imagen corporativa frente a los organismos reguladores, los clientes y público en general.

$\checkmark$ Cumplimiento de la legislación para los gobiernos; las normas internacionales proporcionan las bases tecnológicas y científicas que sostienen la salud, la legislación sobre seguridad y calidad medio ambiental.

$\checkmark$ Mejor relación con los organismos ambientales. 
$\checkmark$ Control de accidentes y de los pasivos ambientales.

$\checkmark$ Mejor control de costos. Reduce el costo de la administración de residuos, promueve el ahorro en el consumo de energía y materiales, y disminuye los costos de distribución.

$\checkmark$ Mejor relación con la comunidad. Para los consumidores, la conformidad de productos y servicios a las normas internacionales proporciona el aseguramiento de la calidad, seguridad y fiabilidad. Para cada uno, las normas internacionales pueden contribuir a mejorar la calidad de vida en general asegurando que el transporte, la maquinaria e instrumentos que se usan sean sanos y seguros.

$\checkmark$ Para las empresas, la adopción de las normas internacionales facilita a los proveedores basar el desarrollo de sus productos en el contraste de amplios datos de mercado de sus sectores, permitiendo así a los industriales concurrir cada vez más libremente y con eficacia en muchos más mercados del mundo.

$\checkmark$ Mayor participación de los empleados.

$\checkmark$ Contribución al esfuerzo de conservar el medio ambiente.

\subsubsection{Aplicación de las normas iso 14000 en una planta procesadora de bebidas naturales}

1. Autoevaluación inicial de la gestión ambiental: se realizará una autoevaluación la cual permitirá saber la posición en la que se encuentra la empresa a fin de desarrollar un SGA.

2. Organización: la empresa no tiene una producción muy elevada que justifique la creación de un departamento encargado exclusivamente de la gestión ambiental, es por ello que el jefe de producción se hará cargo del SGA durante el proceso de elaboración. 
3. Descripción del proceso productivo: es de vital importancia describir los pasos de proceso productivo, puesto que es aquí donde mejor se puede apreciar algunos elementos y factores que impactan el medio ambiente, que es precisamente lo que tenemos que tener claro antes de establecer y desarrollar el sistema de gestión ambiental (SGA).

4. Política ambiental de la empresa: la empresa se compromete al cumplimiento de la ley general de bases del medio ambiente y cualquier otra ley o normativa que regule el medio ambiente, para eso se propone instaurar un sistema de gestión ambiental que será revisado periódicamente cumpliendo a cabalidad el concepto de mejoramiento continuo aplicándolo en todos sus procesos productivos. Se mantendrá información actualizada de todos los documentos medio ambientales que sean de utilidad para los fines que se ha propuesto. En la medida del alcance económico de la empresa, se irá renovando la maquinaria y equipo y haciendo las mejoras correspondientes a todas las áreas de la planta y de esta manera asegurar un entorno de seguridad laboral a todos los empleados de la empresa. Se favorecerá y fomentará la capacitación y entrenamiento a todos los miembros de la organización. La empresa estimulará al personal para que la basura que se elimine tenga un proceso previo que asegure su reciclaje.

\section{Problemas y acciones preventivas del impacto ambiental}

a. Eliminación de residuos sólidos: los deshechos producidos por la planta procesadora de bebidas naturales son completamente orgánicos (cáscaras y fruta descompuestas). Para evitar la contaminación del aire, los desechos de la planta serán destinados a la elaboración de fertilizante orgánico, que es muy utilizado en la agricultura. Todo residuo potencialmente reciclable o valorizable deberá ser destinado a estos fines, evitando su eliminación en todos los casos posibles.

b. Eliminación de residuos líquidos: para disminuir la carga de estos residuos se utlizará la cantidad necesaria de agua. Esta agua puede ser reciclada por métodos de sedimentación, 
foltación con aire o tamices. Las aguas con altos contenidos orgánicos solubles y sólidos se destinarán como alimento para animales o fertilizante orgánico.

c. Uso de detergentes: el uso de detergentes crea un grave problema en el tratamiento de aguas residuales ya que contiene un agente tenso activo que disminuye la tensión superficial del agua, facilitando la formación de espuma e impidiendo su descomposición por la acción bacteriana. Es por eso que se deben de utilizar detergentes que tienen sustitutos de ese agente con la misma actividad y con la ventaja de que puedan ser descompuestos por las bacterias.

d. Aguas residuales: la eliminación de esta agua no tiene mayor impacto ambiental ya que no se empleará sustancias químicas ni desechos peligrosos que puedan dañar el ecosistema. Toda la instalación de las cañerías y las tuberías de eliminación de las aguas residuales (incluidos los sistemas de alcantarillados) deberán ser suficientemente grandes para soportar cargas máximas. Todas las conexiones deberán ser estáticas y disponer de trampas y respiraderos adecuados. La eliminación de aguas residuales se efectuará de tal modo que no pueda contaminarse con el suministro de agua potable. La instalación de cañerías y la forma de eliminación de las aguas residuales deben ser aprobadas por el correspondiente organismo oficial competente..$^{29}$

\subsection{Identificación del marco legal}

\subsubsection{Ordenamiento jurídico de la empresa}

Se formará una empresa SAC (Sociedad Anónima Cerrada) y estará conformada por 04 socios que participaran de forma activa en la administración, gestión y representación social.

a. Las características de este tipo de sociedad son las siguientes:

- Constituido por 2 hasta 20 accionistas.

\footnotetext{
${ }^{29}$ Fuente: file:///G:/PGA/TESIS\%20VARIAS-\%20GUIAS/69.0361.AL.pdf y elaboración propia.
} 
- $\quad$ El accionista que desee transferir sus acciones a otro accionista o a terceros debe comunicarlo a la sociedad y solicitar la aprobación de la misma.

b. Estará regido por los siguientes Órganos:

Junta general de Accionistas.

Directorio, el nombramiento del mismo es facultativo.

Gerencia.

c. Los aportes pueden ser en moneda nacional y/o extranjera, en contribuciones tecnológicas intangibles.

d. El capital es representado por acciones y deberá estar suscrito completamente y cada acción pagada por lo menos en un $25 \%$.

e. El patrimonio personal de los socios no está afecto.

f. El artículo 234 de la Ley General de Sociedades señala expresamente que la sociedad anónima cerrada no tiene acciones inscritas en el Registro Público del Mercado de Valores y que no se puede solicitar la inscripción en dicho Registro de las Acciones de esta modalidad de sociedad anónima.

g. Una vez realizada la minuta de constitución de la empresa, ésta será presentada a una notaría pública, la cual la elevará a escritura pública para poder ingresarla a Registros Públicos y conste la inscripción de la sociedad. Luego, se tramitará el registro único de contribuyentes en la SUNAT. 


\section{Capítulo VI}

\section{ASPECTOS ORGANIZACIONALES}

\subsection{Caracterización de la cultura organizacional deseada}

\subsubsection{Visión}

“Ser reconocidos como la empresa peruana líder en bebidas naturales con los mejores beneficios para la salud"

\subsubsection{Misión}

Ofrecer bebidas naturales de alta calidad, aplicando los mejores estándares tecnológicos de producción, para destacar sus propiedades; contribuyendo con mejorar la salud y calidad de vida de los clientes, en donde destaque la total identificación del personal.

\subsubsection{Principios}

\subsubsection{Responsabilidad}

Realizar las actividades con eficiencia y eficacia, cumpliendo estrictamente las normas y directivas impartidas.

\subsubsection{Conciencia Social}

Estar constantemente relacionada con la comunidad, buscando conciliar el crecimiento de la empresa con el desarrollo de la sociedad a la cual se sirve.

\subsubsection{3. Ética Empresarial y Personal}

Se debe de actuar con respeto a las normas, con transparencia y honestidad, en concordancia con los lineamientos de la empresa. No transgredir las normas. 


\subsubsection{Compromiso}

En cumplir satisfactoriamente con los estándares de calidad en los productos.

\subsubsection{Respeto}

Los clientes son lo más importante para la empresa, por ello, se actuará de manera transparente brindándole un trato cordial y un ambiente seguro.

\subsection{Formulación de estrategias del negocio}

Diferenciación por atributos o características del producto.

\subsection{Determinación de las ventajas competitivas críticas}

La diferenciación del producto se encuentra en el insumo principal, el sanky fruto que produce una serie de beneficios para la salud que hará de este producto una bebida diferente a las existentes en el portafolio del mercado. En la actualidad, existen una serie de bebidas envasadas cuya máxima contribución a la salud es la hidratación a través de la ingesta de electrolitos, o la estimulación al correcto funcionamiento del sistema digestivo a través del té verde.

El producto, a través del sanky, permitirá al consumidor obtener un alto contenido de vitamina "C", calcio, fósforo, magnesio, potasio y gomas naturales, propiedades beneficiosas para el organismo humano; el sanky disminuye el hambre y regula la sed, dado su alto contenido de fibra, posee propiedades curativas y es considerado un antioxidante natural. En la actualidad este producto es único y original en el mercado, lo que permite ser distinguidos entre las bebidas naturales producidas a base de otras frutas y de algunos productos naturales con propiedades medicinales hechos a base de sanky. 
6.4. Diseño de la estructura organizacional deseada

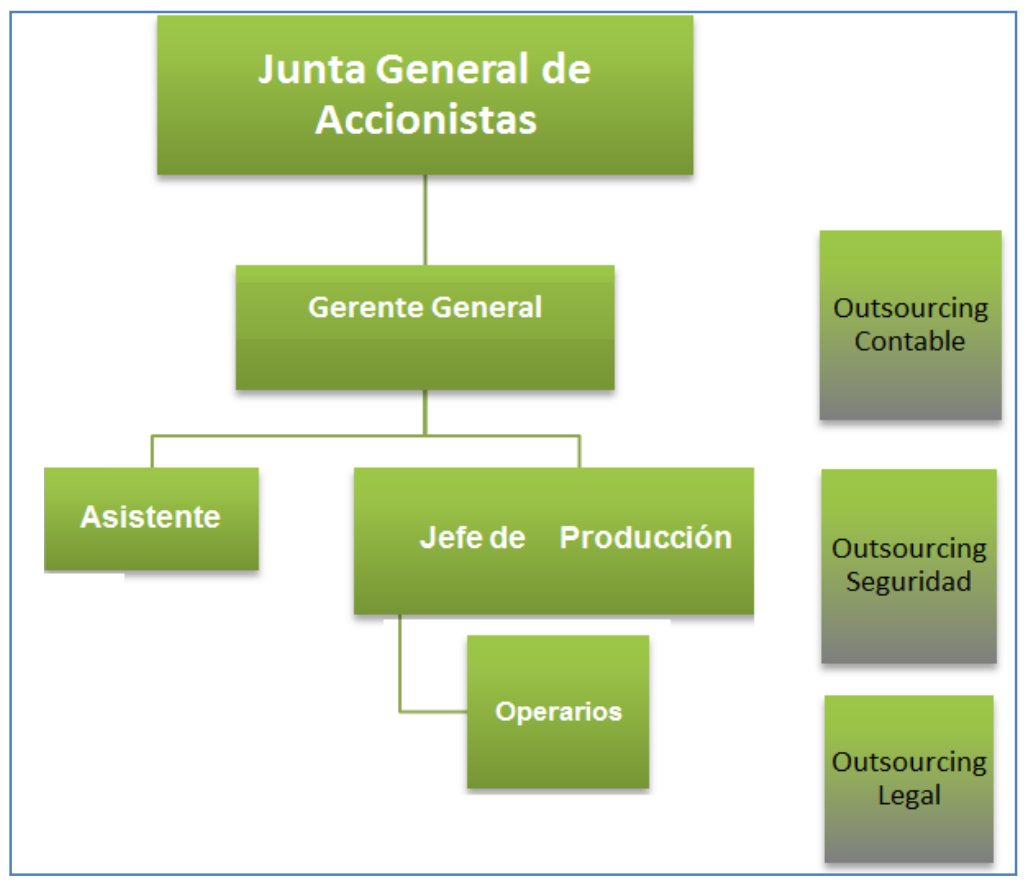

Figura 66. Estructura Organizacional.

Fuente: Elaboración propia. 


\subsection{Diseño de los perfiles de puestos clave}

Tabla 62

Perfil del Gerente General

Posición:

$$
\text { Área }
$$

\section{GERENTE GENERAL}

Ubicación

$$
\begin{aligned}
& \text { Administrativa y } \\
& \text { Operativa }
\end{aligned}
$$

Reporta a:

Junta General

\section{Objetivo:}

Dirección y Administración

Funciones:

Dirigir, coordinar, supervisar y dictar normas para el eficiente desarrollo de las actividades de "Frutos nativos del Sur S.A.C."

Representar a la Empresa como persona jurídica y autorizar con su firma los actos y contratos en que ella tenga que intervenir.

Ordenar los gastos, reconocer y disponer los pagos a cargo de la Empresa.

Distribuir la planta global de personal y crear los grupos internos de trabajo que considere necesarios para el cumplimiento de las funciones propias de la empresa.

Ejercer las demás funciones que le señale o delegue la Junta

Directiva, las normas legales y aquellas que por su naturaleza le correspondan como Funcionario Directivo.

Maneja directamente las áreas de Marketing, Ventas y comercialización.

Personal a Cargo:

Relaciones Internas: Relaciones Externas:

\section{Perfil Técnico}

Supervisor de Administración y Ventas, Supervisor de Producción.

Con el Personal Administrativo, Ventas y Producción. Con Clientes y Proveedores.

- Administrador con experiencia en cargos similares, en Gerencia General de empresas industriales -Optimizar y planificar los recursos productivos de la empresa para obtener un crecimiento progresivo de la productividad a la vez que se respetan los condicionantes y especificaciones de calidad

- Conocimiento Leyes Laborales

- Conocimiento intermedio de Contabilidad

- Manejo de Presupuesto / Finanzas

- Integración y dirección de equipos de trabajo.

- Manejo de conflictos

Perfil de Competencia: - Liderazgo

- Socialización y comunicación.

Fuente: Elaboración propia. 
Tabla 63

Perfil del Jefe de Producción

\section{Posición: JEFE DE PRODUCCIÓN}

Ubicación

Área de Producción

Reporta a:

Gerente

General

Objetivo: Desarrollar la producción de la empresa.

Funciones:

periódica:

-Responsabilidad sobre el funcionamiento del área productiva de la empresa y sobre el cumplimiento de los objetivos y políticas establecidas por el Gerente General.

-Optimizar y planificar los recursos productivos de la empresa para obtener un crecimiento progresivo de la productividad a la vez que se respetan los condicionantes y especificaciones de calidad.

-Organización y seguimiento de la ejecución de todos los trabajos dentro del ciclo de producción garantizando que, individualmente, cumplen con las especificaciones establecidas en el sistema de calidad.

-Seguimiento de la evolución tecnológica analizando la aplicabilidad en la propia empresa y estudiando la posible rentabilidad de su utilización.
Permanente

Permanente

Permanente
Todo el personal de producción, con el área administrativa y de Ventas.

Relaciones Externas: Proveedores y Clientes.

-Técnico Operador de Procesos de Industria Alimentaria, egresado de Instituto superior (Senati).

El Operador de Procesos de la Industria Alimentaria está en capacidad de realizar funciones de abastecimiento, operación, verificación y control de los procesos de producción industrial, aplicando normas técnicas, estándares de calidad, normas de higiene, seguridad en el trabajo y cuidado del medio ambiente.

Perfil de Competencia: Comunicativo.

Fuente: Elaboración Propia 
Tabla 64

Perfil del Operario de Producción

\section{Posición: OPERARIO DE PRODUCCION}

Ubicación Área de Producción Reporta a: Jefe de Producción

Objetivo: Desarrollar la producción de la empresa.

Funciones:

Clasificar y ordenar la materia prima.

Realizar el proceso productivo a través del uso y

control de la maquinaria Industrial.

Empaquetado del producto para ser trasladado y distribución.

\section{periódicas:}

Permanente

Permanente

Permanente
Relaciones Internas
Con el responsable de producción y con los operarios de producción.
Relaciones Externas: No tiene.
Estudios secundarios o técnicos.
Perfil Técnico Conocimientos de producción de bebidas.
Conocimientos de almacenaje.
Capacidad de trabajar en equipo.
Perfil de Competencia: Destrezas manuales finas.
Organizado y responsable.

Fuente: Elaboración propia

Tabla 65

Modulo de cuantificación de operarios

\begin{tabular}{llllllll}
\hline Año & $\begin{array}{c}\text { Demanda } \\
\text { (botellas) }\end{array}$ & $\begin{array}{l}\mathbf{N}^{\circ} \text { horas } \\
\text { anuales }\end{array}$ & $\begin{array}{l}\text { Producción } \\
\text { Botellasxhr }\end{array}$ & Eficiencia & $\begin{array}{l}\text { Producción } \\
\text { Botellasxhr }\end{array}$ & $\begin{array}{l}\text { Prod } \\
\text { Minima } \\
\text { x operario }\end{array}$ & $\begin{array}{l}\mathbf{n}^{\circ} \\
\text { operarios }\end{array}$ \\
\hline 2017 & 232,482 & 2496 & 93.14 & 0.99 & 94 & 51 & 2 \\
2018 & 235,205 & 2496 & 94.23 & 0.99 & 95 & 51 & 2 \\
2019 & 237,927 & 2496 & 95.32 & 0.99 & 96 & 51 & 2 \\
2020 & 240,650 & 2496 & 96.41 & 0.99 & 97 & 51 & 2 \\
2021 & 243,372 & 2496 & 97.50 & 0.99 & 98 & 51 & 2 \\
\hline
\end{tabular}

Fuente: Elaboración propia 
Tabla 66

Perfil del Asistente

\section{Posición: ASISTENTE}

Ubicación Área de Administración Ventas y

Reporta a: Gerente General

Objetivo: Realizar el proceso de Asistencia y apoyo a la Oficina de Administración y al Área de ventas de la empresa.

\section{Funciones:}

Colabora con el desarrollo de las actividades logísticas y de abastecimiento de la empresa. Coordina las actividades de administración y brinda apoyo directo al área de ventas.

\section{Relaciones Internas}

Relaciones Externas:

Perfil Técnico

Perfil de Competencia: periódica:

Permanente

Permanente

Personal de Administración y ventas, personal de producción.

No tiene.

Estudios Técnicos de administración, Contabilidad

Proactivo, Responsable, Servicial, Capacidad para trabajo bajo presión.

Fuente: Elaboración propia

\subsection{Remuneraciones, compensaciones e incentivos}

a. Remuneración del personal

Tabla 67

Cuadro de Mano de Obra Directa

\begin{tabular}{llllll}
\hline Concepto & $\mathbf{2 0 1 7}$ & $\mathbf{2 0 1 8}$ & $\mathbf{2 0 1 9}$ & $\mathbf{2 0 2 0}$ & $\mathbf{2 0 2 1}$ \\
\hline $\begin{array}{l}\text { Operarios } \\
\begin{array}{l}\text { Sueldo Bruto mensual x } \\
\text { operario }\end{array}\end{array}$ & $\mathrm{S} / 930.00$ & $\mathrm{~S} / 930.00$ & $\mathrm{~S} / 930.00$ & $\mathrm{~S} / 930.00$ & $\mathrm{~S} / 930.00$ \\
Gratificaciones x operario & $\mathrm{S} / 71.52$ & $\mathrm{~S} / 71.52$ & $\mathrm{~S} / 71.52$ & $\mathrm{~S} / 71.52$ & $\mathrm{~S} / 71.52$ \\
CTS x operario & $\mathrm{S} / 38.78$ & $\mathrm{~S} / 38.78$ & $\mathrm{~S} / 38.78$ & $\mathrm{~S} / 38.78$ & $\mathrm{~S} / 38.78$ \\
Vacaciones x operario & $\mathrm{S} / 38.73$ & $\mathrm{~S} / 38.73$ & $\mathrm{~S} / 38.73$ & $\mathrm{~S} / 38.73$ & $\mathrm{~S} / 38.73$ \\
Essalud x operario & $\mathrm{S} / 83.70$ & $\mathrm{~S} / 83.70$ & $\mathrm{~S} / 83.70$ & $\mathrm{~S} / 83.70$ & $\mathrm{~S} / 83.70$ \\
Total mensual & $\mathrm{S} / 2,325.47$ & $\mathrm{~S} / 2,325.47$ & $\mathrm{~S} / 2,325.47$ & $\mathrm{~S} / 2,325.47$ & $\mathrm{~S} / 2,325.47$ \\
TOTAL ANUAL MOD & $\mathrm{S} / \mathbf{2 7 , 9 0 5 . 5 2}$ & $\mathbf{S} / \mathbf{2 7 , 9 0 5 . 5 8}$ & $\mathbf{S} / \mathbf{2 7 , 9 0 5 . 5 8}$ & $\mathbf{S} / \mathbf{2 7 , 9 0 5 . 5 8}$ & $\mathbf{S} / \mathbf{2 7 , 9 0 5 . 5 8}$ \\
\hline
\end{tabular}

Fuente: Elaboración propia 
Tabla 68

Cuadro de Mano de Obra Indirecta

\begin{tabular}{|c|c|c|c|c|c|}
\hline Concepto & 2017 & 2018 & 2019 & 2020 & 2021 \\
\hline Jefe de Producción & 1 & 1 & 1 & 1 & 1 \\
\hline Sueldo Neto mensual & $\mathrm{S} / 3,000.00$ & $\mathrm{~S} / 3,000.00$ & $\mathrm{~S} / 3,000.00$ & $\mathrm{~S} / 3,000.00$ & $\mathrm{~S} / 3,000.00$ \\
\hline Gratificaciones mensual & $\mathrm{S} / 230.70$ & $\mathrm{~S} / 230.70$ & $\mathrm{~S} / 230.70$ & $\mathrm{~S} / 230.70$ & $\mathrm{~S} / 230.70$ \\
\hline CTS mensual & $\mathrm{S} / 125.10$ & $\mathrm{~S} / 125.10$ & $\mathrm{~S} / 125.10$ & $\mathrm{~S} / 125.10$ & $\mathrm{~S} / 125.10$ \\
\hline Vacaciones mensual & $\mathrm{S} / 124.95$ & $\mathrm{~S} / 124.95$ & $\mathrm{~S} / 124.95$ & $\mathrm{~S} / 124.95$ & S/ 124.95 \\
\hline Essalud mensual & S/ 270.00 & $\mathrm{~S} / 270.00$ & $\mathrm{~S} / 270.00$ & $\mathrm{~S} / 270.00$ & S/ 270.00 \\
\hline $\begin{array}{l}\text { Total mensual Jefe } \\
\text { producción }\end{array}$ & $\mathrm{S} / 3,751$ & $\mathrm{~S} / 3,751$ & $\mathrm{~S} / 3,751$ & $\mathrm{~S} / 3,751$ & $\mathrm{~S} / 3,751$ \\
\hline $\begin{array}{l}\text { Total Anual Jefe de } \\
\text { Producción }\end{array}$ & $S / 45,009$ & $\mathrm{~S} / \mathbf{4 5 , 0 0 9}$ & $\mathrm{S} / \mathbf{4 5 , 0 0 9}$ & $\mathrm{S} / \mathbf{4 5 , 0 0 9}$ & S/ 45,009 \\
\hline Limpieza & 1 & 1 & 1 & 1 & 1 \\
\hline Sueldo Neto mensual & $\mathrm{S} / 930.00$ & $\mathrm{~S} / 930.00$ & $\mathrm{~S} / 930.00$ & $\mathrm{~S} / 930.00$ & $\mathrm{~S} / 930.00$ \\
\hline Gratificaciones mensual & S/ 71.52 & S/ 71.52 & $\mathrm{~S} / 71.52$ & $\mathrm{~S} / 71.52$ & $\mathrm{~S} / 71.52$ \\
\hline CTS mensual & $\mathrm{S} / 38.78$ & S/ 38.78 & $\mathrm{~S} / 38.78$ & $\mathrm{~S} / 38.78$ & S/ 38.78 \\
\hline Vacaciones mensual & $\mathrm{S} / 38.73$ & S/ 38.73 & $\mathrm{~S} / 38.73$ & $\mathrm{~S} / 38.73$ & $\mathrm{~S} / 38.73$ \\
\hline Essalud mensual & $\mathrm{S} / 83.70$ & S/ 83.70 & $\mathrm{~S} / 83.70$ & $\mathrm{~S} / 83.70$ & $\mathrm{~S} / 83.70$ \\
\hline $\begin{array}{l}\text { Total mensual Jefe } \\
\text { producción }\end{array}$ & S/ 1,163 & S/ 1,163 & $\mathrm{~S} / 1,163$ & $\mathrm{~S} / 1,163$ & $\mathrm{~S} / 1,163$ \\
\hline Total Anual Limpieza & S/ 13,953 & $\mathrm{S} / \mathbf{1 3 , 9 5 3}$ & $\mathrm{S} / \mathrm{13,953}$ & S/ 13,953 & S/ 13,953 \\
\hline TOTAL ANUAL MOI & $\mathrm{S} / 58,961.76$ & $\mathrm{~S} / 58,961.76$ & $\mathrm{~S} / 58,961.76$ & $\mathrm{~S} / 58,961.76$ & $\mathrm{~S} / 58,961.76$ \\
\hline
\end{tabular}


Tabla 69

Cuadro de Gastos Administrativos

\begin{tabular}{|c|c|c|c|c|c|}
\hline Concepto & 2017 & 2018 & 2019 & 2020 & 2021 \\
\hline Gerente General & 1 & 1 & 1 & 1 & 1 \\
\hline Sueldo Neto mensual & $\mathrm{S} / 4,100.00$ & S/ 4100.00 & S/ 4100.00 & S/ 4100.00 & S/ 4100.00 \\
\hline Gratificaciones mensuales & $\mathrm{S} / 315.29$ & $\mathrm{~S} / 315.29$ & $\mathrm{~S} / 315.29$ & $\mathrm{~S} / 315.29$ & $\mathrm{~S} / 315.29$ \\
\hline CTS mensual & S/170.97 & S/ 170.97 & S/ 170.97 & S/ 170.97 & S/ 170.97 \\
\hline Vacaciones mensuales & S/170.77 & S/ 170.77 & S/ 170.77 & S/ 170.77 & S/ 170.77 \\
\hline ESSALUD mensual & $\mathrm{S} / 369.00$ & $\mathrm{~S} / 369.00$ & $\mathrm{~S} / 369.00$ & $\mathrm{~S} / 369.00$ & $\mathrm{~S} / 369.00$ \\
\hline $\begin{array}{l}\text { Total mensual Gerente } \\
\text { General }\end{array}$ & $\mathrm{S} / 5,126.03$ & S/ 5126.025 & S/ 5126.025 & S/ 5126.025 & S/ 5126.025 \\
\hline $\begin{array}{l}\text { Total Anual Gerente } \\
\text { General }\end{array}$ & $\mathrm{S} / 61,512$ & $\mathrm{~S} / 61512$ & S/ 61512 & S/ 61512 & S/ 61512 \\
\hline Asistente & 1 & 1 & 1 & 1 & 1 \\
\hline Sueldo Neto mensual & $\mathrm{S} / 1,500.00$ & $\mathrm{~S} / 1,500.00$ & $\mathrm{~S} / 1,500.00$ & $\mathrm{~S} / 1,500.00$ & $\mathrm{~S} / 1,500.00$ \\
\hline Gratificaciones mensuales & $\mathrm{S} / 115.35$ & $\mathrm{~S} / 115.35$ & $\mathrm{~S} / 115.35$ & $\mathrm{~S} / 115.35$ & $\mathrm{~S} / 115.35$ \\
\hline CTS mensual & $\mathrm{S} / 62.55$ & $\mathrm{~S} / 62.55$ & $\mathrm{~S} / 62.55$ & $\mathrm{~S} / 62.55$ & $\mathrm{~S} / 62.55$ \\
\hline Vacaciones mensuales & $\mathrm{S} / 62.48$ & $\mathrm{~S} / 62.48$ & $\mathrm{~S} / 62.48$ & $\mathrm{~S} / 62.48$ & $\mathrm{~S} / 62.48$ \\
\hline ESSALUD mensual & $\mathrm{S} / 135.00$ & $\mathrm{~S} / 135.00$ & $\mathrm{~S} / 135.00$ & $\mathrm{~S} / 135.00$ & $\mathrm{~S} / 135.00$ \\
\hline Total mensual Asistente & $\mathrm{S} / 1,875.38$ & $\mathrm{~S} / 1,875.38$ & $\mathrm{~S} / 1,875.38$ & $\mathrm{~S} / 1,875.38$ & $\mathrm{~S} / 1,875.38$ \\
\hline Total Anual Asistente & $\mathrm{S} / 22,505$ & $\mathrm{~S} / \mathbf{2 2 , 5 0 5}$ & $\mathrm{S} / 22,505$ & $\mathrm{~S} / \mathbf{2 2 , 5 0 5}$ & $\mathrm{S} / 22,505$ \\
\hline $\begin{array}{l}\text { Total Gastos } \\
\text { Administrativos }\end{array}$ & $\mathrm{S} / 84,016.92$ & $\mathrm{~S} / 84,016.92$ & $\mathrm{~S} / 84,016.92$ & $\mathrm{~S} / 84,016.92$ & $\mathrm{~S} / \mathbf{8 4 , 0 1 6 . 9 2}$ \\
\hline
\end{tabular}

Fuente: Elaboración propia 
b. Beneficios Sociales. Correspondientes a pequeña empresa.

Tabla 70

Beneficios Sociales

\begin{tabular}{ll}
$\begin{array}{ll}\text { Costos } \\
\text { Laborales }\end{array}$ & $\%$ \\
\cline { 1 - 1 } Gratificaciones & $7.69 \%$ \\
CTS & $4.17 \%$ \\
Vacaciones & $4.17 \%$ \\
Essalud & $9 \%$ \\
\cline { 1 - 2 } Fuente: Elaboración propia.
\end{tabular}

\subsection{Política de recursos humanos}

\subsubsection{Contrataciones}

a. Contrato Sujeto a Modalidad: Contrato de Naturaleza Temporal. Contrato bajo el periodo de 6 meses con derecho a renovación, con un tiempo de prueba de tres meses, con el fin de continuar con el personal adecuado y hacer algún cambio, si es que no se estuvieran cumpliendo con los objetivos propuestos. El contrato será por escrito. La duración máxima de un contrato de naturaleza temporal es de 3 años.

El contrato de Trabajo se registra ante el ministerio de trabajo dentro de los 15 días calendarios de su suscripción. Los servicios que percibe el trabajador subordinado, se considera renta de quinta categoría.

Sujetos:

Empleador (persona natural o jurídico)

Trabajador Subordinado (persona natural obligatoriamente)

Regirá para el Administrador, Supervisor de Ventas, Supervisor de Producción, Asistente y Operario de Producción. 
b. Contrato de Locación de Servicios

Para servicios prestados por Outsourcing Legal, Outsourcing Contable y Outsourcing de Seguridad. El periodo del contrato será de un año.

El locador servidor independiente no Figura en la planilla de Frutos Nativos del Sur S.A.C y cobra sus honorarios emitiendo el respectivo comprobante de pago (Recibos por Honorarios), autorizado por SUNAT.

El contrato de locación de servicios no se comunica ni registra ante el Ministerio de Trabajo (No tiene competencia en este tema).

Los honorarios del locador son rentas de cuarta categoría (trabajador independiente).

El Locador no tiene pago de derechos ni beneficios sociales. Tan sólo recibe su retribución (honorarios).

\subsubsection{Régimen Laboral y Beneficios Sociales}

Frutos Nativos del Sur S.A.C trabajará bajo el Régimen Laboral de las MYPES específicamente "Pequeña Empresa" esto es debido a que las ventas anuales superarán los $150 \mathrm{UIT}^{30}$ (Ventas por encima de S/ 622500)

Se reconocerá a los trabajadores lo siguiente:

- Remuneración Mínima S/ 75.

- Jornada 8 horas diarias

- Horas extras

- Descanso semanal y feriados.

- 15 días de vacaciones por año.

- Licencia por maternidad: 90 días.

- Indemnización por despido: 20 remuneraciones diarias por año, con el tope de 4 sueldos.

30 Disponible en: http://www.sunat.gob.pe/indicestasas/uit.html 
- Seguridad Social: Essalud obligatorio (9\%).

- Pensiones: AFP/ONP.

- CTS: 0.5 sueldo por año aproximadamente.

- Gratificaciones: 0.5 sueldo julio y 0.5 sueldo diciembre.

- Seguro complementario de trabajo de riesgo (dependiendo la actividad).

- Seguro de Vida Ley (a partir del 4 año).

- Derechos colectivos: sindicalización, negociación colectiva, huelga.

- Tienen, derecho a participar en las Utilidades ${ }^{31}$ de conformidad con el D.Leg 892 y su reglamento; el porcentaje de PTUE (participación de los trabajadores en las utilidades de la empresa) que corresponde es del $5 \%$.

El trabajador por su parte debe pagar los costos de su afiliación al sistema de pensión provisional de su elección: El estatal (ONP) o el particular de las Administradoras de Fondo de Pensiones (AFP). En el caso del Organismo Nacional de Pensiones, el estatal, el monto a pagar es del 13\% del sueldo bruto y en el caso de las AFP del 10\%, en el cual además deben adicionalmente pagar un seguro previsional de invalidez, sobrevivencia y sepelio y una comisión a su AFP, éstos últimos cargos varían de acuerdo a la competitividad de oferta de cada una de las AFP en el mercado, al final tanto el sistema privado como el estatal demandan casi el mismo costo al trabajador donde, desde el punto de vista de las AFP, la diferencia está en la calidad del servicio prestado.

Para el caso del Seguro de Vida Ley, seguro de vida creado por el Decreto Legislativo 688, de carácter obligatorio para los empleados y asegurados que prestan servicios a un mismo empleador por un lapso de 4 años y opcionalmente, para aquellos trabajadores que prestan servicios a un empleador a partir de los tres meses. Se considerará tomarlo para los empleados de Frutos Nativos del Sur S.A.C., quien estará a cargo del pago de este aporte, al

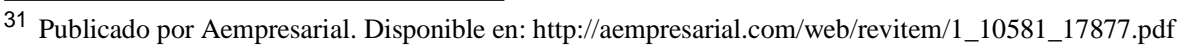


ser de menor cuantía y carga para la empresa y pensando en cubrir cualquier riesgo al que pudiera estar expuestos sus trabajadores.

\subsubsection{Horario de Trabajo}

Se establecerán los sgts. horarios:

- Personal Administrativo: Lunes a Viernes de 8am a 5pm y Sábados de 8 am a 12pm.

- Personal Producción: Lunes a Viernes de 8am a 5pm y Sábados de 8am a 12pm. 


\section{Capitulo VII}

\section{PLAN DE MARKETING}

\subsection{Estrategias de Marketing}

\subsubsection{Estrategia de Producto}

El producto bebida refrescante "Kawsay sankyfruit" está hecho a base de una fruta andina que se produce en el sur del país la cual está dotada de propiedades beneficiosas para la salud.

Se presentará en botella de plástico de 250 mililitros. Para el envasado se utilizará el procedimiento de envase al vacío, el cual consiste en el calentamiento del refresco que oscila entre 55 y 70 grados centígrados, luego se enfría con rapidez y se envasa a una temperatura de 10 grados centígrados, es un método efectivo para destruir las bacterias perjudiciales sin producir cambios materiales en la composición, en el sabor, o en el valor nutritivo del líquido.

$>\quad$ La palabra KAWSAY es un vocablo quechua que significa "VIDA"; por ello con el nombre "KAWSAY Sankyfruit" se desea transmitir una imagen de producto natural, sano y de raíz andina, a la vez que se intenta transmitir un mensaje de seguridad, de fácil recordación y de fácil de comunicación.

Etiqueta: Con colores de tono natural donde se indicará la información nutricional del producto, lugar de elaboración, nombre del productor y registro sanitario. En las Figuras siguientes se muestran las etiquetas ${ }^{32}$ :

$\overline{32 \text { Cumple con requisito NTP 203.110:2009 }}$ 


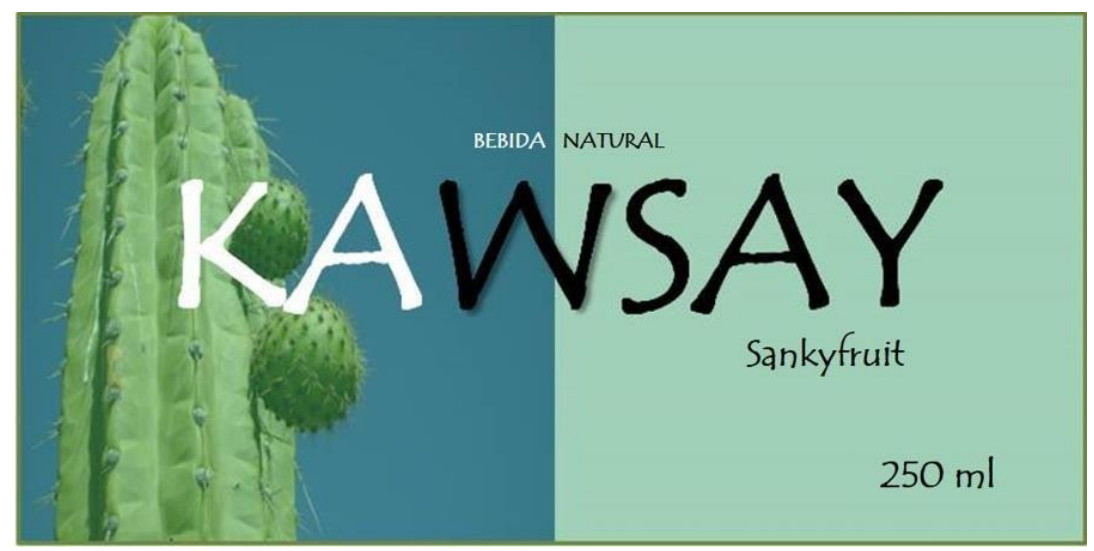

Figura 67. Etiqueta Cara 1

Fuente: Elaboración propia

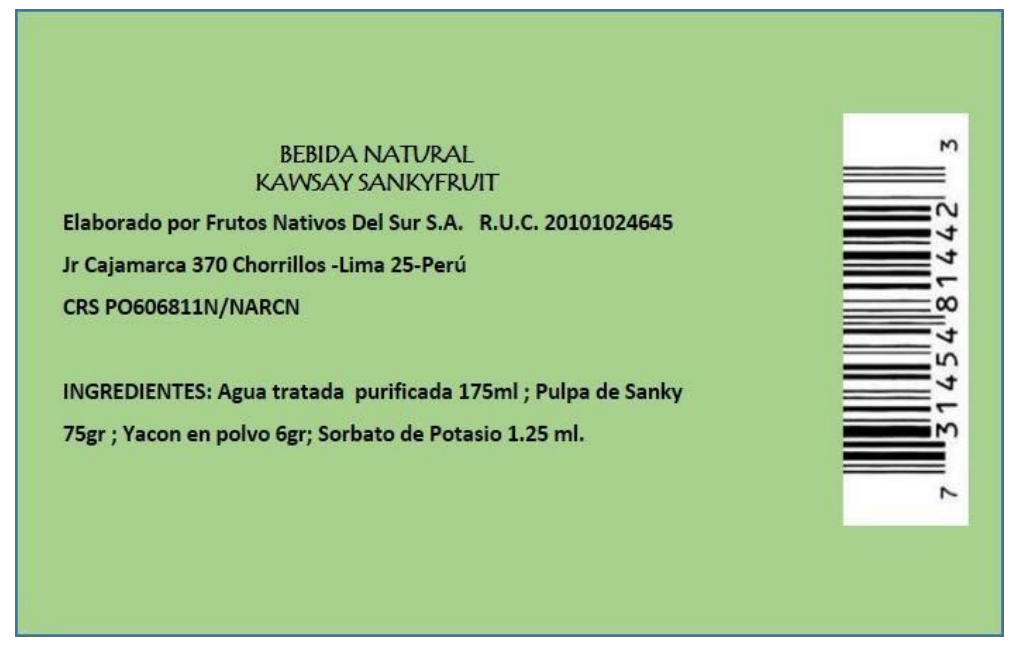

Figura 68. Etiqueta Cara 2.

Fuente: Elaboración propia

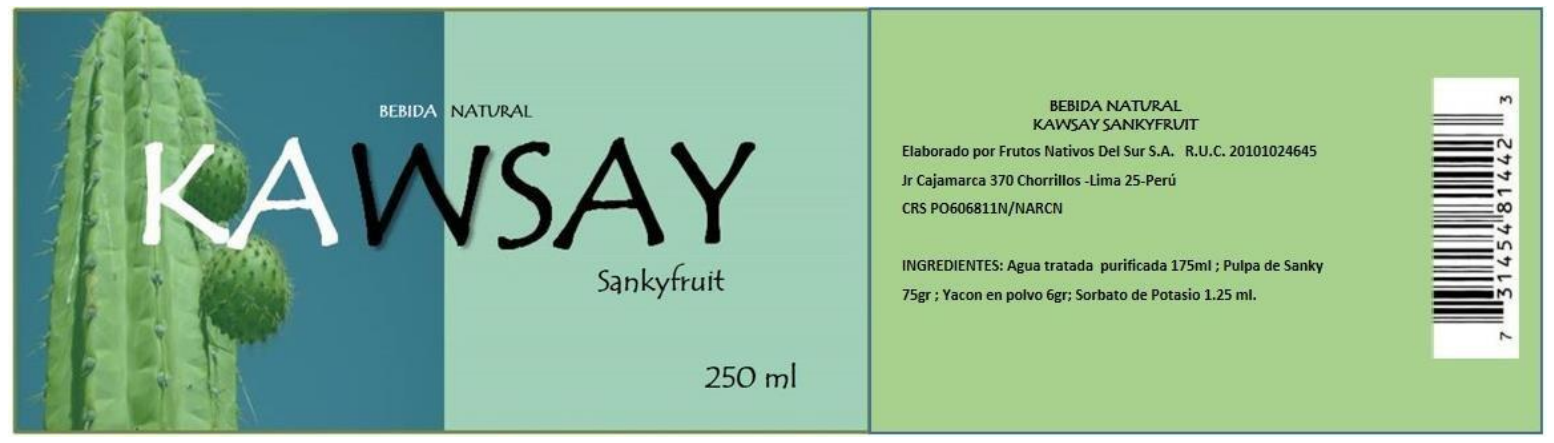

Figura 69. Etiqueta Completa.

Fuente: Elaboración propia 
Factores Nutricionales: Se hará especial énfasis en las propiedades de la fruta Sanky por su alto contenido de vitamina $\mathrm{C}$, potasio y antioxidantes, lo cual es recomendable para mantener la energía y adelgazar. Estas cualidades se reflejarán la característica más importante del refresco: las propiedades beneficiosas para la salud.

Imagen: Será innovadora, moderna, fresca con colores vivos que a la vez muestre que su contenido es natural.

Por lo antes mencionado se usará la estrategia de diferenciación, ya que no existen productos con todas las características mencionadas en el mercado.

Se elegirá un adecuado canal de distribución (moderno) y se realizará la difusión apropiada para dar a conocer los beneficios del fruto.

El producto se encuentra en la etapa de introducción en el mercado local, ya que el fruto no es muy conocido en la zona 7 de Lima lugar donde se realizará inicialmente la distribución; es por eso que se pondrán en marcha las estrategias para promocionarlo de modo que se pueda difundir las bondades del producto y lograr la captación real del mercado objetivo. En esta fase inicial del ciclo de vida del producto también es posible que no se obtenga rentabilidad ya que se reinvertirá con la finalidad de ganar participación de mercado.

\subsubsection{Estrategia de Precio}

a. Precio de la competencia al consumidor, al mayorista productor y su equivalencia con el producto del proyecto.

Los precios se dan de acuerdo al estilo de vida de los consumidores, pues actualmente ya no solo buscan una bebida que pueda refrescarlos, si no también buscan una bebida que cuide su organismo. Esta predisposición del público se incrementará a la par que los precios mostrarán una tendencia a la baja a medida que aumenten los consumidores, y los 
competidores contemplen la producción de productos con más ventajas competitivas adicionales.

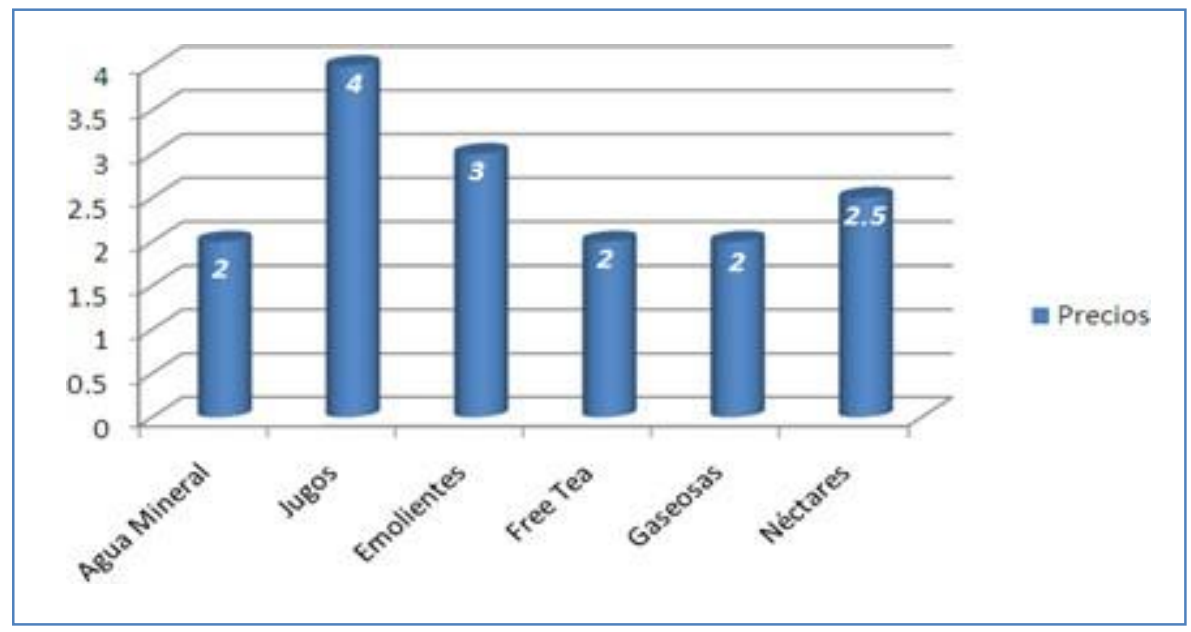

Figura 70. Precio de Bebidas Saludables (en S/)

Fuente: APEIM. Grifos y Farmacias de las zonas 7

Tabla 71

$\underline{\text { Resumen de Precios de la Competencia según Tamaño de Envase }}$

\begin{tabular}{lll}
\hline Producto & Presentación & Precio S/ \\
\hline Aloe Vera & $330 \mathrm{ml}$ & 5.60 \\
Jugos & $350 \mathrm{ml}$ & 4.50 \\
Selva & & 4.90 \\
Fourn\&nat & $300 \mathrm{ml}$ & 6.50 \\
Chia mas & $300 \mathrm{ml}$ & 2.49 \\
Free tea & $475 \mathrm{ml}$ & 4.90 \\
Frumas & $475 \mathrm{ml}$ & \\
\hline
\end{tabular}

Fuente: Elaboración propia

El consumidor evaluará los diferentes refrescos que se encuentran en el mercado y elegirá aquel que le ofrezca un mayor beneficio acompañado de un precio razonable. En ese sentido, evaluando los precios existentes en el mercado con bebidas con perfil natural y según el 
resultado de las encuestas, se estima un precio conveniente de $\mathrm{S} / 4.5$ por botella de $250 \mathrm{ml}$; precio con el cual se podrá cubrir los costos y obtener rentabilidad.

b. Costos unitarios del producto

Tomando como referencia la información proporcionada en el estudio técnico y considerando el alcance de la producción, los costos unitarios se muestran a continuación.

Tabla 72

Costo Unitario del Producto

\begin{tabular}{lrr}
\hline $\begin{array}{c}\text { Costos Unitarios x Botella } \\
\text { Materia Prima }\end{array}$ & \multicolumn{2}{c}{ Soles } \\
\hline Sanky & S/ & $\mathbf{0 . 5 4}$ \\
Agua & S/ & $\mathbf{0 . 0 0 4 1}$ \\
Edulcorante Yacón & S/ & $\mathbf{0 . 0 0 0 0 0 1 6 7}$ \\
NaClO (sol) & S/ & $\mathbf{1 . 3 7 5 0}$ \\
Preservante (Sorbato de Potasio) & S/ & $\mathbf{0 . 2 0}$ \\
Botella+Tapa & S/ & - \\
Tapas & S/ & $\mathbf{0 . 1 5}$ \\
Etiquetas & S/ & $\mathbf{0 . 0 1}$ \\
Plástico (forro packs x12) & S/ & $\mathbf{0 . 0 2}$ \\
Palets & & \\
\end{tabular}

Fuente: Elaboración propia

c. Precio del producto y Margen de Utilidad:

De acuerdo a costos estimados por los expertos entrevistados y tomando como referencia la proyección del volumen de producción, el precio estimado sugerido para el consumidor final con el que sería lanzado el producto al mercado es de: S/ 4.50 aproximadamente. (Incluye IGV). En el siguiente cuadro se describe el valor de venta y el precio de venta tanto a consumidor final como a canal de venta. El valor de venta al canal de venta sería de S/ 3.32. 
Tabla 73

Fijación de precio a canal de venta y a consumidor final

\begin{tabular}{|c|c|c|c|c|c|c|}
\hline & Costo S/IGV & IGV & Ganancia & $\begin{array}{l}\text { Valor } \\
\text { Venta }\end{array}$ & IGV & $\begin{array}{l}\text { Precio } \\
\text { Venta }\end{array}$ \\
\hline Consumidor final & & & & $\mathrm{S} / 3.81$ & S/ 0.69 & $\mathrm{~S} / 4.5$ \\
\hline Canal de venta & & & $15 \%$ & $\mathrm{~S} / 3.32$ & $\mathrm{~S} / 0.60$ & S/ 3.91 \\
\hline $\begin{array}{l}\text { Fruto Nativo del } \\
\text { Sur }\end{array}$ & $\mathrm{S} / 2.16$ & 0.39 & $54 \%$ & $\mathrm{~S} / 3.32$ & $\mathrm{~S} / 0.60$ & S/ 3.91 \\
\hline
\end{tabular}

Fuente: Elaboración propia

\subsubsection{Estrategia de Distribución}

Se estima que el producto se encuentre dentro de la clasificación "producto boutique", es decir exclusivo, por lo que se aplicará una estrategia de distribución indirecta y selectiva, siendo el canal de distribución el canal moderno.

Entiendase por canal moderno, al acceso que tiene el consumidor de manera libre a una variedad de productos, ya sea en supermercados, tiendas por departamento, tiendas de conveniencia, tiendas de autoservicios y tiendas especializadas. ${ }^{33}$. La empresa se enfocará en establecimientos como:

$>$ Supermercados: Vivanda, Plaza Vea, Wong

$>$ Mercados saludables: Punto Organico SAC (Miraflores), Madre Natura e Hijos SAC (Miraflores y Surco) y Flora \& Fauna -Tienda Saludable (Miraflores, San Borja y Surco).

Los mencionados locales, servirán como intermediarios entre público objetivo y los productores, bajo un esquema B2B. La selección se debe a que estos lugares se encuentran ubicados en los distritos interés del estudio y son frecuentados por las personas que pertenecen a los sectores socioeconómicos mencionados anteriormente.

\footnotetext{
33 Fuentes: https://www.youtube.com/watch?v=j-B6xEC_US0 https://es.slideshare.net/yenncash/canal-moderno-de-distribucion
} 


\subsubsection{Estrategia de Promoción y Publicidad}

La publicidad se realizará a través de revistas, catálogos y redes sociales, además del boca a boca que se espera se dé desde los primeros consumidores.

Dado que serán pocos y selectos los canales de distribución, para el lanzamiento se realizará -durante un mes- degustaciones del producto en los establecimientos de mayor afluencia de público, como Vivanda, Plaza Vea y Wong; con el fin de difundir las bondades que este tiene y a la vez hacer que los clientes conozcan el sabor, que definitivamente es diferente a las bebidas existentes en el mercado. Durante la degustación se entregarán volantes con las características y beneficios principales del producto.

Otra herramienta muy importante serán las redes sociales, como lo son Facebook y ecommerce, ya que tienen una capacidad viral que permite que amigos, conocidos o amigos de la gente que se tiene de contacto, puedan ver noticias sobre lo que pasa con el producto, a su vez compartirlo con sus contactos.

Dentro de este plan táctico de un mes y tomando como referencia las entrevistas en profundidad realizadas a los respectivos especialistas del sector, con respecto al plan de inversión en el canal, se presenta el siguiente presupuesto de plan táctico:

Tabla 74

Presupuesto de plan táctico por un mes

\begin{tabular}{lll}
\hline Descripción & Cantidad & Monto \\
\hline Personal para difusión de producto & 3 & $\mathrm{~S} / 1,500.00$ \\
Producto: Kawsay presentación de 250 ml & 118 & $\mathrm{~S} / 300.49$ \\
Vasos descartables (2 onzas) & 1200 & $\mathrm{~S} / 48.00$ \\
Volantes & 1000 & $\mathrm{~S} / 120.00$ \\
$\begin{array}{l}\text { Espacio en canal de venta (cabecera y } \\
\text { revestimiento) }\end{array}$ & 1 & $\mathrm{~S} / 2,100.00$ \\
Total & & $\mathbf{S} / \mathbf{4 , 0 6 8 . 4 9}$ \\
\hline
\end{tabular}

Fuente: Elaboración propia 


\subsubsection{Estrategia de Ventas}

Marketing concentrado del producto para supermercados de la zona 7 de Lima metropolitana, específicamente en los distritos de Miraflores, San Isidro, San Borja, La Molina y Santiago de Surco.

Esto dará la oportunidad de orientar todos los esfuerzos por cautivar este sector con la bebida natural de Sanky y a su vez adquirir la experiencia y madurez empresarial de modo que se pueda competir -en el mediano y largo plazo- en otros segmentos de mercado.

\subsubsection{Plan de Ventas.}

El producto está diseñado para cubrir la demanda de personas comprendidas entre los 18 y 50 años que practican una vida saludable. El mercado objetivo fue establecido considerando la zona 7 de Lima metropolitana para personas con edades comprendidas entre los 18 y 50 años; a quienes se les aplicó una encuesta con degustación de producto.

En cuanto al precio este fue tomado del mercado tomando como referencia los productos que se denominan naturales bebibles que actualmente están en el mercado.

Para determinar el volumen de ventas se consideró la estacionalidad del producto y también la estacionalidad del consumo de bebidas que entre los meses de setiembre a marzo tienen mayor demanda.

La distribución del producto será hacia los puntos de venta tales como supermercados y mercados saludables.

La marca es KAWSAY término quechua que significa "Vida" enfatizando que se trata de una vida digna, una vida de plenitud.

En la etiqueta se ha querido resaltar las características naturales del producto asociando tonalidades de color verde generalmente vinculadas con la naturaleza. 


\section{Capitulo VIII}

\section{PLANIFICACIÓN FINANCIERA}

\subsection{La Inversión:}

La inversión total en este proyecto asciende a S/ 253846.96, el cual será cubierto en su integridad por capital propio.

\subsubsection{Inversión Pre-Operativa}

a) Inversión en activo fijo:

La empresa dispone de un activo fijo que asciende a: S/ 126442.84, el cual está distribuido en activos fijos para operaciones con S/ 119178.84 que representa el $94.26 \%$ y en activos administrativos con S/ 7264.00 que representa el 5.74\%.

\section{Tabla 75}

Inversión en activos fijos tangibles

\begin{tabular}{ll}
\hline $\begin{array}{l}\text { ACTIVOS FIJOS } \\
\text { TANGIBLES } \\
\text { (en soles) }\end{array}$ \\
\hline Operaciones & $\mathrm{S} / 119,178.84$ \\
Administración & $\mathrm{S} / 7,264.00$ \\
Costo Total & $\mathrm{S} / \mathbf{1 2 6 , 4 4 2 . 8 4}$ \\
\hline
\end{tabular}

Fuente: Elaboración propia.

Al detalle se tiene: 
Tabla 76

Inversión en activos fijos Operaciones

\begin{tabular}{ll}
\hline Equipo & $\mathrm{S} /$ \\
\hline $\begin{array}{l}\text { Tanque de Lavado 0.25HP }(65 * 45 * \\
47.8 \mathrm{~cm} 3)\end{array}$ & $\mathrm{S} / 17,325.00$ \\
& \\
Marmita & $\mathrm{S} / 8,250.00$ \\
Licuadora industrial & $\mathrm{S} / 627.00$ \\
Tanque acero inoxidable (mezcladora) & $\mathrm{S} / 8,415.00$ \\
Tanque acero inoxidable (Almacén & $\mathrm{S} / 4,712.40$ \\
Agua) & \\
& $\mathrm{S} / 4,290.00$ \\
Embotelladora, Selladora & $\mathrm{S} / 2,475.00$ \\
Etiquetadora & $\mathrm{S} / 3,960.00$ \\
Retractiladora industrial (empaque x & \\
doc) & $\mathrm{S} / 16,500.00$ \\
Refrigeradora industrial & $\mathrm{S} / 396.00$ \\
Colador industrial ac. Inox & $\mathrm{S} / 759.00$ \\
Balanza industrial capac. $150 \mathrm{~kg}$ & $\mathrm{~S} / 46,200.00$ \\
Camioneta para distribucion & $\mathrm{S} /$ \\
Herramientas & $\mathrm{S} / 3,975.84$ \\
Equipos de analisis (kit para analisis de & \\
pruebas) & $\mathrm{S} / 396.00$ \\
Cuchillos de Corte & $\mathrm{S} / 264.00$ \\
Recipientes de Acero Inox. para Pulpa & $\mathrm{S} / 237.60$ \\
Jabas & Cucharones (acero inoxidable) \\
TOTAL & \\
\hline Fuente: Elaboración propia & \\
\hline
\end{tabular}

Fuente: Elaboración propia 
Tabla 77

Inversión en activos fijos Administración

\begin{tabular}{ll}
\hline Mobiliario & S/ 4,955.00 \\
\hline Armarios & S/ 330.00 \\
Mueble & S/ 396.00 \\
Sistema de Intercomunicacion & S/ 330.00 \\
Fax Multifuncional & S/ 429.00 \\
Computadoras & S/ 2,480.00 \\
Juego de escritorios & S/ 990.00 \\
Equipamiento de Seguridad para la Empresa Industrial & S/ 1,150.00 \\
01 Extintor de PQS 10 Kg. & S/ 110.00 \\
01 Extintor de CO2 10 Lbs. & S/ 60.00 \\
01 Extintor de CO2 6 Lbs. & S/ 40.00 \\
03 Detectores de Humo & S/ 30.00 \\
Instalación detectores de humo y panel de sistema de alarmas & S/ 500.00 \\
01 Panel de Sistema de Alarmas & S/ 350.00 \\
Equipos de Proteccción Personal Planta Industrial & S/ 1,159.00 \\
Gorros desechables (caja x 100) & S/ 25.00 \\
Mascarillas de tejido (caja x 100) & S/ 30.00 \\
Delantales de jebe (6u) & S/ 300.00 \\
Mandiles (6u) & S/ 210.00 \\
Guantes de jebe (12) & S/ 144.00 \\
Botas de Jebe (6) & S/ 450.00 \\
TOTAL & S/ 4,955.00 \\
\hline
\end{tabular}

Fuente: Elaboración propia

De la tabla 77 Inversión en activos fijos Administración, podemos apreciar el equipamiento de seguridad para la empresa y los equipos de protección personal-EPP para la planta industrial y con mayor detenimiento en las tablas 78 y 79 , respectivamente. 
Tabla 78

Equipamiento de Seguridad Empresa Industrial

\begin{tabular}{lll}
\hline Descripción & Cantidad & Monto \\
\hline 01 Extintor de PQS 10 Kg. & 1 & S/ 110.00 \\
01 Extintor de CO2 10 Lbs. & 1 & S/ 60.00 \\
01 Extintor de CO2 6 Lbs. & 1 & S/ 40.00 \\
03 Detectores de Humo & 3 & S/ 90.00 \\
Instaracion aetectores ae numo y paneı ae & 1 & S/ 500.00 \\
sistema de alarmas & 1 & S/ 350.00 \\
01 Panel de Sistema de Alarmas & & S/1,150.00 \\
TOTAL & &
\end{tabular}

Fuente: Elaboración propia

Tabla 79

Equipos de Protección Personal-EPP-Planta Industrial

\begin{tabular}{lcc}
\hline \multicolumn{1}{c}{ Equipos deProtección Personal Planta Industrial } & Unid. & S/ \\
\hline Gorros desechables & Caja x 100 & S/ 25.00 \\
Mascarillas de tejido & Caja x 100 & S/ 30.00 \\
Delantales de jebe & 6 unidades & S/ 300.00 \\
Mandiles & 6 unidades & S/ 210.00 \\
Guantes de jebe & 12 pares & S/ 144.00 \\
Botas de jebe & 6 pares & S/ 450.00 \\
Total & & S/ $\mathbf{1 , 1 5 9 . 0 0}$ \\
\hline
\end{tabular}

Fuente: Elaboración propia

\section{b) Inversión en activo intangible:}

La empresa invierte un total de activos intangibles por S/ 990.00 y de Gastos Pre-

operativos por S/ 22413 los cuales se amortizarán utilizando el método lineal durante 5 años,

tal y como se muestran en los siguientes cuadros.

Tabla 80

Inversión en activos fijos intangibles

\begin{tabular}{ll}
\hline \multicolumn{1}{c}{ ACTIVOS } & \\
\multicolumn{1}{c}{ FIJOS } & (en soles) \\
INTANGIBLES & \\
\hline Software Office & S/990.00 \\
Costo Total & S/990.00 \\
\hline
\end{tabular}

Fuente: Elaboración propia 
Tabla 81

Gastos Pre-operativos

\begin{tabular}{|c|c|c|c|}
\hline Descripción & $\begin{array}{l}\text { Precio } \\
\text { Unitario } \\
\text { (en soles) }\end{array}$ & Cantidad & $\begin{array}{l}\text { Costo Total } \\
\text { (en soles) }\end{array}$ \\
\hline Legales & & & S/ 3743.00 \\
\hline Minuta de constitución de empresa & S/ 300.00 & 1 & $\mathrm{~S} / 300.00$ \\
\hline Escritura Pública & $\mathrm{S} / 90.00$ & 1 & $\mathrm{~S} / 90.00$ \\
\hline Licencia de funcionamiento & $\mathrm{S} / 700.00$ & 1 & $\mathrm{~S} / 700.00$ \\
\hline Registro de Marca & $\mathrm{S} / 500.00$ & 1 & $\mathrm{~S} / 500.00$ \\
\hline Registro Sanitario & $\mathrm{S} / 550.00$ & 1 & $\mathrm{~S} / 550.00$ \\
\hline Inspección INDECI & $\mathrm{S} / 223.00$ & 1 & $\mathrm{~S} / 223.00$ \\
\hline Publicación El peruano & S/ 330.00 & 1 & $\mathrm{~S} / 330.00$ \\
\hline Código de Barras & $\mathrm{S} / 1,050.00$ & 1 & $\mathrm{~S} / 1,050.00$ \\
\hline Adecuación de local & & & $\mathrm{S} / \mathbf{2 5 5 0 . 0 0}$ \\
\hline Obreros & $\mathrm{S} / 250.00$ & 1 & $\mathrm{~S} / 250.00$ \\
\hline Materiales y equipos de seguridad & S/ 2300.00 & 1 & S/ 2300.00 \\
\hline Implementación de Sistemas Normativos & & & $\mathrm{S} / \mathbf{5 0 0 0 . 0 0}$ \\
\hline ISO 9000-9001 & $\mathrm{S} / 1,800.00$ & & $\mathrm{~S} / 1,800.00$ \\
\hline HACCP & $\mathrm{S} / 1,400.00$ & & S/ $1,400.00$ \\
\hline ISO 14000-14001 & $\mathrm{S} / 1,800.00$ & & $\mathrm{~S} / 1,800.00$ \\
\hline Campaña de difusión & & & S/ 4068.49 \\
\hline $\begin{array}{l}\text { Personal para difusión de producto ( } 3 \\
\text { impulsadoras) }\end{array}$ & $\mathrm{S} / 500.00$ & 3 & S. $1,500.00$ \\
\hline $\begin{array}{l}\text { Producto: Kawsay presentación de } 250 \\
\text { ml (300u) }\end{array}$ & $\mathrm{S} / 300.00$ & & $\mathrm{~S} / 300.49$ \\
\hline Vasos descartables (1200 u) & S/ $1,200.00$ & & $\mathrm{~S} / 48.00$ \\
\hline Volantes (1000 u) & S/ 120.00 & & $\mathrm{~S} / 120.00$ \\
\hline $\begin{array}{l}\text { Espacio en canal de venta (cabecera y } \\
\text { revestimiento) }\end{array}$ & $\mathrm{S} / 2,100.00$ & & $\mathrm{~S} / 2,500.00$ \\
\hline Investigación y desarrollo & & & $\mathrm{S} / \mathbf{1 7 5 0 . 0 0}$ \\
\hline $\begin{array}{l}\text { Capacitacion y/o entrenamiento del } \\
\text { personal }\end{array}$ & $\mathrm{S} / 350.00$ & & $\mathrm{~S} / 350.00$ \\
\hline Costos de investigación y organización & $\mathrm{S} / 650.00$ & & $\mathrm{~S} / 650.00$ \\
\hline Costos de ensayos y pruebas & $\mathrm{S} / 750.00$ & & $\mathrm{~S} / 750.00$ \\
\hline Licencias & & & $\mathrm{S} / \mathbf{9 9 0 . 0 0}$ \\
\hline Software Office & $\mathrm{S} / 450.00$ & 2 & 990.00 \\
\hline Otros & & & $\mathrm{S} / \mathbf{7 4 5 0 . 0 0}$ \\
\hline Encuestas & $\mathrm{S} / 1,100.00$ & & S/ $1,100.00$ \\
\hline Estudio de mercado & $\mathrm{S} / 1,350.00$ & & $\mathrm{~S} / 1,350.00$ \\
\hline Alquiler de local (garantía) & $\mathrm{S} / 5,000.00$ & & $\mathrm{~S} / 5,000.00$ \\
\hline SUB-TOTAL & & & $\mathrm{S} / \mathbf{2 5 , 5 5 1 . 4 9}$ \\
\hline
\end{tabular}

Fuente: Elaboración propia 
Dentro de la tabla 81 de los gastos pre-operativos, podemos apreciar la implementación de los sistemas normativos (certificaciones), y que se hallan especificados en la tabla a continuación:

Tabla 82

Implementación de sistemas normativos (certificaciones)

\begin{tabular}{lc}
\hline \multicolumn{1}{c}{ Implementación de Sistemas Normativos } & S/ \\
\hline ISO 9000-9001 & $\mathrm{S} / 1,800.00$ \\
HACCP & $\mathrm{S} / 1,400.00$ \\
ISO 14000-14001 & $\mathrm{S} / 1,800.00$ \\
TOTAL & $\mathrm{S} / 5,000.00$ \\
\hline
\end{tabular}

Fuente; Elaboración propia

Tabla 83

Amortización de Intangibles

\begin{tabular}{lllcccc}
\hline Inversión Diferida & $\mathbf{2 0 1 6}$ & $\mathbf{2 0 1 7}$ & $\mathbf{2 0 1 8}$ & $\mathbf{2 0 1 9}$ & $\mathbf{2 0 2 0}$ & $\mathbf{2 0 2 1}$ \\
\hline Intangibles y Pre- Operativos & $\mathrm{S} / 24,561.49$ & $\mathrm{~S} / 4,912.30 \mathrm{~S} / 4,912.30 \mathrm{~S} / 4,912.30 \mathrm{~S} / 4,912.30 \mathrm{~S} / 4,912.30$
\end{tabular}

Fuente: Elaboración propia

\subsubsection{Inversión en capital de trabajo}

El capital de trabajo se determino utilizando el método del "Déficit Acumulado" que es es el método que se utiliza para este tipo de estudio. Este monto sirve para considerar la posibilidad de financiar parte de los egresos proyectados ante los periodos de desfase que pueden ocurrir por estacionalidad en ventas o adquisición de insumos. ${ }^{34}$

El máximo déficit acumulado resulta luego del siguiente análisis:

\footnotetext{
34 SAPAG, Nassir. Proyectos de Inversión, Formulación y Evaluación. 1ra ed. México D.F.: Pearson Educación de México S.A de C.
} V., 2009. p. 147. 
Tabla 84

Capital de Trabajo (en nuevos soles)

\begin{tabular}{|c|c|c|c|c|c|c|c|c|c|c|c|c|c|}
\hline & ENE & FEB & MAR & ABR & MAY & JUN & JUL & AGO & SEP & OCT & Nov & DIC & TOTAL \\
\hline INGRESOS & $\mathrm{S} / 0.0$ & $\mathrm{~S} / 89,320.10$ & S/ 107,184.10 & $\mathrm{S} / 89,320.10$ & S/ 53,592.10 & S/ 53,592.10 & S/ 53,592.10 & S/ 53,592.10 & S/ 71,456.10 & $\mathrm{S} / 71,456.10$ & S/ 71,456.10 & S/ 89,320.10 & S/ $607,376.80$ \\
\hline Por cobranza a 60 días & & $89,320.10$ & 107.184 .10 & $89,320.10$ & $53,592.10$ & $53,592.10$ & $53,592.10$ & $53,592.10$ & $71,456.10$ & $71,456.10$ & $71,456.10$ & $89,320.10$ & $607,376.80$ \\
\hline EGRESOS & $102,347.63$ & $-80,617.80$ & $-81,568.34$ & $-70,019.27$ & $-72,098.70$ & $-70,140.86$ & $-75,396.21$ & -76.545 .14 & $-76,194.51$ & $-76,223.50$ & $-86,003.23$ & $-88,481.70$ & $-921,336.50$ \\
\hline Pago contado & $-39,356.34$ & $-39,818.12$ & $-34,523.93$ & $-26,106.84$ & $-27,042.20$ & $-26,971.48$ & $-26,971.48$ & $-31,356.58$ & $-30,550.80$ & $-30,585.16$ & $-36,159.85$ & $-35,323.05$ & -594.746 .80 \\
\hline Pago de la deuda & & & & & & & 0.00 & 0.00 & 0.00 & 0.00 & 0.00 & 0.00 & 0.00 \\
\hline Pago CTS & & & & & $-1,889.85$ & & & & & & $-2,384.41$ & & $-4,284.76$ \\
\hline Pago a Cuenta IR (0.02) & & $-1,513.90$ & $-1,816.58$ & $-1,513.90$ & -908.34 & -908.34 & -908.34 & -908.34 & $-1,121.12$ & $-1,121.12$ & $-1,121.12$ & $-1,513.90$ & $-13,615.10$ \\
\hline Pago de IGV & & & $-6,001.20$ & $-3,412.37$ & $-3,244.00$ & $-3,256.73$ & $-3,256.73$ & $-5,196.04$ & $-5,337.48$ & $-5,331.11$ & $-7,052.87$ & $-7,208.49$ & -40.311 .28 \\
\hline Pago MOD & $-2,080.60$ & $-2,080.60$ & $-2,080.60$ & $-2,080.60$ & $-2,080.60$ & $-2,080.60$ & $-2,080.60$ & $-2,080.60$ & $-2,080.60$ & $-2,080.60$ & $-2,080.60$ & $-2,080.60$ & $-24,967.15$ \\
\hline Pago MOI & $-4,396.10$ & $-4,396.10$ & $-4,396.10$ & $-4,396.10$ & $-4,396.10$ & $-4,396.10$ & $-4,396.10$ & $-4,396.10$ & $-4,396.10$ & $-4,396.10$ & $-4,396.10$ & $-4,396.10$ & $-52,753.18$ \\
\hline Pago Sueldo & $-5,600.00$ & $-5,600.00$ & $-5,600.00$ & $-5,600.00$ & $-5,600.00$ & $-5,600.00$ & $-5,600.00$ & $-5,600.00$ & $-5,600.00$ & $-5,600.00$ & $-5,600.00$ & $-5,600.00$ & $-67,200.00$ \\
\hline Pago ESSALUD & -941.40 & -941.40 & -941.40 & -941.40 & -941.40 & -941.40 & -941.40 & -941.40 & -941.40 & -941.40 & -941.40 & -941.40 & $-11,296.80$ \\
\hline Pago CIF Desembolso & $-14,330.59$ & $-14,385.09$ & $-14,276.14$ & $-14,085.47$ & $-14,108.62$ & $-14,108.62$ & $-14,108.62$ & $-14,203.49$ & $-14,194.42$ & -14.194 .42 & $-14,294.29$ & $-14,285.22$ & $-170,599.98$ \\
\hline Pago GO Desembolso & $-11,882.60$ & $-11,882.60$ & $-11,882.60$ & $-11,882.60$ & $-11,882.60$ & $-11,882.60$ & $-11,882.60$ & $-11,882.60$ & $-11,882.60$ & $-11,882.60$ & $-11,882.60$ & $-11,882.60$ & $-140,591.20$ \\
\hline Pago Otros Desembolso & $-23,760.00$ & & & & & & & & & & & & \\
\hline Pago Gratificación & & & & & & $-5,255.35$ & & & & & & $-5,255.35$ & \\
\hline INGRESOS - EGRESOS & $-102,437.63$ & $8,700.32$ & 25.645 .51 & $19,300.85$ & $-18,506.46$ & $-16,548.79$ & $-21,804.14$ & $-22,953.07$ & $-4,738.41$ & $-4,767.40$ & $-14,547.13$ & 838.42 & $-313,959.67$ \\
\hline Saldo Incial & & $-102,347.63$ & $-93,645.31$ & $-67,999.80$ & $-48,698.95$ & $-67,205.41$ & $-65,754.20$ & $-105,558.34$ & $-128,511.41$ & $-133,249.82$ & $-138,017.111$ & -152.564 .35 & \\
\hline $\begin{array}{l}\text { Saldo Acumulado } \\
\text { (Déficit Acumulado) }\end{array}$ & $-102,347.63$ & $-93,645.31$ & $-67,999.80$ & $-48,695.95$ & $-67,205.41$ & $-83,754.20$ & $-105,558.14$ & $-128,511.41$ & -133.249 .82 & $-138,017.22$ & $-152,554.35$ & $-151,775.93$ & \\
\hline
\end{tabular}

Fuente: Elaboración Propia 
Tabla 85

Flujo de Capital de Trabajo

\begin{tabular}{ccc}
\hline Año & $\begin{array}{c}\text { Capital de trabajo } \\
\text { Total }\end{array}$ & $\begin{array}{c}\text { Incremento } \\
\text { CT }\end{array}$ \\
\hline $\mathbf{2 0 1 6}$ & & $-102,391.89$ \\
$\mathbf{2 0 1 7}$ & $-102,391.89$ & $-1,198.70$ \\
$\mathbf{2 0 1 8}$ & $-103,590.59$ & $-1,198.70$ \\
$\mathbf{2 0 1 9}$ & $-104,789.29$ & $-1,198.70$ \\
$\mathbf{2 0 2 0}$ & $-105,988.00$ & $-1,198.70$ \\
$\mathbf{2 0 2 1}$ & $-107,186.70$ & \\
\hline
\end{tabular}

Fuente: Elaboración propia

\subsubsection{Costo del proyecto}

El resultado de la suma del Activo Fijo Tangible, Intangible y Capital de Trabajo determina el total de inversión. Se muestra a continuación el detalle:

Tabla 86

Inversión en Activos Tangibles

\begin{tabular}{lc}
\hline $\begin{array}{l}\text { Activos Fijos } \\
\text { Operacionales }\end{array}$ & S/ \\
\hline Equipo & S/ 113,909.40 \\
Herramientas & S/ 5,269.44 \\
Activos Fijos & \\
Operacionales & \\
Mobiliario & S/ 7,264.00 \\
Total Activos Fijos & S/ 126,442.84 \\
\hline
\end{tabular}

Fuente: Elaboración propia

Tabla 87

Estructura de Inversión

\begin{tabular}{llc}
\hline Concepto & Monto (S/) & Ponderación \\
\hline Activos Tangibles & S/ 126,442.84 & $\mathbf{4 9 . 8 1 \%}$ \\
Activos Intangibles y Pre- & & \\
Operaivos & S/ $25,056.49$ & $\mathbf{9 . 8 7 \%}$ \\
Capital de Trabajo & S/ $102,347.63$ & $\mathbf{4 0 . 3 2 \%}$ \\
Total & S/ 253,846.96 & $\mathbf{1 0 0 \%}$ \\
\hline
\end{tabular}

Fuente: Elaboración propia 


\subsubsection{Inversiones futuras}

No se ha considerado dentro de este estudio el análisis de inversión futura. Se ha decidido que una vez que el proyecto esté en marcha, se realicen planes estratégicos que contemple no necesariamente renovación de equipos si no también adaptación de nuevas estrategias y/o nueva tecnología, según sea necesario.

\subsection{Financiamiento}

Al ser un proyecto que no ha iniciado operaciones, el acceso al crédito via banco o entidad financiera no es accesible ni barato, debido a que las condiciones en algunos casos son seis meses de funcionamiento para acceder a un capital de trabajo (caso mayoría de Bancos); mientras que en algunas CMACs hay disposición de préstamo, pero con requisitos rígidos y tasas muy altas (caso CMAC Cusco) que afectarían el flujo de efectivo que se desea. Por ello es que se decidió que la totalidad de la inversión, que asciende a $\mathbf{S} / \mathbf{2 5 3 , 8 4 6 . 9 6}$ será realizada con aporte de los accionistas es decir cada uno invertirá S/ 63461.74 (25\% cada uno de los cuatro aportantes).

\subsubsection{Capital Propio y Costo de Oportunidad}

El capital propio representó el $100 \%$ de la inversión equivalente a $\mathbf{S} / \mathbf{2 5 3 , 8 4 6 . 9 6}$ que fue divido en partes iguales entre los cuatro inversionistas de manera que cada uno aportó S/63461.74. El Costo de Oportunidad de Capital de los Inversionistas fue determinado utilizando el Modelo de Valoración del Precio de Activos Financieros o conocido también como CAPM (Capital Asset Pricing Model) pero ajustado con un factor adicional llamado Renpe (Riesgo por empresa nueva en país emergente), es decir:

$$
C O K=k e=R f+\beta_{P R O Y}(R m-R f)+R p+\text { Renpe }
$$


Tabla 88

Costo de Oportunidad

\begin{tabular}{|c|c|}
\hline COK (ke) : & 12.19\% TEA \\
\hline Tasa libre de riesgo ( $\mathrm{Rf})$ : & $1.26 \% \mathrm{TEA}$ \\
\hline Prime por riesgo de Mercado & $6.70 \%$ TEA \\
\hline $\begin{array}{l}\text { Beta proyectado; Unlevered beta retail } \\
\text { ( } \beta \text { proy): }\end{array}$ & 1.00 \\
\hline Riesgo País (Perú) & $1.724 \%$ \\
\hline $\begin{array}{l}\text { Riesgo por empresa nueva en país emergente } \\
\text { (Renpe): }\end{array}$ & $2.5 \%$ \\
\hline
\end{tabular}

Fuente: Elaboración Propia

Donde:

$\checkmark \quad$ Rf : Bono del tesoro americano a cinco años ${ }^{35}$.

$\checkmark$ (Rm-Rf): Prima por riesgo de mercado implícita PRMI; según Damodarán y Arzac PRMX=PRMI, Según CAPM PRMX=PRME.

Se asumirá: PRMX=PRME...y se toma el mayor valor promedio $6.7 \%$ según tabla de estudio (ver tabla en enlace).

Tabla 89

Hipótesis sobre Primas de Riesgo

\begin{tabular}{ccccc}
\hline Hipótesis & \multirow{2}{*}{ Número de Libros } & \multicolumn{3}{c}{ Recomendación } \\
& & Max & Min & Promedio \\
\hline PRMX = PRME & 88 & $10.0 \%$ & $3.0 \%$ & $6.7 \%$ \\
No dicen como calcula la PRMX & 5 & $8.0 \%$ & $5.0 \%$ & $6.3 \%$ \\
PRMX = PRMI & 2 & $5.1 \%$ & $4.0 \%$ & $4.5 \%$ \\
Otros & 5 & $6.0 \%$ & $4.0 \%$ & $5.0 \%$ \\
Total & $\mathbf{1 0 0}$ & $\mathbf{1 0 . 0 \%}$ & $\mathbf{3 . 0 \%}$ & $\mathbf{6 . 6 \%}$ \\
\hline
\end{tabular}

Fuente: https://ubr.universia.net/article/viewFile/685/811 
$\checkmark$ Bproy: Beta proyectado: es el Beta desapalancado obtenido en tabla de Damodarán. ${ }^{36}$

$\checkmark$ Riesgo País: 172.35 PBS (puntos básicos) promedio con cifras tomadas desde enero del 2012 hasta julio del $2017 .{ }^{37}$

$\checkmark$ Riesgo por empresa nueva en país emergente: se consideró un estimado del 2.5\% (del rango de $2.5 \%$ y $5 \%$ sugerido por asesor de proyecto) para mantener una posición conservadora, debido a que se trata de una empresa que iniciará operaciones en un país donde la estabilidad económica aún no se puede proyectar como totalmente buena a largo plazo debido a su condición de "país emergente".

\subsection{Presupuesto Base.}

\subsubsection{Presupuesto de ventas.}

Los ingresos del proyecto provendrán exclusivamente por el canal moderno que es la venta a los intermediarios (supermercados y casas naturistas). El valor de venta del producto es de S/ 3.8 y para el consumidor final será de S/ 4.50 .

Tabla 90

Valor venta y precio de venta del producto

\begin{tabular}{|c|c|c|c|}
\hline $\begin{array}{c}\text { Producto presentación } 250 \\
\mathrm{ml}\end{array}$ & $\begin{array}{c}\text { Monto } \\
(\mathrm{S} /)\end{array}$ & $\begin{array}{c}\text { Producto presentación } \\
250 \mathrm{ml} \\
\end{array}$ & $\begin{array}{c}\text { Monto } \\
(\mathrm{S} /)\end{array}$ \\
\hline Valor Venta Canal de venta & $\mathrm{S} / 3.32$ & Valor Venta Consumidor & $\mathrm{S} / 3.82$ \\
\hline $\operatorname{IGV}(18 \%)$ & $S / 0.60$ & $\operatorname{IGV}(18 \%)$ & S/ 0.69 \\
\hline $\begin{array}{l}\text { Precio Venta al Canal de } \\
\text { Venta }\end{array}$ & $\mathrm{S} / 3.92$ & $\begin{array}{l}\text { Precio Venta Consumidor } \\
\text { Final }\end{array}$ & $\mathrm{S} / 4.50$ \\
\hline
\end{tabular}

Fuente: Elaboración propia

\footnotetext{
36 Disponible http://pages.stern.nyu.edu/ adamodar/New_Home_Page/datafile/Betas.html

37 Disponible en https://estadisticas.bcrp.gob.pe/estadisticas/series/mensuales/resultados/PN01129XM/html
} 
Tabla 91

Ingreso anual de ventas 2017-2021

\begin{tabular}{lllllll}
\hline Concepto & Valor Venta & \multicolumn{1}{c}{$\mathbf{2 0 1 7}$} & \multicolumn{1}{c}{$\mathbf{2 0 1 8}$} & \multicolumn{1}{c}{$\mathbf{2 0 1 9}$} & \multicolumn{1}{c}{$\mathbf{2 0 2 0}$} & \multicolumn{1}{c}{$\mathbf{2 0 2 1}$} \\
\hline $\begin{array}{l}\text { Producto } \\
\text { (unidades) }\end{array}$ & & 227,997 & 230,666 & 233,335 & 236,005 & 238,674 \\
Ventas Totales sin & $\mathrm{S} / 3.3$ de 250 & $\mathrm{~S} / 756,950.18$ & $\mathrm{~S} / 765,811.80$ & $\mathrm{~S} / 774,673.42$ & $\mathrm{~S} / 783,535.04$ & $\mathrm{~S} / 792,396.65$ \\
IGV(S/) & $\mathrm{ml}$ & $\mathrm{S} / 136,251.03$ & $\mathrm{~S} / 137,846.12$ & $\mathrm{~S} / 139,441.22$ & $\mathrm{~S} / 141,036.31$ & $\mathrm{~S} / 142,631.40$ \\
IGV & 0.18 & $\mathbf{S / 8 9 3 , 2 0 1 . 2 2}$ & $\mathrm{S} / \mathbf{9 0 3 , 6 5 7 . 9 3}$ & $\mathbf{S} / \mathbf{9 1 4 , 1 1 4 . 6 3}$ & $\mathbf{S} / \mathbf{9 2 4 , 5 7 1 . 3 4}$ & $\mathrm{S} / \mathbf{9 3 5 , 0 2 8 . 0 5}$ \\
Ingresos Totales & & &
\end{tabular}

Fuente: Elaboración propia

\subsubsection{Presupuesto de Costos de Producción}

El presupuesto de costos de producción incluye los conceptos por adquisición de la materia prima e insumos, mano de obra directa y los costos indirectos de fabricación.

En la siguiente tabla se muestra el Costo Total de Producción.

Tabla 92

Presupuesto de Costo de Producción 2017-2021

\begin{tabular}{llllll}
\hline Concepto & $\mathbf{2 0 1 7}$ & $\mathbf{2 0 1 8}$ & $\mathbf{2 0 1 9}$ & $\mathbf{2 0 2 0}$ & $\mathbf{2 0 2 1}$ \\
\hline Botellas + tapas & $\mathrm{S} / 39,435.96$ & $\mathrm{~S} / 39,897.64$ & $\mathrm{~S} / 40,359.32$ & $\mathrm{~S} / 40,820.99$ & $\mathrm{~S} / 41,282.67$ \\
Sanky & $\mathrm{S} / 66,062.19$ & $\mathrm{~S} / 66,835.58$ & $\mathrm{~S} / 67,608.97$ & $\mathrm{~S} / 68,382.36$ & $\mathrm{~S} / 69,155.75$ \\
Yacón & $\mathrm{S} / 47,323.16$ & $\mathrm{~S} / 47,877.17$ & $\mathrm{~S} / 48,431.18$ & $\mathrm{~S} / 48,985.19$ & $\mathrm{~S} / 49,539.20$ \\
Plástico & $\mathrm{S} / 2,809.81$ & $\mathrm{~S} / 2,842.71$ & $\mathrm{~S} / 2,875.60$ & $\mathrm{~S} / 2,908.50$ & $\mathrm{~S} / 2,941.39$ \\
Agua producción & $\mathrm{S} / 262.25$ & $\mathrm{~S} / 265.32$ & $\mathrm{~S} / 268.39$ & $\mathrm{~S} / 271.46$ & $\mathrm{~S} / 274.53$ \\
Hipoclorito de Sodio & $\mathrm{S} / 505.77$ & $\mathrm{~S} / 511.69$ & $\mathrm{~S} / 517.61$ & $\mathrm{~S} / 523.53$ & $\mathrm{~S} / 529.45$ \\
Sorbato de Potasio & $\mathrm{S} / 1,355.61$ & $\mathrm{~S} / 1,371.48$ & $\mathrm{~S} / 1,387.35$ & $\mathrm{~S} / 1,403.22$ & $\mathrm{~S} / 1,419.09$ \\
Etiquetas & $\mathrm{S} / 29,576.97$ & $\mathrm{~S} / 29,923.23$ & $\mathrm{~S} / 30,269.49$ & $\mathrm{~S} / 30,615.75$ & $\mathrm{~S} / 30,962.00$ \\
Electricidad & $\mathrm{S} / 3,885.89$ & $\mathrm{~S} / 3,931.38$ & $\mathrm{~S} / 3,976.87$ & $\mathrm{~S} / 4,022.37$ & $\mathrm{~S} / 4,067.86$ \\
Operarios & $\mathrm{S} / 27,905.58$ & $\mathrm{~S} / 27,905.58$ & $\mathrm{~S} / 27,905.58$ & $\mathrm{~S} / 27,905.58$ & $\mathrm{~S} / 27,905.58$ \\
Jefe de Producción & $\mathrm{S} / 45,009.00$ & $\mathrm{~S} / 45,009.00$ & $\mathrm{~S} / 45,009.00$ & $\mathrm{~S} / 45,009.00$ & $\mathrm{~S} / 45,009.00$ \\
Limpieza de planta & $\mathrm{S} / 13,952.79$ & $\mathrm{~S} / 13,952.79$ & $\mathrm{~S} / 13,952.79$ & $\mathrm{~S} / 13,952.79$ & $\mathrm{~S} / 13,952.79$ \\
Depreciación de Equipos & $\mathrm{S} / 10,983.29$ & $\mathrm{~S} / 10,983.29$ & $\mathrm{~S} / 10,983.29$ & $\mathrm{~S} / 10,983.29$ & $\mathrm{~S} / 10,983.29$ \\
TOTAL & $\mathrm{S} / \mathbf{2 8 9 , 0 6 8 . 2 7}$ & $\mathrm{S} / \mathbf{2 9 1 , 3 0 6 . 8 5}$ & $\mathrm{S} / \mathbf{2 9 3 , 5 4 5 . 4 4}$ & $\mathrm{S} / \mathbf{2 9 5 , 7 8 4 . 0 2}$ & $\mathrm{S} / \mathbf{2 9 8 , 0 2 2 . 6 1}$ \\
\hline
\end{tabular}

Fuente: Elaboración propia

A continuación se detalla el presupuesto desglosado: 


\section{a. Presupuesto anual de materia prima:}

Son todos los ingredientes e insumos que forman parte del producto, a saber: pulpa de sanky, agua, yacón en polvo, hipoclorito de sodio, sorbato de potasio, y los elementos que forman parte de la presentación. Este presupuesto fue estimado de cuerdo a las cantidades sugeridas por el experto en industrias alimentarias y de acuerdo a los precios de los ingredientes e insumos.

Tabla 93

Presupuesto Anual de Materia Prima

\begin{tabular}{|c|c|c|c|c|c|}
\hline Materia Prima & 2017 & 2018 & 2019 & 2020 & 2021 \\
\hline Botellas + tapas & $\mathrm{S} / 39,435.96$ & $\mathrm{~S} / 39,897.64$ & $\mathrm{~S} / 40,359.32$ & $\mathrm{~S} / 40,820.99$ & $\mathrm{~S} / 41,282.67$ \\
\hline Sanky & $\mathrm{S} / 66,062.19$ & $\mathrm{~S} / 66,835.58$ & $\mathrm{~S} / 67,608.97$ & $\mathrm{~S} / 68,382.36$ & $\mathrm{~S} / 69,155.75$ \\
\hline Yacón & $\mathrm{S} / 47,323.16$ & $\mathrm{~S} / 47,877.17$ & $\mathrm{~S} / 48,431.18$ & $\mathrm{~S} / 48,985.19$ & $\mathrm{~S} / 49,539.20$ \\
\hline Plástico & $\mathrm{S} / 2,809.81$ & $\mathrm{~S} / 2,842.71$ & $\mathrm{~S} / 2,875.60$ & $\mathrm{~S} / 2,908.50$ & $\mathrm{~S} / 2,941.39$ \\
\hline Agua & $\mathrm{S} / 262.25$ & $\mathrm{~S} / 265.32$ & $\mathrm{~S} / 268.39$ & $\mathrm{~S} / 271.46$ & $\mathrm{~S} / 274.53$ \\
\hline $\begin{array}{l}\text { Hipoclorito de } \\
\text { Sodio }\end{array}$ & $\mathrm{S} / 505.77$ & $\mathrm{~S} / 511.69$ & $\mathrm{~S} / 517.61$ & $\mathrm{~S} / 523.53$ & $\mathrm{~S} / 529.45$ \\
\hline $\begin{array}{l}\text { Sorbato de } \\
\text { Potasio }\end{array}$ & $S / 1,355.61$ & $\mathrm{~S} / 1,371.48$ & $\mathrm{~S} / 1,387.35$ & $\mathrm{~S} / 1,403.22$ & $\mathrm{~S} / 1,419.09$ \\
\hline Etiquetas & $\mathrm{S} / 29,576.97$ & $\mathrm{~S} / 29,923.23$ & $\mathrm{~S} / 30,269.49$ & $\mathrm{~S} / 30,615.75$ & $\mathrm{~S} / 30,962.00$ \\
\hline Total Sin IGV & $\mathrm{S} / 187,331.72$ & $\mathrm{~S} / 189,524.81$ & $\mathrm{~S} / 191,717.90$ & S/193,910.99 & $\mathrm{S} / 196,104.09$ \\
\hline $18 \%$ IGV & $\mathrm{S} / 33,719.71$ & $\mathrm{~S} / 34,114.47$ & $\mathrm{~S} / 34,509.22$ & $\mathrm{~S} / 34,903.98$ & $\mathrm{~S} / 35,298.74$ \\
\hline $\begin{array}{l}\text { Total Anual } \\
\text { Materia Prima }\end{array}$ & $\mathrm{S} / 221,051.42$ & $\mathrm{~S} / \mathbf{2 2 3 , 6 3 9 . 2 7}$ & $\mathrm{S} / 226,227.12$ & $\mathrm{~S} / \mathbf{2 2 8 , 8 1 4 . 9 7}$ & $\mathrm{S} / 231,402.82$ \\
\hline
\end{tabular}

Fuente: Elaboración propia

b. Presupuesto anual de mano de obra directa: Se considera a los operarios y al jefe de producción. Se consideran los beneficios laborales que aplican para pequeña empresa. 
Tabla 94

Beneficios Laborales Pequeña Empresa

\begin{tabular}{lc}
\hline \multicolumn{1}{c}{$\begin{array}{c}\text { Costos } \\
\text { Laborales }\end{array}$} & $\%$ \\
\hline Gratificaciones & $7.69 \%$ \\
CTS & $4.17 \%$ \\
Vacaciones & $4.17 \%$ \\
Essalud & $9 \%$ \\
\hline Fuente: Elaboración propia
\end{tabular}

Tabla 95

Presupuesto Anual de Mano de Obra Directa

\begin{tabular}{|c|c|c|c|c|c|}
\hline Concepto & 2017 & 2018 & 2019 & 2020 & 2021 \\
\hline Operarios & 2 & 2 & 2 & 2 & 2 \\
\hline $\begin{array}{l}\text { Sueldo Bruto } \\
\text { mensual x operario }\end{array}$ & $\mathrm{S} / 930.00$ & $\mathrm{~S} / 930.00$ & $\mathrm{~S} / 930.00$ & $\mathrm{~S} / 930.00$ & $\mathrm{~S} / 930.00$ \\
\hline $\begin{array}{l}\text { Gratificaciones x } \\
\text { operario }\end{array}$ & $\mathrm{S} / 71.52$ & $\mathrm{~S} / 71.52$ & $\mathrm{~S} / 71.52$ & $\mathrm{~S} / 71.52$ & $\mathrm{~S} / 71.52$ \\
\hline CTS x operario & $\mathrm{S} / 38.78$ & $\mathrm{~S} / 38.78$ & $\mathrm{~S} / 38.78$ & $\mathrm{~S} / 38.78$ & $\mathrm{~S} / 38.78$ \\
\hline $\begin{array}{l}\text { Vacaciones } \mathrm{x} \\
\text { operario }\end{array}$ & $\mathrm{S} / 38.73$ & S/38.73 & S/38.73 & S/38.73 & $\mathrm{S} / 38.73$ \\
\hline Essalud x operario & $\mathrm{S} / 83.70$ & $\mathrm{~S} / 83.70$ & $\mathrm{~S} / 83.70$ & $\mathrm{~S} / 83.70$ & $\mathrm{~S} / 83.70$ \\
\hline $\begin{array}{l}\text { Total mensual } \\
\text { Total Anual }\end{array}$ & $\mathrm{S} / \mathbf{2 , 3 2 5 . 4 7}$ & $\mathrm{S} / \mathbf{2 , 3 2 5 . 4 7}$ & $\mathrm{S} / \mathbf{2 , 3 2 5 . 4 7}$ & $\mathrm{S} / \mathbf{2 , 3 2 5 . 4 7}$ & $\mathrm{S} / \mathbf{2 , 3 2 5 . 4 7}$ \\
\hline MOD & $\mathrm{S} / 27,905.58$ & S/27,905.58 & S/27,905.58 & $\mathrm{S} / 27,905.58$ & $\mathrm{~S} / 27,905.58$ \\
\hline
\end{tabular}

Fuente: Elaboración propia

c. Presupuesto anual de costo indirecto de producción: Se detallan los costos indirectos de fabricación en los que incurrirá la empresa sólo se tiene MOI. 
Tabla 96

Presupuesto Anual de Costos Indirectos de Producción y CIF

\begin{tabular}{|c|c|c|c|c|c|}
\hline Concepto & 2017 & 2018 & 2019 & 2020 & 2021 \\
\hline$\frac{\text { Jefe de }}{\text { Producción }}$ & 1 & 1 & 1 & 1 & 1 \\
\hline $\begin{array}{l}\text { Sueldo Bruto } \\
\text { mensual }\end{array}$ & $\mathrm{S} / 3,000.00$ & $\mathrm{~S} / 3,000.00$ & $\mathrm{~S} / 3,000.00$ & $\mathrm{~S} / 3,000.00$ & $\mathrm{~S} / 3,000.00$ \\
\hline $\begin{array}{l}\text { Gratificacione } \\
\text { s x mes }\end{array}$ & $\mathrm{S} / 230.70$ & $\mathrm{~S} / 230.70$ & $\mathrm{~S} / 230.70$ & $\mathrm{~S} / 230.70$ & $\mathrm{~S} / 230.70$ \\
\hline CTS x mes & $\mathrm{S} / 125.10$ & $\mathrm{~S} / 125.10$ & $\mathrm{~S} / 125.10$ & $\mathrm{~S} / 125.10$ & $\mathrm{~S} / 125.10$ \\
\hline $\begin{array}{l}\text { Vacaciones } \mathrm{X} \\
\text { mes }\end{array}$ & S/124.95 & $\mathrm{S} / 124.95$ & $\mathrm{~S} / 124.95$ & $\mathrm{~S} / 124.95$ & $\mathrm{~S} / 124.95$ \\
\hline Essalud x mes & $\mathrm{S} / 270.00$ & $\mathrm{~S} / 270.00$ & $\mathrm{~S} / 270.00$ & $\mathrm{~S} / 270.00$ & $\mathrm{~S} / 270.00$ \\
\hline $\begin{array}{l}\text { Sub rotal } \\
\text { anual }\end{array}$ & $\mathrm{S} / 45,009.00$ & $\mathrm{~S} / 45,009.00$ & $\mathrm{~S} / 45,009.00$ & $\mathrm{~S} / 45,009.00$ & $\mathrm{~S} / 45,009.00$ \\
\hline Limpieza & 1 & 1 & 1 & 1 & 1 \\
\hline $\begin{array}{l}\text { Sueldo Bruto } \\
\text { mensual }\end{array}$ & $\mathrm{S} / 930.00$ & $\mathrm{~S} / 930.00$ & $\mathrm{~S} / 930.00$ & $\mathrm{~S} / 930.00$ & $\mathrm{~S} / 930.00$ \\
\hline $\begin{array}{l}\text { Gratificacione } \\
\text { s x mes }\end{array}$ & $\mathrm{S} / 71.52$ & $\mathrm{~S} / 71.52$ & $\mathrm{~S} / 71.52$ & $\mathrm{~S} / 71.52$ & $\mathrm{~S} / 71.52$ \\
\hline CTS x mes & $\mathrm{S} / 38.78$ & $\mathrm{~S} / 38.78$ & $\mathrm{~S} / 38.78$ & $\mathrm{~S} / 38.78$ & $\mathrm{~S} / 38.78$ \\
\hline $\begin{array}{l}\text { Vacaciones } \mathrm{X} \\
\text { mes }\end{array}$ & $\mathrm{S} / 38.73$ & $\mathrm{~S} / 38.73$ & $\mathrm{~S} / 38.73$ & $\mathrm{~S} / 38.73$ & $\mathrm{~S} / 38.73$ \\
\hline Essalud x mes & $\mathrm{S} / 83.70$ & $\mathrm{~S} / 83.70$ & $\mathrm{~S} / 83.70$ & $\mathrm{~S} / 83.70$ & $\mathrm{~S} / 83.70$ \\
\hline $\begin{array}{l}\text { Sub rotal } \\
\text { anual }\end{array}$ & $\mathrm{S} / 13,952.79$ & $\mathrm{~S} / 13,952.79$ & $\mathrm{~S} / 13,952.79$ & $\mathrm{~S} / 13,952.79$ & $\mathrm{~S} / 13,952.79$ \\
\hline $\begin{array}{l}\text { Total MOI } \\
\text { anual } \\
\text { CIF }\end{array}$ & S/58,961.79 & S/58,961.79 & S/58,961.79 & S/58,961.79 & $\mathrm{S} / 58,961.79$ \\
\hline Agua & $\mathrm{S} / 1,080.00$ & $S / 1,092.65$ & S/1,105.29 & S/1,117.94 & $\mathrm{S} / 1,130.59$ \\
\hline Electricidad & $\mathrm{S} / 3,885.89$ & $\mathrm{~S} / 3,931.39$ & $\mathrm{~S} / 3,976.90$ & $\mathrm{~S} / 4,022.40$ & $\mathrm{~S} / 4,067.90$ \\
\hline $\begin{array}{l}\text { lelétono e } \\
\text { Internet }\end{array}$ & $\mathrm{S} / 4,560.00$ & $\mathrm{~S} / 4,613.40$ & S/4,666.80 & $\mathrm{S} / 4,720.19$ & $\mathrm{~S} / 4,773.59$ \\
\hline $\begin{array}{l}\text { Depreciación } \\
\text { de Equipos }\end{array}$ & $\mathrm{S} / 11,226.94$ & $\mathrm{~S} / 11,358.40$ & $\mathrm{~S} / 11,489.87$ & $\mathrm{~S} / 11,621.34$ & $\mathrm{~S} / 11,752.80$ \\
\hline $\begin{array}{l}\text { Alquiler de } \\
\text { Local }\end{array}$ & $\mathrm{S} / 71,280.00$ & $\mathrm{~S} / 72,114.69$ & $\mathrm{~S} / 72,949.38$ & $\mathrm{~S} / 73,784.06$ & $\mathrm{~S} / 74,618.75$ \\
\hline $\begin{array}{l}\text { Total CIF } \\
\text { Anual }\end{array}$ & $\mathrm{S} / \mathbf{9 2 , 0 3 2 . 8 3}$ & $\mathrm{S} / \mathbf{9 3 , 1 1 0 . 5 3}$ & $\mathrm{S} / \mathbf{9 4 , 1 8 8 . 2 3}$ & S/95,265.94 & $\mathrm{S} / 96,343.64$ \\
\hline $\begin{array}{l}\text { Total Anual: } \\
\text { MOI + CIF }\end{array}$ & $\begin{array}{l}\text { S/150,994.6 } \\
2\end{array}$ & $\begin{array}{l}\mathrm{S} / 152,072.3 \\
2\end{array}$ & $\begin{array}{l}\mathrm{S} / \mathbf{1 5 3}, \mathbf{1 5 0 . 0} \\
2\end{array}$ & $\begin{array}{l}\text { S/154,227.7 } \\
3\end{array}$ & $\begin{array}{l}\text { S/155,305.4 } \\
3\end{array}$ \\
\hline
\end{tabular}

Fuente: Elaboración propia 
8.3.3. Presupuesto anual de Costo de Ventas. Se detalla el costo de ventas en el que incurre la empresa.

Tabla 97

Presupuesto Anual de Costos de Ventas

\begin{tabular}{|c|c|c|c|c|c|}
\hline Concepto & 2017 & 2018 & 2019 & 2020 & 2021 \\
\hline $\begin{array}{l}\text { Materia } \\
\text { Prima }\end{array}$ & $\mathrm{S} / 187,331.72$ & $\mathrm{~S} / 189,524.81$ & $\mathrm{~S} / 191,717.90$ & S/193,910.99 & S/196,104.09 \\
\hline $\begin{array}{l}\text { Mano de } \\
\text { Obra }\end{array}$ & S/86,867.37 & $\mathrm{S} / 87,884.33$ & $\mathrm{~S} / 88,901.28$ & S/89,918.24 & S/90,935.20 \\
\hline Cif variable & S/4,965.89 & $\mathrm{S} / 5,024.03$ & $\mathrm{~S} / 5,082.16$ & $\mathrm{~S} / 5,140.30$ & $\mathrm{~S} / 5,198.43$ \\
\hline Cif fijo & $\mathrm{S} / 139,820.11$ & S/139,820.11 & $\mathrm{S} / 139,820.11$ & S/139,820.11 & $\mathrm{S} / 139,820.11$ \\
\hline $\begin{array}{l}\text { Total Sin } \\
\text { IGV }\end{array}$ & S/418,985.09 & $\mathrm{S} / 422,253.27$ & $\mathrm{~S} / 425,521.46$ & S/428,789.64 & $\mathrm{S} / 432,057.83$ \\
\hline $18 \%$ IGV & $\mathrm{S} / 75,417.32$ & S/76,005.59 & S/76,593.86 & $\mathrm{S} / 77,182.14$ & $\mathrm{~S} / 77,770.41$ \\
\hline Total & $\mathrm{S} / \mathbf{4 9 4 , 4 0 2 . 4 0}$ & $\mathrm{S} / 498,258.86$ & $\mathrm{~S} / 502,115.32$ & $\mathrm{~S} / \mathbf{5 0 5 , 9 7 1 . 7 8}$ & S/509,828.24 \\
\hline
\end{tabular}

Fuente: Elaboración propia. 
8.3.4. Presupuesto de Gastos Administrativos. Se precisan los gastos administrativos de la empresa.

Tabla 98

Presupuesto Anual de Costos de Ventas

\begin{tabular}{|c|c|c|c|c|c|}
\hline Concepto & 2017 & 2018 & 2019 & 2020 & 2021 \\
\hline Gerente General & 1 & 1 & 1 & 1 & 1 \\
\hline Sueldo Neto mensual & $\mathrm{S} / 4,100.00$ & $\mathrm{~S} / 4,100.00$ & $\mathrm{~S} / 4,100.00$ & $\mathrm{~S} / 4,100.00$ & $\mathrm{~S} / 4,100.00$ \\
\hline Gratificaciones mensual & $\mathrm{S} / 315.29$ & $\mathrm{~S} / 315.29$ & $S / 315.29$ & $\mathrm{~S} / 315.29$ & $\mathrm{~S} / 315.29$ \\
\hline CTS mensual & S/170.97 & S/170.97 & S/170.97 & S/170.97 & S/170.97 \\
\hline Vacaciones mensual & S/170.77 & S/170.77 & S/170.77 & S/170.77 & S/170.77 \\
\hline Essalud mensual & $\mathrm{S} / 369.00$ & $\mathrm{~S} / 369.00$ & $\mathrm{~S} / 369.00$ & $\mathrm{~S} / 369.00$ & $\mathrm{~S} / 369.00$ \\
\hline Total Anual Gerente & $S / 5,126.03$ & $S / 5,126.03$ & $S / 5,126.03$ & $S / 5,126.03$ & $S / 5,126.03$ \\
\hline Asistente & 1 & 1 & 1 & 1 & 1 \\
\hline Sueldo Neto mensual & $S / 1,500.00$ & $S / 1,500.00$ & $S / 1,500.00$ & $S / 1,500.00$ & $S / 1,500.00$ \\
\hline Gratificaciones mensual & S/115.35 & S/115.35 & S/115.35 & S/115.35 & $\mathrm{S} / 115.35$ \\
\hline CTS mensual & $\mathrm{S} / 62.55$ & $\mathrm{~S} / 62.55$ & $\mathrm{~S} / 62.55$ & $\mathrm{~S} / 62.55$ & $\mathrm{~S} / 62.55$ \\
\hline Vacaciones mensual & $\mathrm{S} / 62.48$ & $\mathrm{~S} / 62.48$ & $\mathrm{~S} / 62.48$ & $\mathrm{~S} / 62.48$ & $\mathrm{~S} / 62.48$ \\
\hline Essalud mensual & $\mathrm{S} / 135.00$ & $\mathrm{~S} / 135.00$ & $\mathrm{~S} / 135.00$ & $\mathrm{~S} / 135.00$ & $\mathrm{~S} / 135.00$ \\
\hline Total Anual Asistente & $S / \mathbf{1 , 8 7 5 . 3 8}$ & S/1,875.38 & S/1,875.38 & S/1,875.38 & $S / \mathbf{1 , 8 7 5 . 3 8}$ \\
\hline \multicolumn{6}{|l|}{ Varios } \\
\hline Utiles de oficina & $\mathrm{S} / 1,200.00$ & $\mathrm{~S} / 1,200.00$ & $\mathrm{~S} / 1,200.00$ & $\mathrm{~S} / 1,200.00$ & $\mathrm{~S} / 1,200.00$ \\
\hline Asesoría Contable Tercerizado & $\mathrm{S} / 6,720.00$ & $\mathrm{~S} / 6,720.00$ & $S / 6,720.00$ & $\mathrm{~S} / 6,720.00$ & $\mathrm{~S} / 6,720.00$ \\
\hline Seguridad Tercerizado & $\mathrm{S} / 12,000.00$ & $\mathrm{~S} / 12,000.00$ & $\mathrm{~S} / 12,000.00$ & $\mathrm{~S} / 12,000.00$ & $\mathrm{~S} / 12,000.00$ \\
\hline Asesoría Especializada Tercerizado & $\mathrm{S} / 13,200.00$ & $\mathrm{~S} / 13,200.00$ & $\mathrm{~S} / 13,200.00$ & $\mathrm{~S} / 13,200.00$ & $\mathrm{~S} / 13,200.00$ \\
\hline $\begin{array}{l}\text { Mantenimiento de equipos } \\
\text { Tercerizado }\end{array}$ & $\mathrm{S} / 13,200.00$ & $\mathrm{~S} / 13,200.00$ & $\mathrm{~S} / 13,200.00$ & $\mathrm{~S} / 13,200.00$ & $\mathrm{~S} / 13,200.00$ \\
\hline Agua Oficinas, SSHH, etc & $\mathrm{S} / 360.00$ & $\mathrm{~S} / 360.00$ & $\mathrm{~S} / 360.00$ & $\mathrm{~S} / 360.00$ & $\mathrm{~S} / 360.00$ \\
\hline Electricidad & $\mathrm{S} / 2,160.00$ & $S / 2,160.00$ & $\mathrm{~S} / 2,160.00$ & $S / 2,160.00$ & $\mathrm{~S} / 2,160.00$ \\
\hline Total Anual Varios & $\mathrm{S} / \mathbf{4 8 , 8 4 0 . 0 0}$ & $\mathrm{S} / \mathbf{4 8 , 8 4 0 . 0 0}$ & $\mathrm{S} / \mathbf{4 8 , 8 4 0 . 0 0}$ & $\mathrm{S} / \mathbf{4 8 , 8 4 0 . 0 0}$ & $\mathrm{S} / \mathbf{4 8 , 8 4 0 . 0 0}$ \\
\hline Total Anual Gastos Administrativos & $\mathrm{S} / \mathbf{1 3 2 , 8 5 6 . 8 0}$ & $\mathrm{S} / \mathbf{1 3 2 , 8 5 6 . 8 0}$ & $\mathrm{S} / \mathbf{1 3 2 , 8 5 6 . 8 0}$ & $\mathrm{S} / \mathbf{1 3 2 , 8 5 6 . 8 0}$ & $\mathrm{S} / \mathbf{1 3 2 , 8 5 6 . 8 0}$ \\
\hline
\end{tabular}

Fuente: Elaboración propia

8.3.5. Presupuesto de Gastos de Ventas. En publicidad se considera la colocación de flyers

y la presencia de degustadoras para impulsar las ventas.

Tabla 99

Presupuesto Anual de Gastos de Ventas

\begin{tabular}{llllll}
\hline Concepto & $\mathbf{2 0 1 7}$ & $\mathbf{2 0 1 8}$ & $\mathbf{2 0 1 9}$ & $\mathbf{2 0 2 0}$ & $\mathbf{2 0 2 1}$ \\
\hline $\begin{array}{l}\text { Publicidad (Flyers; } \\
\text { degustaciones) }\end{array}$ & $\mathrm{S} / 72,000.00$ & $\mathrm{~S} / 72,000.00$ & $\mathrm{~S} / 72,000.00$ & $\mathrm{~S} / 72,000.00$ & $\mathrm{~S} / 72,000.00$ \\
Total Anual Gastos de Ventas & $\mathrm{S} / 72,000.00$ & $\mathbf{S} / 72,000.00$ & $\mathrm{~S} / 72, \mathbf{0 0 0 . 0 0}$ & $\mathbf{S} / 72,000.00$ & $\mathrm{~S} / 72,000.00$ \\
\hline
\end{tabular}

Fuente: Elaboración propia. 
8.3.6. Resumen: Módulo de Inversiones, Costos y Gastos Se detalla a continuación el resumen de las inversiones, costos y gastos.

Tabla 100

Resumen: Inversiones, Costos y Gastos

\begin{tabular}{|c|c|c|c|c|c|c|}
\hline Concepto & 2016 & 2017 & 2018 & 2019 & 2020 & 2021 \\
\hline Inversiones & $\mathrm{S} / \mathbf{2 1 7 , 5 4 0 . 1 3}$ & S/ 1,198.18 & S/ 1,198.18 & S/ 1,198.18 & S/ 1,198.18 & $\mathrm{S} / \mathbf{0 . 0 0}$ \\
\hline Maquinas y Herramientas & S/ 100,999.02 & & & & & \\
\hline Mobiliario y Enseres & S/ 8,571.52 & & & & & \\
\hline Intangibles & S/ 419.49 & & & & & \\
\hline Gastos Pre-Operativos & $\mathrm{S} / 20,814.82$ & & & & & \\
\hline Capital de Trabajo & S/ 102,347.63 & S/ 1,198.18 & S/ 1,198.18 & S/ 1,198.18 & S/ 1,198.18 & $\mathrm{S} / 0.00$ \\
\hline Costos ( $x$ ventas) & & 401,636 & 404,892 & 408,147 & 411,345 & 411,345 \\
\hline Materia Prima & & 187,332 & $189,524.81$ & $191,717.90$ & $193,910.99$ & $193,910.99$ \\
\hline Mano de Obra & & 86,867 & $87,872.56$ & $88,877.75$ & $89,882.94$ & $89,882.94$ \\
\hline Cif variable & & $4,965.89$ & $5,022.70$ & $5,079.50$ & $5,079.50$ & $5,079.50$ \\
\hline Cif fijo & & $139,576.47$ & $139,576.47$ & $139,576.47$ & $139,576.47$ & $139,576.47$ \\
\hline Gastos & & 246,714 & 246,714 & 246,714 & 246,714 & 246,714 \\
\hline Planilla de Sueldos MOI & & 142,979 & 142,979 & 142,979 & 142,979 & 142,979 \\
\hline Planilla Sueldos Administrativos & & 48840 & 48840 & 48840 & 48840 & 48840 \\
\hline Publicidad & & 72000 & 72000 & 72000 & 72000 & 72000 \\
\hline TOTAL SIN IGV & $\mathrm{S} /-\mathbf{2 1 7 , 5 4 0 . 1 3}$ & 649,548 & 652,803 & 656,058 & 659,257 & 658,058 \\
\hline IGV $18 \%$ & S/ -39,157.22 & S/ 116,918.68 & S/ 117,504.59 & S/ 118,090.51 & S/ 118,666.20 & S/ 118,450.53 \\
\hline TOTAL CON IGV & S/ -256,697.35 & S/ 766,466.90 & $\mathrm{S} / \mathbf{7 7 0 , 3 0 7 . 9 0}$ & S/ 774,148.90 & S/ 777,922.87 & S/ 776,509.02 \\
\hline
\end{tabular}

Fuente: Elaboración propia 


\subsubsection{Resumen de Liquidación de IGV.}

Tabla 101

Liquidación de IGV

\begin{tabular}{lllllll}
\hline Concepto & $\mathbf{2 0 1 6}$ & $\mathbf{2 0 1 7}$ & $\mathbf{2 0 1 8}$ & $\mathbf{2 0 1 9}$ & $\mathbf{2 0 2 0}$ & $\mathbf{2 0 2 1}$ \\
\hline IGV Ventas & & $\mathrm{S} / 136,251.03$ & $\mathrm{~S} / 137,846.12$ & $\mathrm{~S} / 139,441.22$ & $\mathrm{~S} / 141,036.31$ & $\mathrm{~S} / 142,631.40$ \\
IUV de Inv; costos & $\mathrm{S} / 39,157.22$ & $\mathrm{~S} / 116,918.68$ & $\mathrm{~S} / 117,504.59$ & $\mathrm{~S} / 118,090.51$ & $\mathrm{~S} / 118,666.20$ & $\mathrm{~S} / 118,450.53$ \\
y Gastos & & & & & & \\
IGV Neto & $\mathrm{S} / 39,157.22$ & $\mathrm{~S} / 19,332.35$ & $\mathrm{~S} / 20,341.53$ & $\mathrm{~S} / 21,350.70$ & $\mathrm{~S} / 22,370.11$ & $\mathrm{~S} / 24,180.87$ \\
Crédito Fiscal & $\mathrm{S} / 39,157.22$ & $\mathrm{~S} / 39,157.22$ & $\mathrm{~S} / 19,824.87$ & & & \\
IGV A PAGAR & S/ 0.00 & $\mathrm{S} / \mathbf{1 9 , 8 2 4 . 8 7}$ & S/ 516.66 & $\mathrm{S} / \mathbf{2 1 , 3 5 0 . 7 0}$ & $\mathrm{S} / \mathbf{2 2 , 3 7 0 . 1 1}$ & $\mathrm{S} / \mathbf{2 4 , 1 8 0 . 8 7}$ \\
\hline
\end{tabular}

Fuente: Elaboración propia

\subsubsection{Egresos no desembolsables}

a. Depreciación. A continuación se presenta el detalle de la depreciación para los

cinco periodos anualizados, utilizando el método lineal.

Tabla 102

Depreciación de activo fijo

\begin{tabular}{|c|c|c|c|c|c|c|c|c|c|}
\hline Equipo & Valor Neto & IGV & $\begin{array}{c}\text { Depreciación } \\
\text { anual \% }\end{array}$ & \begin{tabular}{|c|} 
Depreciación \\
Anual
\end{tabular} & 2017 & 2018 & 2019 & 2020 & 2021 \\
\hline Tanque de lavado $0.25 \mathrm{HP}\left(65^{*} 45^{*} 47.8 \mathrm{~cm}^{3}\right)$ & S/14,682.20 & $\mathrm{S} / 2,642.80$ & $10 \%$ & $\mathrm{~S} / 1,468.22$ & $\mathrm{~S} / 264.28$ & $\mathrm{~S} / 0.01$ & $\mathrm{~S} / 146.82$ & $\mathrm{~S} / 26.43$ & $\mathrm{~S} / 0.00$ \\
\hline Marmita & $\mathrm{S} / 6,991.53$ & $\mathrm{~S} / 1,258.48$ & $10 \%$ & S/699.15 & $\mathrm{S} / 125.85$ & $\mathrm{~S} / 0.01$ & S/69.92 & $\mathrm{S} / 12.58$ & $\mathrm{~S} / 0.00$ \\
\hline Licuadora industrial & $\mathrm{S} / 531.36$ & S/95.64 & $10 \%$ & $\mathrm{~S} / 53.14$ & $\mathrm{~S} / 9.56$ & $\mathrm{~S} / 0.01$ & $\mathrm{~S} / 5.31$ & $\mathrm{~S} / 0.96$ & $\mathrm{~S} / 0.00$ \\
\hline Tanque acero inoxidable (mezcladora) & $\mathrm{S} / 7,131.36$ & $\mathrm{~S} / 1,283.64$ & $10 \%$ & $\mathrm{~S} / 713.14$ & $\mathrm{~S} / 128.36$ & $\mathrm{~S} / 0.01$ & $\mathrm{~S} / 71.31$ & $\mathrm{~S} / 12.84$ & $\mathrm{~S} / 0.00$ \\
\hline Tanque acero inoxidable (almacén agua) & $\mathrm{S} / 3,993.56$ & $\mathrm{~S} / 718.84$ & $10 \%$ & $\mathrm{~S} / 399.36$ & $\mathrm{~S} / 71.88$ & $\mathrm{~S} / 0.01$ & S/39.94 & $\mathrm{S} / 7.19$ & $\mathrm{~S} / 0.00$ \\
\hline Embotelladora, selladora & $S / 3,635.59$ & S/654.41 & $10 \%$ & $\mathrm{~S} / 363.56$ & S/65.44 & $\mathrm{S} / 0.01$ & $\mathrm{~S} / 36.36$ & S/6.54 & $\mathrm{S} / 0.00$ \\
\hline Etiquetadora & $\mathrm{S} / 2,097.46$ & S/377.54 & $10 \%$ & $\mathrm{~S} / 209.75$ & $\mathrm{~S} / 37.75$ & $\mathrm{~S} / 0.01$ & S/20.97 & $\mathrm{S} / 3.78$ & $\mathrm{~S} / 0.00$ \\
\hline Retractiladora industrial (empaque $\mathrm{x}$ docena) & $\mathrm{S} / 3,355.93$ & S/604.07 & $10 \%$ & $\mathrm{~S} / 335.59$ & S/60.41 & $\mathrm{S} / 0.01$ & $\mathrm{~S} / 33.56$ & $\mathrm{~S} / 6.04$ & $\mathrm{~S} / 0.00$ \\
\hline \begin{tabular}{|l|} 
Refrigeradora industrial \\
\end{tabular} & $\mathrm{S} / 6,991.53$ & $\mathrm{~S} / 1,258.48$ & $10 \%$ & $\mathrm{~S} / 699.15$ & $\mathrm{~S} / 125.85$ & $\mathrm{~S} / 0.01$ & S/69.92 & $\mathrm{S} / 12.58$ & $\mathrm{~S} / 0.00$ \\
\hline Colador industrial ac. Inox. & $\mathrm{S} / 335.59$ & S/60.41 & $10 \%$ & $\mathrm{~S} / 33.56$ & S/6.04 & $\mathrm{S} / 0.01$ & $\mathrm{~S} / 3.36$ & $\mathrm{~S} / 0.60$ & $\mathrm{~S} / 0.00$ \\
\hline Balanza industrial cap. $150 \mathrm{~kg}$ & $\mathrm{~S} / 643.22$ & $\mathrm{~S} / 115.78$ & $10 \%$ & $\mathrm{~S} / 64.32$ & $\mathrm{~S} / 11.58$ & $\mathrm{~S} / 0.01$ & $S / 6.43$ & $\mathrm{~S} / 1.16$ & $S / 0.00$ \\
\hline Camioneta p/distribución & $\mathrm{S} / 39,152.54$ & $\mathrm{~S} / 7,047.46$ & $10 \%$ & $\mathrm{~S} / 3,915.25$ & $\mathrm{~S} / 704.75$ & $\mathrm{~S} / 0.01$ & $\mathrm{~S} / 391.53$ & $\mathrm{~S} / 70.47$ & $\mathrm{~S} / 0.00$ \\
\hline Equipos de análisis (kit para análisis de pruebas) & $S / 1,684.68$ & $\mathrm{~S} / 303.24$ & $10 \%$ & $\mathrm{~S} / 168.47$ & $\mathrm{~S} / 30.32$ & $\mathrm{~S} / 0.01$ & S/16.85 & $\mathrm{S} / 3.03$ & $\mathrm{~S} / 0.00$ \\
\hline Cuchillos de corte & S/27.97 & $\mathrm{S} / 5.03$ & $10 \%$ & $\mathrm{~S} / 2.80$ & $\mathrm{~S} / 0.50$ & $\mathrm{~S} / 0.01$ & $\mathrm{~S} / 0.28$ & $\mathrm{~S} / 0.05$ & $\mathrm{~S} / 0.00$ \\
\hline Recipientes de ac. Inox. Para pulpa & $\mathrm{S} / 111.86$ & $\mathrm{~S} / 20.13$ & $10 \%$ & $\mathrm{~S} / 11.19$ & $\mathrm{~S} / 2.01$ & $\mathrm{~S} / 0.01$ & $\mathrm{~S} / 1.12$ & $\mathrm{~S} / 0.20$ & $\mathrm{~S} / 0.00$ \\
\hline Jabas & S/27.97 & $\mathrm{S} / 5.03$ & $10 \%$ & $\mathrm{~S} / 2.80$ & $\mathrm{~S} / 0.50$ & $\mathrm{~S} / 0.01$ & $S / 0.28$ & $S / 0.05$ & $S / 0.00$ \\
\hline Cucharones (ac. Inox.) & $S / 33.56$ & S/6.04 & $10 \%$ & $\mathrm{~S} / 3.36$ & $S / 0.60$ & $\mathrm{~S} / 0.01$ & $\mathrm{~S} / 0.34$ & $\mathrm{~S} / 0.06$ & $S / 0.00$ \\
\hline Armarios & S/279.66 & $\mathrm{S} / 50.34$ & $10 \%$ & S/27.97 & $\mathrm{S} / 5.03$ & $\mathrm{~S} / 0.01$ & $\mathrm{~S} / 2.80$ & $\mathrm{~S} / 0.50$ & $S / 0.00$ \\
\hline Mueble & $\mathrm{S} / 335.59$ & $\mathrm{~S} / 60.41$ & $10 \%$ & $\mathrm{~S} / 33.56$ & S/6.04 & $\mathrm{S} / 0.01$ & $S / 3.36$ & $S / 0.60$ & $S / 0.00$ \\
\hline Sistema de intercomunic, & S/279.66 & $\mathrm{S} / 50.34$ & $20 \%$ & $\mathrm{~S} / 55.93$ & $\mathrm{~S} / 10.07$ & $\mathrm{~S} / 0.04$ & $\mathrm{~S} / 11.19$ & $\mathrm{~S} / 2.01$ & $\mathrm{~S} / 0.01$ \\
\hline Fax Multifuncional & $\mathrm{S} / 363.56$ & S/65.44 & $20 \%$ & $\mathrm{~S} / 72.71$ & S/13.09 & $\mathrm{S} / 0.04$ & $\mathrm{~S} / 14.54$ & $\mathrm{~S} / 2.62$ & $\mathrm{~S} / 0.01$ \\
\hline Computadoras & $S / 1,538.14$ & S/276.87 & $25 \%$ & S/769.07 & S/769.07 & S/769.07 & $\mathrm{S} / 769.07$ & S/769.07 & S/769.07 \\
\hline
\end{tabular}

Fuente: Elaboración propia 
b. Amortización de Intangibles Se presenta en la tabla 102 la amortización de Intangibles.

Tabla 103

$\underline{\text { Amortización de intangibles }}$

\begin{tabular}{cc}
\hline Año & Valor \\
\hline 2016 & S/ $24,561.49$ \\
2017 & S/ 4,912.30 \\
2018 & $\mathrm{~S} / 4,912.30$ \\
2019 & $\mathrm{~S} / 4,912.30$ \\
2020 & $\mathrm{~S} / 4,912.30$ \\
2021 & $\mathrm{~S} / 4,912.30$ \\
\hline
\end{tabular}

Fuente: Elaboración propia 


\subsection{Presupuesto de Resultados}

\subsubsection{Estado de Situación Financiera Proyectado:}

Tabla 104

Estado de Situación Financiera Proyectado o Balance General Proyectado

\begin{tabular}{|c|c|c|c|c|c|}
\hline \multicolumn{6}{|c|}{ Estado de Situacion Financiera Proyectado } \\
\hline Años & 2017 & 2018 & 2019 & 2020 & 2021 \\
\hline \multicolumn{6}{|l|}{ ACTIVOS } \\
\hline \multicolumn{6}{|l|}{ ACTIVO CORRIENTE } \\
\hline Efectivo & $5,090.14$ & $5,400.28$ & $5,710.41$ & $6,020.54$ & $6,330.67$ \\
\hline Cuentas por cobrar comerciales & $893,201.22$ & $903,657.93$ & $914,114.63$ & $924,571.34$ & $935,028.05$ \\
\hline Inventarios & 3530.54 & 3618.47 & 3649.84 & 3681.22 & 3712.59 \\
\hline TOTAL ACTIVO CORRIENTE & $901,821.90$ & $912,676.67$ & $923,474.88$ & $934,273.10$ & $945,071.31$ \\
\hline \multicolumn{6}{|l|}{ ACTIVO NO CORRIENTE } \\
\hline Maquinaria y equipos & 119178.84 & 119178.84 & 119178.84 & 119178.84 & 119178.84 \\
\hline Depreciacion de maquinaria y equipos & 10983.29 & 10983.29 & 10983.29 & 10983.29 & 10983.29 \\
\hline Moviliario y Equipo de oficina & 7264 & 7264 & 7264 & 7264 & 7264 \\
\hline TOTAL ACTIVO NO CORRIENTE & 137426.13 & 137426.13 & 137426.13 & 137426.13 & 137426.13 \\
\hline TOTAL DE ACTIVO & $1,039,248.03$ & $1,050,102.80$ & $1,060,901.01$ & $1,071,699.23$ & $1,082,497.44$ \\
\hline \multicolumn{6}{|l|}{ PASIVO } \\
\hline \multicolumn{6}{|l|}{ PASIVO CORRIENTE } \\
\hline Cuentas por pagar comerciales & $221,051.42$ & $239,472.38$ & $259,428.41$ & $281,047.44$ & $304,468.06$ \\
\hline Obligaciones bancarias & 0 & 0 & 0 & 0 & 0 \\
\hline Otras cuentas por pagar & $320,962.43$ & $293,113.98$ & $278,698.80$ & $262,182.50$ & $243,389.99$ \\
\hline Impuestos por pagar & 37540.35 & 40668.71 & 44057.77 & 47729.25 & 51706.69 \\
\hline TOTAL DE PASIVO CORRIENTE & $579,554.20$ & $\mathbf{5 7 3 , 2 5 5 . 0 7}$ & $582,184.98$ & $590,959.19$ & $599,564.74$ \\
\hline \multicolumn{6}{|l|}{ PASIVOS NO CORRIENTE } \\
\hline Impuesto sobre la renta & $10,950.25$ & $11,862.77$ & $12,851.33$ & $13,922.28$ & $15,082.47$ \\
\hline TOTAL PASIVO NO CORRIENTE & 10950.25 & 11862.77 & 12851.33 & 13922.28 & 15082.47 \\
\hline TOTAL DE PASIVO & $590,504.45$ & $585,117.84$ & $595,036.31$ & $604,881.47$ & $614,647.21$ \\
\hline \multicolumn{6}{|l|}{ PATRIMONIO } \\
\hline Capital social & $253,846.96$ & $253,846.96$ & $253,846.96$ & $253,846.96$ & $253,846.96$ \\
\hline Reserva Legal 5\% & $9,744.83$ & $10,556.90$ & $11,436.64$ & $12,389.70$ & $13,422.17$ \\
\hline Utilidades acumuladas & $185,151.79$ & $200,581.10$ & $200,581.10$ & $200,581.10$ & $200,581.10$ \\
\hline TOTAL DE PATRIMONIO & $448,743.58$ & $464,984.96$ & $465,864.70$ & $466,817.76$ & $467,850.23$ \\
\hline TOTAL PASIVO Y PATRIMONIO & $1,039,248.03$ & $1,050,102.80$ & 1,060,901.01 & $1,071,699.23$ & $1,082,497.44$ \\
\hline
\end{tabular}

Fuente: Elaboración propia

El Estado de situación financiera fue elaborado considerando la proyección de activos; de la estructura financiera; del flujo de caja financiero; proyección de inventarios; presupuestos de venta y producción proyectados, información con la cual se pudo estructurar los conceptos considerados en el cuadro. 


\subsubsection{Estado de Ganancias y Pérdidas Proyectado:}

Tabla 105

Estado de Ganancias y Pérdidas

\begin{tabular}{|c|c|c|c|c|c|}
\hline & 2017 & 2018 & 2019 & 2020 & 2021 \\
\hline Ventas & S/ 756,950.18 & S/ $765,811.80$ & S/ 774,673.42 & $\mathrm{S} / 783,535.04$ & S/ 792,396.65 \\
\hline Costo de Ventas & $\mathrm{S} / 401,636.44$ & $\mathrm{~S} / 404,891.53$ & $\mathrm{~S} / 408,146.62$ & $\mathrm{~S} / 411,344.90$ & $\mathrm{~S} / 411,344.90$ \\
\hline Utilidad Bruta & $\mathrm{S} / \mathbf{3 5 5 , 3 1 3 . 7 4}$ & $\mathrm{S} / \mathbf{3 6 0 , 9 2 0 . 2 7}$ & $\mathrm{S} / \mathbf{3 6 6 , 5 2 6 . 8 0}$ & $\mathrm{S} / \mathbf{3 7 2 , 1 9 0 . 1 4}$ & $\mathrm{S} / \mathbf{3 8 1 , 0 5 1 . 7 5}$ \\
\hline Gastos Operativos Totales & $\mathrm{S} / 252,784.58$ & $\mathrm{~S} / 252,784.58$ & $\mathrm{~S} / 252,784.58$ & $\mathrm{~S} / 252,784.58$ & $\mathrm{~S} / 252,784.58$ \\
\hline Gastos administr y de ventas & S/ 246,713.59 & S/ 246,713.59 & S/ 246,713.59 & S/ 246,713.59 & S/ 246,713.59 \\
\hline Depreciaciones & $\mathrm{S} / 10,983.29$ & $\mathrm{~S} / 10,983.29$ & $\mathrm{~S} / 10,983.29$ & $\mathrm{~S} / 10,983.29$ & $\mathrm{~S} / 10,983.29$ \\
\hline Amortización (de Intangibles) & $\mathrm{S} / 4,912.30$ & $\mathrm{~S} / 4,912.30$ & $\mathrm{~S} / 4,912.30$ & $\mathrm{~S} / 4,912.30$ & $\mathrm{~S} / 4,912.30$ \\
\hline Utilidad Operativa & $\mathrm{S} / \mathbf{1 0 2 , 5 2 9 . 1 6}$ & S/ 108,135.69 & $\mathrm{S} / \mathbf{1 1 3 , 7 4 2 . 2 2}$ & S/ 119,405.55 & S/ 128,267.17 \\
\hline Ingresos por Venta de activos & $\mathrm{S} / 0$ & $\mathrm{~S} / 0$ & $\mathrm{~S} / 0$ & $\mathrm{~S} / 0$ & $\mathrm{~S} / 0$ \\
\hline Gastos Financieros & $\mathrm{S} / 0$ & $\mathrm{~S} / 0$ & $\mathrm{~S} / 0$ & $\mathrm{~S} / 0$ & $\mathrm{~S} / 0$ \\
\hline Utilidad Antes de Impuestos & $\mathrm{S} / 102,529.16$ & S/ $108,135.69$ & $\mathrm{~S} / 113,742.22$ & $\mathrm{~S} / 119,405.55$ & S/ $128,267.17$ \\
\hline Impuesto a la Renta ( $29.5 \%$ ) & $\mathrm{S} / 30,246.10$ & S/ 31,900.03 & $\mathrm{S} / 33,553.95$ & $\mathrm{~S} / 35,224.64$ & $\mathrm{~S} / 37,838.82$ \\
\hline Utilidad Neta & $\mathrm{S} / \mathbf{7 2 , 2 8 3 . 0 6}$ & $\mathrm{S} / 76,235.66$ & $\mathrm{~S} / \mathbf{8 0 , 1 8 8 . 2 6}$ & $\mathrm{S} / \mathbf{8 4 , 1 8 0 . 9 2}$ & $\mathrm{S} / \mathbf{9 0 , 4 2 8 . 3 6}$ \\
\hline
\end{tabular}

8.4.3. Flujo de Caja Proyectado: Considerando la información disponible en el Resumen de Inversiones, Costos y Gastos así como también el cuadro de liquidación de IGV, se elabora el Flujo de Caja Proyectado:

Tabla 106

Flujo de Caja Proyectado

\begin{tabular}{lllllll}
\hline & $\mathbf{2 0 1 6}$ & $\mathbf{2 0 1 7}$ & $\mathbf{2 0 1 8}$ & $\mathbf{2 0 1 9}$ & $\mathbf{2 0 2 0}$ & $\mathbf{2 0 2 1}$ \\
\hline INGRESOS & & $\mathrm{S} / 893,201.22$ & $\mathrm{~S} / 903,657.93$ & $\mathrm{~S} / 914,114.63$ & $\mathrm{~S} / 924,571.34$ & $\mathrm{~S} / 935,028.05$ \\
Venta de Mercaderías & & $\mathrm{S} / 893,201.22$ & $\mathrm{~S} / 903,657.93$ & $\mathrm{~S} / 914,114.63$ & $\mathrm{~S} / 924,571.34$ & $\mathrm{~S} / 935,028.05$ \\
EGRESOS & $\mathrm{S} / 256,697.35$ & $\mathrm{~S} / 776,888.13$ & $\mathrm{~S} / 802,724.59$ & $\mathrm{~S} / 829,053.56$ & $\mathrm{~S} / 835,517.62$ & $\mathrm{~S} / 838,528.70$ \\
Inversiones Costos y & $\mathrm{S} / 256,697.35$ & $\mathrm{~S} / 766,466.90$ & $\mathrm{~S} / 770,307.90$ & $\mathrm{~S} / 774,148.90$ & $\mathrm{~S} / 777,922.87$ & $\mathrm{~S} / 776,509.02$ \\
Gastos & & $\mathrm{S} / 19,824.87$ & $\mathrm{~S} / 516.66$ & $\mathrm{~S} / 21,350.70$ & $\mathrm{~S} / 22,370.11$ & $\mathrm{~S} / 24,180.87$ \\
Pago de IGV & & $\mathrm{S} / 30,246.10$ & $\mathrm{~S} / 31,900.03$ & $\mathrm{~S} / 33,553.95$ & $\mathrm{~S} / 35,224.64$ & $\mathrm{~S} / 37,838.82$ \\
Pago IR ( 29.5\% ) & & $\mathrm{S} / \mathbf{1 1 6 , 3 1 3 . 0 9}$ & $\mathrm{S} / \mathbf{1 0 0 , 9 3 3 . 3 4}$ & $\mathbf{S} / \mathbf{8 5 , 0 6 1 . 0 7}$ & $\mathrm{S} / \mathbf{8 9 , 0 5 3 . 7 2}$ & $\mathbf{S} / \mathbf{9 6 , 4 9 9 . 3 5}$ \\
FLUJO DE CAJA & $\mathrm{S} / \mathbf{2 5 6 , 6 9 7 . 3 5}$ & & & & &
\end{tabular}

Fuente: Elaboración propia 


\section{Capitulo IX}

\section{EVALUACIÓN ECONÓMICA Y FINANCIERA}

\subsection{Evaluación Financiera}

Se mostrarán a continuación los indicadores financieros calculados con el fin de evaluar al viabilidad del proyecto.

9.1.1. TIR. La tasa interna de retorno permite conocer la tasa de rentabilidad promedio anual que el proyecto paga a los inversionistas por invertir sus fondos allí. Esa tasa de rentabilidad, se debe comparar contra lo que se deseaba ganar como mínimo en este caso el COK del Flujo de Caja del Inversionista. ${ }^{38}$

En la siguiente tabla se tiene el Flujo de Caja del Inversionista:

Tabla 107

Flujo de Caja Proyectado

\begin{tabular}{lllllll}
\hline & 2016 & 2017 & 2018 & 2019 & 2020 & 2021 \\
\hline $\begin{array}{l}\text { FLUJO DE } \\
\text { CAJA }\end{array}$ & S/ 256,697.35 & S/ 116,313.09 & S/ 100,933.34 & S/ 85,061.07 & S/ 89,053.72 & S/ 96,499.35 \\
\hline
\end{tabular}

Fuente: Elaboración propia

Con esta información se aplica el criterio matemático:

Io $=$ Valor actual de cada flujo al año 2016

En el cuadro siguiente se muestra el resultado:

TIR $=27.50 \%$

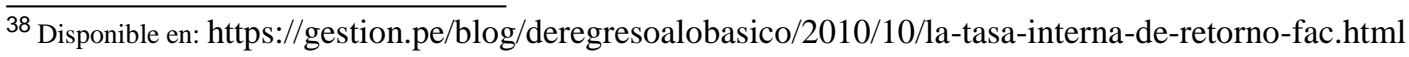


Para los inversionistas, que tienen una expectativa de rendimiento del $12.19 \%$ (cok), resulta atractivo que en promedio se obtenga el $27.50 \%$ anual.

\subsubsection{Valor Actual Neto (VAN).}

El valor actual neto permite saber si el proyecto genera valor; esto es si el flujo de entradas netas futuras descontadas (utilizando el cok) es mayor a la inversión. En el caso del preente proyecto:

\begin{tabular}{|l|l|}
\hline Para: $\mathrm{COK}=12.19 \%$ & VAN $=\mathbf{S} / \mathbf{9 7 9 5 1 . 3 9}$ \\
\hline
\end{tabular}

Para el inversionista, que tiene una expectativa de rendimiento del 12,19\% (cok), resulta atractivo que el proyecto genere valor por S/ 97951.39, pues este monto resulta luego de haber cubierto toda su inversión.

\subsubsection{Retorno sobre el Patrimonio}

El return on equity o "Retorno sobre el patrimonio" (Modelo Dupont) es un indicador financiero de mucho interés para el accionista puesto que mide cuanto beneficio se obtiene por cada sol que se ha invertido. Este análisis le permite al inversionista tener una lectura adecuada sobre el margen de utilidad; la eficiencia en el uso de los activos y el grado del apalancamiento financiero. Se calcula así:

Return On Equity = Beneficio Neto después de Impuestos / Capitales propios

El ROE para este proyecto será:

$\mathrm{ROE}=\mathbf{2 8 . 4 8 \%}$ 
Este resultado nos indica que las utilidades netas corresponden al $28.48 \%$ del capital entregado por los inversionistas.

\subsubsection{Periodo de Recuperación Descontado (PRD) o Payback Descontado.}

Con este procedimiento se logrará medir el tiempo en el que se recupera la inversión, incluyendo costo de capital (cok) involucrado ${ }^{39}$. Se calcula así:

Tabla 108

Determinación del Periodo de Recuperación Descontado

\begin{tabular}{|c|c|c|c|c|c|c|}
\hline & & Flujos Descon & dos al 2016 & & & \\
\hline & 2016 & del 2017 & del 2018 & del 2019 & del 2020 & del 2021 \\
\hline FC Actualizado: & S/ 256,697.35 & S/ 103,679.25 & S/ 80,197.57 & S/ 60,244.95 & S/ 56,221.86 & $\mathrm{S} / \mathbf{5 4 , 3 0 5 . 1 2}$ \\
\hline $\begin{array}{l}\text { Saldo de } \\
\text { inversión: }\end{array}$ & & $\mathrm{S} / \mathbf{1 5 3 , 0 1 8 . 1 0}$ & S/ 72,820.54 & S/ 12,575.58 & S/ 43,646.27 & \\
\hline PRD(E): & 3 años & 2.68 meses & & & & \\
\hline
\end{tabular}

Fuente: Elaboración propia

Se observa que al actualizar los flujos de efectivo futuros se obtienen cantidades que deben ir cubriendo la inversión inicial. Al realizar los cálculos apropiados tenemos que el periodo de recuperación es de cuatro año y aproximadamente siete meses.

\subsubsection{Análisis de Beneficio-Costo (B/C):}

La relación beneficio costo es un análisis que se hace al comparar el flujo de entradas futuras proyectadas actualizadas con la inversión. Si el Beneficio costo es un valor por encima de la unidad $(>1)$ se puede decir que por cada unidad monetaria invertida existe un beneficio.

\footnotetext{
${ }^{39}$ SAPAG, Nassir. Proyectos de Inversión, Formulación y Evaluación. 1ra ed. México D.F.: Pearson Educación de México S.A de C. V., 2009. p. 307
} 
Si hacemos una comparación con los resultados del VAN, se tiene que si la relación $\mathrm{B} / \mathrm{C}$ es igual a 1, entonces el VAN del proyecto es "cero"; Si la relación B/C es mayor que 1, entonces el VAN del proyecto es positivo y finalmente si la relación B/C es menos que 1, entonces el VAN del proyecto es negativo ${ }^{40}$

Tabla 109

Análisis Beneficio-Costo

Valor Actual del $\quad$ S/ 354,648.74
Flujo

\begin{tabular}{ll}
\hline Inversión: & S/ $256,697.35$ \\
B/C: & $\mathbf{1 . 3 8}$ \\
\hline
\end{tabular}

Fuente: Elaboración propia

Esto nos da la información que por cada sol invertido en el proyecto se obtendrá un beneficio del 1.38 soles.

\subsection{Análisis de Riesgos.}

\subsubsection{Análisis de Punto de Equilibrio.}

La cantidad de unidades anuales que se debe producir para cubrir los costos se determinó de la siguiente manera:

$$
P E Q=\frac{C F T}{\text { Precio Venta Unitario }- \text { Costo VariableUnitario }}
$$

Se dispone de la siguiente información:

\footnotetext{
${ }^{40}$ SAPAG, Nassir. Proyectos de Inversión, Formulación y Evaluación. 1ra ed. México D.F.: Pearson Educación de México S.A de C. V., 2009. p. 307
} 
Tabla 110

Cálculo del Punto de Equilibrio (botellas)

\begin{tabular}{|c|c|c|c|c|c|}
\hline $\begin{array}{l}\text { Concepto } \\
\text { Costos Fijos }\end{array}$ & 2017 & 2018 & 2019 & 2020 & 2021 \\
\hline Depreciación & $\mathrm{S} / 10,099.90$ & $\mathrm{~S} / 10,099.90$ & $\mathrm{~S} / 10,099.90$ & $\mathrm{~S} / 10,099.90$ & $\mathrm{~S} / 10,099.90$ \\
\hline Sueldos (Fijo) & $\mathrm{S} / 86,867.37$ & $\mathrm{~S} / 86,867.37$ & $\mathrm{~S} / 86,867.37$ & $\mathrm{~S} / 86,867.37$ & $\mathrm{~S} / 86,867.37$ \\
\hline Gastos Distribución & $\mathrm{S} / 48,840.00$ & $\mathrm{~S} / 49,411.77$ & $\mathrm{~S} / 49,983.54$ & $\mathrm{~S} / 50,555.31$ & $\mathrm{~S} / 51,127.08$ \\
\hline Gastos Administrativos & $\mathrm{S} / 84,016.80$ & $\mathrm{~S} / 84,016.80$ & $\mathrm{~S} / 84,016.80$ & $\mathrm{~S} / 84,016.80$ & $\mathrm{~S} / 84,016.80$ \\
\hline Gasto de Marketing & $\mathrm{S} / 72,000.00$ & $\mathrm{~S} / 72,000.00$ & $\mathrm{~S} / 72,000.00$ & $\mathrm{~S} / 72,000.00$ & $\mathrm{~S} / 72,000.00$ \\
\hline Total Costo Fijo & S/301,824.07 & $\mathrm{S} / 302,395.84$ & $\mathrm{~S} / 302,967.61$ & $\mathrm{~S} / \mathbf{3 0 3 , 5 3 9 . 3 8}$ & S/304,111.15 \\
\hline Costos Variables & & & & & \\
\hline Materia Prima, Cif & $\mathrm{S} / 580,606.26$ & $\mathrm{~S} / 587,403.42$ & S/594,200.58 & $\mathrm{S} / 600,997.73$ & $\mathrm{~S} / 607,794.89$ \\
\hline Total Costo Variable & S/580,606.26 & $\mathrm{S} / \mathbf{5 8 7 , 4 0 3 . 4 2}$ & S/594,200.58 & $S / 600,997.73$ & S/607,794.89 \\
\hline $\begin{array}{l}\text { Costo Variable Unitario } \\
\text { Precio de Venta }\end{array}$ & $\mathrm{S} / 2.55$ & $\mathrm{~S} / 2.55$ & $\mathrm{~S} / 2.55$ & $\mathrm{~S} / 2.55$ & $\mathrm{~S} / 2.55$ \\
\hline Precio de venta unitario & $\mathrm{S} / 3.92$ & $\mathrm{~S} / 3.92$ & $\mathrm{~S} / 3.92$ & $\mathrm{~S} / 3.92$ & $\mathrm{~S} / 3.92$ \\
\hline $\begin{array}{l}\text { Punto de Equilibrio Anual } \\
\text { (unidades) }\end{array}$ & 220,141 & 220,558 & 220,975 & 221,392 & 221,809 \\
\hline
\end{tabular}

Fuente: Elaboración propia

\subsubsection{Análisis de Sensibilidad}

Se evaluará la sensibilidad del proyecto ante los cambios que puedan sufrir las variables críticas del estudio: la demanda, el precio de venta y el costo del insumo principal; los cuales afectarán los indicadores financieros y por tanto la decisión final de viabilidad del proyecto.

\section{A. Demanda}

Es una variable crítica porque impacta en los ingresos de la empresa. Se realizó una simulación de variación en la variable demanda hasta que se encontró que: "Si la demanda disminuye en un $8 . \%$ aproximadamente, la TIR (nueva) sería $11.55 \%$ que resulta estar por debajo del rendimiento esperado por el inversionista $\mathrm{COK}=12.55 \%$ (TIR $<=\mathrm{COK}$ ); el VAN saldría negativo (-3542.73) y el Beneficio/Costo estaría por debajo de 1 lo que se entiende que es un escenario imposible para los inversionistas. Se concluye entonces que el proyecto sólo permitiría una variaciones por encima de $-8 . \%$ en el promedio de ventas para generar rendimiento a los inversionistas. Ver la siguiente tabla: 
Tabla 111

Indicadores ante variación de Demanda

\begin{tabular}{lllll}
\hline & & COK & $\mathbf{1 2 . 1 9 \%}$ & \\
\hline Variación & Nuevo Demanda & & & \\
Demanda & Promedio & VAN & TIR & B/C \\
Original & 233335 & S/ $97,951.39$ & $27.50 \%$ & 1.38 \\
$\mathbf{5 \%}$ & 245002 & S/ $175,078.46$ & $39.11 \%$ & 1.68 \\
$\mathbf{- 5 \%}$ & 221669 & S/ $37,677.54$ & $18.62 \%$ & 1.15 \\
$\mathbf{- 8 \%}$ & 214669 & $-S / 3,542.73$ & $11.55 \%$ & 0.99 \\
\hline
\end{tabular}

Fuente: Elaboración propia

\section{B. Valor de venta unitario al canal de venta y al consumidor final:}

El valor de venta también es una variable muy sensible puesto que puede cambiar debido a factores externos como una regulación de precios por oferta y demanda en el mercado. En este caso se hizo una variación en el precio y se encontró que si el precio varía en -5.\% (nuevo valor de venta de: $\mathrm{S} / 3.15$ ), la tasa interna de retorno sería: $\mathrm{TIR}=12.76 \%$ lo cual nos indica que el proyecto aparentemente generaría valor; sin embargo, al ver el beneficio/costo $(\mathrm{B} / \mathrm{C}=1.01)$ prácticamente el beneficio estaría cubriendo la inversión. Desde otra perspectiva si elevamos el valor de venta los precios al canal de venta se elevarían, y por consiguiente, se contraería gradualmente el mercado objetivo.

Tabla 112

Indicadores ante variación del Valor de Ventas al canal de ventas y al consumidor final

\begin{tabular}{llllll}
\hline $\begin{array}{l}\text { Variación del Valor } \\
\text { Venta } \\
\text { a Canal de Venta }\end{array}$ & $\begin{array}{l}\text { Nuevo } \\
\text { Valor } \\
\text { Venta }\end{array}$ & $\begin{array}{l}\text { Nuevo } \\
\text { Precio } \\
\text { Cliente }\end{array}$ & VAN & TIR & B/C \\
\hline Original & $\mathrm{S} / 3.32$ & $\mathrm{~S} / 4.50$ & $\mathrm{~S} / 97,951.39$ & $27.50 \%$ & 1.38 \\
$\mathbf{5 \%}$ & $\mathrm{S} / 3.49$ & $\mathrm{~S} / 4.74$ & $\mathrm{~S} / 192,492.40$ & $40.71 \%$ & 1.75 \\
$\mathbf{1 0 \%}$ & $\mathrm{S} / 4.02$ & $\mathrm{~S} / 5.46$ & $\mathrm{~S} / 487,237.92$ & $77.48 \%$ & 2.90 \\
$\mathbf{- 1 \%}$ & $\mathrm{S} / 3.15$ & $\mathrm{~S} / 4.27$ & $\mathrm{~S} / 3,410.37$ & $12.76 \%$ & 1.01 \\
\hline
\end{tabular}

Fuente: Elaboración propia 


\section{Costo del Insumo Principal (Sanky):}

El costo del insumo principal (sanky) resulta sensible ya que, pese a que la fruta está permanentemente disponible en el Mercado $\mathrm{N}^{\circ} 2$ de Frutas de Lima en cantidades suficientes para poder abastecer el negocio, el precio no siempre se mantiene estable, más bien hay temporadas donde la demanda se incrementa debido a que existe fabricantes de ungüentos, extractos, shampoos ${ }^{41}$, etc. Al hacer el análisis se observa que ante un aumento del $25 \%$ en el precio del insumo (de S/ 4.00 a S/ 5.00 aproximadamente) se obtendría una TIR del $21.15 \%$ reduciéndose en 6 puntos porcentuales, por tanto un incremento mayor disminuiría este indicador hasta hacerlo inviable al llegar al 12.19\% (cok del inversionista).

Por el contrario, si disminuimos el precio (que se podría presentar ante una sobreproducción del insumo) tendriamos un incremento en todos los indicadores, en el cuadro se disminuyó en $2.5 \%$ dando como resultado un VAN de S/102137.15 y una TIR del $28.12 \%$.

Tabla 113

Indicadores ante variación del costo del insumo principal

\begin{tabular}{lllll}
\hline $\begin{array}{l}\text { Costo Sanky (x } \\
\text { kilo) }\end{array}$ & S/4.00 & COK & $\mathbf{1 2 . 1 9 \%}$ & \\
Variación del costo & Nuevo Costo & VAN & TIR & B/C \\
\hline $\mathbf{2 5 \%}$ & S $/ 5.00$ & S/ 56093.78 & $21.15 \%$ & 1.22 \\
$\mathbf{- 2 . 5 \%}$ & S/3.90 & S/ 102137.15 & $28.12 \%$ & 1.4 \\
\hline
\end{tabular}

Fuente: Elaboración propia

\footnotetext{
41 Disponible en: https://perunatural.files.wordpress.com/2009/12/gigaextracto.jpg Disponible en: https://peru21.pe/emprendimiento/peru-natural-afan-difundir-recursos-pais-185254 Disponible en: http://www.agraria.pe/noticias/productos-innovadores-a-base-de-aguaymanto-pitahaya-11453
} 


\section{CONCLUSIONES Y RECOMENDACIONES}

\section{Conclusiones:}

La bebida natural Kawsay elaborada a base de Sanky en un periodo de un año debe de tener una participación de mercado del 0.9\% del mercado potencial este año 2017.

Que se logre la utilidad esperada, desde el año uno, es decir el 2017 al año cinco o año 2021, de acuerdo al estudio realizado.

La bebida natural Sanky, tiene altos contenidos de calcio, potasio, fosforo, antioxidantes, vitamina $\mathrm{C}$, que son beneficiosos para atacar el sobrepeso, combatir la hipertensión arterial y sobretodo el cansancio. Es considerado un antioxidante natural

Una limitación que se tiene es la información muy restringida en el sector de bebidas naturales

La industria de bebidas dentro del sector manufactura es uno de los que ha venido creciendo en manera sostenida desde al año 2005 al año 2016

En el nivel de competitividad, no existen competidores directos que ofrezcan bebidas refrescantes naturales a base de Sanky, pero si existen competidores que ofrecen bebidas naturales a base de otras frutas.

De acuerdo al análisis cultural las ventas combinadas de bebidas energéticas y deportivas a nivel mundial alcanzaron los US\$ 50 mil millones en 201442

Las conclusiones del estudio cualitativo y cuantitativo, nos dan como resultado los lugares de compra más comunes de bebidas envasadas, las marcas más recurrentes que tienen los consumidores en su mente, las marcas con las que más se identifican

\footnotetext{
${ }^{42}$ Disponible en *https//www.imf.org/external/spanish/pubs/ft/wco/2017/update/01/pdf/0117s.pdf.
} 
Se cuenta con la debida infraestructura, mediante la Ingeniería del Proyecto para resolver todo lo concerniente a la instalación y el funcionamiento de la planta.

Con el Estudio de Localización se ha podido determinar mediante una ponderación la mejor opción para la ubicación de nuestra planta.

Luego de revisar los flujos de caja obtenidos en el análisis financiero se observa que el proyecto resulta rentable tanto a nivel de empresa como a nivel de inversionista, esto es debido a que el rubro de bebidas es una de los rubros más dinámicos del mercado.

El proyecto es económicamente viable porque sí se recupera la inversión realizada; se genera valor en ambos niveles (empresa, inversionista) y se tiene un spread tanto para el análisis económico como para el financiero para seguir incrementando ese valor generado (TIR).

\section{Recomendaciones:}

Se recomienda que la bebida natural Kawsay Sankyfruit, a base del fruto Sanky debe de ser incluida en la dieta diaria aprovechando sus bondades para fidelizar a nuestros clientes.

Las recomendaciones del estudio cualitativo y cuantitativo son cumplir con las expectativas respecto de cómo desean que sea un refresco natural: color, preferencia por los envases de plástico, tamaño, sabor, textura y precio. 


\section{Bibliografía}

A. Saldaña (2011) Plan de negocios para la elaboración de jugos naturales a base de frutas y hortalizas. Chile: Repositorio Universidad de Chile.

J. Palma (2013) Plan Negocios: Empresa de Jugos Naturales (Bar de Jugos) Argentina: bdigital Universidad Nacional de Cuyo Argentina.

David Fred R. (2013) Conceptos de Administración Estratégica. Decimocuarta edición. México, Pearson Educación-

Lawrence J., Gitman y Chad J. Zutter (2012) Principios de Administración Financiera. Decimosegunda edición. México: Pearson Educación

Kotler Philips (2007) Marketing vp Latinomérica. Decimoprimera edición. México, Pearson Educación

Disponible en: http://bdigital.uncu.edu.ar/objetos_digitales/5615/tesis-cs-ec-palma.pdf Disponible en: http://es.slideshare.net/erikcortezgarcia/tesis-planta-productora-de-jugos Disponible en: http://repositorio.ucsg.edu.ec/bitstream/123456789/1629/1/T-UCSG-PREECO-ADM-66.pdf

Disponible en: http://www.tesis.uchile.cl/tesis/uchile/2011/cf-ayala_az/html/indexframes.html

Kotler Philips (2007) Marketing vp Latinomérica. Decimoprimera edición. México, Pearson Educación

Lawrence J. Gitman y Chad J. Zutter (2012) Principios de Administración Financiera Tesis: “Jugo Nutritivo S21”, Universidad Católica de Santiago de Guayaquil Seminario"Ecuador, 2010

Tesis: "Planta Industrializadora de Jugos de Fruta en el Departamento de Tarija-Bolivia", 2008 
SAPAG, Nassir. Proyectos de Inversión, Formulación y Evaluación. 1ra ed. México D.F.: Pearson Educación de México S.A de C. V., 2009. p. 147.

\section{Referencias Electrónicas}

\section{Capítulo I}

http://abresa.pe/wp-content/uploads/2014/06/Aguas-y-energizantes-seguir\%C3\%A1nrevitalizando-el-mercado-de-bebidas.pdf http://emprendedorestv.pe/historia-de-exito-jugo-natural-y-energizante/ http://www.andina.com.pe/agencia/noticia-demanda-bebidas-saludables-peru-crece-a-ritmo300-ultimos-meses-senala-ajegroup-262394.aspx http://www.consumer-truth.com.pe/global-thinking-las-4-tendencias-mas-importantes-enalimentos-y-bebidas/ http://www.inei.gob.pe/media/MenuRecursivo/publicaciones_digitales/Est/Lib0883/Libro.pdf

\section{Capítulo II}

http://es.slideshare.net/Yenichulita/anlisis-estructural-de-los-sectores-industriales http://gestion.pe/economia/bcp-recuperacion-demanda-interna-se-sentira-negocios-desdesegundo-semestre-2180369

http://gestion.pe/economia/precios-al-consumidor-lima-metropolitana-subieron-323-20162178561

http://gestion.pe/economia/tipo-cambio-cerro-caida-17-todo-2016-2178519 http://larepublica.pe/impresa/economia/823583-peru-con-menor-inflacion-y-mayorcrecimiento-el-2017 http://peru21.pe/economia/peru-liderara-crecimiento-economico-2017-2268677 
http://peru21.pe/economia/zavala-economia-peruana-crecio-entre-39-y-4-2016-2267347

http://proexpansion.com/es/articles?tag=gaseosas\#more_article_1010Z

http://proexpansion.com/es/articles/1138

http://www.americaeconomia.com/negocios-industrias/aprueban-lineamientos-depolitica-

agraria-que-impulse-crecimiento-e-inclusion-enAnálisis EconómicoAnálisis

Económico

http://www.americaeconomia.com/negocios-industrias/sepa-como-el-holding-aje-group-

busca-encontrar-la-senda-del-crecimiento

http://www.inei.gob.pe/estadisticas/indice-tematico/sector-statistics/

http://www.innovateperu.pe/incentivo-tributario/

http://www.madrid.org/cs/Satellitecid=1133275743558\&idioma=_es\&pagename=Emprende dores\%2FEMPR_Metodologia_Proc\%2FEMPR_DetalleProceso

http://www.minam.gob.pe/wp-content/uploads/2013/06/ley-general-del-ambiente.pdf http://www.produce.gob.pe/index.php/estadistica/exportaciones

https://www.ajegroup.com/es/acerca-de-aje/key-facts/

https://www.ajegroup.com/wp-content/uploads/2015/11/np-multilatinasmundo.pdf https://www.google.com.pe/webhp?sourceid=chromeinstant\&ion=1\&espv=2\&ie=UTF8\#q=P roducto+Bruto+Interno+Por+Sectores+Productivos+20042014+\%28Millones+De+Nue vos+Soles $\% 29$

www.bcrp.gob.pe/docs/Estadisticas/Cuadros-Anuales/ACuadro_07.xls

https://www.google.com.pe/search?espv=2\&biw=931\&bih=606\&q=memoria + anual+UCP+B

ACKUS+y+JOHNSTON+2015\&spell=1\&sa=X\&ved=0ahUKEwiQ7b6Ws_HMAhWB MyYKHX63AbcQBQgYKAA

http://www.smv.gob.pe/ConsultasP8/temp/MEMORIA\%202015\%20y\%20anexo\%20sostenib ilidad.pdf 
http://www.bvl.com.pe/jsp/ShowEEFF_new.jsp?Ano=2015\&Trimestre=A\&Rpj=006166\&Ra zoSoci=GLORIA\%20S.A.\&TipoEEFF=MA\&Tipo1=A\&Tipo2=I\&Dsc_Correlativo=0 000\&Secuencia $=1 \&$ Cod_Secuencia $=1$

http://www.bvl.com.pe/inf_corporativa42500_TEFJVkVCQzE.html https://www.datosperu.org/empresa-abt-productos-naturales-sac-20517535851.php http://www.sites.upiicsa.ipn.mx/polilibros/portal/polilibros/p_terminados/Planeacion_Estrate gica_ultima_actualizacion/polilibro/Unidad\%20IV/Ejemplo_MPC.htmhttp://www.sites. upiicsa.ipn.mx/polilibros/portal/polilibros/p_terminados/Planeacion_Estrategica_ultima _actualizacion/polilibro/Unidad\%20IV/Ejemplo_MPC.htm

http://rankings.americaeconomia.com/2010/500/analisis-sector-bebidas.php http://rankings.americaeconomia.com/las-500-mayores-empresas-de-peru-2014/ranking500/las-mayores-empresas-del-peru/bebidas-y-licores/ http://rankings.americaeconomia.com/las-500-mayores-empresas-de-peru-2014/introduccion/ http://www.ipsos.pe/tendencias_mercado?page=1

http://www.bcrp.gob.pe/docs/Publicaciones/Presentaciones-Discursos/2016/presentacion-042016.pdf

http://www.bcrp.gob.pe/docs/Publicaciones/Reporte-Inflacion/2016/marzo/reporte-deinflacion-marzo-2016.pdf

https://www.imf.org/external/spanish/pubs/ft/weo/2017/update/01/pdf/0117s.pdf http://laprensa.peru.com/actualidad/noticia-inei-inflacion-peru-fue-44-durante-2015-56869 http://peru21.pe/economia/peru-liderara-crecimiento-economico-2017-2268677 http://peru21.pe/economia/fmi-peru-tendria-mejor-desempeno-region-2237250 http://peru21.pe/economia/pbi-2015-aumentaria-28-mientras-que-2016-podria-llegar-al-322236777 
http://www.asbanc.com.pe/Publicaciones/ASBANC\%20SEMANAL\%20N\%C2\%BA\%2018

1.pdf

http://wenssilvestre.blogspot.pe/2015/10/a-donde-va-la-economia-peruana.html

http://es.actualitix.com/pais/per/peru-pib-per-capita.php\#tabla-de-datos

http://www.mef.gob.pe/contenidos/tributos/tbl_imp_er/DL_00776.pdf

http://larepublica.pe/impresa/economia/730212-desde-hoy-baja-el-impuesto-la-renta-27-y-uitsube-s-3950

http://www.asesormype.com/etiqueta/tasa-dividendos-2017/

http://www.munichorrillos.gob.pe/home/modernizamuni.php

http://peru.com/2011/08/18/actualidad/economia-y-finanzas/jugos-londa-son-beneficiosos-

salud-noticia-16653

http://www.londabeverage.com/es/

\section{Capitulo III}

http://www.apeim.com.pe/wp-content/themes/apeim/docs/nse/APEIM-NSE-2016.pdf http://www.apeim.com.pe/wp-content/themes/apeim/docs/nse/APEIM-NSE-2015.pdf http://www.apeim.com.pe/wp-content/themes/apeim/docs/nse/APEIM-NSE-2014.pdf http://www.apeim.com.pe/wp-content/themes/apeim/docs/nse/APEIM-NSE-2013.pdf http://www.apeim.com.pe/wp-content/themes/apeim/docs/nse/APEIM-NSE-2012.pdf http://www.apeim.com.pe/wp-content/themes/apeim/docs/nse/APEIM-NSE-2011.pdf http://www.apeim.com.pe/wp-content/themes/apeim/docs/nse/APEIM-NSE-2010-LIMA.pdf https://es.scribd.com/doc/12594780/PERU-NIVELES-SOCIOECONOMICOS-2009 http://www.apeim.com.pe/wp-content/themes/apeim/docs/nse/APEIM-NSE-2007-2008-

LIMA.pdf 


\section{Capítulo IV}

http://bebidaenergizantedesanki.blogspot.com/ http://es.slideshare.net/Delgado_Azana/investigacin-de-mercado-tipos-de-investigacin http://proyectos.inei.gob.pe/web/biblioineipub/bancopub/Est/Lib1010/index.htm http://proyectos.inei.gob.pe/web/biblioineipub/bancopub/Est/Lib1010/index.htm (Fuente propia, estimación utilizando regresión lineal) http://repositorio.utp.edu.co/dspace/bitstream/11059/1824/1/66407S486.pdf http://semanaeconomica.com/article/extractivos/agropecuario/94164-sierra-exportadorapromovera-el-sanky-al-mercado-de-bebidas-energizantes/ http://www.apeim.com.pe/wp-content/themes/apeim/docs/nse/APEIM-NSE-2016.pdf http://www.apeim.com.pe/wp-content/themes/apeim/docs/nse/APEIM-NSE-2015.pdf http://www.apeim.com.pe/wp-content/themes/apeim/docs/nse/APEIM-NSE-2014.pdf http://www.apeim.com.pe/wp-content/themes/apeim/docs/nse/APEIM-NSE-2013.pdf http://www.apeim.com.pe/wp-content/themes/apeim/docs/nse/APEIM-NSE-2012.pdf http://www.apeim.com.pe/wp-content/themes/apeim/docs/nse/APEIM-NSE-2011.pdf http://www.apeim.com.pe/wp-content/themes/apeim/docs/nse/APEIM-NSE-2010-LIMA.pdf http://www.apeim.com.pe/wp-content/themes/apeim/docs/nse/APEIM-NSE-2007-2008-

\section{LIMA.pdf}

http://www.arellanomarketing.com/inicio/las-consecuencias-sociales-economicas-y-politicas- delos-estilos-de-vida-parte-ii/ http://www.bristhar.com.ve/sorbato.html http://www.digesa.minsa.gob.pe/norma_consulta/proy_microbiologia.htm http://www.lamolina.edu.pe/gaceta/edicion2006/notas/nota153.htm https://books.google.com.pe/books?id=PxrIhy9UbZkC\&pg=PA91\&lpg=PA91\&dq=que+tipo $\mathrm{s}+\mathrm{de}+\mathrm{an} \% \mathrm{C} 3 \% \mathrm{~A} 1$ lisis+laboratorio+realizan+bebidas+naturales\&source=bl\&ots=Jv6w 
43nIdH\&sig=mDv8crqPRrdyDAPveNibf7EpgwA\&hl=es\&sa=X\&ved=0ahUKEwjJ2d 3cyuLMAhXK7iYKHSC0ArwQ6AEISDAH\#v=onepage $\& q=q u e \% 20$ tipos $\% 20 \mathrm{de} \% 20 \mathrm{a}$ n\%C3\%A1lisis\%20laboratorio\%20realizan\%20bebidas\%20naturales\&f=false https://es.scribd.com/doc/12594780/PERU-NIVELES-SOCIOECONOMICOS-2009 https://prezi.com/9opoymadysst/sanky-bebida-energizante/

\section{Capítulo V}

http://www.aulafacil.com/cursos/119693/empresa/organizacion/gestion-deproyectos/ingenieria-del-proyecto

\section{Capítulo VIII}

http://gestion.pe/economia/riesgo-pais-peru-sube-cuatro-puntos-basicos-175-puntosporcentuales-2135593

http://www.aai.com.pe/

http://www.blackrockblog.com/blackrock-sovereign-risk-indicator/ http://www.equilibrium.com.pe/ http://www.sbs.gob.pe/app/stats/TasaDiaria_18A.asp http://www.sbs.gob.pe/app/stats/TasaDiaria_6A.asp https://www.mef.gob.pe/index.php?option=com_content\&view=article\&id=222\%3Aprincipa les-calificaciones-de-riesgo-soberano\&catid=90\%3Aconsulta4\&Itemid=101017\&lang=es 


\section{Anexos}

\section{Anexo 1: Relacion de puntos de venta}

Se lista la relación de puntos de venta en Lima Zona 7, se consideran supermercados, tiendas de convenierncia así como tiendas ecológicas.

\begin{tabular}{|c|c|c|c|}
\hline Orden & Tipo & Nombre & Distrito \\
\hline 1 & Supermercado & Tottus & La Molina \\
\hline 2 & Supermercado & Tottus & Surco \\
\hline 3 & Supermercado & Tottus & La Molina \\
\hline 4 & Supermercado & Tottus & San Isidro \\
\hline 5 & Supermercado & Tottus & Miraflores \\
\hline 6 & Supermercado & Tottus & San Borja \\
\hline 7 & Supermercado & Tottus & Surco \\
\hline 8 & Supermercado & Plaza Vea & Surco \\
\hline 9 & Supermercado & Plaza Vea & Miraflores \\
\hline 10 & Supermercado & Plaza Vea & Surco \\
\hline 11 & Supermercado & Plaza Vea & San Isidro \\
\hline 12 & Supermercado & Plaza Vea & San Isidro \\
\hline 13 & Supermercado & Plaza Vea & Surco \\
\hline 14 & Supermercado & Plaza Vea & La Molina \\
\hline 15 & Supermercado & Plaza Vea & La Molina \\
\hline 16 & Supermercado & Plaza Vea & Surco \\
\hline 17 & Supermercado & Plaza Vea & Surco \\
\hline 18 & Supermercado & Plaza Vea & Surco \\
\hline 19 & Supermercado & Plaza Vea & San Borja \\
\hline 20 & Supermercado & Plaza Vea & San Borja \\
\hline 21 & Supermercado & Plaza Vea & Miraflores \\
\hline 22 & Supermercado & Plaza Vea & San Isidro \\
\hline 23 & Supermercado & Plaza Vea & Surco \\
\hline 24 & Supermercado & Plaza Vea & Surco \\
\hline 25 & Supermercado & Metro & La Molina \\
\hline 26 & Supermercado & Metro & Miraflores \\
\hline 27 & Supermercado & Metro & Miraflores \\
\hline 28 & Supermercado & Metro & San Borja \\
\hline 29 & Supermercado & Wong & La Molina \\
\hline 30 & Supermercado & Wong & La Molina \\
\hline 31 & Supermercado & Wong & La Molina \\
\hline 32 & Supermercado & Wong & Miraflores \\
\hline 33 & Supermercado & Wong & Miraflores \\
\hline 34 & Supermercado & Wong & Miraflores \\
\hline 35 & Supermercado & Wong & Miraflores \\
\hline 36 & Supermercado & Wong & Miraflores \\
\hline 37 & Supermercado & Wong & San Borja \\
\hline 38 & Supermercado & Wong & San Isidro \\
\hline 39 & Supermercado & Wong & Surco \\
\hline 40 & Supermercado & Wong & Surco \\
\hline 41 & Supermercado & Wong & Surco \\
\hline
\end{tabular}




\begin{tabular}{|c|c|c|c|}
\hline 42 & Supermercado & Vivanda & La Molina \\
\hline 43 & Supermercado & Vivanda & Miraflores \\
\hline 44 & Supermercado & Vivanda & Surco \\
\hline 45 & Supermercado & Vivanda & Miraflores \\
\hline 46 & Supermercado & Vivanda & San Isidro \\
\hline 47 & Supermercado & Vivanda & San Isidro \\
\hline 48 & Supermercado & Vivanda & San Isidro \\
\hline 49 & Gimnasio & Sportlife & Surco \\
\hline 50 & Gimnasio & Sportlife & San Isidro \\
\hline 51 & Gimnasio & Sportlife & La Molina \\
\hline 52 & Gimnasio & Sportlife & La Molina \\
\hline 53 & Gimnasio & GoldGym & La Molina \\
\hline 54 & Gimnasio & GoldGym & San Isidro \\
\hline 55 & Gimnasio & GoldGym & San Borja \\
\hline 56 & Gimnasio & GoldGym & Surco \\
\hline 57 & Gimnasio & GoldGym & Surco \\
\hline 58 & Gimnasio & Fight \& Fitness & Miraflores \\
\hline 59 & Gimnasio & Body Tech El Polo & Surco \\
\hline 60 & Gimnasio & Uno A1 Circuits & La Molina \\
\hline 61 & Bioferia & $\begin{array}{l}\text { Mercado } \\
\text { Saludable }\end{array}$ & La Molina \\
\hline 62 & Bioferia & Eco Market & San Borja \\
\hline 63 & Bioferia & Bioferia & Miraflores \\
\hline 64 & Bioferia & Eco Market & San Isidro \\
\hline 65 & Tienda & $\begin{array}{l}\text { Eco Tienda } \\
\text { Natural }\end{array}$ & Miraflores \\
\hline 66 & Tienda & La Sanahoria & San Isidro \\
\hline 67 & Tienda & La Sanahoria & Surco \\
\hline 68 & Tienda & La Zanahoria & Surco \\
\hline 69 & Tienda & $\begin{array}{l}\text { Organico y natural } \\
\text { ECONA }\end{array}$ & La Molina \\
\hline 70 & Tienda & Ecotienda Walwa & La Molina \\
\hline 71 & Tienda & $\begin{array}{l}\text { Casa Naturista } \\
\text { Esquina Orgánica }\end{array}$ & La Molina \\
\hline 72 & Tienda & $\begin{array}{l}\text { Thika Thani } \\
\text { Market }\end{array}$ & San Borja \\
\hline 73 & Tienda & Inka Natura & San Borja \\
\hline 74 & Tienda & $\begin{array}{l}\text { Inka Millennium } \\
\text { Natural products }\end{array}$ & San Borja \\
\hline 75 & Tienda & Madre Natura & Surco \\
\hline 76 & Tienda & $\begin{array}{l}\text { El Templo de la } \\
\text { Vida }\end{array}$ & Surco \\
\hline 77 & Tienda & Josbend Natural's & Surco \\
\hline 78 & Tienda & La Esquina Verde & Miraflores \\
\hline 79 & Tienda & $\begin{array}{l}\text { Mara Biomarket \& } \\
\text { Cafe }\end{array}$ & Miraflores \\
\hline 80 & Tienda & $\begin{array}{l}\text { El Paraiso Bio - } \\
\text { Health Food Shop }\end{array}$ & Miraflores \\
\hline
\end{tabular}




\begin{tabular}{|c|c|c|c|}
\hline & & $\begin{array}{l}\text { With A Vegetarian } \\
\text { And Vegan Cafe }\end{array}$ & \\
\hline 81 & Tienda & Yauvana & Miraflores \\
\hline 82 & Tienda & Bodega & Miraflores \\
\hline 83 & Tienda & $\begin{array}{l}\text { ECO Tienda } \\
\text { Natural - Organic } \\
\text { Natural Market }\end{array}$ & Miraflores \\
\hline 84 & Tienda & Aranda & Miraflores \\
\hline 85 & Tienda & $\begin{array}{l}\text { Cosecha del } \\
\text { Paraiso }\end{array}$ & Miraflores \\
\hline 86 & Tienda & Tellevo Perú & Miraflores \\
\hline 87 & Tienda & Madre Natura & Miraflores \\
\hline 88 & Tienda & $\begin{array}{l}\text { Madre Natura e } \\
\text { Hijos }\end{array}$ & Miraflores \\
\hline 89 & Tienda & Mara Biomarket & Miraflores \\
\hline 90 & Tienda & Punto Orgánico & Miraflores \\
\hline 91 & Tienda & Alma Botánica & Miraflores \\
\hline \multirow[t]{2}{*}{92} & Tienda & $\begin{array}{l}\text { La Colorada } \\
\text { Bódega Orgánica }\end{array}$ & Miraflores \\
\hline & Cantidad Total de Puntos de Venta & 92 & \\
\hline
\end{tabular}

Fuente: Elaboración a base de información electrónica

- http://tienda.vivanda.com.pe/tiendas?_ga=2.259637514.1621238734.14980081521604610945.1498008152

- http://vea.plazavea.com.pe/principal/nuestras-tiendas

- http://www.goldsgymperu.com/localizagimnasio.aspx

- $\quad$ http://www.sportlifeperu.com/\#1

- https://metro.com.pe/tiendas/lima/lima 


\section{Anexo 2: Transcrpiciones y entrevistas}

\section{FICHA TÉCNICA ENTREVISTAS DE PROFUNDIDAD}

Tipo de estudio:

Participantes:

Selección de los participantes:
Objetivo de

Entrevista

Recolección de información:

Lugar y Fecha:
Cualitativo

02 participantes, especializados en el sector de industrias alimentarias. 02 participantes, especializado en el sector retail.

01 proveedor de fruto sanky en el Mercado de frutas $\mathrm{N}^{\circ} 2$

Se consideraron a cuatro participantes:

1. Ing. Rosa Temrán, especialista en Industrias Alimentarias.- con 10 años de experiencia como inspectora evaluadora de alimentos para SGS del Perú e Inspectorate Services Perú SAC. Con 6 años de experiencia como consultora en Nutrición para centro médico Brasil, 2. Ing. Cynthia Peralta de Industrias Alimentarias-Nutrición. Con 7 años de experiencia en Andina: Alimentos y Bebidas de Calidad 3. Mg. Manuel Miranda: Jefe de Gerente Comercial de Abarrotes Comestibles Supermercados Peruanos S.A. experiencia comercial y en operaciones en hipermercados Santa Isabel (Chile) y actualmente docente de post grado de UPC.

4. Mg. Ricardo Palacios Landa: Jefe de Categoría Bebidas Cencosud S.A. experiencia comercial en Cencosud, anteriormente en Hipermercados Tottus como Jefe de Desarrollo de marcas propias.

5. Sr. Moises Apolin Fernadez, comerciante de frutas exóticas del Mercado de frutas $\mathrm{N}^{\circ} 2$

Conocer sus apreciaciones respecto de la propuesta que se tiene sobre el refresco de Sanky; los requisitos básicos a tener en cuenta para el manejo de alimento; la dosis adecuada para el impacto adecuado para la salud y la introducción de ésta bebida en el mercado.

Las entrevistas de profundidad fueron moderadas por Karelia Aguilar; David Olaechea y Carlos M. García, integrantes del proyecto. 1ra. Entrevista: Domingo 15 de Mayo 2016, en Surco, 8.30 p.m. 2da. Entrevista: Martes 17 de Mayo 2016, ISIL Miraflores, 12:30 p.m. 3ra entrevista: Martes 18 de Setiembre 2018, Supermercados Peruanos S.A. San Borja, 12:00 p.m.

4ta. Entrevista: Viernes 25 de Enero 2019, Cencosud, Miraflores, 9:00 a.m.

5ta. Entrevista: Sabado 26 de Enero 2019, La Victoria. 9:30 AM

\section{PRIMERA ENTREVISTA EN PROFUNDIDAD - Ing. CYNTHIA PERALTA}

\section{Formato}

Buenos días/tardes/noches. Mi nombre es Karelia Aguilar soy alumna de la Maestría en

Ciencias Empresariales de USIL. El objetivo de la entrevista es para poner en marcha un nuevo proyecto de elaboración y comercialización de una bebida hecha a base de Sanky. 
1. ¿Cuál es su apreciación acerca del sector de refrescos envasados? Respecto a: Calidad de los productos, presentación, precios.

2. ¿Le parece a usted el fruto Sanky apropiado para la elaboración de este tipo de bebidas?

3. ¿Cómo maneja la perecibilidad del producto?

4. ¿Cuál sería el proceso productivo de un refresco a base de Sanky?

5. ¿Cuál es la maquinaria básica para su producción? (¿Características especiales?)

6. ¿Cuál sería la dosificación en el uso del insumo para el refresco? (punto de vista nutricional)

7. Técnica de almacenamiento, uso de preservantes, etc.

8. ¿Qué consideraciones se debe tener en cuenta para el manejo de productos estacionales? ¿Cómo podríamos conservarlo para evitar el desabastecimiento?

9. ¿Qué bebidas cree usted que son las más demandadas en el mercado? Considerando el sector al que nos dirigimos.

10. ¿Qué cuidados se debe tener para la óptima producción de nuestro producto?

11. ¿Cómo manejar el tema de transporte del fruto? ¿Qué cuidados se deben tener?

12. ¿Qué tipo de personal necesitaríamos para este proyecto? ¿Qué funciones hacen cada uno? ¿Qué nivel de capacitación mínima se debe considerar?

13. ¿Cuál es el problema más complicado con el que podríamos enfrentarnos en la elaboración de una bebida a base de un fruto exótico?

14. ¿Cuál es el costo promedio unitario que estima usted para la elaboración de nuestra bebida? Considere sólo insumos.

15. ¿Cuánto es margen promedio que se debe considerar para calcular los precios de venta en este tipo de productos?

16. ¿Considera que es necesario un local propio para operar en este negocio? 
17. ¿Cuáles fueron las limitaciones que ha encontrado cuando ha evaluado empresas de este tipo en sus inicios?

18. ¿Considera adecuado el sector del mercado al que estamos apuntando?

19. ¿Qué recomendaciones daría como experto en la industria?

\section{Respuestas}

Buenos días/tardes/noches. Mi nombre es Karelia Aguilar soy alumna de la Maestría en Ciencias Empresariales de USIL. El objetivo de la entrevista es para poner en marcha un nuevo proyecto de elaboración y comercialización de una bebida hecha a base de Sanky.

1. ¿Cuál es su apreciación acerca del sector de refrescos envasados?

Mi apreciación es que el sector de bebidas envasadas se encuentra en crecimiento, sobre todo debido al repunte que ha tenido en este primer trimestre del año, por lo que sí sería posible el ingreso de la bebida en el mercado, esta tendencia de crecimiento no sólo se encuentra en el país, sino también en países de la región.

2. Respecto a: Calidad de los productos, presentación, precios.

Respecto de la calidad, las bebidas que se encuentran en el mercado, todas tienen un alto nivel de calidad, ya que necesariamente han pasado todas las pruebas reglamentarias, como son las normas fisicoquímicas, organolépticas, microbiológicas, ISO 9000, ISO 22000, ISO 9001, Sistema de Análisis de Peligros y de los Puntos Críticos de Control (Sistema HACCP). La presentación puede ser en vidrio, tetra pak, plástico o lata. Con respecto al precio, este depende del mercado al que va dirigido y estar dentro del rango de precios que están siendo ofrecidos productos similares.

3. ¿Le parece a usted el fruto Sanky apropiado para la elaboración de este tipo de bebidas? Considero que, dada la consistencia y naturaleza del fruto, se puede fabricar de la pulpa el néctar sin descartar la elaboración de un refresco. 
4. ¿Cómo maneja la perecibilidad del producto?

La perecibilidad del producto se puede manejar con el uso de preservantes que debe darse de acuerdo a lo indicado por las normas de la OMS, dicho preservante ayudará a conservar el producto durante un aproximado de 6 meses después de su elaboración y no altera las propiedades naturales ni el sabor del fruto.

5. ¿Cuál sería el proceso productivo de un refresco a base de Sanky?

El proceso productivo sería el siguiente: pesado del producto, selección, lavado, corte y pelado, pesado, licuado y filtrado, embotellado, sellado/enroscado, etiquetado, control de calidad, empaquetado y almacenamiento.

6. ¿Cuál es la maquinaria básica para su producción? (¿Características especiales?)

Para la planta se debe de contar mínimamente, con una máquina envasadora y una cocina industrial, considerando que los envases se comprarían ya esterilizados.

7. ¿Cuál sería la dosificación en el uso del insumo para el refresco?

La dosificación de los insumos para el refresco seria en los porcentajes o medidas determinados en la formulación del producto de acuerdo al valor nutricional.

8. Técnica de almacenamiento, uso de preservantes, etc.

El almacenamiento sería un almacén de insumos para el fruto y un almacén de productos terminados donde se almacenen las bebidas, que deben de estar en lugar seco y de preferencia a temperatura ambiente. Como dije anteriormente es necesario el uso de preservantes para la conservación del producto.

9. ¿Qué consideraciones se debe tener en cuenta para el manejo de productos estacionales? ¿Cómo podríamos conservarlo para evitar el desabastecimiento?

Dados los cuatro meses del año en el que se puede extraer el fruto, la técnica de conservación de la pulpa es la refrigeración, que permitirá conservar el fruto en buen estado un tiempo aproximado de mes y medio. 
10. ¿Qué bebidas cree usted que son las más demandadas en el mercado? Considerando el sector al que nos dirigimos.

Las bebidas envasadas más consumidas o demandadas en el mercado son las de tipo bebible (más líquidas, más contenido de agua que fruta), esto debido a la tendencia de cuidado de imagen y salud que existe en los sectores hacia los que está dirigido, sin embargo, apelando a los beneficios adicionales que tiene el producto si podría calzar dentro de esta tendencia, sumado a que no existe en el mercado un producto similar.

11. ¿Qué cuidados se debe tener para la óptima producción de nuestro producto?

Para una óptima producción, es esencial que se cuide el tema de la temperatura, desde el momento del transporte hasta la etapa misma de la producción. Y seguir el proceso productivo con buenas prácticas de manejo.

12. ¿Cómo manejar el tema de transporte del fruto? ¿Qué cuidados se deben tener?

El transporte del fruto debe ser refrigerado, en javas esterilizadas de acuerdo a la norma, las cuales se apilarán y se transportarán a su destino.

13. ¿Qué tipo de personal necesitaríamos para este proyecto? ¿Qué funciones hacen cada uno? ¿Qué nivel de capacitación mínima se debe considerar?

Los profesionales necesarios para la empresa son, un administrador, uno o dos ingenieros alimentarios, un laboratorista (sin embargo, esta función puede tercerizarse), tres técnicos en producción que conozcan el manejo de las maquinarias y unos ocho auxiliares.

14. ¿Cuál es el problema más complicado con el que podríamos enfrentarnos en la elaboración de una bebida a base de un fruto exótico?

A mi criterio sería el de la estacionalidad del producto el cual lo deberían tener en stock y utilizar la técnica de la conservación de la pulpa que es la refrigeración y luego el producto en si con el respectivo preservante para poder conservar el producto un tiempo aproximado de 6 meses. 
15. ¿Cuál es el costo promedio unitario que estima usted para la elaboración de nuestra bebida? Considere sólo insumos.

Dada mi experiencia en este tipo de rubro, considero que el costo promedio unitario para la elaboración de este tipo de bebida estaría en el rango de S/ 1.50 - S/ 1.80.

16. ¿Cuánto es margen promedio que se debe considerar para calcular los precios de venta en este tipo de productos?

Desde mi apreciación el margen de ganancia aplicable para este tipo de productos es aproximadamente un $70 \%$.

17. ¿Considera que es necesario un local propio para operar en este negocio?

No necesariamente, es viable que se cuente con un local alquilado para la implementación de la planta, luego con el tiempo

18. ¿Cuáles fueron las limitaciones que ha encontrado cuando ha evaluado empresas de este tipo en sus inicios?

Las empresas de este giro han tenido la limitante de no encontrar a los productores de ciertos frutos organizados para poder realizar un trabajo serio y garantizado para poder tener los productos en el momento oportuno y no generar un sobrecosto de transporte o un falso flete.

También otra limitación es la seriedad en el transporte que cumpla con los requisitos de como transportar los productos y lo haga en el tiempo adecuado.

19. ¿Considera adecuado el sector del mercado al que estamos apuntando?

Si me parece adecuado dirigirse al segmento A, B y C, pues su estilo de vida les permite asociar las propiedades nutrientes con el precio.

20. ¿Qué recomendaciones daría como experto en la industria?

Que se cumplan con los requisitos de proceso de producción, buenas prácticas de manufactura y que se mantenga la calidad en el producto final. 


\section{SEGUNDA ENTREVISTA EN PROFUNDIDAD - Ing. ROSA TERAN}

Buenos tardes. Mi nombre es Edgardo Olaechea alumno de la Maestría de Ciencias Empresariales de la Escuela de Post Grado de USIL. El objetivo de la entrevista es saber su apreciación profesional respecto a la puesta en marcha de un nuevo proyecto de elaboración y comercialización de una bebida refrescante envasada hecha a base de Sanky.

1. ¿Cuál es su apreciación acerca del sector de refrescos envasados existentes en el mercado? (Calidad de los productos, presentación, precios)

2. ¿Cuál sería la dosificación en el uso del insumo para el refresco?

3. ¿Cómo manejar el tema de transporte del fruto? ¿Qué cuidados hay que tener?

4. ¿Cuál es el problema más complicado con el que podríamos enfrentarnos en la elaboración de una bebida a base de un fruto exótico como lo es el Sanky?

5. ¿Qué implementos o maquinarias mínimas se requiere para operar este negocio?

6. ¿Considera que es necesario un local propio para operar en este negocio?

7. ¿Cuáles fueron las limitaciones que ha encontrado cuando usted ha evaluado empresas de este tipo en sus inicios?

8. ¿Considera adecuado el sector del mercado al que estamos apuntando?

9. ¿Qué recomendaciones daría como experto en la industria?

\section{Respuestas}

Buenas tardes. Mi nombre es Edgardo Olaechea alumno de la Maestría de Ciencias Empresariales de la Escuela de Post Grado de USIL. El objetivo de la entrevista es saber su apreciación profesional respecto a la puesta en marcha de un nuevo proyecto de elaboración y comercialización de una bebida refrescante envasada hecha a base de Sanky. 
1. ¿Cuál es su apreciación acerca del sector de refrescos envasados existentes en el mercado? (Calidad de los productos, presentación, precios)

Mi opinión es que en este sector de refrescos envasados de frutos con propiedades alimenticias es poco explotado. Actualmente hay una difusión de productos elaborados a base de fruta, pero con un proceso de producción donde se pierden muchas de las propiedades de esta, lo que da como resultado una bebida con sabor a fruta con pocos nutrientes.

2. ¿Cuál sería la dosificación en el uso del insumo para el refresco?

Considero que la dosificación de pulpa de fruta, agua y otros insumos que se utilizara en la producción, se debe de hacer una evaluación sensorial y otra de costos.

La evaluación sensorial consiste en la elaboración de distintas formulaciones o propuestas con diferentes dosificaciones y realizar una degustación con un numero considerable de personas y luego de ser recolectada la información se debe de procesar estadísticamente, para obtener la dosificación más conveniente para la utilización de la pulpa y el resto de los insumos.

3. ¿Cómo manejar el tema de transporte del fruto? ¿Qué cuidados hay que tener? El Sanky es un producto perecible y sensible, esto último hace referencia a su cáscara blanda lo que en un escenario de transporte se convertiría en un alto riesgo para que el insumo pierda su calidad. Se sugiere que la planta procesadora para el producto esté muy cerca del proveedor para evitar la pérdida del insumo que se reflejaría en el costo de producción. En el caso de que la planta no estuviera cerca de los proveedores sería necesario la habilitación de un transporte de adecuada refrigeración para que el producto llegue en las mejores condiciones al lugar de almacenamiento. 
4. ¿Cuál es el problema más complicado con el que podríamos enfrentarnos en la elaboración de una bebida a base de un fruto exótico como lo es el Sanky?

La estacionalidad es uno de los problemas vitales a los que tendría que hacer frente, el fruto no crece todo el año, de modo que se tendría que extraer la pulpa del fruto y envasarlas al vacío para que se mantenga en las mejores condiciones de refrigeración de modo que dure el mayor tiempo posible, con buenas técnicas se puede lograr una vida de 5 meses sin que la fruta pierda sus propiedades.

El otro problema que se puede avizorar es la competencia por parte de las grandes empresas elaboradoras de bebidas, quienes cuentan con la infraestructura adecuada y canales de comercialización.

5. ¿Qué implementos o maquinarias mínimas se requiere para operar este negocio? El equipo mas importante es el de pasteurización (ya que el tratado artesanal en olla no logra el mismo efecto) UHT, máquinas de envasado, máquinas de sellado, cámaras para mantener en condiciones adecuadas los insumos y ambientes adecuados para el almacenamiento del producto final.

6. ¿Considera que es necesario un local propio para operar en este negocio? Es tal vez oportuno al ser una empresa nueva en el mercado, se maquile la producción para que se evite costos excesivos iniciales, esto hasta que se cuente con equipos propios.

7. ¿Cuáles fueron las limitaciones que ha encontrado cuando usted ha evaluado empresas de este tipo en sus inicios?

Una de las limitaciones que se ve con frecuencia es la gradual baja de calidad en los productos terminados a través del tiempo, esto es muchas veces originado porque no se tiene una adecuada estrategia de costos. 
8. ¿Considera adecuado el sector del mercado al que estamos apuntando? ¿Qué recomendaciones daría como experto en la industria?

Por la forma de procesar el producto sin sacrificar la mayor parte de los nutrientes o insumos es oportuno dirigirse al segmento A, B y C. Se debe de asegurar que el cliente pueda asociar el precio con las propiedades nutricionales del fruto.

\section{TERCERA ENTREVISTA A GERENTE COMERCIAL DE ABARROTES COMESTIBLES EN SUPERMERCADOS PERUANOS S.A.}

\section{Magister Manuel Miranda}

\section{Formato}

Buenos días. Mi nombre es Carlos Martín García Arana, soy alumno de la Maestría en Ciencias Empresariales de USIL. El objetivo de la entrevista es para poner en marcha un nuevo proyecto de elaboración y comercialización de una bebida natural hecha a base de Sanky y necesitamos saber los requisitos para el ingreso de un nuevo producto en Supermercados Peruanos S.A.

1. Cuáles son los requisitos formales para poder ingresar a ofrecer nuestro producto?

2. ¿Qué tipo de documentación en la parte comercial se necesita en el proceso de calificación de nuevos productos?

3.¿Qué tipo de documentación con respecto a la calidad se necesitan para la calificación de nuevos productos?

4. En el caso de ser un proveedor nuevo, ¿hay algún requisito adicional?

5. Adicionalmente, nuestro producto ¿qué otros requisitos deben de cumplir?

6. Con respecto a los costos que nosotros damos ¿hay algún descuento que ustedes realizan para la colocación del costo final?

7. ¿Cuál seria nuestro posicionamiento en la categoría en las tiendas? 
8. ¿Cuál considera usted, que debería ser nuestro plan de inversión en el canal?

9. Con respecto a la colocación de nuestros productos, estamos dirigidos al NSE de la zona

7 de Lima Metropolitana, es decir a los distritos de Miraflores, San Isidro, San Borja,

Santiago de Surco y La Molina, queremos colocarlos en los Supermercados de Vivanda y

Plaza Vea de esos distritos, ¿hay algún tipo de restricción?

10. ¿Cual es el tiempo de pago a proveedores?

\section{Respuestas}

1. Cuáles son los requisitos formales para poder ingresar a ofrecer nuestro producto? Deben de ser una empresa formal, con RUC vigente y una cuenta corriente de la empresa.

2. ¿Qué tipo de documentación en la parte comercial se necesita en el proceso de calificación de nuevos productos?

Para la codificación de nuevos productos en la parte comercial se necesitan los siguientes requisitos:

$\checkmark$ Formato de precios. Se adjunta archivo

$\checkmark$ Formato de DL. Se adjunta archivo

$\checkmark$ La confirmación del pago indicado en el acuerdo comercial vigente por producto nuevo. En caso no se tenga el dato el monto es de S/ $300.00+$ IGV por ítem codificado.

3. ¿Qué tipo de documentación con respecto a la calidad se necesitan para la calificación de nuevos productos?

Los requisitos para la calificación de nuevos productos es la siguiente:

Solicitud de Incorporación Regular de Nuevos Productos-Nuevos Proveedores SPSA (ASC-FR293), consignando información requerida. 
$\checkmark$ Registro Sanitario

$\checkmark$ Muestra del producto

$\checkmark$ Registro de marca para productos nacionales o declaración jurada de marca registrada para productos importados.

4. En el caso de ser un proveedor nuevo, ¿hay algún requisito adicional?

Si, deben de pasar la auditoría sanitaria de su almacén o planta de producción de ser el caso o informe de auditoría realizada por la entidad acreditada el mismo año de la postulación (con calificativo aprobado) o sino un voucher de pago por servicio de auditoría a SGS del Perú a una Cta. Del BCP.

Y la respectiva firma de convenios.

5. Adicionalmente, nuestro producto ¿qué otros requisitos deben de cumplir?

Además de los registros mencionados anteriormente, debe de tener su etiqueta, empaque y código de barras.

6. Con respecto a los costos que nosotros damos ¿hay algún descuento que ustedes realizan para la colocación del costo final?

Si en el formato de costos para producto nuevo, hay hasta 3 descuentos que deben ser llenados por parte del proveedor en \%, es decir hay: \% Dcto. 1, \% Dcto. 2, \% Dcto. 3, lo cual dará un P.V. P. sugerido nuevo con IGV y se verá el margen.

7. ¿Cuál seria nuestro posicionamiento en la categoría en las tiendas?

Su posicionamiento en la categoría sería a la par de quienes se colocan, es decir de "tu competidor"

8. ¿Cuál considera usted, que debería ser nuestro plan de inversión en el canal?

$\checkmark$ En el punto de venta debe de haber impulso y degustación.

$\checkmark$ En las redes sociales: Facebook y e-commerce 
9. Con respecto a la colocación de nuestros productos, estamos dirigidos al NSE de la zona 7 de Lima Metropolitana, es decir a los distritos de Miraflores, San Isidro, San Borja, Santiago de Surco y La Molina, queremos colocarlos en los Supermercados de Vivanda y Plaza Vea de esos distritos, ¿hay algún tipo de restricción?

No hay ningún tipo de restricción al respecto. Los productos si son dirigidos a ese NSE, se pueden colocar en nuestras tiendas de Vivanda que son Clúster "A": 08 tiendas y 01 adicional en verano, la que esta en ASIA. Y con respecto a Plaza Vea tenemos Clúster A1, A2 y A3, que son en total 24 tiendas, repartidos en los distritos mencionados en su consulta.

10. ¿Cuál es el tiempo de pago a proveedores?

El tiempo de pago a proveedores es de 60 días.

\section{CUARTA ENTREVISTA A JEFE DE CATEGORIA DE BEBIDAS CENCOSUD S.A. Magister Ricardo Palacios Landa}

\section{Formato}

Buenos días/tardes. Mi nombre es Carlos Martín García Arana, soy alumno de la Maestría en Ciencias Empresariales de USIL. El objetivo de la entrevista es para poner en marcha un nuevo proyecto de elaboración y comercialización de una bebida natural hecha a base de Sanky y necesitamos saber los requisitos para el ingreso de un nuevo producto en

\section{SUPERMERCADOS WONG.}

1. ¿Cuáles son los requisitos formales para poder ingresar a ofrecer nuestro producto?

2. ¿Qué tipo de documentación en la parte comercial se necesita en el proceso de calificación de nuevos productos?

3. ¿Qué tipo de documentación con respecto a la calidad se necesitan para la calificación de nuevos productos? 
4. En el caso de ser un proveedor nuevo, ¿hay algún requisito adicional?

5. Adicionalmente, nuestro producto ¿qué otros requisitos deben de cumplir?

6. Con respecto a los costos que nosotros damos ¿hay algún descuento que ustedes realizan para la colocación del costo final?

7. ¿Cuál sería nuestro posicionamiento en la categoría en las tiendas?

8. ¿Cuál considera usted, que debería ser nuestro plan de inversión en el canal?

9. Con respecto a la colocación de nuestros productos, estamos dirigidos al NSE de la zona 7 de Lima Metropolitana, es decir a los distritos de Miraflores, San Isidro, San Borja, Santiago de Surco y La Molina, queremos colocarlos en los Supermercados de WONG de esos distritos, ¿hay algún tipo de restricción?

\section{Respuestas}

1. ¿Cuáles son los requisitos formales para poder ingresar a ofrecer nuestro producto? Aprobación del jefe de categoría y aprobación de calidad.

2 ¿Qué tipo de documentación en la parte comercial se necesita en el proceso de calificación de nuevos productos?

$\checkmark$ Ficha técnica, estructura de costos

$\checkmark$ presentación de producto generalmente en una ppt

$\checkmark$ degustación de producto a ingresar.

3 ¿Qué tipo de documentación con respecto a la calidad se necesitan para la calificación de nuevos productos?
$\checkmark$ Ficha técnica del producto
$\checkmark$ registrso sanitario de productos (número) DIGESA,
$\checkmark$ análisis microbilogico y fisicoquímico
$\checkmark$ estudio de vida útil del producto 
$\checkmark$ etiqueta

$\checkmark$ informe de inspección de planta

$\checkmark$ carta de compromiso firmado

4. En el caso de ser un proveedor nuevo, ¿hay algún requisito adicional?

No, ninguno

5. Adicionalmente, nuestro producto ¿qué otros requisitos deben de cumplir?

Ninguno

6. Con respecto a los costos que nosotros damos ¿hay algún descuento que ustedes realizan para la colocación del costo final?

$\mathrm{Si}$, los descuentos son: desarrollo comercial $18 \%$ en promedio, tasa logística entre 2 y $4 \%$, uso de plataformas b2b $0.2 \%$

7. ¿Cuál sería nuestro posicionamiento en la categoría en las tiendas?

Esto depende de la marca, no del retail. Debe de ir a la par de los posibles competidores.

8. ¿Cuál considera usted, que debería ser nuestro plan de inversión en el canal?

Por lanzamiento de productos de baja rotación como Jugos premium la inversión dentro de la cadena debería ser alrededor de S/ 5,000 a S/ 10,000 en los primeros 3 meses, esto solo contabilizando el uso de espacios, no se considera la inversión por fuera.

Por ejemplo: una cabecera cuesta S/ 3,000 al mes. Pero además el revestimiento puede costar S/ 500, no tengo estos datos exactamente porque no lo vemos directamente.

9. Con respecto a la colocación de nuestros productos, estamos dirigidos al NSE de la zona 7 de Lima Metropolitana, es decir a los distritos de Miraflores, San Isidro, San Borja, Santiago de Surco y La Molina, queremos colocarlos en los Supermercados de WONG de esos distritos, ¿hay algún tipo de restricción?

No hay ningún tipo de restricción, se pueden colocar sus productos en los supermercados de los distritos donde están dirigidos. 
10. ¿Cuál es el tiempo de pago a proveedores?

El tiempo de pago a proveedores es de 60 días.

\section{ENTREVISTA A PROVEEDOR DE FRUTO SANKY- MERCADO DE FRUTAS $\mathrm{N}^{\circ} 2$}

\section{Sr. Moisés Apolin Fernández}

\section{Formato}

Buenos días/tardes. Mi nombre es Carlos Martín García Arana, soy alumno de la Maestría en Ciencias Empresariales de USIL. El objetivo de la entrevista es para poner en marcha un nuevo proyecto de elaboración y comercialización de una bebida natural hecha a base de Sanky y necesitamos saber cómo es la comercialización del fruto Sanky acá en el mercado de frutas $\mathrm{N}^{\circ} 2$

1. ¿Me puede dar su razón social y RUC por favor Sr. Moisés Apolin?

Soy persona natural con RUC 10224498018

2. ¿Emite usted factura?

Si tengo autorización para poder emitir facturas.

3. ¿Cuál es su dirección y número de puesto por favor?

La dirección es Antonio Alarco N 403 -Lima/ Puesto 741- Mercado Mayorista N² de Frutas.

4. ¿Qué sección es esta parte del mercado de frutas y que tipo de frutas comercializa usted? Esta sección es de "frutas exóticas” y yo comercializo aguaymanto, cocona, carambola, camu camu, frambuesa y sanky.

5. ¿El fruto sanky, de donde se lo traen?

Los cosechadores lo traen de Ayacucho entre mayo y octubre y los de Arequipa entre noviembre y marzo, es decir tenemos sanky casi todo el año.

6. ¿Como es la presentación del sanky, cuando lo traen? 
Lo traen en javas plásticas o cajas de cartón (de manzanas).

7. ¿A qué precio lo comercializan ustedes acá en el mercado de frutas?

El precio al por mayor es de S/ 4.00, pero en cantidad a partir de 0.5 TM y ente mayo a julio por haber bastante producción se podría llegar a los S/ 2.50 el precio al por mayor.

8. El sanky tiene espinas, al comprar en cantidad ¿lo pueden comercializar ustedes sin espinas?, y generaría algún costo adicional?

$\mathrm{Si}$, se le pide a los cosechadores que lo traigan sin espinas y no tendría ningún costo adicional 9. Si deseo comprar más de 1 TM, ¿con cuánto tiempo de anticipación tendría que avisarle para que lo puedan tener esa cantidad disponible acá en el Mercado?

Generalmente los cosechadores traen la fruta los días sábados y si ya lo tienen en cosecha, lo traen en cinco días, es decir el jueves siguiente.

10. ¿Como sería la forma de pago, para comprar en volumen el sanky a ustedes?

Se haría un deposito a mi cuenta bancaria del 50\% como adelanto y la diferencia cuando recogen el producto y se le emitiría su respectiva factura. 
Anexo 3: Ficha de reclutamiento, ficha técnica, guía de pautas y focus group

\section{Ficha de Reclutamiento:}

Tiene por objetivo conocer las características del posible invitado desde el punto de vista de nivel socioeconómico para tener la seguridad de contar con personas que corresponden al publico de interés.

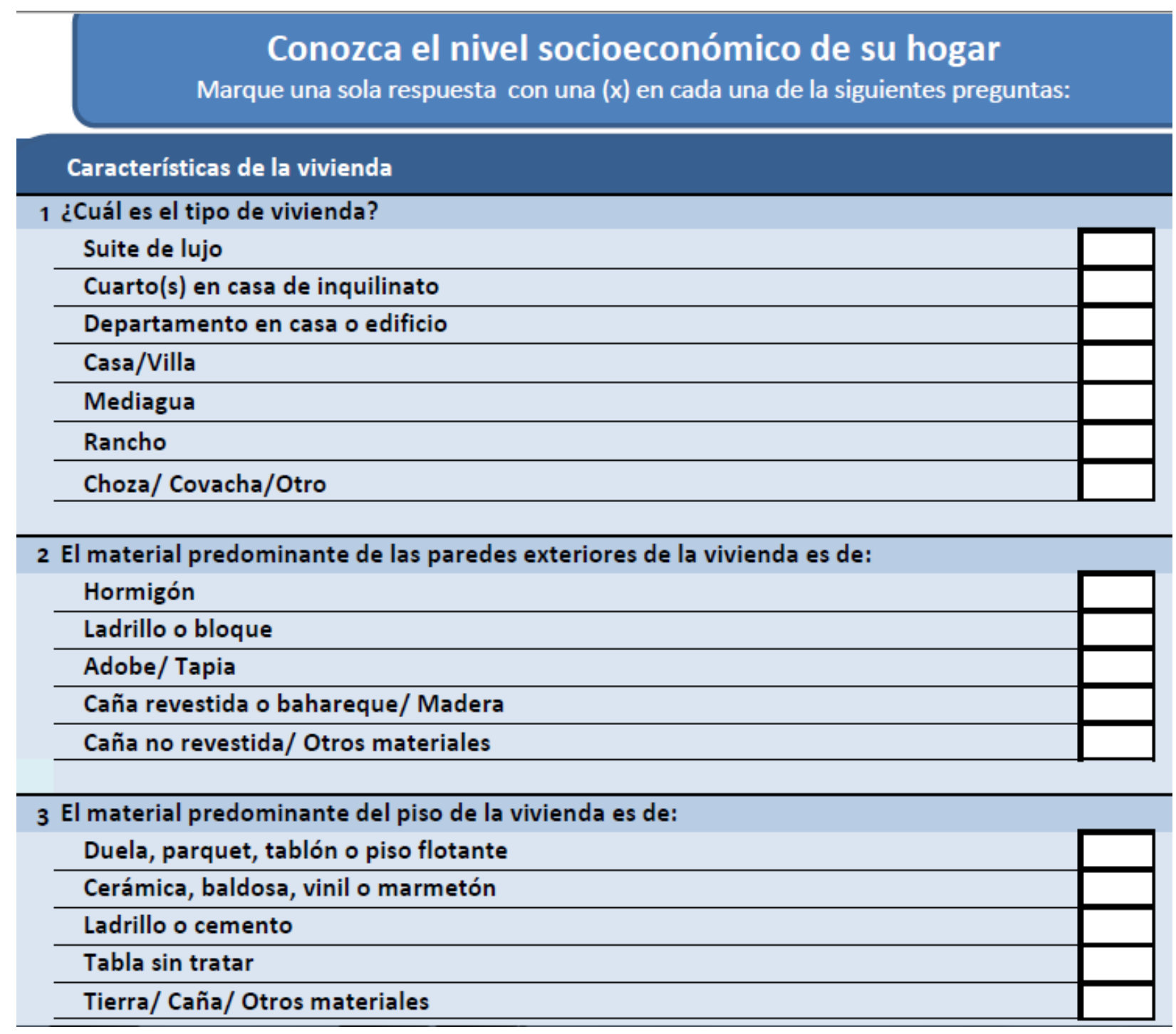


4 ¿Cuántos cuartos de baño con ducha de uso exclusivo tiene este hogar?

No tiene cuarto de baño exclusivo con ducha en el hogar

Tiene 1 cuarto de baño exclusivo con ducha

Tiene 2 cuartos de baño exclusivos con ducha

Tiene 3 o más cuartos de baño exclusivos con ducha

$\square$

5 El tipo de servicio higiénico con que cuenta este hogar es:

No tiene

Letrina

Con descarga directa al mar, río, lago o quebrada

Conectado a pozo ciego

Conectado a pozo séptico

Conectado a red pública de alcantarillado

\section{Acceso a tecnología}

1 ¿Tiene este hogar servicio de internet?

No

Sí

2 ¿Tiene computadora de escritorio?

No

Sí

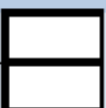




\section{Posesión de bienes}

1 ¿Tiene este hogar servicio de teléfono convencional?

\begin{tabular}{l|l|} 
No & \\
\hline Sí & \\
\hline
\end{tabular}

2 ¿Tiene cocina con horno?

No

3 ¿Tiene refrigeradora?

No

Sí

4 ¿Tiene lavadora?

No

Sí

5 ¿Tiene equipo de sonido?

No

6 ¿Cuántos TV a color tienen en este hogar?

No tiene TV a color en el hogar

Tiene 1 TV a color

Tiene 2 TV a color

Tiene 3 ó más TV a color

7 ¿Cuántos vehículos de uso exclusivo tiene este hogar?

No tiene vehículo exclusivo para el hogar

Tiene 1 vehículo exclusivo

Tiene 2 vehículo exclusivo

Tiene 3 ó más vehículos exclusivos 


\section{Nivel de educación}

\begin{tabular}{l|l|}
\hline 1 ¿Cuál es el nivel de instrucción del Jefe del hogar? & \\
\hline Sin estudios & \\
\hline Primaria incompleta & \\
\hline Primaria completa & \\
\hline Secundaria incompleta & \\
\hline Secundaria completa & \\
\hline Hasta 3 años de educación superior & \\
\hline 4 ó más años de educación superior (sin post grado) & \\
\hline Post grado & \\
\hline
\end{tabular}

\section{Actividad económica del hogar}

1 ¿Alguien en el hogar está afiliado o cubierto por el seguro del IESS (general, voluntario o campesino) y/o seguro del ISSFA o ISSPOL?

No

Sí

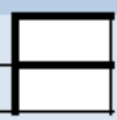

2 ¿Alguien en el hogar tiene seguro de salud privada con hospitalización, seguro de salud privada sin hospitalización, seguro internacional, seguros municipales y de Consejos Provinciales y/o seguro de vida?

No

Sí

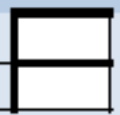

3 ¿Cuál es la ocupación del Jefe del hogar?

Personal directivo de la Administración Pública y de empresas

Profesionales científicos e intelectuales

Técnicos y profesionales de nivel medio

Empleados de oficina

Trabajador de los servicios y comerciantes

Trabajador calificados agropecuarios y pesqueros

oficiales operarios y artesanos 


\section{Ficha Técnica}

\section{Ficha Técnica del Focus Group:}

\section{Tipo de Estudio:}

Estudio Cualitativo,a través de la técnica del Focus Group

Universo en estudio:

Personas de 18 a 50 años que residen en la Zona 7 de Lima Metropolitana (San Borja; San Isidro; Santiago de Surco; Miraflores y La Molina)

\section{Muestra}

Se realizaron tres (03) Focus Group con 8 personas por focus totalizando 24 personas segmentadas por edad de la siguiente forma: de 18-25 años ; de 26-35 añosy 36-50 años.

\section{Selección de participantes}

Estuvo a cargo de los especialistas de "Asesoría Integral" quienes hicieron el filtro adecuado para tener participantes representativo de cada segmento y con el perfil que exige la naturaleza del producto motivo del proyecto.

\section{Recolección de información}

Los tres focus estuvieron moderados por el Psic Julius Silva CPSP 19038 y se desarrollo en base a una guía de pautas de dialogo radial.

Realización del estudio

Fue realizado en las instalaciones del instituto ISIL sede San Isidro en tres turnos distintos

\section{Guía de Pautas:}

\section{GUIA DE PAUTAS FOCUS GROUP:}

\section{KAWSAY}

\section{Presentación y establecimiento de las normas}

Buenos Días/Tardes/Noche, mi nombres es , veo el nombre de cada uno de ustedes, eso va a facilitar la comunicación.

Bien, ahora ¿quisiera que me digan si saben para que estamos reunidos? Estamos acá para conversar acerca de sus preferencias diarias respecto del consumo de bebidas refrescantes envasadas, por tal razón me gustaría decirles que sean totalmente sinceros, libres para opinar y no dejarse influenciar por las experiencias u opiniones de otros.

Además me interesa que sepan que no existen respuestas incorrectas y que todas sus respuestas son igualmente válidas. También quisiera solicitarles autorización para grabar 
esta sesión ya que sus opiniones son importantes y no quisiera olvidar alguna información útil que me den.

\section{Calentamiento}

Me gustaría saber su edad y el lugar donde laboran,

¿A qué se dedican?

¿Cuál es su profesión?

¿Qué les gusta hacer en sus tiempos libres?

¿Qué hacen los fines de semana?

¿Con quienes suelen salir los fines de semana?

\section{Estudio en Profundidad}

\section{SOBRE EL INTERÉS EN CONSUMIR REFRESCOS NATURALES ENVASADOS}

¿Qué bebidas cree usted que deberían tomar las personas? ¿Por qué?

¿Por qué cree usted que es importante consumir refrescos naturales envasados?

¿En qué momento del día considera que debemos consumirlas?

Particularmente ¿Cuantas bebidas de este tipo consume usted al día?

¿Cuántas considera usted que son necesarias al día?

¿Qué características principales busca usted o qué es lo que más valora en estas bebidas?

¿Dónde suele comprarlas? ¿Por qué?

\section{SOBRE LA COMPETENCIA}

¿Qué marcas de refrescos conoce usted en el mercado? Nombrarlos

¿Se identifica usted con alguna en particular? ¿Por qué?

\section{$\underline{\text { SOBRE EL PRODUCTO }}$}

¿Qué espera usted de un refresco natural?

¿Cuáles son los sabores o colores de su preferencia?

¿Qué experiencia tiene respecto a los refrescos envasados consumidos hasta la fecha? 
¿Le parece adecuada una presentación de $475 \mathrm{ml}$ ?

¿En qué lugares le gustaría encontrar la bebida?

¿Cuál es el precio que estaría dispuesto a pagar?

¿Cuál considera usted que sería la forma más adecuada para el envase?

¿Luego de probar el producto que le parece:

El sabor; la consistencia; el color

Si tienen alguna sugerencia pueden expresarla.

¿Qué les parece el nombre KAWSAY?

¿Les agrada la idea de doble funcionalidad del producto? Poder obtener beneficios adicionales para el bienestar de su organismo y a la par de refrescarse a través de la bebida.

Cierre

Resumen de los resultados

¿Quisieran agregar algún comentario final?

Muchas Gracias por su colaboración.

\section{Transcripción Focus Group 1}

Moderador: Este Focus Group es con el fin de saber un poco sus preferencias, intereses, deseos usos, sobres sus vidas vamos hablar un poco el día de hoy sobre todo esto sobre sus vidas y no cualquier tipo de vida sino de sus vidas refrescante la vida producidas basadas y queremos recolectar un poco de información y para eso me gustaría que pudiéramos iniciar conociéndonos un poco más. Comenzamos por el lado derecho aquí observamos su nombre para facilitar el trabajo me gustaría que se presenten por el lado derecho y colocar a que se dedican, que edad tienen, en que trabajan y que es lo que suelen hacer los fines de sema en sus tiempos libres. 
Participante: Buenos días soy Johana Ruiz soy bachiller de Contabilidad acabe la carrera en Diciembre del año pasado acabe la carrera y no he podido hacer los trámites de título y tesis porque mi madre estaba un poco delicada pero eso no impide que no pueda lograrlo, estoy trabajando en una empresa internacional algo así para Colombia vendo servicios para Colombia, en lo que respecta atención al cliente en la creación de códigos para el cliente, tiene una pizquita de contabilidad, tengo trabajando en el área contable ya más de 5 años casi 6 años y me he desarrollado siempre ...ha pero antes he trabajado en muchas cositas más de todo un poco al menos, bueno vivo en lince tengo 25 años ... mi familia es del norte yo vivo acá en lima por más de un buen tiempo.

Moderador: Interesante Y que tal el tiempo libre Las actividades de los fines de semana. Participante: Yo soy cristiana evangélica, mayormente los fines de semana voy a la iglesia también me voy con mis amigas, inclusive ayer ha llegado a mi casa Irma buen tiempo hemos pasado, salgo... si salgo a compartir, pero con prudencia trato de lo posible conservar la prudencia trato en lo posible de no desbaratarme, buen tiempo.

Moderador: Muy bien muchas gracias Johana.

Moderador: Señorita Michell

Participante: Buenos días mi nombre es Michell Villafanqui titulada en Contabilidad tengo 24 años trabajo como analista contable en el Colegio Médico del Perú y los fines de semana me dedico hacer planes en casa porque me voy a casar por lo menos tengo que disfrutar la soltería.

Moderador: Y que bueno sé que el tema de planificar una boda es complicado y como consigues relajarte entre la planificación y las actividades laborales que realizas, como haces. Participante: Es que como tengo trabajo desde carrera porque yo he empezado en Instituto y convalidado en Universidad y tengo mucha experiencia porque comencé a trabajar desde los 18 años en contabilidad porque eso es lo que te ayuda bastante en el Instituto y como tengo 
experiencia como trabajo ahora actualmente si puedo manejarlo y aparte todo depende mucho del clima laboral en el colegio médico es bien tranquilo porque todos en su mayoría son doctores, todos son ambles porque tienen su vocación hacia el paciente, como tú eres el analista contable también son muy amables conmigo y te transmiten esa tranquilidad entonces me siento tranquila salgo de trabajar, no es como antes trabajaba en Outsourcing Contable era contadora pero no firmaba, pero era estresante porque tenía responsabilidad de contadora es bastante riguroso, me llegué a enfermar de parálisis facial es muy intenso era bien estricta tenía mucha carga laboral, tenia carga familiar y carga de amigos pero cuando estoy con mis amigas me olvido que tengo que hacer, son mis amigas y punto y si tienes que gritar grita y hay tiempo para todo, pero no descuiden su salud, primeros eres tu... no primero es dios tu familia y amor propio siempre. Después eso es todo.

Moderador: Muchas gracias Michell que bonito testimonio la verdad.

Moderador: Bensamin y tú que tal que nos puedes contar.

Participante: Buenos tardes mi nombre es Bensamin Chaparro tengo 25 años estudio en la universidad San Ignacio de Loyola la carrera de marketing, el próximo año si Dios quiere en agosto ya me gradúo y bueno en mis tiempos libres me paso con mis perritos me encantan, los adoro y los fines de semana paso con mi novio y los domingos son familiares.

Moderador: Ya q bueno y cuando sales con tu novio que actividades sueles realizar. Participante: A ver... salimos por ejemplo a cenar a lugares que nos gustan comemos carnes, pastas, luego al parque...me encanta ir al gimnasio salgo con él y mis perritos al parque me encanta el cine también.

Moderador: Que bueno gracias Bensamin.

Moderador: Marcela que tal, que nos puedes contar.

Participante: Soy Marcela Sandini, tengo 21 años estudio para Marketing estoy en sexto ciclo, en mis tiempos libres voy al gimnasio a entrenar, correr o bailar, también cocinar todo 
saludable, después los sábado o viernes a fiestas o al cine o a la playa con mis hermanas y mi papa.

Moderador: Muchas gracias Marcela.

Moderador: Lizy, que tal q nos puedes contar.

Participante: Soy Lizy Rojas tengo 24 años, estudio la carrera de Marketing estoy en octavo ciclo de lunes a viernes estoy enfocada en la universidad y los fines de semana trabajo con deportivos gatorade y eventos corporativos en hoteles, aparte de eso rara vez voy a fiestas, porque mis eventos son super-temprano y es como amanecerse.

Moderador: Muchas gracias Lizy.

Moderador: Antonella que nos puedes decir.

Participante: Soy Antonella estudio administración hotelera en USIL, ahora estoy practicando en un hotel en Miraflores y los horarios del hotel son rotativos de 7 a 3 de 3 a 7 y de 11 a 3 ahora estoy Part Time y en mis tiempos libres salgo con mi enamorado voy al cine a comer normalmente o con mi familia y nada tranquila.

Moderador: A qué bueno de verdad muchas gracias.

Moderador: Aby

Participante: Hola chicas, mi nombre es Aby Argueda tengo 25 años estudio la carrera de administración en USIL, me falta un semestre para acabar la carrera ojala se de, estuve practicando en una consultoría y no ha dado para nada así q me conozco y no soy tolerante para nada, este... eran puros ingenieros de sistemas no hablan y yo soy comunicativa de administración de empresas era un poco estresante el echo la distancia era bien lejos no dormía bien el doble grado es pesado sumamente pesado bueno los fines de semana es estar con mi hermana, soy bastante sedentaria, me gusta cocinar soy bastante ahorrativa y eso es todo.

Moderador: Muchas gracias Aby 
Moderador: Muchas gracias por la presentación ... ahora vamos a entrar al intermedio del focus group ahora desde las preguntas que voy a hacer no hay respuestas correctas e incorrectas todas las respuestas son válidas como saben esto es group estamos grabando ... ahora vamos a hablar sobre el consumo de refrescos naturales envasados, que bebidas suelen consumir durante el transcurso del día, que saben sobre las bebidas naturales...

Moderador: Con Aby ahora, ¿qué bebidas sueles consumir durante el día?

Participante: La verdad soy bien honesta yo tomo gaseosa.

Moderador: La gaseosa no se preocupe... no se juzga acá ... más honesto mejor...

Participante: Antes no me gustaba el azúcar, mi mejor opción fue tomar gaseosa, Moderador: Entonces sueles consumir gaseosas y conoces algo sobre bebidas naturales.

Participante: Bebidas naturales... lo que me gustan mucho son las infusiones y los tés Moderador: Que otras conoces.

Participante: Me gustan lo que son hierbas aromáticas, me encanta el cedrón, hierba luisa, bueno todos los que son té.

Moderador: Los tés, es lo que le gusta a usted muy bien, usted cree que es importante poder consumir una bebida envasada.

Participante: Yo creo que es más por practicidad a que me guste consumir.

Moderador: Mas que digamos, que le guste plenamente es mucho más práctico.

Participante: Claro si se adapta a mi gusto...

Moderador: Y por las temperaturas.

Participante: Yo creo que, según el clima.

Moderador: Y en qué momento del día, para ti, seria consumir una bebida.

Participante: Ahora q es primavera, me gusta en el almuerzo, por ejemplo

Moderador: Qué características usted está buscando.

Participante: No me gustan los colores, ni el ácido. 
Moderador: Donde suele comprar la bebida de estas características. Algún mercado en especial.

Participante: Bueno envasado en los supermercados Tottus.

Moderador: Muchas gracias.

Moderador: Ahora vamos a pasar con Antonella.

Moderador: Que bebidas sueles consumir durante el día.

Participante: Agua, infusiones, más que todo, agua.

Moderador: Que me puedes decir sobre las bebidas naturales

Participante: Eso no entiendo mucho.

Moderador: Bebidas naturales, por ejemplo, alguien de que le viene a la mente cuando decimos bebidas naturales.

Participante: Jugos de frutas, extractos

Participante: Me gusta jugo de naranja siempre.

Moderador: Donde compra el jugo envasado

Participante: Mas que todo en Tottus y cuando acompaño con las comidas.

Moderador: Y fuera del restaurante en el día a día, por ejemplo, cuando estas en la universidad o en el trabajo y quiere una bebida con esas características a donde iría.

Participante: A Tottus porque es más cerca.

Moderador: ¿Y en qué momento sería perfecto de tomar esa bebida?

Participante: Cuando estoy en clases.

Moderador: ¿Considera usted importante consumir estas bebidas envasadas?

Participante: Es práctico, no estas preparando... perdiendo tiempo.

Moderador: No Solamente eso a mí me gusta ese tipo de bebida y a veces no sé... lo siento medio extraño, cuando lo tengo guardado, se siente distinto.

Moderador: ¿Cuántas veces a la semana consumes este tipo de bebidas? 
Participante: Una vez por semana.

Moderador: ¿Qué características buscas?

Participante: Que no se sienta mucho el químico, algo natural que parezca... que hagan el esfuerzo...

Moderador: ¿Conoces de alguna bebida que esté haciendo el esfuerzo?

Participante: Si, en el grifo es bueno, cero azúcares en envase de vidrio es Selva el de mango...

Moderador: Muchas gracias Antonella.

Moderador: ¿Lizy, que bebidas tomas durante el día?

Participante: La verdad es que casi no compro. Yo tengo mi tomatodo...

Moderador: ¿Y qué sabes sobre las bebidas naturales?

Participante: Prefiero extractos de fruta, pero a veces tomo selva, el de mango.

Moderador: ¿En qué momento tomarías una bebida?

Participante: Todo el día estoy con agua.

Moderador: ¿Y si quisieras querer darte un gusto, qué características buscarías?

Participante: Que sea natural... la verdad hay una gaseosa que me gusta y ya ni la encuentro... si me daría gusto bueno puede ser lo de selva.

Moderador: ¿Qué fruta te llama la atención?

Participante: El mango y el maracuya.

Moderador: ¿Y cómo cuánto de azúcar?

Participante: Si me voy a dar el gusto más o menos azucarada.

Moderador: ¿Si lo sientes muy azucarada pesarías que ya no es tan natural?

Participante: Así es.

Moderador: Marcela que bebidas sabes consumir. 
Participante: La verdad es que todo el día es agua.

Moderador: Digamos esa disciplina y por ejemplo si tuviese que consumir alguna bebida natural que vista te llamaría la atención para que dejes el agua.

Participante: A veces hago jugos de apio, espinaca, kion, pepino una manzana, zanahoria, betarraga, son bien ricos, pero si voy a comprar es en Tottus, me compraría una botella.

Moderador: ¿Que botellas conoces?

Participante: Era transparente de color verde, era como...

Moderador: ¿Te acuerdas las características de ese producto?

Participante: El sabor... la verdad, le invite a mis amigos y nadie le gusto... pero para mí estaba rico.

Moderador: ¿Y las características que estás buscando en caso de comprar una bebida, ¿cuál sería?

Participante: Vegetales más que frutas.

Moderador: ¿Muy bien... y en qué momento, es el momento ideal para consumir esto?

Participante: En la mañana

Moderador: ¿Hasta qué hora más o menos?

Participante: Hasta el mediodía, pero puede ser en la noche.

Moderador: Por ejemplo, desde el mediodía, ¿hasta lo noche que bebidas consumirías?

Moderador: Interesante escucharla Antonella.

Moderador: ¿Bisamine que bebidas naturales consumirías?

Participante: Yo también me dedico al mundo saludable en todas las comidas agua, extractos de piñal, espinaca, apio, kion, pepino todas las mañanas y este... bueno té verde también me encanta y no me gusta las bebidas azucaradas. Sólo en casos extremos...siempre tomo hierba luisa... no soy mucho de azúcar y gaseosa muy rara vez.

Moderador: ¿Y de las gaseosas tomas regularmente? 
Participante: No.

Moderador: ¿Y qué sabes de las bebidas naturales?

Participante: En verdad, me encanta son buenas.

Moderador: ¿Qué clases de bebida te llamaría la atención?

Participante: Combinada fruta con verduras.

Moderador: ¿Conoces alguna bebida natural envasada?

Participante: En Wong... de toronja y de piña, si las he probado, pero se siente agrio.

Moderador: ¿Cuál es el mejor momento de consumir?

Participante: En la mañana.

Moderador: ¿Cuántas bebidas en el día consumirías?

Participante: Una.

Moderador: Usted

Participante: Una máximo.

Moderador: Muchas gracias.

Moderador: Ahora con Michelle. qué bebidas sueles consumir.

Participante: Yo con mi tomatodo con muña.

Moderador: ¿Con azúcar o sin azúcar?

Participante: Depende si lo llevo congelado.

Moderador: ¿Conoces alguna bebida natural?

Participante: Trabajaba en Perucola y tomaba Vida...

Moderador: ¿Y qué le parece?

Participante: Si... estaba bien.

Moderador: ¿Cuántas veces recomendaría?

Participante: Hasta 2 veces.

Moderador: Mucha gracias Michelle. 
Moderador: A ver Johana qué bebidas sueles tomar durante el día.

Participante: La verdad no soy de ir a tomar agua... estuve mal y busqué ayuda entonces la nutricionista me recomendó jugos naturales.

Moderador: ¿Cómo qué?

Participante: Me recomendaron los combinados. Piña con manzana, fresa cono piña y así los verdes, pero no me gustas el metakion.

Moderador: Por ejemplo, ¿qué tipo de bebidas sueles conocer?

Participante: No me gusta porque son muy dulces todo lo que tomo lo endulzo con estevia.

Moderador: Digamos entre las características que no sea muy dulce. ¿Qué bebidas envasadas conoces?

Participante: Selva, pero no sé si está en mi cabeza o algo, pero sé que es artificial.

Moderador: ¿Cuántas veces recomendaría usar las bebidas

Participante: Yo no lo recomendaría lo considero artificial, pero si quisiera si hubiera un producto que sea verdadera fruta sí.

Moderador: Ahora vamos a conversar un poco más abierto del mercado, qué marca de bebidas conocen.

Participante: Cifruts, monster, aloe vera, etc.

Moderador: ¿Qué bebidas naturales podríamos encontrar?

Participante: Naturale, aloe vera, zuma, zolie, jugos ditox.

Moderador: ¿Y dónde consiguieron estos jugos?

Participante: Por las redes sociales y eso de los que te llevan a tu casa y todo el tema.

Moderador: Alguno de ustedes se identifican con algún refresco en particular

Participante: Coca-Cola.

Moderador: Coca-Cola por acá, porque q le llama la atención.

Participante: No sé será porque yo no consumo el azúcar por eso consumo cocacola. 
Participante: Porque compensa.

Moderador: Michelle.

Moderador: ¿Usted también la coca cola?

Participante: Porque cansada en clase he tomado coca cola.

Moderador: ¿Y con qué bebida se identifica?

Participante: Me encanta la leche de coco, la leche de almendra, en verdad la consumo parar todo porque es natural no hace daño ... también la limonada de hierba luisa.

Moderador: ¿Y usted Antonella con qué se identifica?

Participante: Limonada de camu camu y el agua de camu camu.

Moderador: ¿Y por qué te gusta el camu camu?

Participante: Porque se siente más natural y se siente el sabor.

Moderador: ¿Lizy y usted?

Participante: El agua... amo el maracuyá.

Moderador: Johana

Participante: Yo soy más de limonada no tan acida porque el agua sola no pasa...

Moderador: Ahora vamos a hablar sobre el producto. ¿Qué esperaría usted de un refresco natural?

Participante: 100\%natural libre de persevantes endulzado con estevia.

Participante: Yo quisiera con jarabe de yacón, por que la estevia no parece natural.

Participante: Yo quisiera que aporte beneficios para la salud, reducir colesterol.

Participante: Que sea una bebida funcional.

Moderador: ¿Qué color le gustaría?

Participante: Del jugo de la fruta y color bajito pasteles.... Del color de la fruta de la materia prima, 
Participante: Si es de color depende de las combinaciones.

Moderador: ¿Cómo diría que ha sido su experiencia hasta el momento con bebidas naturales?

Participante: No he encontrado hasta el momento ningún jugo que sea completamente natural y que cumpla con mis expectativas... Lo único que creo en el restaurante, pero envasados no.

Moderador: Ahora me gustaría pasar los productos que queremos mostrarles.

Moderador: A ver empezamos con la degustación.

Moderador: Vamos a empezar con la presentación, empezamos con la chía.

Moderador: ¿Qué le parece la presentación?

Participante: Muy bien es el a combinación de la guanábana con chía.

Moderador: Vamos pasando ..las botellas.

Participante: Este se ve rico.. pero ese no se ve natural......

Participante: Este tiene quinua... no se ve natural.

Moderador: A ver vamos a ver... vamos a hablar de los envases en vidrio y el color de la botella.

Participante: Transparente.

Participante: Puede que sí pero depende del tipo de jugo...

Moderador: ¿Qué le motivaría tomar por ejemplo?

Moderador: Y digamos la tapa está bien.

Moderador: Ahora vamos a ver el contenido, le ha llamado la atención?

Participante: La de chía y la de quinua.

Participante: El envase... selva.

Moderador: El contenido.

Participante: Chía y de quinua. 
Moderador: Ahora vamos a hablar de la etiqueta.

Participante: El de selva.

Moderador: ¿Digamos que se pueda observar el contenido y el color que le parece el juego de combinaciones que tenemos?

Participante: La de chía y el de guanábana porque se muestra tal como es.

Moderador: ¿Qué les parecen la muestras?

Participante: Se ve raro.

Moderador: Si pensaríamos si fuera para niños.

Participante: El envase más ergonómico.

Sonrisas....

Participante: Probando el jugo

Participante: Parece pancho una frutita del norte

Participante: Sabe como a manzana.

Participante: Han probado la futa dragón ... hacen pitajaya,

Moderador: ¿Que les parece?

Participante: Buenazo ...

Moderador: A que sabe...

Participante: Parece pitajaya con camu camu.

Moderador: ¿Qué le parece el nivel de azúcar?

Participante: Esta perfecto parece estevia... esta perfecto

Moderador: ¿Qué tal la consistencia?

Participante: Espesito rico pasa suave, yo no soy de mucho acido, pero creo que va ser valorado por la gente que sabe de nutrición. ... si esta pasable.

Moderador: ¿Y qué del color?

Participante: A mí no me parece mal. 
Participante: Lo veo desabrido.

Moderador: Como se imaginan en un envase

Participante: Como la de quinua

Moderador: ¿Qué opinan por ahí?

Moderador: ¿Ya se lo acabaron?

Moderador: ¿Qué les pareció el color, la consistencia?

Participante: Sabe rico, pero visual no tanto.

Moderador: ¿Qué podría ayudarle al tema visual?

Participante: Algo transparente o blanco de repente o color de la fruta.

Moderador: ¿Cómo se le viene a la mente una botella acompañada con un textil que lo cubre?

Participante: Pero la persona quiere ver lo que hay adentro.

Moderador: Digamos no sé si han visto algún textil como de una canasta ahí. Para la presentación.

Moderador: ¿Qué otra cosa podría ayudar en lo visual?

Moderador: ¿Qué color le llamaría la atención

Participante: Dependiendo

Moderador: Algún color especifico

Participante: El de cereza... o rosado bajito o rojo bajito..

Participante: A la vista parece avena

Moderador: El sabor si les ha gustado

Participante: SI

Moderador: Tienen alguna sugerencia adicional que no hayamos mencionado

Participante: Si la gente no sabe como alimentarse como que me ha gustado... 
Participante: Para que el producto sea vendido y llegue al público tiene que expresar los nutrientes, los beneficios, si la persona no es consciente de lo que estan tomado no llega.

Participante: Yo creo que todo el mundo moderno sabe que es pitajaya.

Participante: Si es la fruta del dragón

Moderador: Sabiendo que tiene pitajaya. En qué lugares le gustaría encontrar este producto

Participante: Supermercados grifos

Moderador Cuál es el precio que podrían pagar

Participante: Dependiendo del tamaño

Moderador: Que tamaño le gustaría

Participante: De 250 a 300 mililitros porque mucho no...

Moderado: Ya muy bien

Moderador: El material del envase

Moderador: Nos quedamos con vidrio

Moderador: Y que nombre se les ocurre para este producto

Participante: Es algo exótico usa muchos como pitahaya

Moderador: Que nombre se les puede ocurrir.

Participante: Esta difícil.

Moderador: Que les parece el nombre kawsay

Participante: Que significa

Moderador: Significa vida

Participante: Ah, pero suena raro ... no jala la atención

Moderador: ¿Y a que lo asocian?

Participante: A bebida natural

Moderador: Que les parece de una doble funcionalidad del producto

Participante: A mi provocaría tomar en la mañana ... yo a media mañana... 
Moderador: Que se les ocurre que nombre puede recomendar

Moderador: ¿Pitaplus?

Participante: Suena como medicina

Moderador: Enfocado a desayuno o a refresco.

Participante: Quitadìa... Pitasawer.

Moderador: No, suena a trago

Moderador: Quisieran agregar un comentario final

Moderador:

A cuanto pagaría Máximo 3 soles

Aperitivo

Moderador: Este es el famoso sanky

Participante: Eso da en la zona donde yo he nacido en Ancash pero se le conoce como

Pancho.

Moderador: Tiene antioxidante vitamina $\mathrm{C}$ antioxidante natural

Moderador: Este producto es silvestre de 2 a 3 años de crecimiento.

Moderador: Esta bien rico el jugo...solamente el jugo de sanky combinado con yacón.

Moderador: Lo básico que tiene es sanky edulcorante natural de yacón y usa Bromato de Potasio

Moderador: Que beneficio te da la fruta.

Moderador: Antioxidante el color es como el jugo lechoso con puntitos negros. 


\section{Transcripción Focus Group 3}

Moderador: Buenas tardes mi nombre es Julius Silva vamos a participar en Focus Group, como saben va a ser grabado, así que traten de ignorar las cámaras, voy a hacerles una serie de preguntas y unas respuestas y no hay respuestas ni buenas ni malas lo importante es por el tema de saber sus apreciaciones sus intereses las creencias que puedan tener sobre el producto que vamos a presentar, hoy vamos a tratar sobre bebidas naturales. Antes de pasar a este tema me gustaría conocerlos veo que su nombre esta ahí eso va a facilitar el trabajo y les parecería si se presentan con su nombre a que se dedican en tiempos libres los fines de semana cual es su profesión etc.

Participante: Mi nombre es Sonia Vargas he estudiado administración de empresas, soy full deportes, mi gimnasio, creo esa parte de vida saludable ayuda mucho conforme vas avanzando en la edad.

Moderador: Muy bien, muchas gracias.

Moderador: Señorita Martha

Participante: Soy profesora de Educación Inicial, me gusta ir al cine.

Moderador: Y los fines de semana.

Participante: Me gusta salir ir a comer con mis tres sobrinos.

Moderador: Y que tal salen hacer compras.

Participante: Me gustas de todo u poco.

Moderador: Muy bien muchas gracias

Moderador: Gracias

Moderador: Señor Manuel

Participante: Mi nombre es Manuel soy ingeniero, los fines de semana hago ejercicio y cada quince días me gusta jugar fulbito, soy bien entusiasta para el deporte y no me gusta perder. Moderador: Bueno acá no hay respuestas ni buenas ni malas 
Participante: Muchas gracias

Moderador: Que tal Carolina

Participante: Mi nombre es Carolina, y soy profesora de acá de ISIL tengo 2 hijitos en mis ratos libres la paso con ellos me gusta ir al cine pero cuando hay hijos es distinto, pero si, trato de salir los fines de semana.

Participante: Algún sitio predilecto que tengan sus hijos o usted.

Moderador: El cine les gusta bastante.

Participante: El cine me gusta bastante

Moderador: Bien, muchas gracias

Moderador: Jorge que tal.

Participante: Hola Julius, mi nombre es Jorge del Águila soy economista de profesión y me encanta la profesión que dedico aquí, que es la docencia es hobby prácticamente para mí, mi hobby es el atletismo toda la vida la he practicado en la Universidad en el barrio, luego en la universidad salimos campeones, ahora corro maratones corro 60 a 80 kilómetros a la semana. he corrido en otros Berlín Washington y en mis ratos libres suelo practicar el deporte tengo 64 años.

Moderador: Muchas gracias

Moderador: Y los fines de semana te dedicas a correr.

Participante: Si los sábados me dedicaba a correr, pero por cambio de horario, me bloquearon los sábados, ahora todo lo he pasado para el domingo, y aprovecho esta reunión para que sean testigos de lo que me esta pasando.

Moderador: Muchas gracias Jorge,

Moderador: Mónica

Mi nombre Mónica Carreteros soy profesora de educación inicial tengo 50 años, mi pasión aparte de mi hijo son mis alumnos hago actividad funcional, que nunca jamás pensé que lo 
iba hacer que me encanta después del estrés de la vida, si me encanta ver sonreír a la gente y si se sonríen par algo que digo me gusta más.

Moderador: Que bueno los fines de semana le gusta pasarla con sus hijos.

Participante: Con mis hijos mis sobrinos y algunos galanes por ahí.

Participante: Esa última parte no me gusto.

Moderador: Silvia García.

Participante: Soy Silvia García soy periodista trabajo en la Ricardo Palma, los fines de semana me gusta pasear salir a comer y pasarla en familia

Moderador: Alguna actividad que resalte.

Participante: Antes hacía baile seguido, pero voy a retomar...

Moderador: Bueno yo soy Julius Silva psicólogo de profesión 31 años, estoy conduciendo el focus ahora y bueno ya que nos conocemos, bueno pasemos a hablar de un poco de las bebidas

Moderador: Pasaremos a hablar un poco de las bebidas naturales y comenzamos por la derecha voy a hacerles una serie de preguntas.

Moderador: Señora Sonia

Moderador: Qué bebidas suele consumir durante el día.

Participante: Siempre agua o algunas infusiones, trato de buscar lo natural, cuando veo las etiquetas siempre me decepciono. Porque siempre encuentro con químicos.

Moderador: ¿Que bebida natural conoce?

Participante: He visto varios en el mercado, he visto con sábila, con chía, camu camu nombres específicos ninguna que tengo en mente.

Moderador: ¿Considera que es importante que las bebidas naturales sean envasadas?

Participante: Si fuesen realmente naturales yo creo que sí, hay una que te preparan en el momento si creo. 
Moderador: De la fruta al envase.

Participante: Al menos que sean mas sinceros en la etiqueta.

Moderador: Lo primero q pensamos al ver un producto no pensamos q sea $100 \%$ natural.

Moderador: Usted que recomendaría consumir estas bebidas naturales cuantas veces al día.

Participante: Debería de ser diario.

Moderador: Alguna cantidad en especial.

Moderador: ¿En cantidades qué medida sugeriría?

Participante: En botellitas de 200 mililitros, si sería importantes consumirlas menos de medio litro, sobre todo si son frutas netas del país como la chirimoya así una vez al día. Moderador: ¿Usted suele consumir ese tipo de bebidas?

Moderador: Martha

Moderador: Que bebida suele consumir durante el día.

Participante: Jugo de naranja, agua y gaseosas de vez en cuando.

Moderador: ¿Y qué me puede decir sobre bebidas naturales?

Participante: Estuve consumiendo aloe vera y me dijeron que no la consuma a diario.

Moderador: Conoce alguna bebida natural que se venda en el mercado

Participante: El jugo de naranja de Wong que se da en ese momento.

Moderador: Ninguna otra.

Moderador: Que opinión tiene de los néctares los zumos,

Participante: Bueno en los juguitos de caja tiene mucho colorante y azúcar

Moderador: Que característica debería tener al momento de adquirir un de estos productos

Participante: Que tengan poco azúcar, y no muchos colorantes.

Moderador: Incluso si afectaríamos el sabor que no sea así tan dulce...

Participante: Yo tengo la opinión que a veces calculan mal el azúcar.

Moderador: ¿Y las bebidas gaseosas que usted toma son regulares? 
Participante: De vez en cuando, son normales.

Moderador: Sr. Manuel q bebida suele tomar?

Participante: Antes del desayuno tomo un vaso de agua tibia y generalmente y si tomo bebidas naturales de casa como Hierba Luisa digamos infusiones como boldo y tomo ese tipo de bebidas siempre he llevado al trabajo.

Moderador: Es decir siempre en el transcurso del día toma eso.

Moderador: ¿Qué me puede decir sobe las bebidas naturales envasadas, conoce alguna?

Participante: Si bueno siempre veo en supermercados. en Tottus, Wong, Plaza Vea, en Metro veo bastante bebidas naturales que han salido, esas que son de camu camu, de chía que he visto y de diferentes presentaciones.

Moderador: Que le ha llamado la atención de estas presentaciones.

Participante: Bueno el tamaño, el color también de la fruta que a veces llama la atención.

Moderador: ¿Consumiría estos productos?

Participante: Bueno si yo preferiría si esta bien etiquetado y que sean naturales, si yo lo consumiría sabiendo que es natural pero que no tiene colorantes y el mínimo de persevantes, Moderador: Sobre la cantidad de azúcar.

Participante: Yo preferiría un edulcorante natural no muy bajo, tiene que ser bajo y lo mas natural posible.

Moderador: Muchas gracias.

Moderador: Señora Carolina que bebidas suele consumir durante el transcurso del día.

Participante: Normalmente debería decir agua, pero tomo muy poco un vasito pero si me gusta el jugo de maracuyá, no suelo tomar en la calle pero si en mi casa.

Moderador: ¿Y cuándo ha tenido que comprar que ha comprado?

Participante: El Free tea pero no mucho envasado, estaba escuchando si a él le gusta el te con azúcar a mi si me gusta el azúcar, me satisface. 
Moderador: Y cuantas veces al día suele tomar alguna bebida...

Participante: Como le digo si estoy trabajando tomo un poquito de agua, pero en mi casa si tomo jugos naturales en el almuerzo acompaño en los almuerzos con jugos naturales.

Moderador: ¿Qué otros productos conocen que vendan jugos naturales envasados?

Participante: Bueno en supermercados, Plaza Vea, Wong, etc.

Moderador: Conoce alguna marca en especifico.

Participante: Me atrae el camu camu, la chía. La chía se puso de modo sacaron bastantes jugos y se vendía todo lo que es chía.

Moderador: Jorge que tal.

Moderador: ¿Qué bebida sueles tu consumir?

Participante: Yo he tenido varias etapa ahora no tomo frugos ahora tomo jugos en mi casa en base a fresa o plátanos o papapa combinados leche o polvos vitamínicos o cuando entreno es con energizante y si me preguntaras sobre el tema de bebidas naturales no tomo muy frecuente, de vez en cuando porque voy a una a tienda y me es indiferente la cantidad de azúcar que tenga ni me fijo lo q dice en realidad no lo tomo porque siento q me va causar muchos problemas y si me preguntas por una marca watts es un buen producto, del valle es otro.

Moderador: Gracias por adelantarse con las preguntas.

Moderador: Muchas gracias Jorge.

Moderador: ¿Señorita Mónica qué bebidas suele tomar?

Participante: La verdad soy bien gaseosera, soy poco jugo, he bajado la gaseosa por que es lo que tengo que hacer y el único natural que tomo es el jugo de naranja y el jugo del Valle porque se siente mas esencia.

Participante: Por el azúcar no me preocupa, soy azucarera, 
Moderador: Y qué me puede decir sobre alguna bebida natural que le llame la atención o que diga este es mas natural. ¿Qué le llame la atención?

Participante: Voy a ser honesta, ni siquiera lo miro, paso por el jugo y tomo jugo gloria, lo máximo que me fijo es en la fecha de vencimiento. Yo simplemente compro el jugo que me encanta maracuyá, naranja, piña y manzana.

Moderador: ¿Y cuantas ves al día suele consumir estos jugos?

Participante: Este tipo de caja todo el día y gaseosas extractos trato de que sea 4 veces.

Participante: Ahora entiendo por q tenias vergüenza contarlo.

Participante: En el colegio no se puede consumir nada de esto todo modo USIL.

Participante: Ahora que suele consumir en el colegio.

Participante: Solo aguas, agua y agua.

Moderador: ¿Y en el colegio hay jugos naturales?

Participante: A los niños le mandan jugos de casa, naranja piña ahora lo bueno que los niños ahora consumen agua.

Moderador: Donde suele comprar estos productos

Participante: En metro.

Moderador: Muchas gracias.

Moderador: Señora Silvia

Moderador: Cuantos días suele consumir estos productos.

Participante: Este tipo de jugos todos los días en la noche, trato de q sea 4 veces y agua si bastante.

Participante: En el colegio solo agua modo USIL entonces tiene que ser lo mas natural posible.

Moderador: ¿Y que consume?

Participante: Solo agua 
Moderador: Señora Silvia

Participante: Todos los días mis vasos de infusión, después todo sin azúcar siempre sin azúcar de casa, si tomo mi jugo de papaya.

Moderador: ¿Y en caso de que tenga de que fuera comprar algunas bebidas naturales y de que tipo son?

Participante: Los néctares o los jugos y bebidas de naranja, de piña mientras sean mas natural seria mejor

Moderador: ¿Qué tipo de bebidas naturales podría beber usted?

Participante: Me gusta piña, maracuyá, papaya.

Moderador: ¿Alguna marca en especial?

Participante: Que recuerde no.

Moderador: Muy bien

Moderador: El dulce

Participante: Si me gusta

Participante: No que tanto dulce en la bebida

Participante: Casi nada

Moderador: Para todo el grupo Que tipo de bebidas naturales conocen alguna marca en específico.

Participante: Si lo veo lo recuerdo... Aloe Vera,

Participante: Yo no sé, pero han pasado tantos años y tantas cosas han dicho de todos los productos, que de repente hay un interés, pero yo pienso, que cada organismo es diferente y cada uno reacciona diferente entonces es muy relativo, yo no le doy mucho pie a que un jugo te va a curar de algo.

Moderador: No hay verdad absoluta todo es relativo.

Moderador: Que productos o que marca, ya no de zumos sino algún tipo de refrescos. 
Participante: Yo sugiero bien fácil es lo que venden los market de jugos de naranja, toronja, maracuyá

Moderador: Dentro de la línea tú te identificas en algo natural del momento.

Moderador: Porqué te identificas más con este tipo de refresco.

Participante: Yo tengo entendido que si no tomas en el instante un jugo en el momento se oxida, entonces se tiene buscar lo más real posible... porque una vez que le ponen preservantes, los edulcoran ya no se va comparar con lo natural.

Moderador: Señora Carolina usted porque se identifica más con el jugo

Participante: Si yo veo una naranja y el jugo yo prefiero el jugo porque me refresca más...

Moderador: ¿Señora Silvia con qué bebidas naturales se identifica?

Participante: Me gusta de papaya, fresa, piña.

Moderador: ¿Por qué escoge estos productos?

Participante: Más refrescantes, mas ricos mas heladitos.

Moderador: Señora Mónica

Moderador: Con que producto de identifica mas usted

Participante: Yo soy práctica, me iría para beber algo que ya está listo, para no perder tiempo. Por eso el jugo de Wong es un éxito y seria fabuloso que el mismo producto varíe en frutas.

Moderador: Entonces usted se inclina por lo práctico.

Participante: Si.

Moderador: Sr. Manuel usted porque se identifica? Participante:

Participante: Trabajé en Lurín y había dispensadora de refrescos ahí yo escogía jugo de manzana porque lo veía bien natural prefería siempre el de manzana.

Moderador: ¿Que le gustaba a parte de lo practico que veía?

Participante: Sentía siempre, he sido minucioso con la etiqueta y daba bastante naturalidad. 
Moderador: Muy bien

Moderador: Señora Martha

Participante: Señorita Martha

Participante: Yo ya le había respondido

Moderador: ¿Ya me había olvidado, entonces Sonia qué tal?

Participante: Yo optaría mas por comprar un producto que sea raro

Moderador: Entonces se identifica más con lo inusual o con lo diferente

Participante: Si porque lo normal lo puedo hacer en casa. Pero si encuentro algo como la pitajaya o algo que llame la atención con un sello ecológico, sería diferente.

Moderador: ¿Y alguna en especial le llamaría la atención?

Participante: Si para comprarlo mas seguido

Moderador: Que bueno

Moderador: ¿Que esperan ustedes sobre lo natural hemos visto característica que tan importante es para ustedes de un producto natural?

Participante: Por la salud mientras mas natural, nuestro organismo estaría mejor, también sería que refuercen con vitamina, entonces natural saludable y práctico.

Moderador: ¿La presentación?

Participante: Quisiera algo mas ecológico.

Participante: La tendencia en estos últimos años es comer o tomar mas saludable para cuidarnos bien, por ejemplo, si tomo vitamina $\mathrm{C}$ me contrarresta algunas enfermedades, por ejemplo, la maca el camu camu.

Moderador: Estamos hablando sobre valores nutricionales, salud, etc.

Moderador: Como seria el tema del color el sabor

Participante: Si no tiene sabor es mejor para mi, me he acostumbrado muy bajo de dulce Moderador: ¿Y en cuestión de color? 
Participante: No me identifica el color.

Moderador: Señorita Martha

Participante: El color no importa el sabor si

Participante: Como venga el producto si es del color de la fruta el sabor de la fruta estaría bien.

Participante: En realidad entre el color intenso y que tenga relación con la fruta depende de la característica de la fruta.

Participante: En mi caso si tendría que el color sea algo importante cuando paso en el mercado yo veo el color llamativo me jala tender a probarlo.

Moderador: Manuel sobre el tema de color y sabor.

Participante: También tiene que jalar llamar el color tiene que ir con lo de la fruta y con lo de sabor ni muy dulce ni muy agrio lo normal pero que se sienta el sabor real

Moderador: Es importante que tenga esa característica del aroma

Participante: $\mathrm{Si}$

Moderador: En el dulce

Participante: Edulcorante

Moderador: Que experiencia tiene sobre algunas bebidas naturales cuál es su experiencia en esa línea ya sea envasada o o preparada en restaurante.

Participante: Siempre el del restaurante es mejor

Moderador: Y si han sentido algo tan parecido.

Participante: En mi experiencia en tetrapak me parece algo bueno como el frugos o watts

Participante: Había un jugo de marca selva

Participante: El que mas se parece a lo real para mí era el selva.

Moderador: Perfecto 
Moderador: Ahora voy ha salir un ratito para traer diferentes muestras de los diferentes empaques.

Comentarios entre los participantes...

Moderador: ¿Ahora vamos a presentar algunos empaques y cuál es el que más le gusta en función al envase?

Participante: A mi me gusta selva, también el de chía, de quinua

Moderador: ¿Y en cuestión de contenido cuál se ve más natural?

Participante: La botella verde,

Participante: A mi no porque esconde el color verde.

Moderador: Tres personas selva, dos transparentes, una chía la de quinua está bien

Moderador: En que lugares preferirían encontrar estos productos.

Participante: En grifos y supermercados.

Moderador: ¿Cuánto podrían pagar por este producto?

Participante: S/ 2.50, pero si fuera el de chía, el de quinua, máximo 5 soles... según el tamaño también... porque fuera mejor de botella de vidrio.

Moderador: Ahora vamos a ver el producto.

Comentarios ....

Moderador: A ver

Moderador: Que les parece el sabor

Participante: Francamente me encanta...

Participante: $\mathrm{Si}$ esta rico

Moderador: El nivel de acido que le parece.

Participante: A mi me ha gustado.

Moderador: ¿Jorge por qué te ha gustado este tipo de ácido?

Participante: Esta en su punto de acidez. 
Moderador: ¿Qué tal la consistencia y el color del producto?

Participante: Medio cremoso.

Moderador: ¿Qué tal al momento de probar y que tal se sintió?

Participante: Es rico

Moderador: ¿Qué le recomendaría al producto?

Participante: Mas azúcar un poquito menos acido y el color mas subido y mas heladito.

Moderador: Que les parece el nombre el nombre kawsay

Participante: ¿Qué significa?

Moderador: Significa: vida

Participante: ¿Y cómo se llama la fruta?

Moderador: sanky

Moderador: Se desarrolla en Arequipa

Moderador: Considerando las botellas

Moderador: A que producto se inclinaría

Participante: Seria la de chía

Participante: Yo creo la verde, pero en blanco

Participante: $\mathrm{O}$ sino en la quinua sana

Participante: Como no tiene un color llamativo la pondría en la botella verde.

Moderador: ¿Que me dirían de la etiqueta?

Participante: La etiqueta es importante por ejemplo lo de chía

Moderador: Que precio sería a pagar

Participante: Tiene que ver el precio competitivo, empezaríamos por el tamaño también tendríamos que hacer varias combinaciones para un precio accesible y competitivo.

Participante: Yo pienso 2.50 por el envase chico del envase de 300 mililitros 
Moderador: ¿Qué le parece el producto en tanto a este doble beneficio en lo nutritivo y lo de refresco?

Participante: Según el tipo de beneficio

Moderador: Digamos a una idea de venderle un producto nutritivo y beneficios para ustedes.

Participante: Conociendo que es así si lo compro

Moderador: ¿Que otra recomendación?

Participante: Pienso yo que en esta gran batalla de las gaseosas... hubo un slogan que decía "ya viene la chaposa mas sabrosa" y luego llego la kola-inglesa y luego llegó y tuvo éxito en el mercado.

Moderador: Alguna otra recomendación...

Participante: Siempre hay un tema de degustación de publicidad y presentar la imagen de la fruta.

Moderador: Estaba en el tema de ponerle kawsay y vida

Participante: Algo natural me parece bien.

Moderador: Y kawsay es vida

Moderador: Ahora el examen.

Moderador: Alguna recomendación

Participante: Lo mas probable en el caso de aloe porque me lo recomendaron y de ahí no deje de cómpralo

Moderador: Quienes volverían a probar este producto

Participante: Si yo si

Muchas gracias por su participación. 


\section{Anexo 4 Encuesta Comprobatoria}

\section{ENCUESTA COMPROBATORIA}

Buenos Días /Tardes/ Noches, gracias por participar en nuestra encuesta. Somos alumnos de la Universidad San Ignacio de Loyola y estamos realizando una investigación sobre una bebida "Refresco natural en base al fruto SANKY". Entendiéndose por bebida natural, la que será elaborada a base del fruto andino sanky, edulcorante natural (yacón), agua, con un mínimo de preservantes, que no contiene alcohol, ni azúcar, ni cafeína que se elaborara de manera industrial y será envasada. Le agradeceremos conteste con total sinceridad las preguntas que le voy a formular. 


\section{ENCUESTA COMPROBATORIA}

a) ¿Qué edad tiene usted?

18 a 25 años

26 a 35 años

36 a 50 años b) ¿Consume bebidas naturales envasadas?

Sí

No

Si es "No", fin de la encuesta

Si se encuentra en otro rango de edad, fin de la encuesta.

C. ¿Cuáles de estas marcas de bebidas naturales usted conoce?

Chia

Free Tea

Frumas

Kero

Jugos Selva

Aloe Vera

Petit

Beverage

Otros

D. ¿Considera usted que las características de la bebida natural que más consume, es todo lo que usted necesita?
1. Totalmente de
2. De acuerdo
3. No precisa
4. En desacuerdo
5. Muy importante acuerdo.

E. Identifique el nivel de importancia con respecto a los siguientes atributos que usted busca en las bebidas naturales.

$\begin{array}{lllll}\text { 1. Nada } & \text { 2. Poco } & 3 . & 4 . & 5 . \text { Muy } \\ \text { Importante } & \text { Importante } & \text { Medianamente } & \text { Importante } & \text { Importante } \\ & & \text { Importante } & & \end{array}$


Textura

Color

Contenido Calórico

Imagen de la

Marca

Presentación

Precio

Propiedades

Naturales

Tamaño

Valor Nutricional

Variedad de

Sabores

F. ¿Con qué frecuencia consume bebidas naturales?

1. Diariamente.

2. Dos veces por semana.

3. Semanalente.

4. Quincenalmente.

5. Mensualmente.

G. ¿Cuántas unidades de este tipo de bebida compra cada vez que se acerca al punto de venta para realizar la compra?

1. Una unidad.

2. Entre dos y tres unidades.

3. Entre tres y cinco unidades. 
4. Seis unidades (six pack).

H. ¿Conoce la fruta Sanky?
( ) $\mathrm{Si}$
( ) No

El Sanky es una fruta oriunda de la sierra del Perú. Esta es rica en vitaminas y minerales como el potasio, calcio, fósforo, etc. Es rica en vitamina $\mathrm{C}$ que fortalece el sistema inmunológico. Es rica también en antioxidantes, contiene fibra que mejora la digestión, regula la presión arterial y controla la diabetes.

I. ¿Qué tan satisfecho está con los siguientes atributos del producto que acaba de probar?

El encuestado realiza un test de sabor sobre el producto en mención.
1. Muy
Atributos
2. Satisfecho
3. No precisa
4. Insatisfecho
5. Muy
Satisfecho
insatisfecho

Sabor

Color

Textura

Sabor Residual

Aroma

J. ¿Estaría dispuesto a consumir una nueva bebida natural?

1. Totalmente de

2. De acuerdo

3. No precisa

4. En desacuerdo

5. Muy importante acuerdo.

K. ¿Qué tipo de envase prefiere para el producto?

1. Lata 
2. Plástico

3. Tetrapack

4. Vidrio

5. Le es indiferente

L. ¿En qué tamaño le gustaría que se venda el producto?

Presentación de tarjeta con los tamaños a escala natural los diferentes tamaños.

1. Envase de $250 \mathrm{ml}$.

2. $\quad$ Envase de $300 \mathrm{ml}$.

3. Envase de $450 \mathrm{ml}$.

4. Envase de $600 \mathrm{ml}$.

M. ¿Cuánto estaría dispuesto a pagar por el producto seleccionado.

1. $\mathrm{S} / 2.00-\mathrm{S} / 2.50$

2. $\mathrm{S} / 3.00-\mathrm{S} / 3.50$

3. $\mathrm{S} / 4.00-\mathrm{S} / 4.50$

4. $\mathrm{S} / 5.00-\mathrm{S} / 5.50$

5. $\mathrm{S} / 6.00-\mathrm{S} / 6.50$

N. ¿Dónde le gustaría encontrar esta nueva bebida natural?

1. Bodegas

2. Gimnasios

3. Grifos

4. Mercados saludables / Ecológicos

5. Supermercados

6. Otros 
O. ¿Cuál de los siguientes nombres prefiere para el nuevo producto natural?

1. Sankyfruit

2. Sankyfrush

3. SankyNatural

4. Otro

P. ¿Por cuál de los medios desearía conocer sobre esta nueva bebida natural?

1. Redes sociales

2. Paneles publicitarios

3. Radio

4. Revistas

5. Otros

\section{Datos de Control}

\section{Q. Género}

( ) Masculino ( ) Femenino
R. ¿En qué distrito vive?
S. ¿Cuál es el tipo de vivienda donde
1. San Borja.
resides?
2. San Isidro.
1. Casa de concreto
3. Miraflores.
2. Departamento
4. La Molina.
3. Cuarto
5. Santiago de Surco. 

T. Material predominante en su vivienda U. El piso predominante de su vivienda es:
1. Ladrillo
1. Parquet
2. Adobe
2. Cerámica
3. Madera
3. Ladrillo o cemento
4. Otros materiales
4. Otros materiales

V. ¿Cuántos cuartos con baño exclusivo W. ¿Cuenta su hogar con servicio a tiene? internet?

1. No tiene cuarto con baño exclusivo

2. Tiene 1 cuarto con baño exclusivo

( ) $\mathrm{Si}$

( ) No

3. Tiene 2 o más cuartos con baño

exclusivo,

X. ¿Tiene computadora de escritorio

Y. ¿Tiene cocina con horno?

( ) $\mathrm{Si}$

( ) No

( ) $\mathrm{Si}$

( ) No

Z. ¿Tiene refrigeradora?

AA. ¿Tiene Secadora de ropa?

( ) $\mathrm{Si}$

( ) No

( ) $\mathrm{Si}$

( ) No

BB. ¿Cuántos TV tiene en su hogar?

CC. ¿Cuántos vehículos de uso exclusivo tiene en su hogar? 
DD. ¿Cuál es el nivel de instrucción del jefe del hogar?

1. Sin estudios.

2. Primaria incompleta.

3. Primaria completa.

4. Secundaria incompleta.

5. Secundaria completa.

6. Educación superior. 
Anexo 5: Estimación de la Población en Zona 7 de Lima Metropolitana 2016-2021

Distrito de La Molina

\begin{tabular}{|c|c|c|c|c|c|}
\hline AÑOS & $\begin{array}{c}\text { LA } \\
\text { MOLINA }\end{array}$ & & $\mathbf{y}$ & \multicolumn{2}{|c|}{ Regresión Lineal } \\
\hline 2000 & 108,227 & -7.5 & 108,227 & $a+b x=f(x)$ & \\
\hline 2001 & 112,179 & -6.5 & 112,179 & $b$ & $4,193.25$ \\
\hline 2002 & 116,170 & -5.5 & 116,170 & $a$ & $138,949.25$ \\
\hline 2003 & 120,194 & -4.5 & 120,194 & $R^{\wedge} 2$ & $99.96 \%$ \\
\hline 2004 & 124,243 & -3.5 & 124,243 & AÑOS & $\begin{array}{l}\text { LA } \\
\text { MOLINA }\end{array}$ \\
\hline 2005 & 128,306 & -2.5 & 128,306 & 2016 & 174,592 \\
\hline 2006 & 132,343 & -1.5 & 132,343 & 2017 & 178,785 \\
\hline 2007 & 136,350 & -0.5 & 136,350 & 2018 & 182,978 \\
\hline 2008 & 140,381 & 0.5 & 140,381 & 2019 & 187,172 \\
\hline 2009 & 144,491 & 1.5 & 144,491 & 2020 & 191,365 \\
\hline 2010 & 148,738 & 2.5 & 148,738 & 2021 & 195,558 \\
\hline 2011 & 153,133 & 3.5 & 153,133 & & \\
\hline 2012 & 157,638 & 4.5 & 157,638 & & \\
\hline 2013 & 162,237 & 5.5 & 162,237 & & \\
\hline 2014 & 166,912 & 6.5 & 166,912 & & \\
\hline 2015 & 171,646 & 7.5 & 171,646 & & \\
\hline
\end{tabular}

Fuente: Elaboración Propia

Distrito de Miraflores

\begin{tabular}{llllll}
\hline \multicolumn{1}{c}{ ANOS } & MIRAFLORES & \multicolumn{1}{r}{$\mathbf{x}$} & $\mathbf{y}$ & \multicolumn{2}{c}{ Regresión Lineal } \\
\hline 2000 & 92,093 & -7.5 & 92,093 & $\mathrm{a}+\mathrm{bx}=\mathrm{f}(\mathrm{x})$ & \\
2001 & 91,848 & -6.5 & 91,848 & $\mathrm{~b}$ & 708.37 \\
2002 & 91,522 & -5.5 & 91,522 & $\mathrm{a}$ & $87,758.56$ \\
2003 & 91,114 & -4.5 & 91,114 & $\mathrm{R}^{\wedge} 2$ & $98.35 \%$ \\
2004 & 90,623 & -3.5 & 90,623 & AÑOS & MIRAFLORES \\
2005 & 90,049 & -2.5 & 90,049 & 2016 & 81,737 \\
2006 & 89,371 & -1.5 & 89,371 & 2017 & 81,029 \\
2007 & 88,596 & -0.5 & 88,596 & 2018 & 80,321 \\
2008 & 87,767 & 0.5 & 87,767 & 2019 & 79,612 \\
2009 & 86,920 & 1.5 & 86,920 & 2020 & 78,904 \\
2010 & 86,091 & 2.5 & 86,091 & 2021 & 78,196 \\
2011 & 85,284 & 3.5 & 85,284 & & \\
2012 & 84,473 & 4.5 & 84,473 & & \\
2013 & 83,649 & 5.5 & 83,649 & & \\
2014 & 82,805 & 6.5 & 82,805 & & \\
2015 & 81,932 & 7.5 & 81,932 & & \\
\hline
\end{tabular}

Fuente: Elaboración Propia 


\section{Distrito de San Borja}

\begin{tabular}{|c|c|c|c|c|c|}
\hline A ÑNOS & $\begin{array}{l}\text { SAN } \\
\text { BORJA }\end{array}$ & $\mathbf{x}$ & $\mathbf{y}$ & \multicolumn{2}{|c|}{ Regresión Lineal } \\
\hline 2000 & 109,543 & -7.5 & 109,543 & $a+b x=f(x)$ & \\
\hline 2001 & 109,886 & -6.5 & 109,886 & $\mathrm{~b}$ & 143.87 \\
\hline 2002 & 110,179 & -5.5 & 110,179 & $\mathrm{a}$ & $110,952.25$ \\
\hline 2003 & 110,418 & -4.5 & 110,418 & $\mathrm{R}^{\wedge} 2$ & $96.86 \%$ \\
\hline 2004 & 110,602 & -3.5 & 110,602 & AÑOS & $\begin{array}{l}\text { SAIV } \\
\text { BORJA }\end{array}$ \\
\hline 2005 & 110,728 & -2.5 & 110,728 & 2016 & 112,175 \\
\hline 2006 & 110,848 & -1.5 & 110,848 & 2017 & 112,319 \\
\hline 2007 & 110,968 & -0.5 & 110,968 & 2018 & 112,463 \\
\hline 2008 & 111,088 & 0.5 & 111,088 & 2019 & 112,607 \\
\hline 2009 & 111,208 & 1.5 & 111,208 & 2020 & 112,751 \\
\hline 2010 & 111,328 & 2.5 & 111,328 & 2021 & 112,895 \\
\hline 2011 & 111,448 & 3.5 & 111,448 & & \\
\hline 2012 & 111,568 & 4.5 & 111,568 & & \\
\hline 2013 & 111,688 & 5.5 & 111,688 & & \\
\hline 2014 & 111,808 & 6.5 & 111,808 & & \\
\hline 2015 & 111,928 & 7.5 & 111,928 & & \\
\hline
\end{tabular}

Fuente: Elaboración Propia

Distrito de San Isidro

\begin{tabular}{llllll}
\hline AÑNS & $\begin{array}{l}\text { SAN } \\
\text { ISIDRO }\end{array}$ & $\mathbf{x}$ & $\mathbf{y}$ & \multicolumn{2}{l}{ Regresión Lineal } \\
& & & & & \\
\hline 2000 & 64,741 & -7.5 & 64,741 & $\mathrm{a}+\mathrm{bx}=\mathrm{f}(\mathrm{x})$ & \\
2001 & 64,309 & -6.5 & 64,309 & $\mathrm{~b}$ & -724.48 \\
2002 & 63,822 & -5.5 & 63,822 & $\mathrm{a}$ & $59,902.25$ \\
2003 & 63,280 & -4.5 & 63,280 & $\mathrm{R}^{\wedge} 2$ & $99.45 \%$ \\
& & & & ANOS & SAIN \\
2004 & 62,685 & -3.5 & 62,685 & 2016 & ISIDRO \\
2005 & 62,037 & -2.5 & 62,037 & 2017 & 53,020 \\
2006 & 61,321 & -1.5 & 61,321 & 2018 & 52,295 \\
2007 & 60,544 & -0.5 & 60,544 & 2019 & 51,571 \\
2008 & 59,735 & 0.5 & 59,735 & 2019 & 50,846 \\
2009 & 58,920 & 1.5 & 58,920 & 2020 & 50,122 \\
2010 & 58,123 & 2.5 & 58,123 & 2021 & \\
2011 & 57,345 & 3.5 & 57,345 & & \\
2012 & 56,570 & 4.5 & 56,570 & & \\
2013 & 55,792 & 5.5 & 55,792 & & \\
2014 & 55,006 & 6.5 & 55,006 & & \\
2015 & 54,206 & 7.5 & 54,206 & & \\
\hline
\end{tabular}

Fuente: Elaboración Propia 
Distrito de Santiago de Surco

\begin{tabular}{|c|c|c|c|c|c|}
\hline AÑOS & $\begin{array}{c}\text { STGO DE } \\
\text { SURCO }\end{array}$ & $\mathbf{x}$ & $\mathbf{y}$ & \multicolumn{2}{|c|}{ Regresión Lineal } \\
\hline 2000 & 256,761 & -7.5 & 256,761 & $a+b x=f(x)$ & \\
\hline 2001 & 263,165 & -6.5 & 263,165 & $b$ & $5,759.41$ \\
\hline 2002 & 269,488 & -5.5 & 269,488 & $a$ & $301,292.56$ \\
\hline 2003 & 275,711 & -4.5 & 275,711 & $R^{\wedge} 2$ & $99.95 \%$ \\
\hline 2004 & 281,817 & -3.5 & 281,817 & A ̃̃NOS & $\begin{array}{l}\text { S IGU. } \\
\text { SURCO }\end{array}$ \\
\hline 2005 & 287,788 & -2.5 & 287,788 & 2016 & 350,248 \\
\hline 2006 & 293,534 & -1.5 & 293,534 & 2017 & 356,007 \\
\hline 2007 & 299,054 & -0.5 & 299,054 & 2018 & 361,766 \\
\hline 2008 & 304,466 & 0.5 & 304,466 & 2019 & 367,526 \\
\hline 2009 & 309,889 & 1.5 & 309,889 & 2020 & 373,285 \\
\hline 2010 & 315,447 & 2.5 & 315,447 & 2021 & 379,045 \\
\hline 2011 & 321,157 & 3.5 & 321,157 & & \\
\hline 2012 & 326,928 & 4.5 & 326,928 & & \\
\hline 2013 & 332,725 & 5.5 & 332,725 & & \\
\hline 2014 & 338,509 & 6.5 & 338,509 & & \\
\hline 2015 & 344,242 & 7.5 & 344,242 & & \\
\hline
\end{tabular}

Fuente: Elaboración Propia 
Anexo 6: Calculo de la proporción de la población de la Zona Lima 7 comprendida entre los 18 y 50 años.

Segemento de Interés: 18 a 50 años

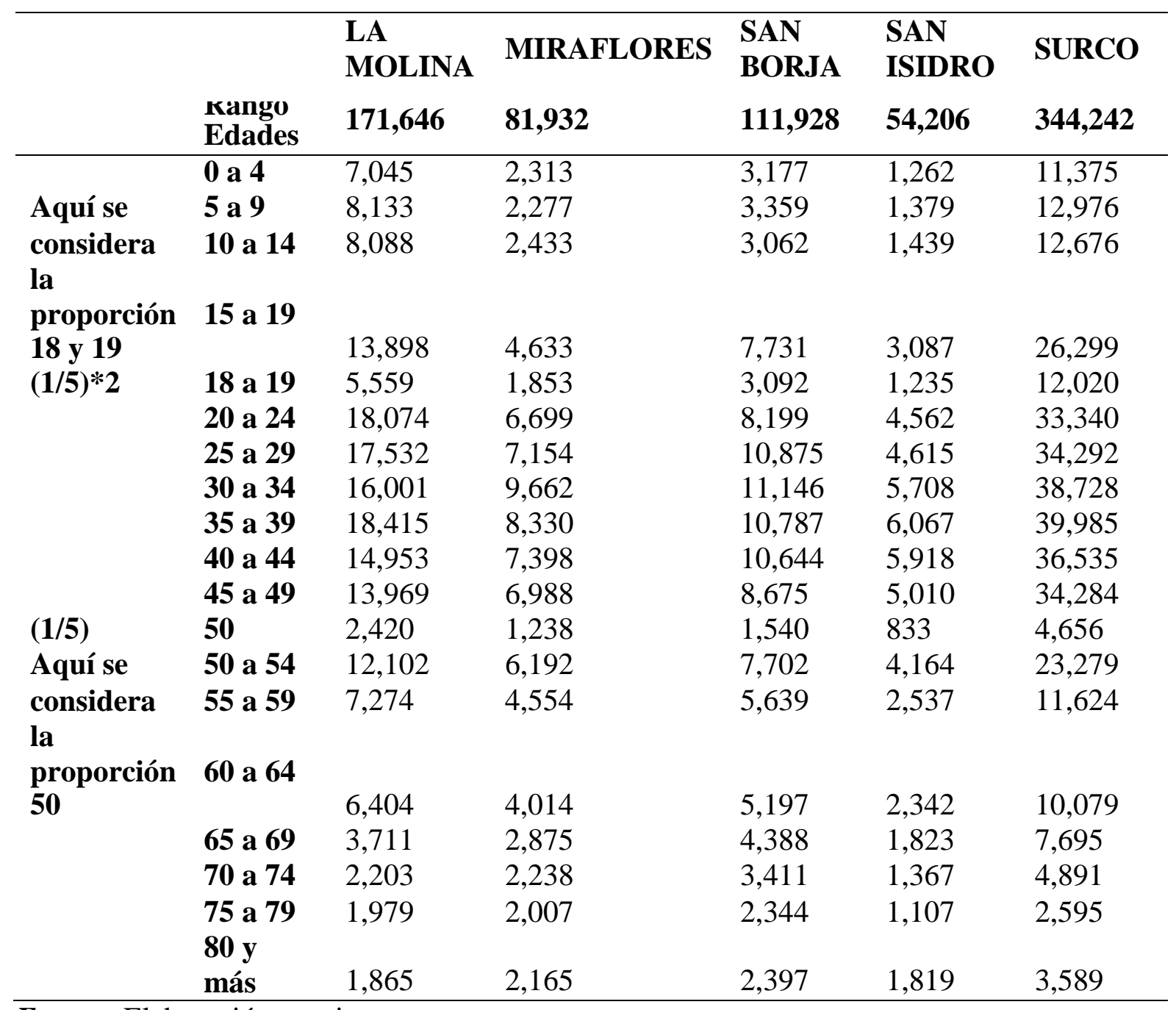

Fuente: Elaboración propia

Proporción: (Suma de segmento/ Población del distrito)

\begin{tabular}{llllll}
\hline Distrito & LA & MIRAFLORES & $\begin{array}{l}\text { SAN } \\
\text { BORJA }\end{array}$ & $\begin{array}{l}\text { SAN } \\
\text { ISIDRO }\end{array}$ & SURCO \\
Proporción & $62.29 \%$ & $60.20 \%$ & $58.04 \%$ & $62.63 \%$ & $67.93 \%$ \\
\hline
\end{tabular}


Anexo 7: Tabla de contingencia para el cálculo de la proporción del Mercado Efectivo

(disposición de adquisición del producto).

\section{¿Estarías dispuesto a consumir esta nueva bebida natural? ¿ ¿Cuál es su distrito de residencia?* Precio}

\begin{tabular}{|c|c|c|c|c|c|c|c|c|}
\hline \multirow{2}{*}{\multicolumn{3}{|c|}{ Factor Precio: $55.84 \%$}} & \multicolumn{6}{|c|}{ Cuál es su distrito de residencia? } \\
\hline & & & San Borja & San Isidro & Miraflores & La Molina & Surco & Total \\
\hline \multirow{13}{*}{ 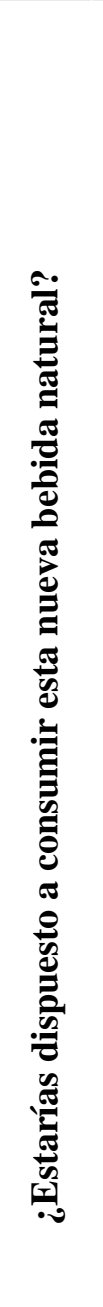 } & \multirow{3}{*}{ 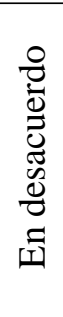 } & Recuento & 4 & 2 & 3 & 7 & 12 & 28 \\
\hline & & $\begin{array}{l}\text { \% dentro de Estarías } \\
\text { dispuesto a consumir esta } \\
\text { nueva bebida natural? } \\
\% \text { dentro de Cuál es su }\end{array}$ & $14.3 \%$ & $7.1 \%$ & $10.7 \%$ & $25.0 \%$ & $42.9 \%$ & $100.0 \%$ \\
\hline & & distrito de residencia? & $7.3 \%$ & $8.3 \%$ & $5.8 \%$ & $8.0 \%$ & $7.3 \%$ & $7.3 \%$ \\
\hline & \multirow[b]{2}{*}{ 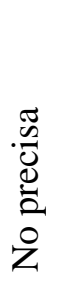 } & Recuento & 12 & 4 & 8 & 13 & 26 & 63 \\
\hline & & $\begin{array}{l}\% \text { dentro de Estarías } \\
\text { dispuesto a consumir esta } \\
\text { nueva bebida natural? } \\
\% \text { dentro de Cuál es su }\end{array}$ & $19.0 \%$ & $6.3 \%$ & $12.7 \%$ & $20.6 \%$ & $41.3 \%$ & $100.0 \%$ \\
\hline & & distrito de residencia? & $21.8 \%$ & $16.7 \%$ & $15.4 \%$ & $14.9 \%$ & $15.8 \%$ & $16.4 \%$ \\
\hline & \multirow[b]{2}{*}{ 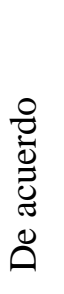 } & Recuento & 6 & 2 & 4 & 5 & 13 & 30 \\
\hline & & $\begin{array}{l}\% \text { dentro de Estarías } \\
\text { dispuesto a consumir esta } \\
\text { nueva bebida natural? } \\
\% \text { dentro de Cuál es su }\end{array}$ & $20.0 \%$ & $6.7 \%$ & $13.3 \%$ & $16.7 \%$ & $43.3 \%$ & $100.0 \%$ \\
\hline & $\Delta$ & distrito de residencia? & $10.9 \%$ & $8.3 \%$ & $7.7 \%$ & $5.7 \%$ & $7.9 \%$ & $7.8 \%$ \\
\hline & \multirow{4}{*}{ 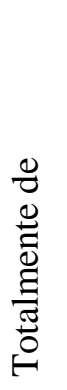 } & Recuento & 33 & 16 & 37 & 62 & 114 & 262 \\
\hline & & $\begin{array}{l}\% \text { dentro de Estarías } \\
\text { dispuesto a consumir esta } \\
\text { nueva bebida natural? }\end{array}$ & $12.6 \%$ & $6.1 \%$ & $14.1 \%$ & $23.7 \%$ & $43.5 \%$ & $100.0 \%$ \\
\hline & & \% dentro de Cuál es su & & & & & & \\
\hline & & distrito de residencia? & $60.0 \%$ & $66.7 \%$ & $71.2 \%$ & $71.3 \%$ & $69.1 \%$ & $68.4 \%$ \\
\hline \multirow{3}{*}{ Total } & & Recuento & 55 & 24 & 52 & 87 & 165 & 383 \\
\hline & & $\begin{array}{l}\text { \% dentro de Estarías } \\
\text { dispuesto a consumir esta } \\
\text { nueva bebida natural? } \\
\% \text { dentro de Cuál es su }\end{array}$ & $14.4 \%$ & $6.3 \%$ & $13.6 \%$ & $22.7 \%$ & $43.1 \%$ & $100.0 \%$ \\
\hline & & distrito de residencia? & $100.0 \%$ & $100.0 \%$ & $100.0 \%$ & $100.0 \%$ & \multicolumn{2}{|c|}{$100.0 \% 100.0 \%$} \\
\hline
\end{tabular}

Fuente: Elaboración propia 


\section{Anexo 8: Cálculo del COK del inversionista (Modelo CAPM)}

\begin{tabular}{|c|c|c|c|}
\hline Término & Significado & \multicolumn{2}{|l|}{ ¿Cómo? / Fuente } \\
\hline $\begin{array}{l}\mathrm{COK}= \\
\mathrm{ke}:\end{array}$ & $\underline{\text { Rentabilidad esperada }}$ & \multicolumn{2}{|c|}{ Método CAPM: ke=Rf+ $\beta$ proy $(\mathrm{Rm}-\mathrm{Rf})+\mathrm{R}$.país } \\
\hline Rf : & $\frac{\text { Bono del tesoro }}{\text { americano }}$ & \multicolumn{2}{|c|}{ http://indicadoreseconomicos.bccr.fi.cr/indicadoreseconomicos/Cuadros/frmVerCatCuadro.aspx?idioma=1\&CodCuadro=\%20677 } \\
\hline $\begin{array}{l}(\mathrm{Rm}- \\
\mathrm{Rf}):\end{array}$ & $\begin{array}{l}\text { mercado } \\
\text { Implícita } \\
\text { PRMX=PRME=PRMI } \\
\text { Beta proyectado: es el }\end{array}$ & \multicolumn{2}{|c|}{$\begin{array}{l}\text { (Damodarán / Arzac / CAPM) Tomamos el mayor valor promedio del cuadro } \\
\text { https://ubr.universia.net/article/viewFile/685/811 }\end{array}$} \\
\hline Bproy & $\begin{array}{l}\text { Beta desapalancado } \\
\text { obtenido en tabla de } \\
\text { Damodarán y luego es } \\
\text { apalancado teniendo } \\
\text { en cuenta la razón: } \\
\text { "Deuda; Capital de } \\
\text { socios" y el impuesto }\end{array}$ & $\begin{array}{l}\text { Deuda }=0.00 \% \\
\text { Capital }=100.00 \% \\
\text { Impuesto }=29.50 \% \\
\beta U=0.95\end{array}$ & $\beta_{\text {proy }}=\left[1+\left.\frac{D}{E} *(1-T)\right|^{*} \beta_{U}\right.$ \\
\hline $\mathrm{T}=\mathrm{IR}$ & Impuesto a la renta & \multicolumn{2}{|c|}{$\begin{array}{l}\text { http://orientacion.sunat.gob.pe/index.php/empresas-menu/impuesto-a-la-renta-empresas/regimen-general-del-impuesto-a-la-renta- } \\
\text { empresas/calculo-anual-del-impuesto-a-la-renta-empresas/2900-03-tasas-para-la-determinacion-del-impuesto-a-la-renta-anual }\end{array}$} \\
\hline Rp: & $\underline{\text { Riesgo país }}$ & \multicolumn{2}{|c|}{$\begin{array}{l}172.35 \text { PBS (puntos básicos) promedio desde enero } 2012 \text { al mes de julio del } 2017 \\
\text { https://estadisticas.bcrp.gob.pe/estadisticas/series/diarias/resultados/PD04709XD/html }\end{array}$} \\
\hline
\end{tabular}




\section{Anexo 9: BASE DE DATOS DE PROVEEDORES}

A continuación, se lista la relación de proveedores de maquinaría e insumos para la operación de producción de la bebida a base de Sanky.

\begin{tabular}{|c|c|c|}
\hline ITEM & PROVEEDOR & PRODUCTOS \& SERVICIOS \\
\hline 1 & $\begin{array}{l}\text { Agroindustrias Alimenticias } \\
\text { Natura }\end{array}$ & $\begin{array}{l}\text { Marmitas, Licuadora Industrial, Lavadora de } \\
\text { Frutas }\end{array}$ \\
\hline 2 & Devon SAC & Accesorios de seguridad \\
\hline 3 & High Tech Service SAC & Equipos de laboratorio \\
\hline 4 & Crafiflex Perú & Etiquetas \\
\hline 5 & Control Union & Inspección y Certificación \\
\hline 6 & Drafpsck & $\begin{array}{l}\text { Llenadoras, Etiquetadora, Tapadoras, } \\
\text { Codificadora. }\end{array}$ \\
\hline 7 & Algarrobos Orgánicos del Perú & Varios insumos en polvo incluyendo yacón \\
\hline 8 & Comercial Maderera Andina & Pallets para almacenamiento \\
\hline 9 & TComp & Venta de computadores. \\
\hline 10 & Ancona & Venta de computadores. \\
\hline 11 & $\begin{array}{l}\text { AB Importaciones Industriales } \\
\text { S.A.C. }\end{array}$ & $\begin{array}{l}\text { Controles digitales de temperatura, humedad, } \\
\text { tiempo y presión, equipos de aire acondicionado, } \\
\text { evaporadores, gases refrigerantes. }\end{array}$ \\
\hline 12 & Bitzer Compressores LTDA & $\begin{array}{l}\text { Compresores, equipos de refrigeración industrial, } \\
\text { refrigeración comercial, sistema de refrigeración } \\
\text { para camiones. }\end{array}$ \\
\hline 13 & $\begin{array}{l}\text { CNTA Sociedad Anónima } \\
\text { Cerrada }\end{array}$ & $\begin{array}{l}\text { Análisis físico químicos, análisis } \\
\text { microbiológicos, capacitación y asistencia } \\
\text { técnica, innovación y mejora de procesos, } \\
\text { investigación, desarrollo e innovación. }\end{array}$ \\
\hline 14 & $\begin{array}{l}\text { Cruz Verde Fumigación y } \\
\text { Limpieza industrial S.A. }\end{array}$ & $\begin{array}{l}\text { Servicio de control de plagas y fumigación } \\
\text { roedores \& insectos. }\end{array}$ \\
\hline
\end{tabular}




\section{Anexo 10: FORMATO DE COSTOS PROVEEDOR NUEVO}

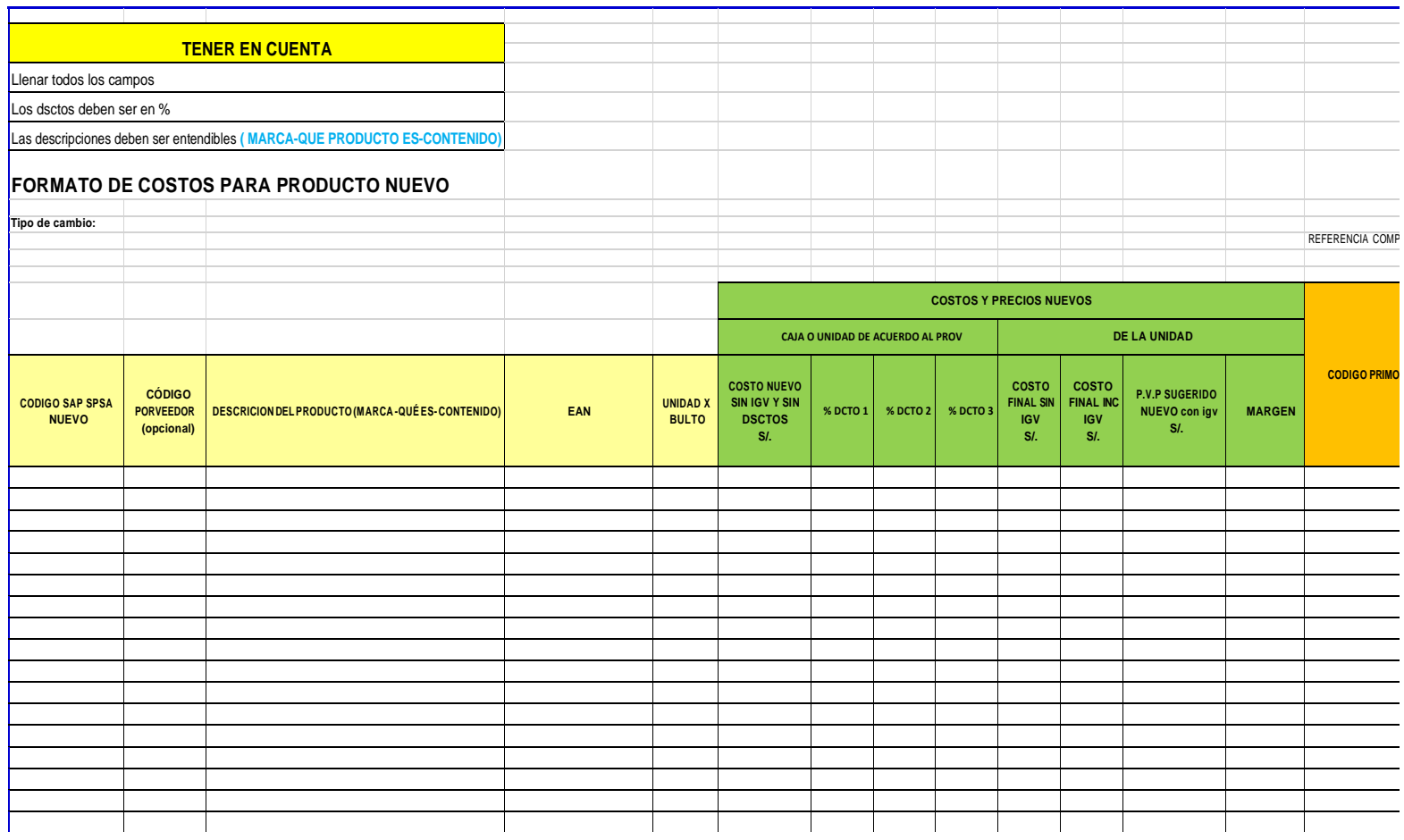




\section{Anexo 11: FORMATO DE DECLARACIÓN JURADA}

Versión 03

ASC-FR293

Supermercados

Peruanos SA
DECLARACIÓN JURADA

PARA LA INCORPORACIÓN DE NUEVOS PROVEEDORES / NUEVOS PRODUCTOS REGULARES

LA INFORMACIÓN VERTIDA EN EL PRESENTE DOCUMENTO DEBE SER VERAZ Y VERIFICABLE. ES UNA "DECLARACIÓN JURADA"

Instrucciones:

* Para iniciar Proceso de Calificación debe completar la información solicitada y adjuntar los documentos que se indican en "Documentos Obligatorios para Iniciar Proceso de Calificación".

* Todas las celdas son obligatorias.

* Debe presentar una Solicitud por cada tipo de producto. Puede usar una misma solicitud para diferentes presentaciones del mismo producto.

* Al final de la página encuentre las Declaraciones Juradas que debe completar según corresponda.

* Las Declaraciones Juradas contenidas en este documento deben ser firmadas a manuscrito en tinta azul ( no usar tinta negra). El documento final completo debe ser remitido escaneado a colores en formato PDF.

1. SELECCIONE en el recuadro la opción que corresponda:

\begin{tabular}{|c|l|c|}
\hline 1.1 & TIPO DE PROVEEDOR & Click para Seleccionar \\
\hline 1.2 & TIPO DE PROCESO DE CALIFICACIÓN & Click para Seleccionar \\
\hline
\end{tabular}

2. INFORMACION DEL PROVEEDOR
\begin{tabular}{|c|l|l|l|}
\hline 2.1 & Razón Social & \\
\hline 2.2 & Dirección & Representante Comercial & Responsable de Control de Calidad \\
\hline \multirow{4}{*}{2.3} & Persona(s) de Contacto & & \\
\cline { 2 - 5 } & Nombre & & \\
\cline { 2 - 5 } & Teléfonos (fijo/ móvil) & & \\
\cline { 2 - 5 } & Correos electrónicos & & \\
\hline
\end{tabular}

3. INFORMACION DEL ESTABLECIMIENTO

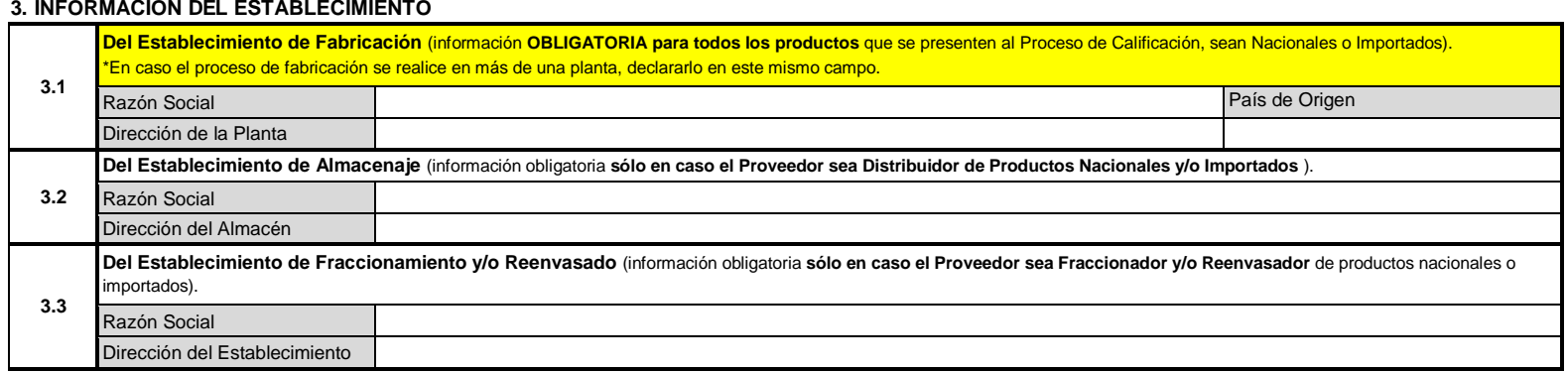

\section{FICHA TÉCNICA DEL NUEVO PRODUCTO}

\begin{tabular}{|c|c|c|c|c|}
\hline 4.1 & \multicolumn{4}{|c|}{$\begin{array}{l}\text { Nombre Técnico del Producto y Denominación Comercial (Deben coincidir con los nombres declarados en el Registro Sanitario y en el Rótulo. Ejemplo: Bizcochuelo de Vainilla } \\
\text { Relleno con Manjar (nombre técnico) - Torta de Manjar (denominación comercial)). }\end{array}$} \\
\hline \multirow{2}{*}{4.2} & \multicolumn{4}{|c|}{ Marca (Debe coincidir con la marca declarada en el Registro Sanitario y en el Rótulo. Si tuviera Marca Registrada debe indicarlo). } \\
\hline & Es dueño de la marca & Click para Seleccionar & La marca está registrada & Click para Seleccionar \\
\hline & Código de Registro Sanitario & & & \\
\hline \multirow{5}{*}{4.3} & \multicolumn{4}{|l|}{ Presentación de la Unidad de Venta } \\
\hline & $\begin{array}{l}\text { a) Envase Primario (Envase de contacto directo con el } \\
\text { producto) }\end{array}$ & Click para Seleccionar & *Indicar en caso sea otro & .. \\
\hline & b) Material de Envase Primario & Click para Seleccionar & *Indicar en caso sea otro & $\ldots \ldots \ldots \ldots \ldots \ldots \ldots$ \\
\hline & $\begin{array}{l}\text { c) Material de Envase Secundario (Empaque que } \\
\text { contiene al Envase Primario) }\end{array}$ & Click para Seleccionar & *Indicar en caso sea otro & \\
\hline & d) Contenido Neto & Click para Seleccionar & Indicar cantidad & $\ldots \ldots \ldots \ldots$ \\
\hline \multirow[b]{2}{*}{4.4} & \multicolumn{4}{|c|}{$\begin{array}{l}\text { Ingredientes y Aditivos (Usar nombres específicos, no genéricos. Para la declaración de aditivos debe incluir : clase funcional + nombre específico del aditivo o su número de } \\
\text { identificación según el Sistema Numérico Internacional del CODEX, incluyendo la sub división cuando corresponda. Ej: color (SIN } 160 \text { a (i)), sustancia conservadora (sorbato de potasio)) }\end{array}$} \\
\hline & & & & \\
\hline 4.5 & Método de Producción & Click para Seleccionar & *Indicar en caso sea otro & \\
\hline 4.6 & Método de Envasado & Click para Seleccionar & *Indicar en caso sea otro & \\
\hline 4.7 & \multicolumn{3}{|c|}{$\begin{array}{l}\text { Características Microbiológicas: De acuerdo a la Norma Sanitaria que Establece los Criterios Microbiológicos de Calidad Sanitaria e } \\
\text { Inocuidad para los Alimentos y Bebidas de Consumo Humano" - R.M.№ 591-2008/MINSA }\end{array}$} & Click para Seleccionar \\
\hline 4.8 & Tiempo de Vida Útil & Click para Seleccionar & Indicar tiempo & \\
\hline 4.9 & $\begin{array}{l}\text { Incluir Fotografía que evidencie rotulado de: } \\
\text { 1) Lote o Fecha de Producción y } \\
\text { 2) Fecha de Vencimiento: }\end{array}$ & & & \\
\hline 4.10 & \multicolumn{3}{|l|}{ Condiciones de Conservación } & Click para Seleccionar \\
\hline
\end{tabular}




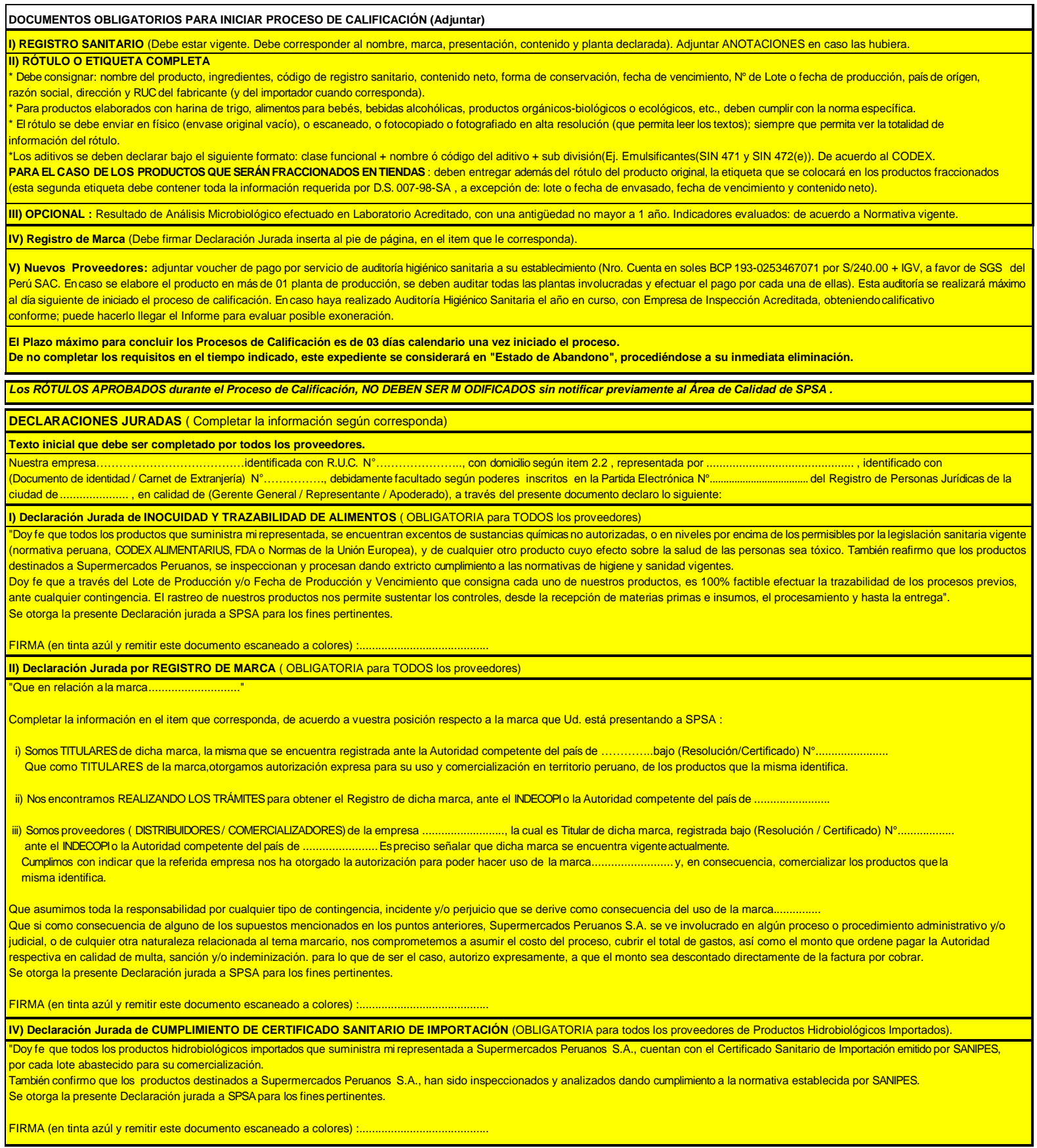


Anexo 12: FORMATO INGRESO DE PRODUCTO/ PROVEEDOR NUEVO

\begin{tabular}{|c|c|c|c|}
\hline \multicolumn{3}{|l|}{ Wonc } & 71"Me \\
\hline \multicolumn{3}{|c|}{$\begin{array}{l}\text { FORMATO: } \\
\text { INGRESO DE PRODUCTO/PROVEEDOR NUEVO }\end{array}$} & 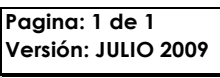 \\
\hline TIPO DE SOLICITUD: & & FECHA DE SOLICITUD: & \\
\hline NUEVO PRODUCTO ( ) & PROVEEDOR NUEVO ( ) & & \\
\hline \multicolumn{4}{|c|}{ DATOS GENERALES DEL PROVEEDOR } \\
\hline \multicolumn{4}{|c|}{ RAZON SOCIAL DEL PROVEEDOR: } \\
\hline \multicolumn{2}{|l|}{$\mathrm{N}^{\circ} \mathrm{RUC}$} & \multicolumn{2}{|c|}{ DESTINO DEL PRODUCTO: INSUMO () VENTA () } \\
\hline PROCEDENCIA & NACI ONAL () IMPORTADO ( & PAIS DE ORI GEN: & \\
\hline TIPO DE ACTIVIDAD: & DISTRIBUIDOR（） & FABRICANTE（） & AQUILA ( ) \\
\hline
\end{tabular}

\begin{tabular}{|l|l|l|l|}
\hline PERSONAS DE CONTACTO & GERENCIA COMERCIAL & GERENTE GENERAL & RESPONSABLE DE CALIDAD \\
\hline DATOS & & & \\
\hline Nombres y Apellidos & & & \\
\hline Teléfono fijo/ Celular & & & \\
\hline Correo Electrónico & & & \\
\hline
\end{tabular}

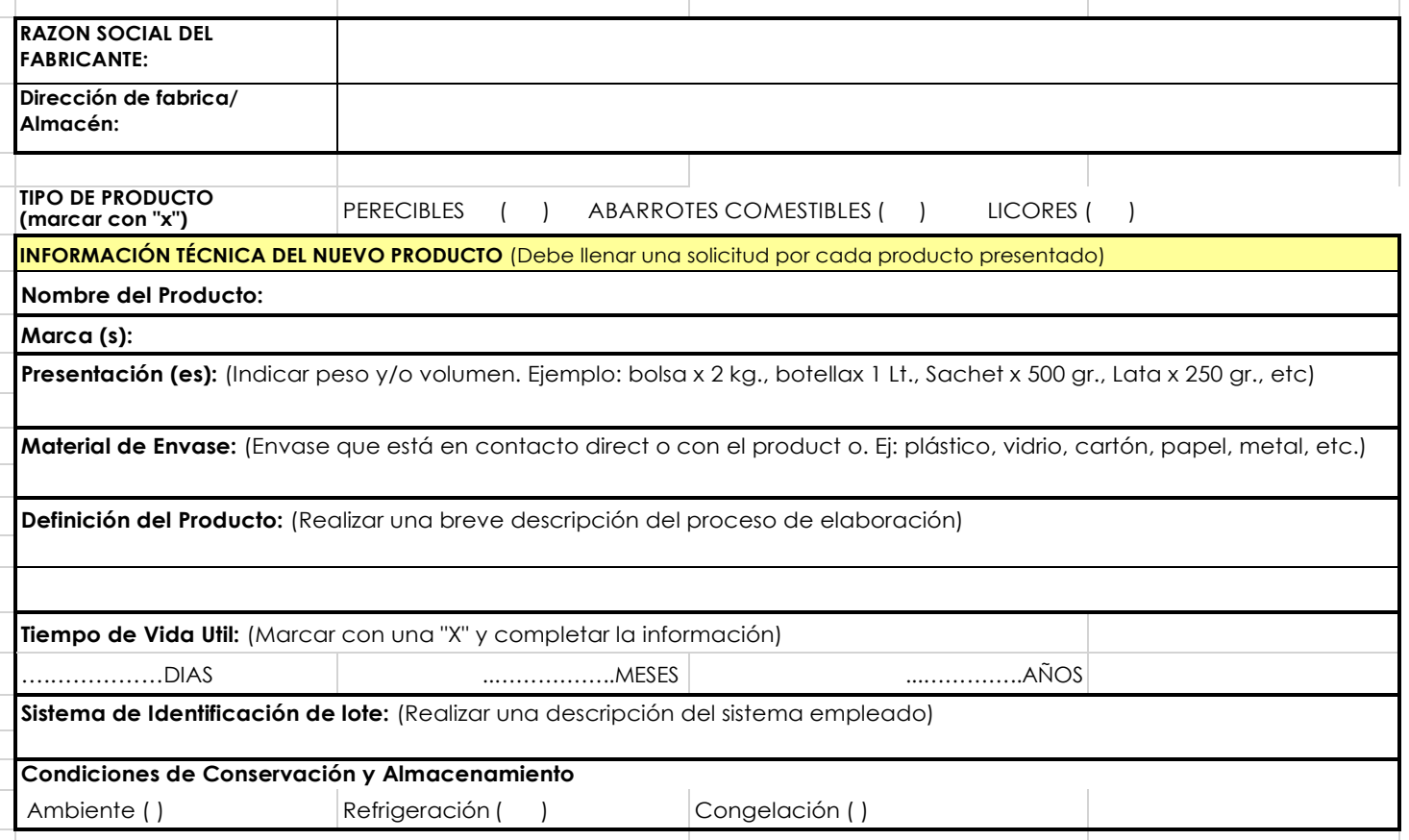

Se debe adiuntar copia de los siguientes Documentos:

1) REGISTRO SANITARIO (Verificar que corresponda al nombre del product o presentado, marca, presentación(es), contenido(s) y planta que se declara en el presente document o)

2) ETIQUETA COMPLETA ( debe consignar: nombre del product o, ingredient es, código de registro sanitario, forma de conservación, fecha de vencimiento, N de Lote o fecha de producción, razón social y dirección del fabricante e importador de ser el caso).

3) RESULTADOS DE ANALISIS FISICO-QUIMICOS Y MICROBIOLOGICOS (Efectuado en Laboratorio Acreditado y de acuerdo a la norma sanitaria de los criterios microbiológicos de calidad sanitaria e inocuidad para los alimentos y bebidas de consumo humano: NTS N071-MINSA/DIGESA)

\section{PARA NUEVOS PROVEEDORES:}

*Certificado de Calidad de la Planta o Almacén (Infome de Inspección reciente (no mayor a 6 meses) o Certificación de Calida Desde el inicio del proceso, el proveedor tiene 30 días como máximo para completar los requisitos solicitados en este formato. 


\section{Anexo 13: FORMATO FICHA TÉCNICA ALIMENTOS}

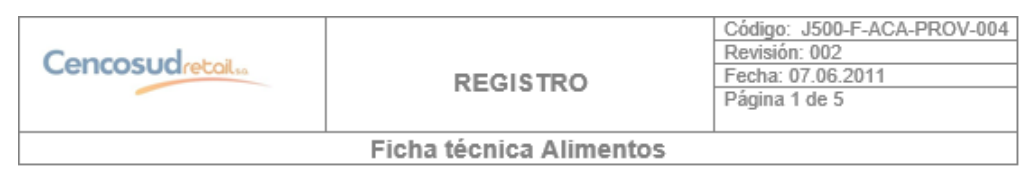

\begin{tabular}{|l|l|}
\hline ANTECEDENTES GENERALES & \\
\hline Nombre del Proveedor e importador & \\
\hline Dirección & \\
\hline Razón social & \\
\hline Rut & \\
\hline Nombre del Fabricante & \\
\hline Dirección & \\
\hline Razón social & \\
\hline Rut & \\
\hline Nombre del producto & \\
\hline Resolución Sanitaria & \\
\hline Sistema de calidad implementado & \\
\hline Contacto Comercial & \\
\hline Email & \\
\hline Fono & \\
\hline Responsable de Calidad & \\
\hline Email & \\
\hline Fono & \\
\hline Fecha & \\
\hline 1. DESCRIPCION DEL PRODUCTO & \\
\hline 1.1. Descripción del alimento & \\
\hline 1.2. Referente & \\
\hline 2. DIAGRAMA DE FLUJO DEL PROCESO DE ELABORACION \\
\hline \multicolumn{2}{|l}{} \\
\hline 3. INGREDIENTES \\
\hline 3.1. Listado de ingredientes
\end{tabular}

\begin{tabular}{|c|c|c|c|c|}
\hline \multicolumn{5}{|l|}{ 3.2. Limites de aditivos } \\
\hline \multicolumn{5}{|c|}{ 4. INFORMACION NUTRICIONAL } \\
\hline \multicolumn{5}{|c|}{ 4.1. Tabla de información nutricional (en caso de existir otros nutrientes, agregar más filas) } \\
\hline & \multicolumn{3}{|c|}{ Porción: medida casera $(X X \mathrm{~g} / \mathrm{ml})$} & \\
\hline & \multicolumn{3}{|l|}{ Porciones por envase: } & \\
\hline & & $100 \mathrm{~g} / \mathrm{ml}$ & Porción & \\
\hline & Energía (kcal) & & & \\
\hline & roteínas $(\mathrm{g})$ & & & \\
\hline & Yrasa total $(\mathrm{g})$ & & & \\
\hline & Grasa saturada $(\mathrm{g})$ & & & \\
\hline & Grasa monoinsaturada $(\mathrm{g})$ & & & \\
\hline & Grasa poliinsaturada $(\mathrm{g})$ & & & \\
\hline & Grasa trans $(g)$ & & & \\
\hline & Colesterol (mg) & & & \\
\hline & 1. de C. disp. (g) & & & \\
\hline & Azúcares totales $(\mathrm{g})$ & & & \\
\hline & Sodio (mg) & & & \\
\hline
\end{tabular}

\begin{tabular}{|c|c|c|c|c|}
\hline Cencosudretails.s & & \multicolumn{2}{|c|}{ REGISTRO } & \begin{tabular}{|l|} 
Código: J500-F-ACA-PROV-004 \\
Revisión: 002 \\
Fecha: 07.06.2011 \\
Página 2 de 5 \\
\end{tabular} \\
\hline \multicolumn{5}{|c|}{ Ficha técnica Alimentos } \\
\hline \multicolumn{3}{|c|}{ 4.2. Fuente Información Nutricional } & \multicolumn{2}{|c|}{$\begin{array}{l}\text { Tablas referenciales: Indicar nombre de la tabla de } \\
\text { referencia utilizada y método de cálculo. } \\
\text { Análisis de laboratorio: Indicar el método y } \\
\text { procedimiento de análisis (adjuntar protocolo de } \\
\text { análisis). }\end{array}$} \\
\hline \multicolumn{5}{|c|}{\begin{tabular}{|l|} 
5. ESPECIFICACIONES DE CALIDAD \\
5.1. Caracteristicas físicas (en caso de
\end{tabular}} \\
\hline \multicolumn{5}{|l|}{ Cont. neto } \\
\hline \multicolumn{5}{|l|}{\begin{tabular}{|l|l} 
Cont. drenado \\
\end{tabular}} \\
\hline & Declarado & Min. & Máx. & Método \\
\hline \multicolumn{5}{|l|}{ Volumen } \\
\hline \multicolumn{5}{|l|}{\begin{tabular}{|l} 
Dimensiones \\
\end{tabular}} \\
\hline \multicolumn{5}{|l|}{\begin{tabular}{|l|} 
Defectos \\
\end{tabular}} \\
\hline $\begin{array}{l}\text { Unid. por envase } \\
\end{array}$ & & & & \\
\hline
\end{tabular}


5.2. Características químicas (en caso de existir más mediciones, agregar las filas que sean necesarias)

\begin{tabular}{|l|l|l|l|l|}
\hline & Declarado & Mín. & Máx. & \\
\hline pH & & & & \\
\hline Aw & & & & \\
\hline${ }^{\circ}$ Brix & & & & \\
\hline Humedad & & & & \\
\hline
\end{tabular}

5.3. Características microbiológicas (indicar artículo del RSA al que se hace referencia)

Artículo:

\begin{tabular}{|c|c|c|c|c|c|c|}
\hline \multirow{2}{*}{ Parámetro } & \multicolumn{4}{|c|}{ Plan de muestreo } & \multicolumn{4}{|c|}{ Limite por gramo } \\
\hline & Categoría & Clases & $\mathrm{n}$ & $\mathrm{c}$ & $\mathrm{m}$ & $\mathrm{M}$ \\
\hline & & & & & & \\
\hline & & & & & & \\
\hline
\end{tabular}

5.4. Características sensoriales

\begin{tabular}{|l|l|}
\hline Apariencia & \\
\hline Aroma & \\
\hline Color & \\
\hline Sabor & \\
\hline Resabio posterior & \\
\hline
\end{tabular}

5.5. Uso previsto

5.6. Modo de preparación

6. EMPAQUE

6.1. Tipo de envase primario

Cantidad de colores para impresión

6.2. Tipo de envase secundario

6.3. Presentación

6.4. Código (Especificación Técnica del envase) (Especificación Técnica del envase) EAN-13:

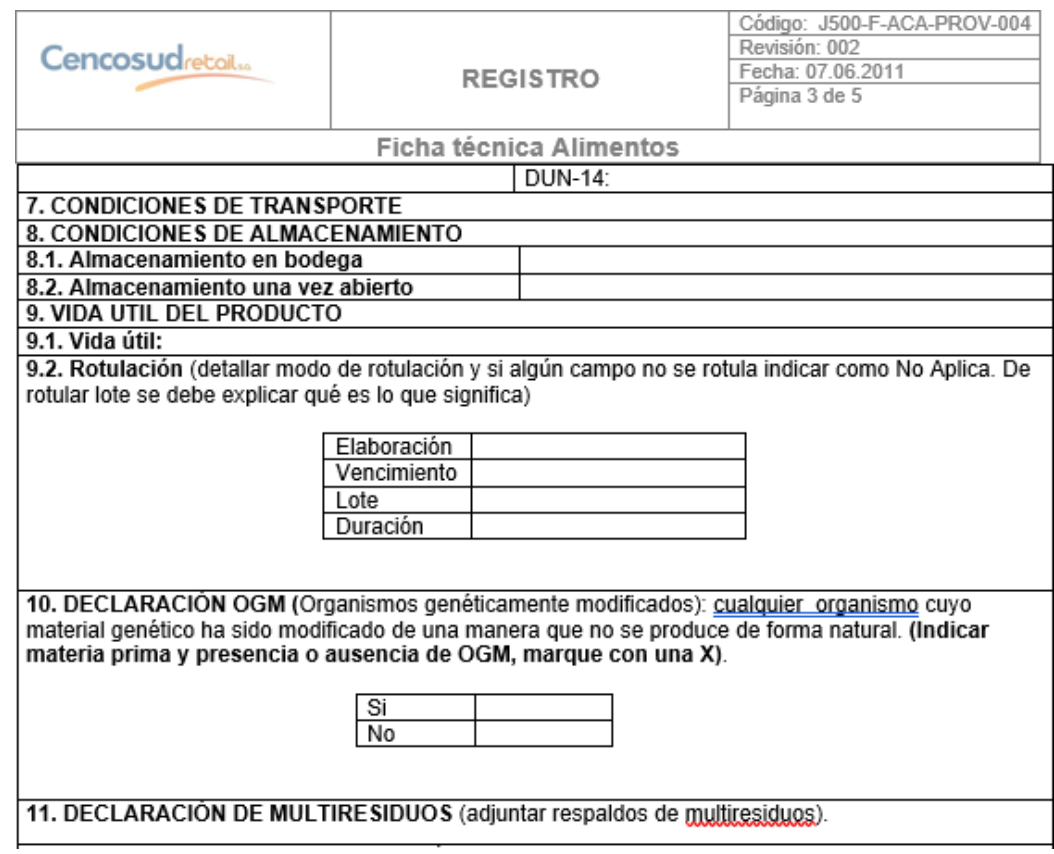

\begin{tabular}{|c|c|}
\hline \multicolumn{2}{|c|}{$\begin{array}{l}\text { 12. CONTENIDO DE POTENCIALES ALERGENOS: Presencia o compuesto que provoca ur } \\
\text { reacción adversa a la población (Marcar con una } \mathrm{X} \text { ) }\end{array}$} \\
\hline Cereales con gluten & Mani, soya y sus productos \\
\hline Crustáceos y productos & Leche y productos lácteos \\
\hline Huevos y sus derivados & Nueces y sus derivados \\
\hline Pescados y derivados & Sulfitos en concentraciones de $10 \mathrm{mg} / \mathrm{kg}$ o más \\
\hline
\end{tabular}




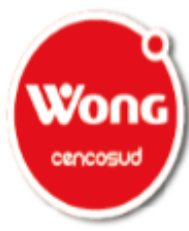

\section{CARTA DE COMPROMISO}

NORMAS DE CALIDAD DE CENCOSUD PERU RETAIL S.A.

La Empresa con Razón Social , actualmente proveedora de productos alimenticios de marca (s) para Cencosud Perú Retail S.A.

Wong ha recibido la carta de Normas de Calidad el día ; con ello ,toma conocimiento de las mismas, así como también se compromete a cumplirlas .

También se compromete a hacer extensiva todas estas a todos los miembros de la empresa.

NOMBRES Y APELLIDOS :

CARGO/PUESTO:

EMPRESA (RAZON SOCIAL) :

MARCA (S) QUE PROVEE: 